\title{
Desenvolvimento de um Sistema servidor de vídeo para Aplicações Multımídia
}

\author{
Antonio Marcos M. Hachisuca
}

Orientação: Prof. Dr. Edson dos Santos Moreira

Dissertação apresentada ao Instituto de Ciências Matemáticas de São Carlos, como parte dos requisitos para a obtenção do título de Mestre em Ciências Área de Ciências de Computação e Matemática Computacional

USP - São Carlos

Dezembro 1997 
Aos meus pais.

Antonio Shiro Hachisuca e

Tereza T. Kato Hachisuca 


\section{Agradecimentos}

Ao professor Edson, pela amizade, apoio, orientação, paciência e ensinamentos sem os quais esse trabalho não teria sido concluído.

Aos meus pais, Antonio Shiro Hachisuca e Tereza T. Kato Hachisuca, pelo enorme apoio, compreensão, educação, paciência a mim dedicados durante toda a vida e em especial nesse período.

Aos amigos da república: André, Mário Teixeira, Mário, Milton, Robson, Rogério, Ronaldo e Silvio, pela amizade, companheirismo, apoio e paciência.

Ao amigo Ronaldo M. Correia, pela grande ajuda na realização dos testes.

A Fipp, Faculdade de Informática de Pres. Prudente, pelo apoio, fundamentais no decorrer desse trabalho, em especial ao Diretor Moacir Del Trejo.

Aos colegas de mestrado do ICMSC pelos momentos de estudo e alegria compartilhados.

Aos colegas do Intermídia, em especial ao Fábio, Rogério, Roger, Pissioli, Elder, Taboca, Manzato, Rudinei; pela camaradagem, apoio e festas.

Aos técnicos do LDCC: Sônia, Ângelo, Luciano e Rogério, pela atenção dispensada.

Às jovens da secretaria da Pós: Andressa, Beth, Laura e Marília, e da biblioteca: Silvana, Gislene, Maria, Sandra, Rose e Giselda, pela atenção, simpatia e prestatividade sempre demonstradas.

À FAPESP, Fundação de Amparo à Pesquisa do Estado de São Paulo, e ao Cnpq, pelo apoio financeiro. 


\section{Resumo}

A criação de um ambiente para provimento de dados multimídia sobre uma rede de computadores, apresenta vários limitantes, sendo um deles a arquitetura do servidor responsável pela entrega de vídeo. Esse trabalho investiga, define e implementa os componentes que compõem um servidor de vídeo. Para contornar os problemas oriundos da precariedade dos protocolos TCP/IP e ethernet para a transmissão de mídia contínua, nota-se o aparecimento de várias tecnologias que possibilitam o uso de um sistema de armazenamento remoto de vídeo e sua apresentação local com razoável qualidade sem a utilização de sincronismo durante todo o processo (p. ex. Vxtreme, RealVideo, CUSeeme e o padrão JMF). Desta forma, a questão principal torna-se o provimento de largura de banda necessária para a aplicação. A maioria dos problemas inseridos pela rede e pelos sistemas operacionais são resolvidos através de esquemas avançados de bufferização. Como resultado desse trabalho, foi definido um sistema bem ajustado para o provimento de dados multimídia sobre uma rede de computadores, um sistema básico para o gerenciamento dos dados multimídia através do ambiente WWW, a avaliação de desempenho do sistema e detecção de possíveis gargalos do sistema. O trabalho mostra também algumas configurações possíveis de serem utilizadas para o serviço de armazenamento e distribuição de vídeo. Os testes realizados mostram que é perfeitamente possível a implementação de sistemas de distribuição de vídeo via tecnologias de rede Internet. 


\section{Abstract}

The development of na enviroment to support multimedia data transmission over computers network. pose. several problems, one of which design of the video server architecture responsible for the video storage and delivery. This work investigates, defines and implements components that compose the video server. To bandle the problems from the TCP/IP and Ethernet protocols weaknesses to transmit continuous media, several have been developed to enable the use of the remote video storage and local presentation with reasonable quality, with no synchronization, during all process (p.ex Vxtreme, realVideo, CU-Seeme and JMF Standard). In this way, the main question is the network bandwidth provision for the application. The several problems inserted by the network and operation system are resolved through the use of an advanced scheme of bufferization. The result of. this work are the definition of a configuration for a server system tunned to provide multimedia transmission over the Internet and a basic management system to support the multimedia data storage and search via WWW environment. The system performance and the eventual system bottlenecks are analised. The work also shows some possible alternative configurations to store and distribute video services. The tests showed the real feasibility of the implemantation of a distributed video system to work over Internet network technologies. 


\section{Índice Analítico}

1.INTRODUÇÃO. 1

2.SISTEMAS MULTIMÍDIA 3

2.1 INTRODUÇÃO. 3

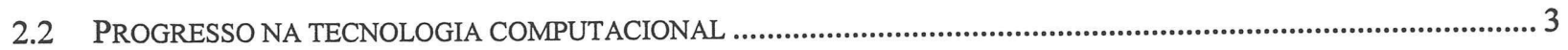

2.3 PROGRESSO NA INTERFACE DO USUÁRIO, SOFTWARE E CONCEITOS .......................................................... 5

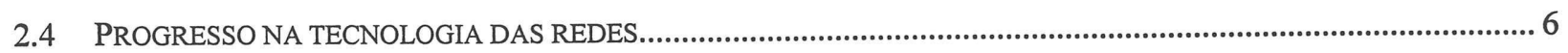

2.5 PROGRESSO NAS TÉCNICAS DE COMPRESSÃO_....................................................................................

2.6 CARACTERÍSTICAS DE UM SISTEMA MULTIMIIDIA................................................................................ 7

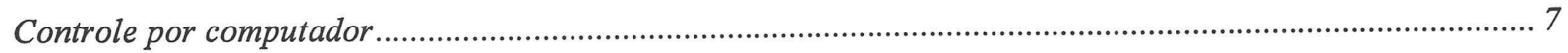

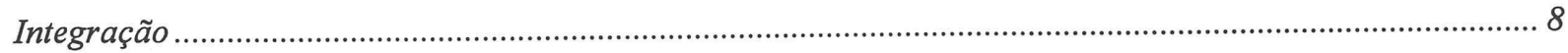

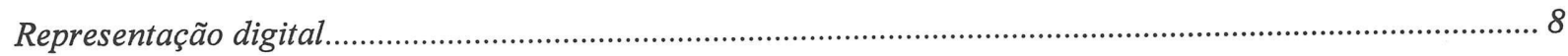

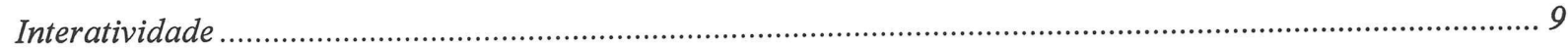

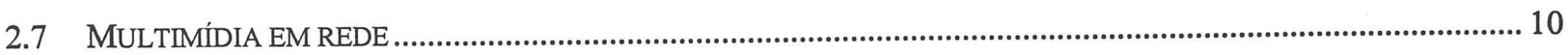

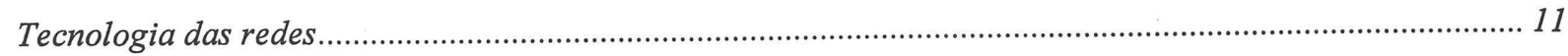

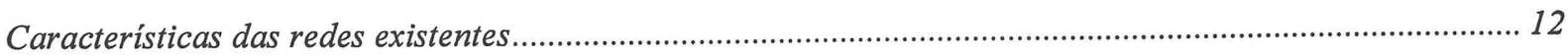

ATM

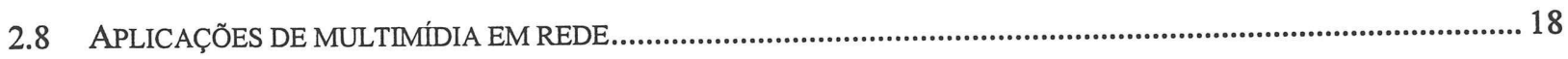

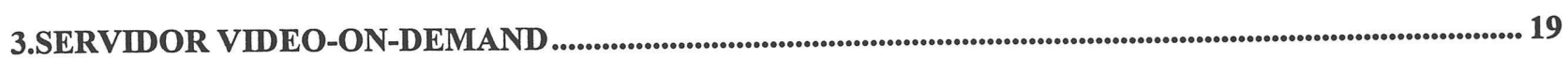

3.1 TIPOS DE SERVIÇOS INTERATIVOS....................................................................................................... 19

3.2 - COMPONENTES DO SISTEMA PARA VIDEO-ON-DEMAND …............................................................... 20

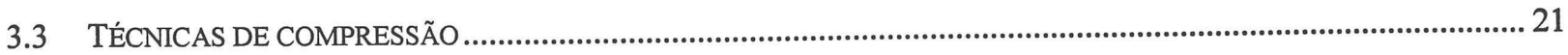

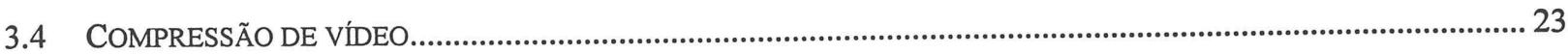

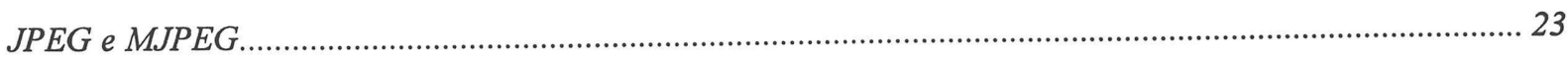

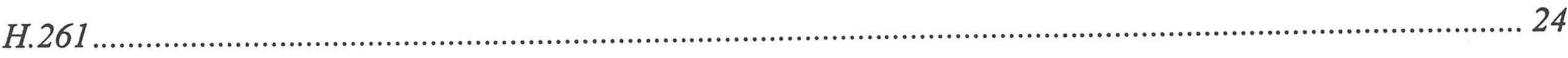

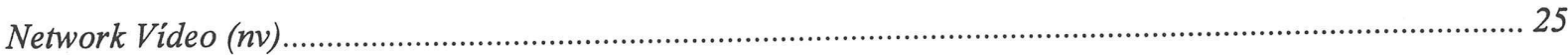

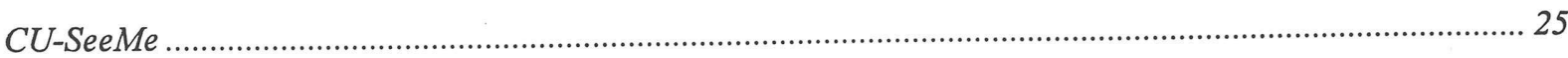

Indeo

MPEG

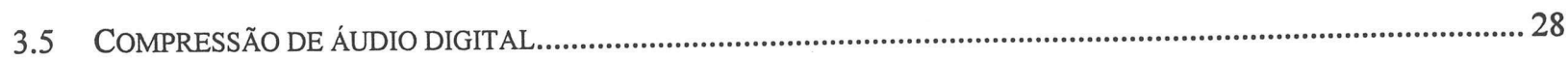

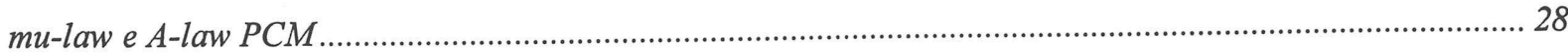

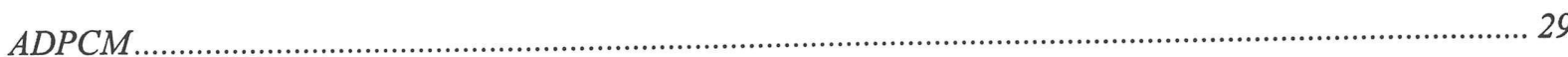

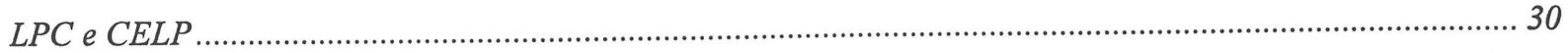

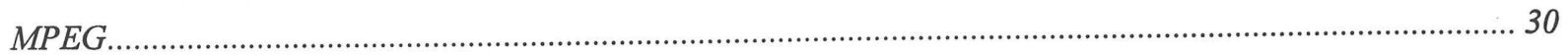




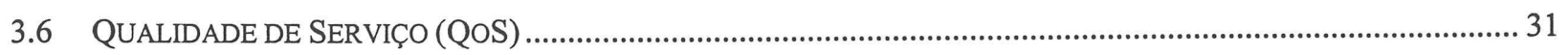

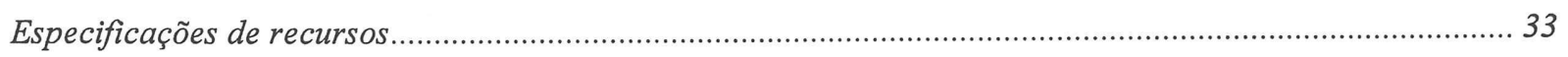

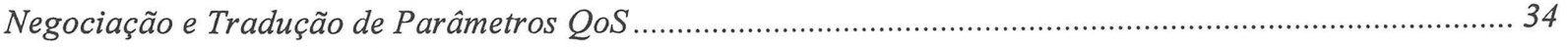

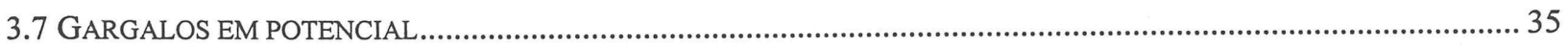

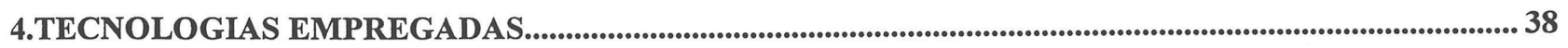

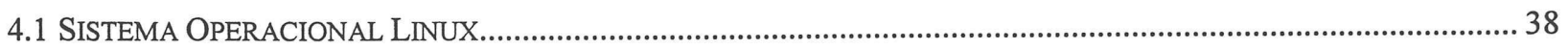

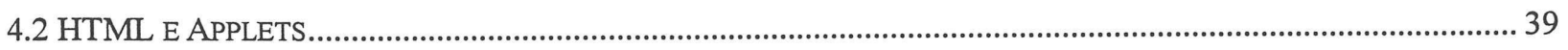

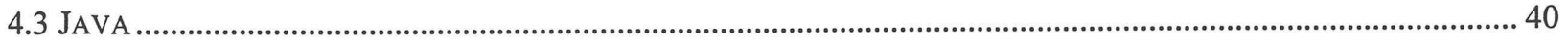

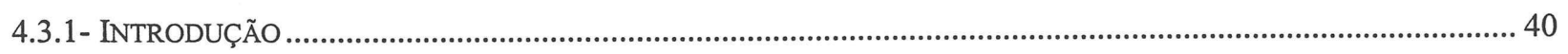

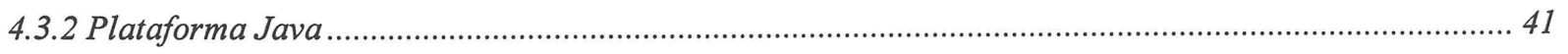

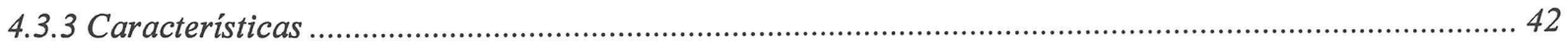

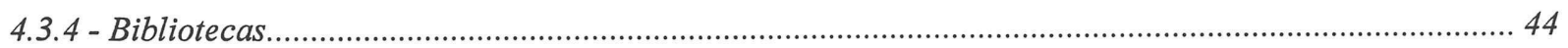

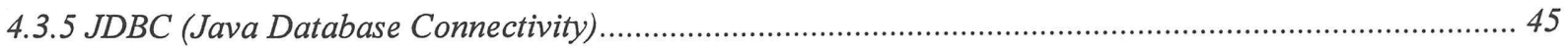

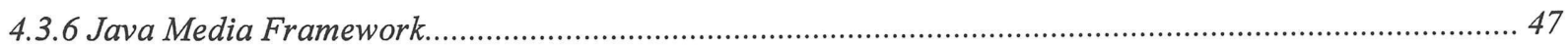

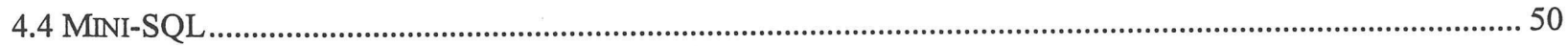

4.4 .1 - Introdução

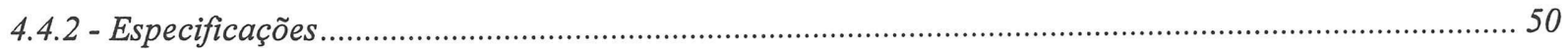

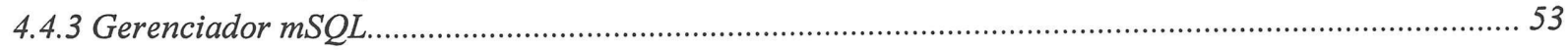

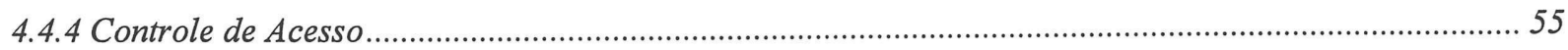

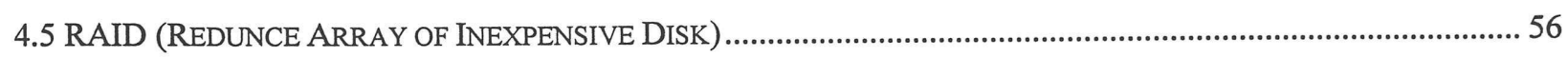

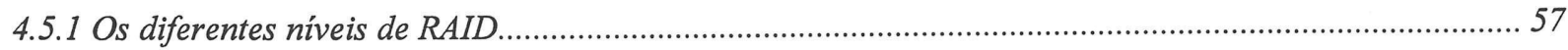

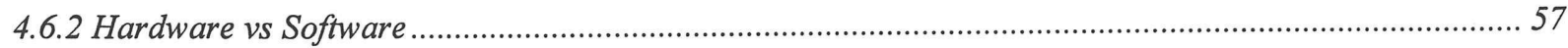

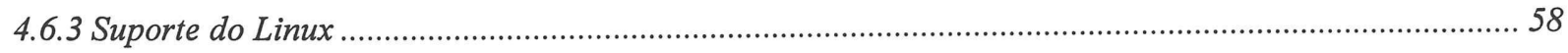

5. DESENVOLVIMENTO DO SISTEMA SERVIDOR DE VÍDEO ........................................................................ 59

5.1 HARDWARE.

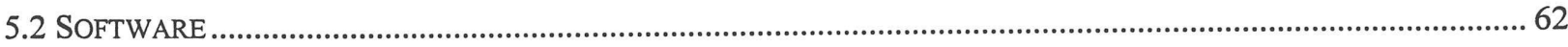

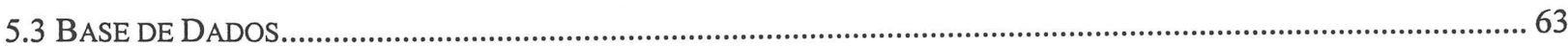

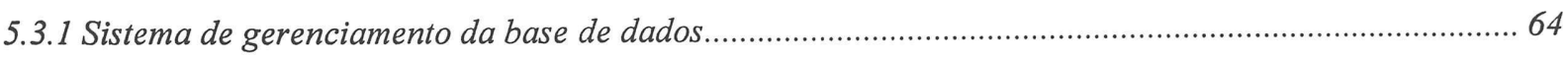

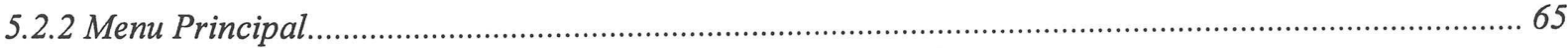

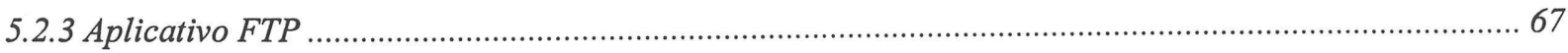

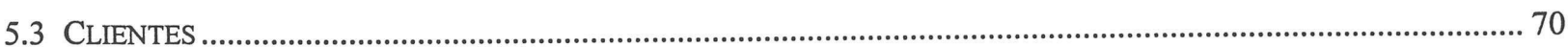

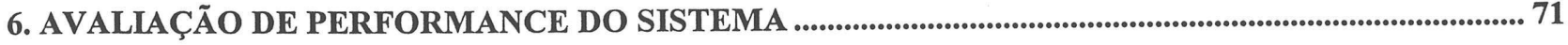

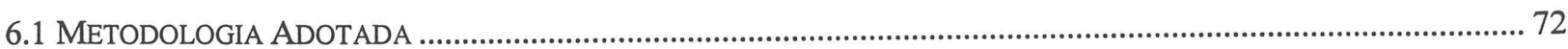

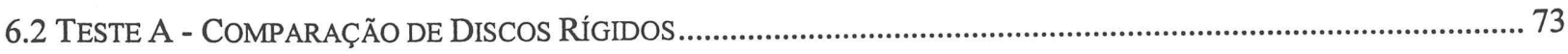

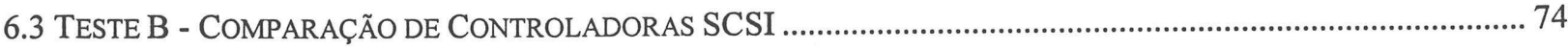

6.4 TESTE C - COMPARAÇÃO DE SISTEMAS OPERACIONAIS............................................................................. 75 


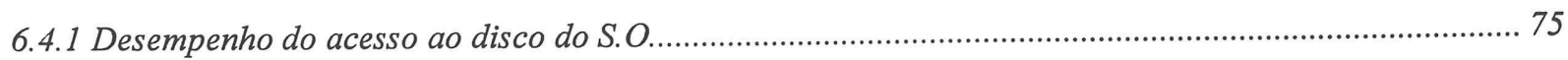

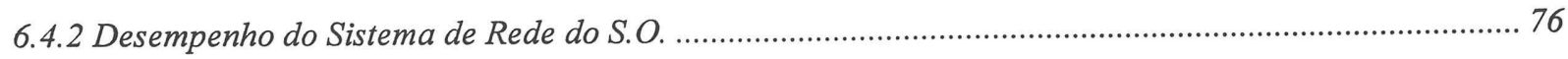

6.5 TESTE D - DESEMPENHO COMPARATIVO DO SISTEMA DE ARQUIVO(MELHORIA MOSTRADA PELO RAID) ......... 78

6.6 TESTE E - DESEMPENHO DO SISTEMA DE ARQUIVO SOBRE UMA REDE ETHERNET ......................................... 79

6.7 TESTE F - DESEMPENHO DO SISTEMA DE ARQUIVO SOBRE UMA REDE FDDI................................................... 80

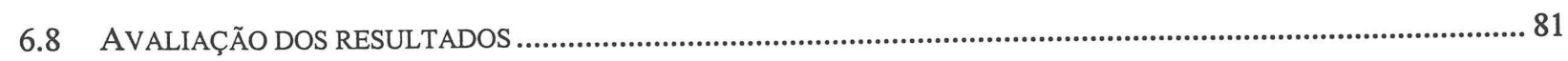

7.CONCLUSÕES E TRABALHOS FUTUROS .............................................................................................................. 84

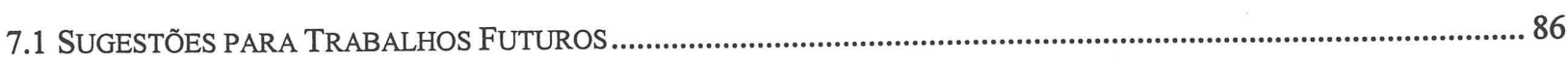

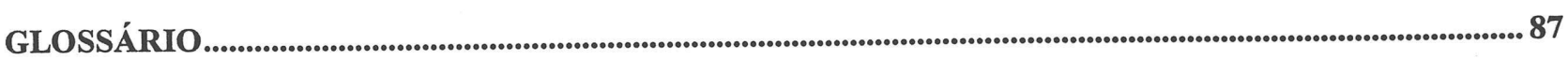

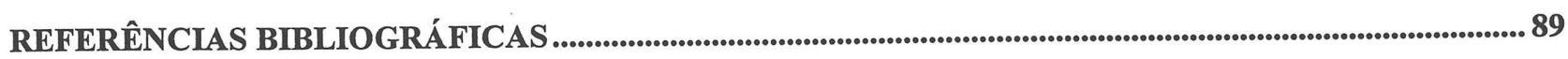

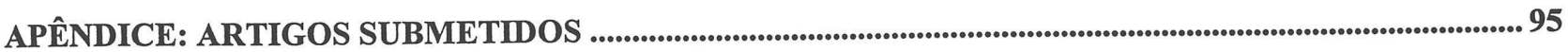




\section{Lista de Figuras e Tabelas}

FIGURA 2.1 - ESPAÇO DE ARMAZENAMENTO REQUERIDO PARA ARQUIVOS MULTIMÍDIA [BO94A].................................. 4

TABELA 2.2 - AS TRÊS GERAÇÕES DE SISTEMAS MULTIMÍDIA [BO94A] ……............................................................... 5

FIGURA 2.3 - CONVERSÃO DE ANALÓGICO-EM-DIGITAL [FL95] ................................................................................... 8

FIGURA 2.4 - CONVERSÃO DE ANALÓGICO EM DIGITAL E DIGITAL EM ANALÓGICO [FL95] ........................................... 9

TABELA 2.5 - COMUNICAÇÃO TRADICIONAL X COMUNICAÇÃO MULTIMÍDIA [FL95] .................................................... 11

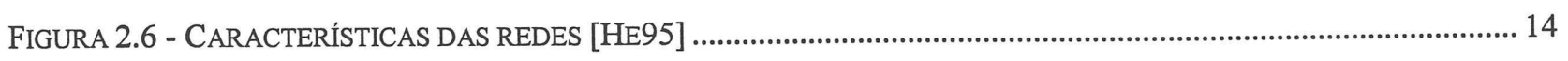

FIGURA 2.7 - MODELO DE REFERÊNCIA DO PROTOCOLO PARA B-ISDN [HE95] ........................................................... 15

FIGURA 2.8 - CLASSES DE SERVIÇO PARA CAMADA DE ADAPTAÇÃO ATM \{GU94] ..................................................... 17

TABELA 3.1 - TIPOS DE SERVIÇOS INTERATIVOS [FL95] ……............................................................................... 20

FIGURA 3.2 - CLASSIFICAÇÃO PARA TÉCNICAS DE COMPRESSÃO (A) LOSSLESS E (B) LOSSY [TA93].......................... 22

FIGURA 3.3 - PADRÕES DE COMPRESSÃO MULTIMÍDIA [FL95] ................................................................................ 22

FIGURA 3.4 - ARQUITETURA DE UM SISTEMA MULTIMÍDIA EM REDE [TA93] ............................................................. 31

FIGURA 3.5 - PARÂMETROS DE QUALIDADE DE SERVIÇO (QOS) [TA93] .................................................................... 33

FIGURA 3.6 - EXEMPLO DE GERENCIAMENTO DE RECURSOS ENVOLVIDO NO PROCESSO DE NEGOCIAÇÃO QOS ............ 34

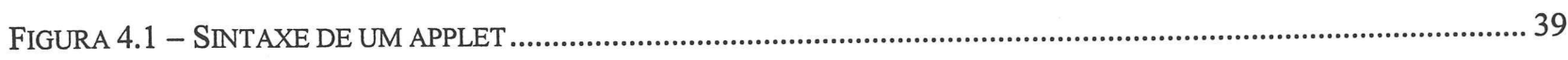

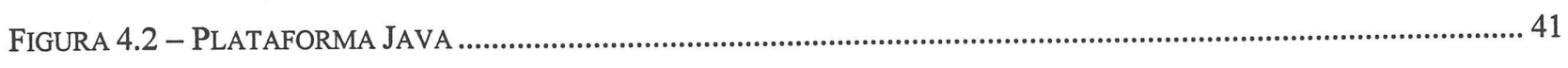

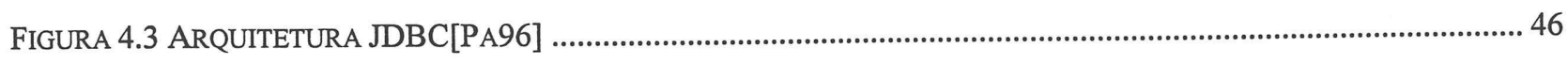

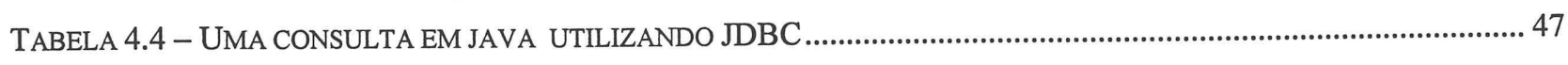

FIGURA 4.5 - PLAYER DE UM VIDEO MPEG SOBRE UMA PÁGINA HTML....................................................................... 50

FIGURA 4.6 - TELA DO RESULTADO DE UMA QUERY UTILIZANDO O PROGRAMA MSQL................................................. 54

FIGURA 4.7 - TELA DE RESULTADO DA QUERY DO PROGRAMA RELSHOW................................................................... 55

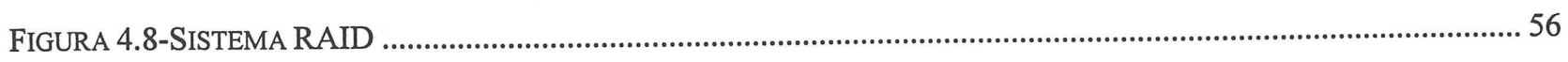

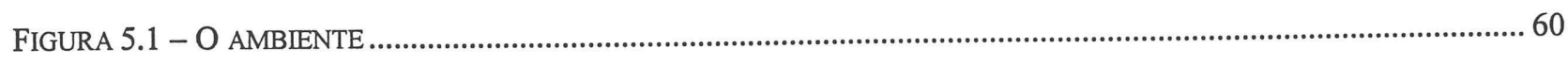

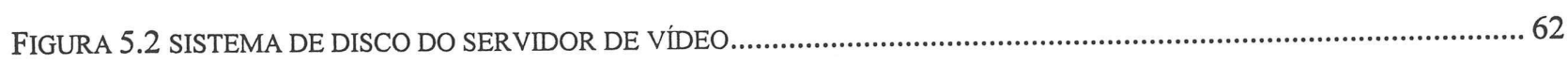

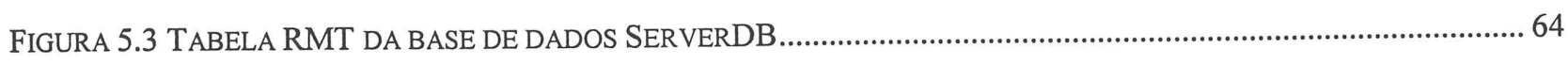

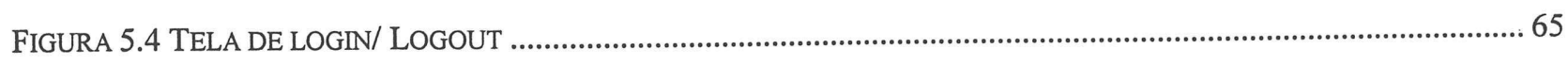

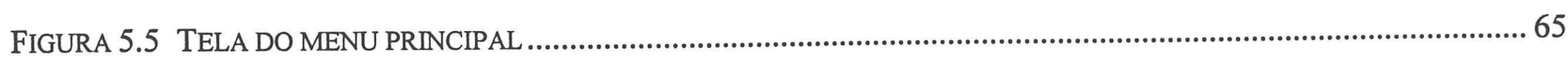

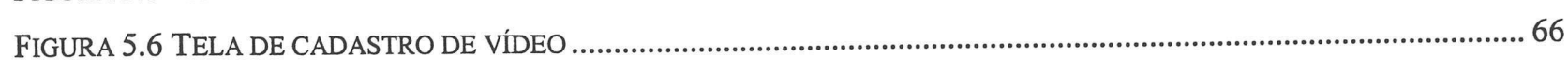

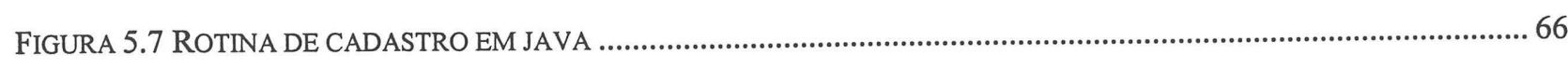

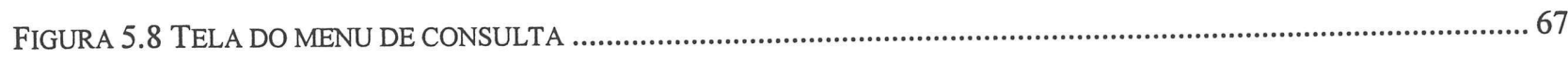

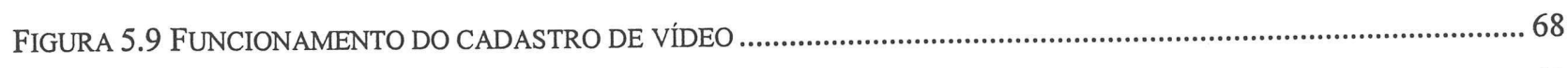

FIGURA 5.10 - ROTINA DE CONEXÃO E TRANSMISS ÃO DO ARQUIVO VIA FTP..............................................................69

FIGURA 5.11 - FUNCIONAMENTO DO CLIENTE DO SERVIDOR DE VÍDEO ……………................................................ 70

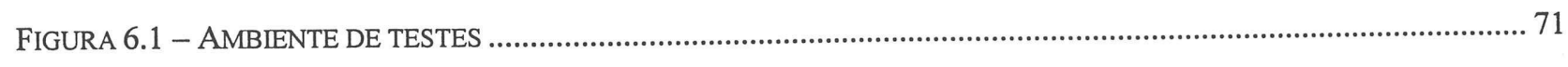

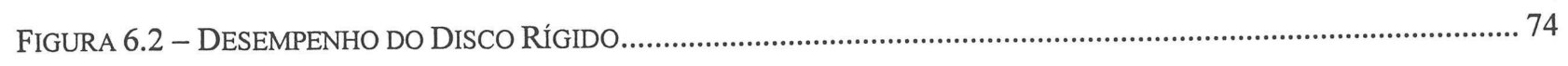




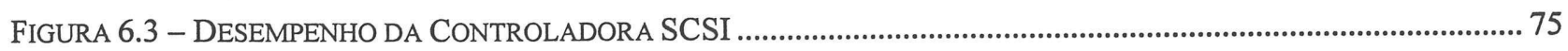

FIGURA 6.4 - DESEMPENHO DO S.O. - SISTEMA DE ARQUIVO .................................................................................76

FIGURA 6.5 - DESEMPENHO DO S.O. - SISTEMA DE REDE ETHERNET ……................................................................. 77

FIGURA 6.6 AMBIENTE DE TESTES COM FDDI E SWITCH ETHERNET …................................................................ 77

FIGURA 6.7 - DESEMPENHO DO S.O. - SISTEMA DE REDE FDDI + SWITCH ETHERNET ……......................................... 78

FIGURA 6.8 - DESEMPENHO DO SISTEMA DE ARQUIVO .......................................................................................... 79

FIGURA 6.9 - DESEMPENHO DO SISTEMA DE ARQUIVO SOBRE UMA REDE ETHERNET(10MBPS) ................................. 80

FIGURA 6.10 - DESEMPENHO DO SISTEMA DE ARQUIVO SOBRE UMA REDE FDDI E SWITCH ETHERNET........................ 81

FIGURA 6.11 - PERCENTUAL DE UTILIZAÇÃO DA REDE ETHERNET ………................................................................. 83 


\section{Introdução}

Com o recente avanço tecnológico na área computacional, houve o surgimento de um novo tipo de sistema de computadores: os sistemas multimídia. Esses sistemas apresentam as informações, não mais somente através de texto, e sim através de imagens (fotos), animações feitas por computador, vídeos gravados, som (voz e música), podendo todos estarem integrados ou não.

Para isso, a tecnologia computacional teve que sofrer avanços nos seus mais diversos componentes, na velocidade de processamento, algoritmos de compressão de imagens e sons, sistemas operacionais com características especiais para multimídia, rede de computadores, linguagem de programação, etc.

Esse novo tipo de aplicação está sendo largamente utilizado hoje, em todas as áreas: na área médica, na visualização de imagens de alta resolução, sistemas de videoconferências, sistemas de aprendizado à distância, trabalhos em grupos.

No caso de sistema multimídia em rede(ambiente WWW), a questão do armazenamento e a questão da entrega de dados de vídeo (e de dados multimídia em geral) em ambientes WWW são ponto chave, uma vez que o fornecimento do material desejado deve atender a uma comunidade de usuários dispostos na rede em plataformas heterogêneas. O grande volume dos dados multimídia e o eventual grande número de usuários acessando o sistema (simultaneamente) podem levar sistemas convencionais (de armazenamento e entrega) à sobrecarga, compremetendo o atendimento da demanda.

Surge, deste modo, a oportunidade de investigar como sistemas multimídias podem ser utilizados eficientemente sobre uma rede de ccomputadores.

Nesse sentido, os objetivos do trabalho reportado nesta dissertação são:

- Investigar os padrões de sistemas multimídia, principalmente os Sistemas Video-OnDemand.

- Estudo, especificação e desenvolvimento de um sistema bem ajustado para o provimento de dados multimídia sobre uma rede de computadores. Desde a especificação do 
hardware até a programação de um sistema de gerenciamento para controlar os dados multimídia armazenados no servidor.

- Testes e avaliação do sistema servidor de vídeo, medindo com isso o desempenho do sistema e detecção dos gargalos inerentes ao sistema.

Os demais capítulos desse trabalho estão assim organizados: o próximo capítulo apresenta uma visão geral dos conceitos relacionados a sistema multimídia; o Capítulo 3 discorre sobre servidores Video-On-Demand (VOD), tipos de serviços interativos, técnicas de compressão de áudio e vídeo; o Capítulo 4: descreve sobre as tecnologias empregadas para o desenvolvimento do sistema servidor de aplicações multimídia; Capítulo 5: apresenta a definição, implementação e configuração do servidor de vídeo, onde esta especificado o hardware, as tecnologias empregadas, implementação do sistema de gerenciamento, etc.; oCapitulo 6 - discorrre os testes realizados com o objetivo de medir o desempenho do servidor de vídeo e a avaliação e detecção dos possíveis gargalos do sistema e o último capítulo apresenta as conclusões e as propostas de continuidade desse trabalho 


\section{Sistemas Multimídia}

\subsection{Introdução}

A Multimídia tornou-se viável graças aos recentes avanços tecnológicos, basicamente pelo barateamento de hardware, aumento na capacidade de processamento das CPU's, aumento da memória dos computadores, diminuição do custo das memórias secundárias e desenvolvimento de algoritmos de compressão.

O passo seguinte foi o surgimento dos Sistemas Multimídias Distribuídos, onde os dados multimídias trafegam pela rede de um servidor para um cliente, ou entre os clientes. A vantagem desse tipo de sistema é o custo, já que cada cliente não necessita mais ter um disco rígido grande ou uma unidade de $C D$-ROM para armazenar os arquivos multimídias; pode-se concentrá-los no servidor que atende a todos.

\subsection{Progresso na tecnologia computacional}

O poder de processamento das Unidades Centrais de Processamento (CPU) dos computadores duplica-se a cada ano. Por exemplo, hoje um único microprocessador pode ter mais de 60 vezes o número de transistores em relação aos fabricados em 1980 [F195].

Os chips de memória também tiveram uma evolução muito grande; atualmente um único chip pode ter mais de 500 vezes a capacidade se comparado aos chips fabricados em 1980. Como resultado, um único chip pode armazenar mais de 32 Mbytes, e não é difícil produzir chips capazes de armazenar 64 Mbytes.

Esses avanços foram de grande importância para a multimídia, já que a digitalização, compressão, descompressão, renderização e transmissão de animações necessitam de programas grandes e complexos que consomem grande quantidade de memória e requerem grande velocidade de processamento.

Mas a evolução da multimídia não seria possível, se não houvesse ocorrido também o progresso dos meios de armazenamento, já que os arquivos multimídia (sons digitalizados, animações, figuras) necessitam de grande quantidade de armazenamento (vide figura 2.1, na página seguinte). Por exemplo, uma hora de vídeo comprimido utiliza de 0.6 a 2 gigabytes de memória, 
dependendo da qualidade do vídeo. Discos magnéticos atualmente podem armazenar vários gigabytes de informação por disco. No entanto, para um servidor que possui várias horas de animações, esse não é o meio de armazenamento mais recomendado. Já existem outros dispositivos que possuem capacidades maiores, como é o caso de [Bo94a]:

- Compact Disc-Read Only Memory (CD-ROM) : pode armazenar 72 minutos de um vídeo comprimido com qualidade de estúdio (TV), ou 15.000 figuras escaneadas comprimidas. Pode prover interatividade, mas não pode ser alterado pelo usuário final. Pode ser usado em servidores multimídia, especialmente quando montados em jukebox. Um CD-ROM jukebox típico contém 25 discos, mas pode ter mais de 250 discos.

- Write-Once-Read-Many (WORM) : WORM pode ser escrito por um raio laser diretamente pelo usuário final, mas somente uma vez; após gravada, a informação não pode ser mais alterada, somente lida. Um único disco WORM pode armazenar de 6 a 10 gigabytes - 3 a 5 gigabytes por lado - isto dá um total de 10 a 15 horas de vídeo a nível de qualidade de TV.

- Magneto-Optic disks (MO disks) : discos óticos magnéticos representam a tecnologia mais recente que combina as técnicas óticas e magnéticas para escrever e apagar e ler as informações gravadas no disco., utilizando essas propriedades presentes em materiais nobres.

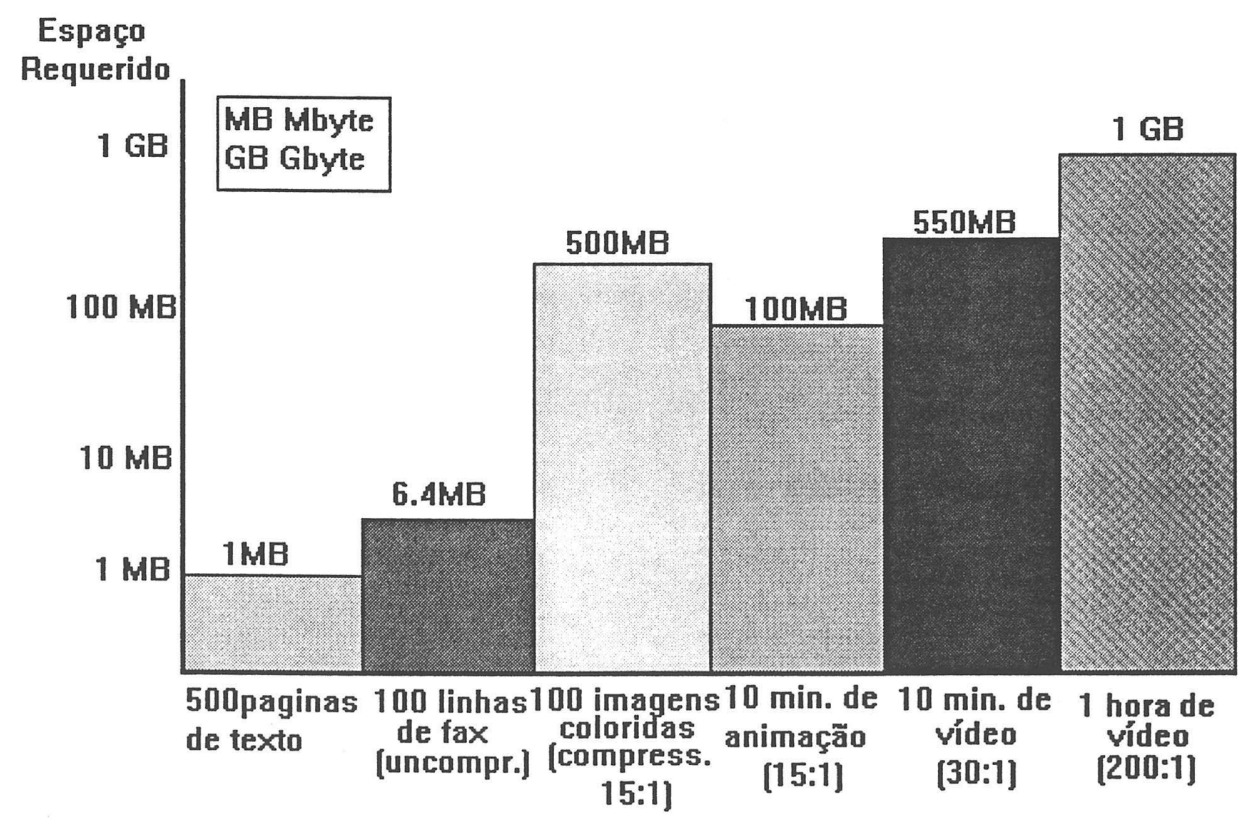

Figura 2.1 - Espaço de armazenamento requerido para arquivos multimídia [Bo94a] 
O custo é obviamente um fator muito importante. Em 1980, 1 megabyte de disco magnético custava 100 vezes mais que atualmente. Um jukebox totalmente carregado com discos pode armazenar mais que 1.000 gigabytes de dados. Em 1995, um único CD-ROM pode ser produzido por custo baixo, enquanto que o custo pode cair ainda mais, se a produção for em larga escala [F195]. Como o avanço tecnológico dos computadores é bastante rápido, utilizam-se padrões (vide tabela 2.2) que determinam em que geração os sistemas multimídia se encontram e qual geração é necessária para a apresentação de uma determinada aplicação multimídia [Bo94a].

\begin{tabular}{|c|c|c|c|}
\hline 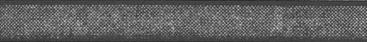 & $1^{2}$ Geraça 1989.91 & $2^{2}$ Geração 1992-94. & $3^{2}$ Geraç̃̃o $1995-96$ \\
\hline Mídia & $\begin{array}{l}\text { Texto } \\
\text { gráficos preto/ branco } \\
\text { imagens Bit-mapped } \\
\text { Animações }\end{array}$ & $\begin{array}{l}\text { Bit-Mapped coloridas } \\
\text { 16-bit áudio } \\
\text { imagens em movimento } \\
\text { vídeo full-motion - } 15 \mathrm{fps}\end{array}$ & $\begin{array}{l}\text { Video full-motion }-30 \mathrm{fps} \\
\text { qualidade NTSC/PAL e } \\
\text { HDTV }\end{array}$ \\
\hline Capacidade de Autoria & $\begin{array}{l}\text { Hipertexto } \\
\text { Hipermídia }\end{array}$ & $\begin{array}{l}\text { Multimidia orientada-a-objeto } \\
\text { com texto, gráficos, sons, } \\
\text { animações, imagens e vídeos } \\
\text { full-motion }\end{array}$ & 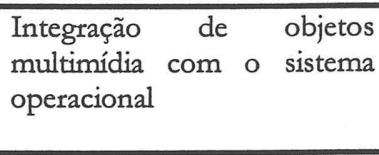 \\
\hline $\begin{array}{l}\text { Técnicas de Compressão } \\
\text { de Vídeo }\end{array}$ & $\begin{array}{l}\text { DCT } \\
\text { JPEG }\end{array}$ & $\begin{array}{l}\text { Motion JPEG } \\
\text { MPEG-1 }\end{array}$ & $\begin{array}{l}\text { MPEG-2,3,4 } \\
\text { Wavelets }\end{array}$ \\
\hline Plataforma Básica & $\begin{array}{l}25 \mathrm{Mhz} 386(68030) \\
2 \mathrm{MB} \text { DRAM } \\
40 \mathrm{MB} \text { Hard disk } \\
\text { VGA Color. }(640 \mathrm{x} 480) \\
500 \mathrm{MB} \text { CD-ROM-150 Kb/s }\end{array}$ & $\begin{array}{l}50 \mathrm{Mhz} 486(68040) \\
\text { 8-16 MB DRAM } \\
240 \mathrm{MB} \text { Hard disk } \\
\text { 1-2 } 1.5 \mathrm{MB} \text { Floppies } \\
\text { VGA with } 256 \quad \text { cores } \\
(1024 \times 768) \\
500 \mathrm{MB} \text { CD-ROM- } 150 \mathrm{~KB} / \mathrm{s}\end{array}$ & $\begin{array}{l}\text { 50-100 Mhz Pentium (Power } \\
\text { PC) } \\
\text { 16-32 MB DRAM } \\
\text { 1-2 600 MB Hard disk } \\
\text { 20-30 MB Floppies } \\
\text { SVGA (1280 x 960) } \\
50 \mathrm{MB} \text { Writable CD-ROM } \\
(300 \mathrm{~KB} / \mathrm{s})\end{array}$ \\
\hline Sistema Operacional & DOS & $\begin{array}{l}\text { DOS } 5.0 \\
\text { Windows } 3 . x \\
\text { OS } / 2 \text { Presentation Manager }\end{array}$ & $\begin{array}{l}\text { Windows NT } \\
\text { Pink (IBM/Apple) }\end{array}$ \\
\hline Rede Local & $\begin{array}{l}\text { Ethernet }(10 \mathrm{Mb} / \mathrm{s}) \\
\text { Token ring }(16 \mathrm{Mb} / \mathrm{s})\end{array}$ & FDDI $(100 \mathrm{Mb} / \mathrm{s})$ & $\begin{array}{l}\text { Ethernet, Token ring }(100 \\
\mathrm{Mb} / \mathrm{s}) \\
\text { FDDI }(500 \mathrm{MB} / \mathrm{s}) \\
\text { ATM }\end{array}$ \\
\hline
\end{tabular}

Tabela 2.2 - As três gerações de sistemas multimídia [Bo94a]

\subsection{Progresso na interface do usuário, software e conceitos}

Paralelamente ao progresso do hardware, os softwares e conceitos desenvolveram-se rapidamente. Algumas inovações ocorridas na última década, que possuem particularidades com multimídia, são :

- Graphical User Interface (GUI) : Com este novo tipo de interface, o usuário não necessita mais digitar os comandos para executar funções do programa. Utilizam-se, ao invés disso, ícones gráficos e dispositivos como o mouse que resultam numa interface mais próxima entre o usuário e o computador. 
- Conceito Orientado a Objeto : Este é o conceito pelo qual componentes dos sistemas computacionais, como pedaços de programas ou elementos de dados, são considerados como elementos individuais que podem ser descritos por atributos e inter-relacionados entre si. $O$ conceito pode ser aplicado sobre um número de modos, como é o caso de softwares orientado a objeto (Object Oriented Software - OOS) ou banco de dados orientado a objeto (Object Oriented DataBaseS - OODBS). Esse conceito é particularmente bem adaptado a aplicações multimídia. $\mathrm{Na}$ verdade é vantajoso em descrever informações multimídia como objetos, primeiramente por causa das naturezas múltiplas, e também por causa do grande volume de informações multimídia a ser controlado. O conceito orientado a objeto permite a quebra em vários componentes pequenos tratados como objetos.

\subsection{Progresso na tecnologia das redes}

A transmissão de informações multimídia geralmente coloca uma alta requisição na rede. Em particular, mídias contínuas como é o caso do som ou de vídeos requerem tanto altas taxas de transmissão, como limites pequenos no delay de transmissão de um pacote para outro [F195] [Bo94a].

O desenvolvimento de fibras óticas na tecnologia de transmissão abriu uma nova era nas comunicações. Uma única fibra ótica hoje pode transmitir mais de 2.500 milhões de bits por segundo e suporta 32.000 chamadas telefônicas ao mesmo tempo. Ela pode suportar uma centena de canais de TV comprimidas ao nível de qualidade de TV ao mesmo tempo. Atualmente, o protocolo mais utilizado em redes de conputadores de fibra ótica é FDDI, que opera a $100 \mathrm{Mbps}$, como sucessora da FDDI, foi desenvolvida a FDDI II, com alterações para suportar um tráfico constante de informações, característico de alguns tipos de informações multimídia (WAV, AVI), porém possui muitas desvantagens também, quanto à complexidade e compatibilidade[St95]. Outras formas de comunicação também foram desenvolvidas, como a Rede Digital de Serviços Integrados (ISDNs) foi introduzida na forma de faixa estreita (narrowband), chamada de N-ISDN, no fim dos anos 80 , como uma extensão moderna do serviço telefônico. Foi criada para transferir dados a uma taxa fixa de 64 Kbits, porem pode ser utilizados vários canais de 64 Kbits ao mesmo tempo, conseguindo-se com isso uma taxa de transferência mais alta [Di87] [Da94] [St94] [Ra94].

Logo se percebeu que o mercado exigia taxas de transmissão mais altas, para dados multimídia, tais como vídeos com resolução a nível de TV, som com qualidade de CD, etc. Desta 
forma foi desenvolvido o sucessor da N-ISDN, chamado de broadband-ISDN (B-ISDN), que permite a transmissão a taxas de 2 Mbps, utilizando o método de transferência ATM (Asynchronous Transfer Mode) [Gu94].

\subsection{Progresso nas técnicas de compressão}

Poderia não haver multimídia hoje se não houvesse ocorrido o grande progresso dos últimos cinco anos nos algoritmos de compressão e suas implementações. A compressão é necessária para reduzir o volume de memória de armazenamento necessária para arquivos de som, imagem e vídeo. As técnicas de compressão serão mais detalhadas no capítulo seguinte.

\subsection{Características de um sistema multimídia}

Um sistema multimídia pode armazenar informações de áudio e vídeo para serem utilizadas mais tarde por aplicações, como treinamento, ou transmitidas em tempo real. Áudio e vídeos podem ser interativos, como é o caso de conferências multimídia, ou não interativos, como é o caso da televisão. Similarmente, imagens armazenadas podem ser usadas no modo interativo ou no modo não interativo [Bo94].

Para que um sistema possa ser chamado de multimídia interativa, ele deve possuir algumas características, que são :

\section{Controle por computador}

Sistemas multimídia requerem que as apresentações das informações (chamadas de playout) para o usuário final sejam controladas por computador. $\mathrm{Na}$ prática, sistemas multimídias envolvem um computador, ou um conjunto de computadores, para apresentar as informações e possibilitar a interatividade com o usuário final. $\mathrm{Na}$ maioria dos casos, os computadores que fazem parte do sistema necessitam de periféricos especiais, como por exemplo, placa de som, unidade de CD-ROM, caixas de som, microfone, câmera de vídeo, etc. 


\section{Integração}

Para ilustrar a noção de integração, considere-se um sistema multimídia composto por um monitor para mostrar texto e um alto falante para reproduzir os sons gravados. Imagine-se agora um sistema capaz de suportar uma câmera de vídeo e um microfone para capturar o rosto e a voz do usuário, e um teclado para capturar o texto que o usuário possa digitar. Finalmente, pequenas seqüências de vídeos pré-gravadas também podem ser mostradas para o usuário. Todos os dispositivos, incluindo o microfone e a câmera, são conectados e controlados por um único computador [F195].

É claro que todos os tipos de informações não podem ser mostrados no mesmo dispositivo de saída (Ex: Monitor de Vídeo), simplesmente porque possuem formas diferentes. Por exemplo, o som, para ser ouvido, precisa de um falante, não podendo ser mostrado como uma imagem, no monitor.

\section{Representação digital}

Num sistema Multimídia, todas as informações devem estar na forma digital, ou seja, devem ser representadas por um código binário. Mas como a voz, os sinais de vídeo são sinais analógicos. Para fazerem parte do sistema multimídia, devem ser digitalizados, ou seja, sofrer um processo que transforma o sinal analógico para um sinal digital.

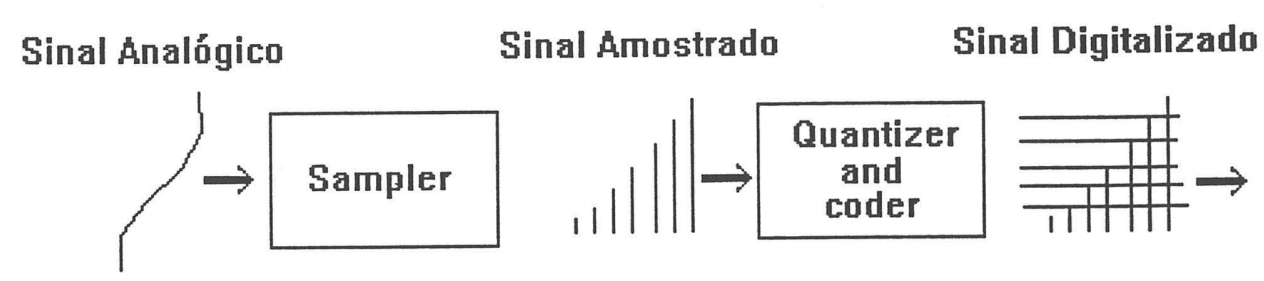

Figura 2.3 - Conversão de analógico-em-digital [F195] 


\section{Amostragem, quantização e codificação}

O processo de digitalização requer dois passos. Primeiro, o sinal analógico precisar ser amostrado (sampled). Neste processo, somente um conjunto discreto de valores é representado (ou pelo tempo ou pelo intervalo de espaço).

O segundo passo é formado por dois processos lógicos. No primeiro processo, o sinal amostrado é quantizado, resultando num valor representado por um conjunto de bits, chamada de palavra-código (code-word). No segundo essa palavra-código é associada a um valor quantizado.

\section{Conversão}

Todas as informações multimídia são representadas na forma digital, e os seres humanos somente reagem a estímulos físicos analógicos. Assim para apresentar as informações multimídia, aquelas em forma digital precisam ser transformadas em analógicas.

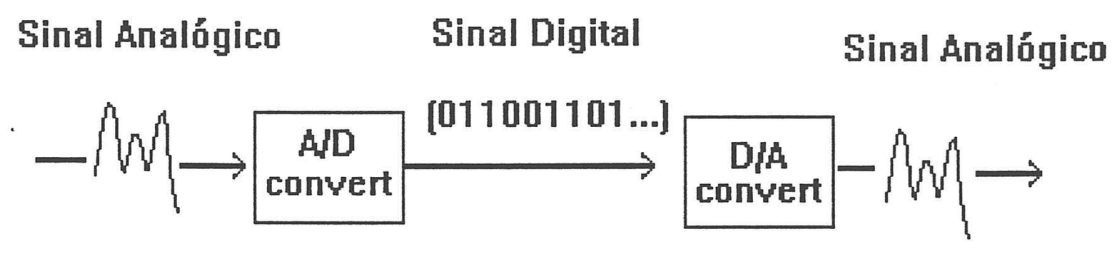

Figura 2.4 - Conversão de analógico em digital e digital em analógico [F195]

Contudo não são todas as informações digitais que necessitam ser convertidas: texto, gráficos ou imagens geradas por computador não necessitam ser convertidas, pois essas informações podem ser mostradas na forma digital.

\section{Interatividade}

A maioria dos sistemas multimídias suporta interatividade.Existem dois modos de apresentação da informação para o usuário:

- Passiva : a seqüência das informações é pré-definida, e o usuário não possui controle algum. Este tipo de apresentação é conhecido por apresentação linear. Exemplos: programa de TV, filmes. 
- Interativa : conhecida como apresentação não-linear, e alguma interação é possível. No momento em que a apresentação é iniciada, a ordem em que os vários itens de informação são apresentados, a velocidade da apresentação, a forma de apresentação estão sob o controle do usuário. Esses parâmetros são chamados de graus de customização, e não necessariamente toda a apresentação interativa deve prover todos estes tipos de interação. Uma analogia simples de um sistema de informação interativa é o jornal, pois pode ser lido a qualquer hora, em qualquer seqüência, e a qualquer velocidade.

\subsection{Multimídia em rede}

Com o avanço tecnológico das redes de computadores e algoritmos de compressão, viabilizou-se a criação de servidores de sistemas multimídia.

Sistemas multimídia distribuídos necessitam de transferência contínua de dados, por um longo período de tempo (por exemplo, a apresentação de um vídeo de uma câmera remota), sincronização dos dados, grande capacidade de armazenamento, e técnicas especiais de busca e recuperação de informações para dados multimídia [Bo94].

Várias aplicações multimídia, como servidor de vídeo, requerem um sistema multimídia em rede. Nestas aplicações, os aplicativos e dados multimídia são armazenados num servidor e ficam disponíveis para os clientes.[Li95]

Existem vantagens em usar um sistema de rede, na construção de um sistema multimídia. A mais significativa é a não necessidade de possuir os arquivos multimídia em todas as máquinas, reduzindo com isso o custo, já que estes são considerados grandes em relação aos arquivos tradicionais, necessitando de grande espaço de armazenamento; outra é a possibilidade de compartilhamento de periféricos mais caros (por exemplo : Câmera de Vídeo, CD-ROM) com todos os clientes.

Normalmente redes locais tradicionais, como é o caso da Ethernet, não suportam acessos remotos de dados multimídia para um número razoável de clientes. A tabela 2.5 mostra a diferença entre a transferência de dados tradicionais e dados multimídia. 


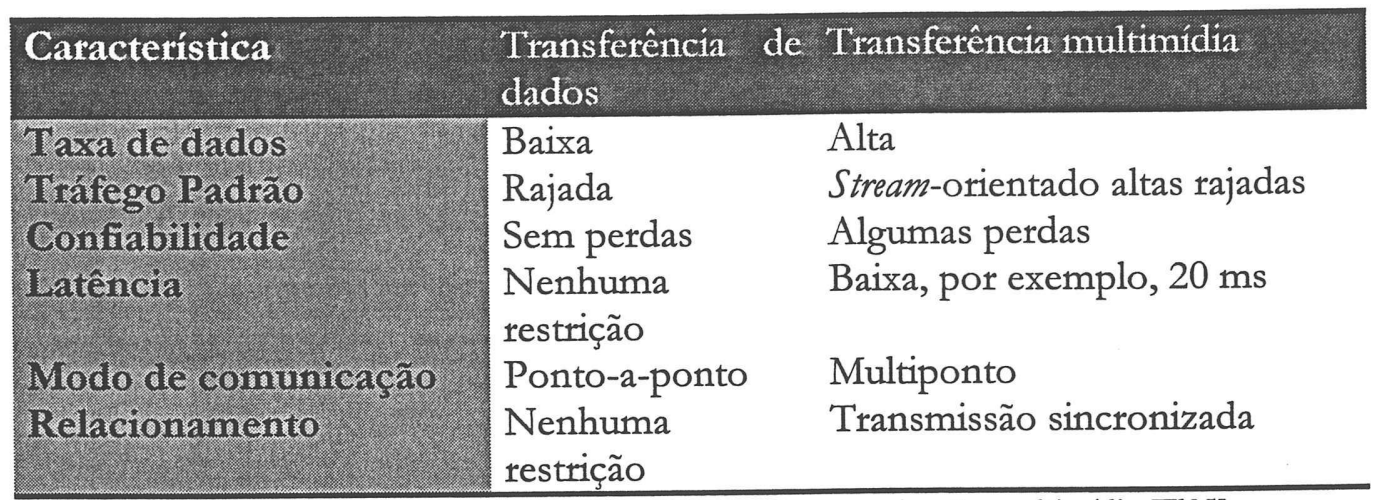

Tabela 2.5 - Comunicação tradicional x comunicação multimídia [Fl95]

Redes multimídia necessitam de uma alta taxa de transferência, mesmo quando os dados estão compactados. Por exemplo, um arquivo MPEG-1 necessita de uma taxa de transmissão de 1.5 Mbps. MPEG-2 precisa de 4 a 10 Mbps, enquanto que para HDTV é de 5 a 20 Mbps.

Redes tradicionais foram feitas para serem livres de erros. Contudo, a maioria das aplicações multimídia pode tolerar transmissão de pacotes com erro, ou perda de pacotes, sem precisar que estes pacotes sejam retransmitidos ou corrigidos. Em alguns casos, para manter o tempo-real ou para manter a sincronização, alguns pacotes são descartados. Como resultado, os protocolos de transmissão não possuem muitas validações dos dados transmitidos, pois não podem possuir retransmissões. Isso implica num atraso indesejado, resultando na perda do sincronismo.

Redes multimídia têm que prover uma baixa latência para operações interativas. Como os dados multimídia precisam ser sincronizados, a rede deve prover sincronismo na transmissão com baixo jitter (é a variação sobre o tempo de atraso do tráfego da rede). Algumas comunicações multimídia são multipontos ao invés de ponto-a-ponto por exemplo, conferências envolvem mais de duas pessoas, e estas aplicações utilizam multicasting e método de distribuição bridging. Multicasting replica um único sinal de entrada e envia para os múltiplos destinos. Bridging combina múltiplos sinais de entrada dentro de um ou mais sinais de saída, que então são enviados para os participantes.

\section{Tecnologia das redes}

As redes tradicionais não suportam multimídia. Ethernet provê somente $10 \mathrm{Mbps}$, e seu tempo de acesso não é constante. A latência e jïtter são imprevisíveis. Token ring provê 16 Mbps e é determinística; de um ponto de vista, suporta multimídia. Contudo, no pior caso, o tempo de 
latência pode ser muito alto. Uma rede FDDI provê 100 Mbits, suficiente para multimídia. No seu modo síncrono, possui baixo tempo de latência e baixo jitter, garantindo um tempo de acesso previsível. Contudo, seu custo é muito alto. Geralmente é utilizada somente no backbone da rede, e não em todas as estações.[Ba93]

Uma forma alternativa mais barata é utilizar a tecnologia Fast Ethernet, ou a 100 VGAnylan, que provêem uma taxa de transferência de $100 \mathrm{Mbps}$, porém a $100 \mathrm{VG}$-Anylan possui um custo maior em relação a Fast Ethernet. Essas duas tecnologias surgiram como a finalidade de aumentar a taxa de transferência das redes.

Uma rede, para transmitir multimídia (vídeos gravados), deve possuir algumas características [F195] :

- Taxa de transferência : Maior de 1.4 Mbps para cada direção (full-duplex).

- Delay de transmissão : No máximo de 10 a $15 \mathrm{~ms}$, por causa do esquema de buferização de um playout.

- Comunicação multiponto: Funções de multicast devem estar embutidas na rede.

- Confiabilidade : Deve possuir um mecanismo de checagem diferente para dados multimídia.

\section{Características das redes existentes}

- Ethernet : É a tecnologia mais utilizada, trabalhando a uma taxa de transferência de $10 \mathrm{Mbps}$, com isso pode transmitir no máximo quatro vídeos comprimidos ao mesmo tempo. Utiliza o protocolo CSMA/CD o que é uma desvantagem, pois esse protocolo é não determinístico. Em situações de alta carga não há controle sobre o delay de acesso. Em aplicações tradicionais, não há problema, mas em aplicações multimídia, onde existe a necessidade de sincronismo e tempo real torna-se um problema sério, impossibilitando com isso a criação de um sistema multimídia satisfatório, a não ser que seja controlado o número de estações [St95].

- Token Ring : O protocolo de acesso é muito melhor que o da Ethernet para suportar dados multimídia. Uma vantagem é a taxa de transferência que é de $16 \mathrm{Mbps}$, ao invés de $10 \mathrm{Mbps}$. A característica mais importante é o nível MAC de prioridades. Ele pode ser usado para separar 
dados em tempo real (alta prioridade) e dados normais (baixa prioridade). Desta forma, as estações determinam que tipo de dado vai ser transmitido e se é de alta ou baixa prioridade, conseguindo com isso viabilizar comunicação multimídia.

- 100 Base-T : É a evolução da Ethernet (IEEE 802.3), e utiliza o mesmo protocolo de acesso CSMA/CD. Com isso, raramente excede $50 \%$ de utilização da bandwidth, porém como a taxa de transferência é de $100 \mathrm{Mbps}$, consegue uma taxa de transferência real de $50 \mathrm{Mbps}$, Transmitindor um grande número de dados multimídia, mas não garantindo o delay. 100 Base-T é uma escolha satisfatória para pequenas e médias configurações.

- 100 VG-Anylan : Outra tecnologia de rede a $100 \mathrm{Mbps}$, também conhecida por 100-Mbps Demanda de Prioridade, é uma evolução do padrão Ethernet e Token-Ring para 100 Mbps sobre par trançado categoria 3. Seu principal objetivo é aumentar a taxa de transferência, utilizando-se dos cabos e interconexões existentes. Uma rede 100VG-Anylan consiste em um bub central ou repetidor, que é um controle central que gerencia o acesso da rede por execução contínua de um esquema de controle de acesso "round robin", que garante que todas as requisições serão atendidas por ordem de chegada e por prioridade (neste esquema não há colisões). Este tipo de rede é melhor que a 100 Base-T, e é uma alternativa viável para comunicações multimídia, em particular para topologias que possui um pequeno número de estações.

- FDDI : Conceitualmente o FDDI é um superconjunto de fast token ring. A grande badwridth pode suportar um grande número de estações multimídia. Para utilizar FDDI para comunicações multimídia necessita-se de um esquema de gerenciamento de taxa de transferência adicional, porém o seu custo é bastante alto.

- FDDI II : É uma rede baseada sobre um protocolo de slotted-ring, derivada da FDDI para suportar melhor o tráfico em tempo-real, que consegue pré-alocar slots. Possui um complexo esquema de gerenciamento dinâmico da bandwridth entre dados assíncrono, síncrono e isócrono. FDDI II é parcialmente compatível com FDDI, já que toda a estação FDDI II suporta o tráfego de pacotes FDDI, mas o contrário não acontece.

- X.25 : É baseado no protocolo sliding windows e no mecanismo de recuperação de erros, obtendo desta forma uma variação e delay incontrolável. É utilizado em links com velocidades acima de 64 Kbps. Não possui multicasting. Por esses motivos, não é recomendado para redes multimídia. 
- ISDN : Foi desenvolvido para suportar uma grande variedade de serviços diferentes, sobre dados, fax e vídeo. É construído sobre um canal síncrono de $64 \mathrm{Kbps}$, que pode ser usado para bitstreams contínuos ou no tráfico de taxa de bits constante, como o H.261 vídeo, ou para comunicação por pacotes. ISDN é largamente utilizado na Europa. Pode ser utilizado na comunicação multimídia, tanto na ponto-a-ponto como na multiponto.

- ATM : Na rede ATM, todas as informações são adicionadas dentro de um slot de tamanho fixo chamado de célula, a qual é identificada e comutada por um rótulo (label) no cabeçalho (beader). A arquitetura ATM provê os ingredientes necessários para suportar requisições de aplicações multimídia.[Bi93]

\begin{tabular}{|c|c|c|c|c|}
\hline Rede & Bandwidth-Mbps & Delay: & Variância Delay & Broadcast \\
\hline Ethemet & 10 & Random & $\infty$ & + \\
\hline Token Ring & $4 / 16$ & $<20 \mathrm{~ms}$ & 0 & - \\
\hline 100 Base- $\mathrm{T}$ & 100 & Random & $\operatorname{Max}$ & + \\
\hline 100 Vg-Anylan & 100 & $<10 \mathrm{~ms}$ & $\operatorname{Max}$ & + \\
\hline FDDI & 100 & depende configuração & $\operatorname{Max}$ & + \\
\hline FDDI II & 100 & fixa $<1 \mathrm{~ms}$ & 0 & + \\
\hline $\mathrm{X} .25$ & $<2$ & Random & $\infty$ & - \\
\hline ISDN & $\mathrm{n} \times 0.064$ & fixa $<10 \mathrm{~ms}$ & 0 & - \\
\hline ATML & $25-155$ & limite $<10 \mathrm{~ms}$ & $\operatorname{Max}(\mathrm{AAI}, 5)$ & $(+)$ \\
\hline \multicolumn{5}{|c|}{$\begin{array}{l}\infty=\text { rede assíncrona sem controle da variância do delay } \\
\text { rede síncrona com variância do delay entre } 0 \text { e o delay máximo } \\
\quad 0 \text { - redes isócronas com delay constante }\end{array}$} \\
\hline
\end{tabular}

Figura 2.6 - Características das redes [He95]

\section{ATM}

Baseada em padrões internacionais, utiliza a tecnologia de comutação que acompanha o crescimento das taxas de dados e de número de usuários. Está sendo bastante difundida, e vários fabricantes já estão comercializando produtos que utilizam esta tecnologia. A rede ATM resulta da junção de dois conceitos: o de comutação de pacotes e o de multiplexação de divisão de tempo (Time Division Multiplexing, TDM).[Bi93]

ATM é a tecnologia que está sendo utilizada na rede pública B-ISDN. ITU define o modelo de referência do protocolo para B-ISDN, mostrado na figura2.7. 


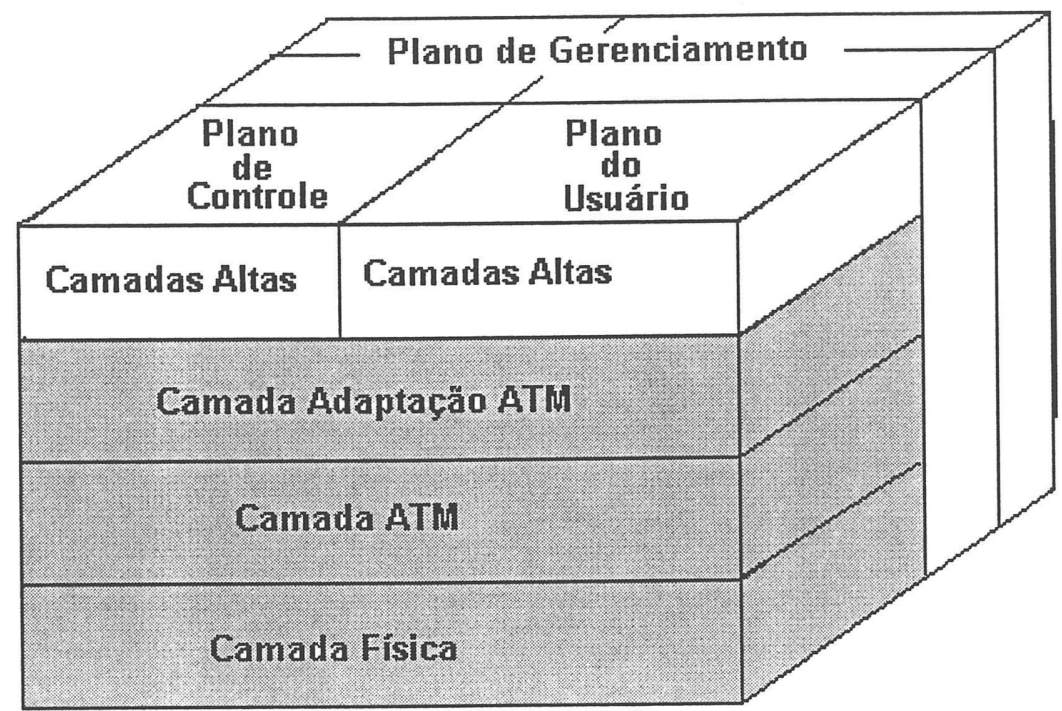

Figura 2.7 - Modelo de referência do protocolo para B-ISDN [He95]

\section{Camada física}

A camada física fica responsável pela definição da transmissão física. CCITT tinha como objetivo inicial a transmissão a uma taxa de $155 \mathrm{Mbps}$ através de um meio ótico. O fórum ATM definiu o uso de uma interface FDDI a 100 Mbps para LAN ATM. Outras opções incluíam pares trançados (UTP-3) a 25 ou $51 \mathrm{Mbps}$, e linhas síncronas (T3). No futuro, interfaces ATM poderão transmitir a 622 Mbps e poderão chegar até 2.4 Gbps.

\section{Camada ATM}

A camada seguinte, a camada ATM, é uma camada de chaveamento e multiplexação independentes da física. Para isso, foi introduzido o conceito de canal Virtual (VC), que é responsável pelo transporte unidirecional de células ATM, associado a um identificador único, conhecido como identificador VC ou VCI (Virtual Channel Identificator).

A camada ATM possui as seguintes características :

-Multiplexação e desmultiplexação de células de diferentes conexões (VCIs diferentes) sobre um único fluxo de células. 
- O cabeçalho (beader) das células é extraído/adicionado antes/depois na célula. A célula ATM é então entregue para/da camada de adaptação.

-A translação dos VCI deve ser requisitada pelo nós de comutação ATM.

-A implementação sobre a interface de rede do usuário de um mecanismo de controle de fluxo de acesso.

A camada ATM é responsável pelo gerenciamento das células ATM, e cada célula é formada por dois campos: um cabeçalho (header) de 5 bytes e um campo de dados com 48 bytes, totalizando 53 bytes.

Para fazer os roteamentos, as células ATM utilizam informações de endereçamento em rótulos (labels), e com isso conseguem manter um tamanho pequeno e fixo. Quando uma unidade de chaveamento lê uma célula entrando pela porta $\mathbf{i}$ com um rótulo $\mathbf{m}$, ela consulta sua tabela de roteamento, que foi iniciada anteriormente, e com esses dados determina uma porta de saída $\mathbf{j}$ e um novo rótulo $\mathbf{n}$ para essa célula, que assim será enviada a outra unidade de chaveamento. Chegando a essa nova unidade, o processo é repetido até que a célula encontre seu destino [Bo92].

\section{Camada de adaptação (AAL)}

Esta camada é responsável por fornecer serviços para a camada ATM de acordo com os requisitos de serviços especificados; com isso, permite o uso de diferentes protocolos pelas camadas superiores. Ela é responsável pela segmentação e montagem das células, controle de fluxo, de erros, etc. Essa camada é especificada segundo a CCITT em quatro classes de serviços, mostradas na figura 2.8, e sua classificação é feita de acordo com três parâmetros: tempo de espera entre a fonte e o destino, a taxa de bits constante ou variável, e o modo de conexão [Ba93]. 


\begin{tabular}{|c|c|c|c|c|}
\hline & Classe A & Classe B & Classe C & Classe D \\
\hline $\begin{array}{l}\text { Tempo de } \\
\text { Espera }\end{array}$ & \multicolumn{2}{|c|}{ relacionado } & \multicolumn{2}{|c|}{ sem relação } \\
\hline Taxa de Bits & constante & \multicolumn{3}{|c|}{ variável } \\
\hline $\begin{array}{l}\text { Modo de } \\
\text { Conexão }\end{array}$ & \multicolumn{3}{|c|}{ orientado a conexão } & sem conexão \\
\hline
\end{tabular}

Figura 2.8 - Classes de serviço para camada de adaptação ATM \{Gu94]

$\mathrm{Na}$ classe A existe uma relação de tempo entre a fonte e o destino. A taxa de bit é constante e o serviço é orientado a conexão. Um exemplo típico é o sinal voz a uma taxa de $64 \mathrm{Kbps}$. Esta classe possui a finalidade de transportar dados isócronos, como por exemplo, voz e vídeo H.261.

$\mathrm{Na}$ classe B também existe uma relação de tempo entre a fonte e o destino e o serviço também é orientado a conexão. Entretanto, possui uma taxa de bit variável, sendo isso de dificil implementação. Um exemplo típico é a taxa de bit variável para vídeo e áudio.

$\mathrm{Na}$ classe $\mathrm{C}$ não há relação tempo entre a fonte e o destino e a taxa de bit é variável. O serviço é orientado a conexão. Por exemplo, a transferência de dados orientados a conexão no plano do usuário e sinalização no plano de controle.

A classe $\mathrm{D}$ apresenta as características da classe $\mathrm{C}$, porém não possui conexão. Um exemplo é o tráfico entre interconexões de LANs.

A camada AAL ainda pode ser subdividida em duas subcamadas: a de segmentação e reencapsulamento (SAR) e a de convergência (CS). A subcamada SAR possui as funções de segmentação de PDUs (Protocol Data Unit - mais detalhes em [Br94]) sobre células ATM e reencapsulamento de células sobre PDUs. A subcamada de convergência é um serviço independente [Pr93]. 


\subsection{Aplicações de multimídia em rede}

Sistemas Multimídia possuem uma grande variedade de aplicações. Entre elas, estão sistemas de correio eletrônico multimídia, sistemas de conferência multimídia, e sistema de trabalho cooperativos pois estas aplicações necessitam de um sistema de rede. Nesses tipos de aplicações, os objetos multimídia são armazenados em um servidor e executados nas estações dos clientes [Fu95].

Uma aplicação que está sendo largamente utilizada é o Video-On-Demand, onde todos os vídeos e animações ficam concentradas num servidor, e disponivéis para os clientes. Maiores detalhes, sobre esta aplicação serão dados no capítulo seguinte. 


\section{Servidor Video-On-Demand}

Serviços de vídeo interativos são similares ao serviço de difusão de TV, mas apresentam uma alteração fundamental no paradigma da interface de TV. Eles foram projetados para suportar muitos canais simultâneos sobre um mesmo banco de dados. No sistema de TV tradicional, cada estação executa sua programação simultaneamente, e o usuário seleciona um canal especifico. Em contraste, um sistema interativo faz com que toda a programação seja apresentada ao usuário sem nenhuma restrição. O usuário pode executar qualquer parte da programação a qualquer hora [Li94].

\subsection{Tipos de serviços interativos}

Pode-se classificar os serviços de vídeo interativos em muitas categorias, dependendo do nível de interatividade que fornecem :

- Serviços Broadcast (No-VOD), similar aos canais de televisão, em que o usuário é um participante passivo e não possui nenhum controle sobre a sessão.

- Serviço Pay-Per-View (PPV) em que o usuário paga por uma programação especifica, similar ao serviço existente CATV (Cable TV).

- Serviço Quasi video-on-demand (Q-VOD), em que os usuários são agrupados pelo interesse comum que possuem. Os usuários possuem um controle rudimentar, ativado por chaveamento para os diferentes grupos.

- Serviços Near Video-On-Demand (N-VOD), em que funções de avançar e voltar são simuladas por transições em um intervalo de tempo discreto (da ordem de 5 minutos). Isto é feito utilizando vários canais que possuem a mesma programação, porém em tempos diferentes.

- Serviço True Video-On-Demand (T-VOD), em que o usuário possui total controle sobre a apresentação. O usuário tem todas as funções de VCR, incluindo avançar, voltar, congelar e posicionar diretamente. T-VOD aloca para cada usuário um canal exclusivo; com isso, o número de usuários do serviço fica limitado pelo número de canais disponíveis. 
T-VOD necessita de um sinal bidirecional entre o usuário e o controle central. Serviços T-VOD são essenciais para aplicações de jogos interativos, onde todas as ações dos jogadores são vistas pelos outros jogadores.

Os serviços interativos podem ser usados nas mais diversas aplicações, como se mostra na tabela 3.1, abaixo.

\begin{tabular}{|l|l|}
\hline Aplicacão & Descricão \\
\hline Movies-on-Demand & O consumidor pode selecionar e ver o vídeo com total \\
Filmes sob Demanda & capacidade de interação \\
Vídeos Games & Pode jogar o jogo sem ter que comprar uma cópia do jogo \\
Interativos & $\begin{array}{l}\text { O consumidor é capaz se selecionar uma noticia, e se quiser } \\
\text { Noticiário de TV interativo } \\
\text { Catálogos interativos }\end{array}$ \\
$\begin{array}{l}\text { Aprendizado a distância } \\
\text { ver mais detalhes a noticia }\end{array}$ & O consumidor examina e pode comprar produtos \\
& estudante pode ter preferências e horários individuais. \\
\hline
\end{tabular}

Tabela 3.1 Tipos de serviços interativos [F195]

\section{2 - Componentes do sistema para Video-On-Demand}

Um sistema VOD pode ser acessado simultaneamente por centenas de usuários com diferentes preferências. $O$ sistema tem que ser capaz de garantir a qualidade de serviço satisfatória ao consumidor. Um cenário típico de um VOD consiste em um banco de dados local e conectado com a casa dos usuários por uma rede de comunicação. Na casa do usuário, há uma interface de rede e um monitor. A interação do usuário com o sistema pode ser feita através de um controle remoto ou um teclado de computador. Esse sistema consiste na informação/ arquivo de programação no servidor que está conectado a uma rede de alta velocidade entre as regiões, e que estão conectadas com as casas dos usuários. Informações são copiadas do servidor principal e armazenadas nos servidores regionais, ficando a disposição dos usuários.[Fe94][OH94]

Sessões VOD possuem tempo de duração longo, se comparadas às tradicionais, e requerem uma continua transferência de dados. Os dados transmitidos (vídeo, áudio) necessitam de grande banda passante para serem transmitidos para as casas dos consumidores. Por esse motivo, utilizam métodos de compressão, com a finalidade de diminuir o volume de bits a serem transmitidos. As técnicas de compressão de vídeo e áudio serão explicadas a seguir. 


\subsection{Técnicas de compressão}

A compressão de dado digital é baseada em vários algoritmos computacionais, que podem ser implementados tanto em software quanto em hardware. Técnicas de compressão são classificadas em duas categorias: lossless e lossy. A técnica lossless é capaz de recuperar perfeitamente a representação original. A técnica lossy envolve algoritmos que recuperam a representação semelhante à original. A técnica lossy é mais utilizada na compressão de imagens gráficas e vídeos, porque essa técnica geralmente consegue alta taxa de compressão para esse tipo de mídia. Os esquemas de classificação para compressão lossless e lossy são mostrados nas figuras 3.2(a) e 3.2(b), respectivamente.[Fu95][Mo95a]

As técnicas lossy são classificadas em : (i) técnica baseada em predição, (ii) técnica orientada a freqüência, (iii) técnica orientada a importância, (iv) híbridas. A técnica baseada em predição, tal como ADPCM (adaptive differential PCM) prediz os valores subseqüentes, analisando os valores anteriores. A técnica orientada à freqüência usa a transformação Co-seno Discreta (Discrete Cosine form, DCT), que utiliza a transformação de Fourier. A técnica orientada à importância usa uma sa característica da imagem, como por exemplo, a base da imagem para compressão.

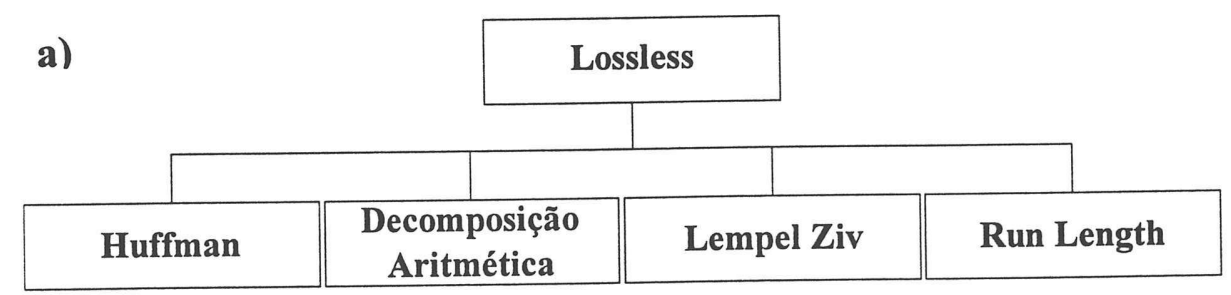




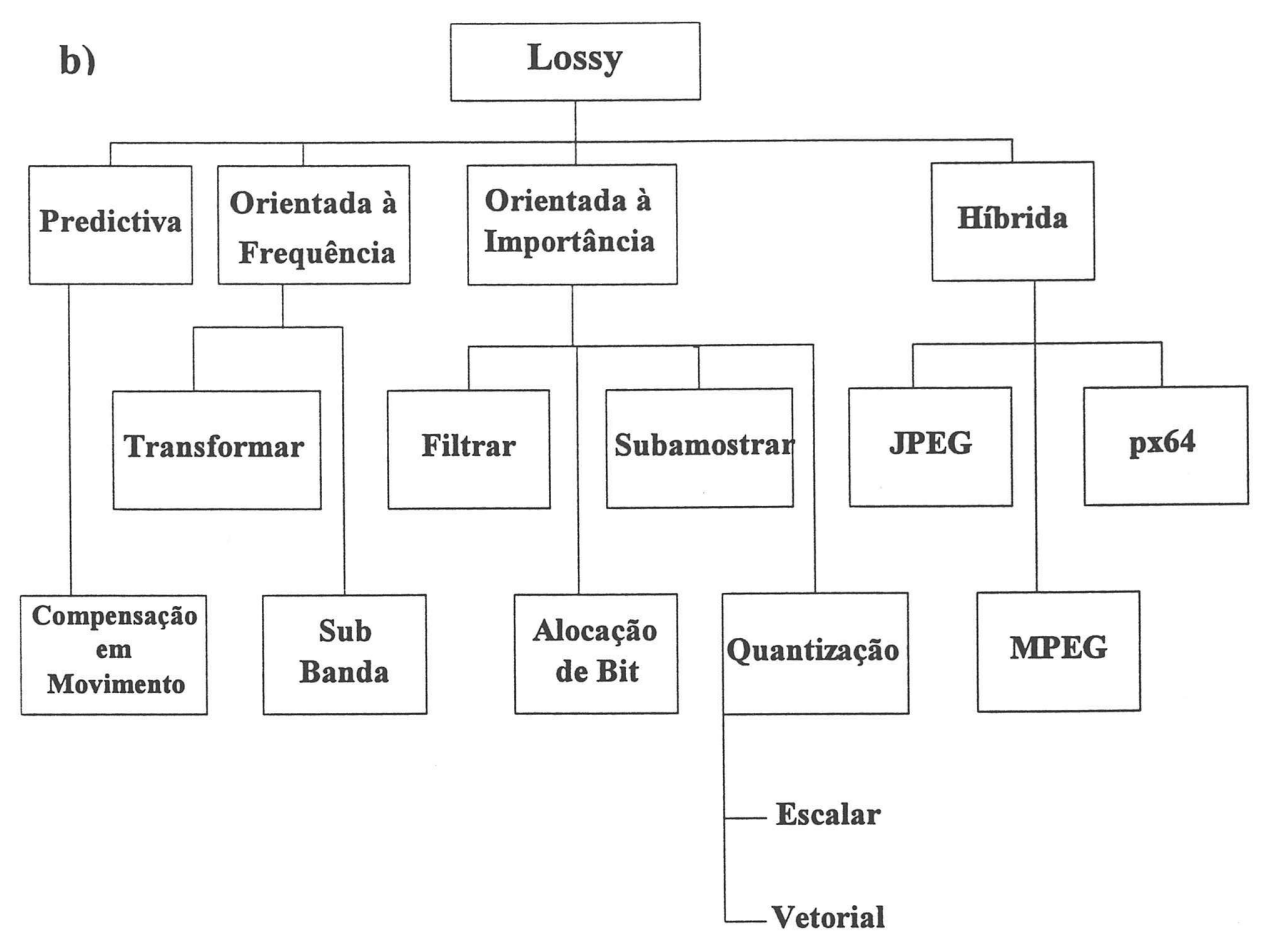

Figura 3.2 - Classificação para técnicas de compressão (a) Lossless e (b) Lossy [Ta93]

Existem também as técnicas de compressão híbridas, como por exemplo, JPEG, MPEG, H.261 e px64, que combinam várias técnicas, como por exemplo, DCT e quantização vetorial ou modulação por código de pulso diferencial (Differential Pulse Code Modulation, DPCM). Atualmente padrões para multimídia digital têm sido desenvolvidos baseando-se nessas três técnicas, como ilustra a figura 3.3.

\begin{tabular}{|c|c|c|c|}
\hline tipo & Designação & Grupo de Padróes & Ravaro de Compressão \\
\hline JPEG & $\begin{array}{l}\text { Compressão Digital e } \\
\text { codificação de imagens } \\
\text { paradas com tonalidade } \\
\text { contínua }\end{array}$ & $\begin{array}{l}\text { Grupo especialista em } \\
\text { fotografias }\end{array}$ & $\begin{array}{l}15: 1 \text { (aplicaçöes com } \\
\text { quadros parados cheio) }\end{array}$ \\
\hline H.261 px64 & $\begin{array}{c}\text { Codificador/Decodificad } \\
\text { or para serviços } \\
\text { audiovisuais no px64 } \\
\text { Kbps }\end{array}$ & $\begin{array}{l}\text { Grupo especialista em } \\
\text { codificação para } \\
\text { transmissão visual sobre } \\
\text { linhas telefônicas. }\end{array}$ & $\begin{array}{l}\text { 100:1 até } 2000: 1 \\
\text { (telecomunicações } \\
\text { baseadas em vídeo) }\end{array}$ \\
\hline MPEG & $\begin{array}{l}\text { Codificação de figuras em } \\
\text { movimento e áudio } \\
\text { associado }\end{array}$ & $\begin{array}{l}\text { Grupo de especialista em } \\
\text { figuras em movimento }\end{array}$ & $\begin{array}{l}200: 1 \\
\text { aplicaçós intensivas em } \\
\text { movimento }\end{array}$ \\
\hline
\end{tabular}

Figura 3.3 - Padrões de compressão multimídia [F195] 


\subsection{Compressão de vídeo}

Os arquivos de imagens e vídeos necessitam de grande volume de armazenamento. Desta forma é necessário adotar algum método de compressão para que possam ser transmitidos e armazenados. Existem algumas medidas importantes de compressão, dentre elas a taxa de compressão e bits por pixel. As principais técnicas de compressão são :

\section{JPEG e MJPEG}

JPEG é um padrão de codificação para imagens paradas desenvolvido pelo Joint Photographic Experts Group. Embora apresente essa característica, com a utilização de hardware especial é possível codificar e decodificar uma série de imagens JPEG em tempo real na velocidade requerida por vídeo em movimento [Re95]. Apesar de utilizar o método de codificação JPEG, esta abordagem é chamada de Motion JPEG ou MJPEG. Ainda não foi oficialmente padronizada.

Existem 4 tipos de operação para JPEG: seqüencial, progressivo, lossless e hierárquico [Cr95].

- Seqüencial é o modo mais simples é de fácil implementação, tanto em software como em bardware. Neste modo cada imagem é codificada em uma simples leitura da imagem da esquerda para direita e de cima para baixo.

- Progressivo: a imagem é codificada em múltiplas leituras. É utilizado para aplicações onde o tempo de transmissão é longo - o usuário vê a construção da imagem em múltiplos passos e a cada passo a qualidade da imagem vai melhorando.

- Lossless: a imagem é codificada de tal forma que sua recuperação é exatamente a imagem original. É bastante utilizada nas aplicações que necessitam de imagens de alta qualidade, como por exemplo, aplicações médicas onde qualquer perda é significativa.

- Hierárquico: Neste tipo a imagem é codificada em múltiplas resoluções; se a versão é de baixa resolução, deve ser decodificada sem interferir na decodificação de versões de alta resolução. Este modo é de grande ajuda quando se utiliza uma rede de comutação de pacotes. Em que somente os dados significantes para um determinado QoS (Quality of Service) serão transmitidos, permitindo assim que mais aplicações compartilhem os mesmos recursos de rede. Em casos de transmissão em 
tempo real em uma rede sobrecarregada, pode-se perder pacotes contendo dados de alta resolução, resultando na perda da qualidade, porém mantendo o sincronismo.

JPEG utiliza uma técnica de compressão espacial intraframe, codificação com transformação de Co-seno Discreta (DCT). Este tipo de técnica é usado também por outros métodos de codificação tal, como o H.261.

Codificação JPEG obtém compressão na ordem de 10:1 até 20:1 [Re95].

H.261

O H.261 é um padrão de compressão de vídeo desenvolvido para redes que trabalham em taxa de transferência entre $64 \mathrm{Kbps}$ a $2 \mathrm{Mbps}$, medida em intervalos de $64 \mathrm{Kbps}$. Esta técnica é também conhecida como "px64" onde " $p$ " varia de 1 até 30.

H.261 utiliza um método de codificação temporal interframe e codificação espacial intraframe. O algoritmo usado na codificação intraframe é baseado em DCT. No modo de codificação interframe, a compensação em movimento é executada para calcular as diferenças entre os quadros. A diferença, geralmente possui pequena magnitude; é então codificada em DCT.

O padrão H.261 suporta dois tipos de formatos, o CIF (Common Intermediate Format) que possui 288x352 pixels e o QCIF (Quarter CIF) que possui 144x176 pixels. O QCIF é uma operação mandatária, enquanto que o CIF é uma operação opcional. O QCIF é geralmente utilizado para taxa de bits pequena, na faixa de $\mathrm{p}<3$.

A codificação intraframe trabalha basicamente como em JPEG. Blocos de 8x8 são transformados em DCT, quantizados e codificados com entropy/run-length. Na codificação interframe, uma predição para blocos no frame corrente é feita se baseando-se nos frames anteriores. Se a diferença entre o bloco corrente e o bloco preditivo estiver abaixo de um certo valor, nenhum dado é transmitido. De outro modo, a diferença é calculada e transformada com DCT, quantizada e codificada com codificação entropy/run-length.

$\mathrm{Na}$ quantização, qunado é determinada a quantidade de informação que será transmitida, quanto mais informação for transmitida melhor a qualidade da imagem. O codificador H.261 ajusta o valor quantizado para conseguir uma taxa de bits constante [Re95]. 


\section{Network Vídeo (nv)}

Network Video (nv) foi desenvolvido pela Xerox/ PARC e é uma ferramenta de videoconferência para Internet. Esta é uma das ferramentas de videoconferência comumente utilizada sobre o Mbone Internet [Re95]. O Network Video utiliza a técnica de codificação compressão temporal (interframe) e espacial (intraframe). Essa técnica compara o frame corrente com o frame anterior e marcar as áreas que sofreram alterações significativas; então cada área alterada é comprimida, utilizando uma codificação de transformação. Periodicamente, partes não alteradas da imagem são transmitidas com alta resolução, alcançada pela eliminação do passo de quantização. Network video pode alcançar taxas de compressão de 20:1 ou mais [Re95].

\section{CU-SeeMe}

CU-SeeMe foi desenvolvido pela Universidade de Cornell, e é uma ferramenta de videoconferência para Internet. CU-SeeMe trabalha em 16 tonalidades de cinza usando 4 bits por pixel. Também utiliza método de compressão temporal (interframe) e espacial (intraframe). A imagem é dividida em blocos de $8 \times 8$ pixels para análise. Novos frames são comparados com os frames anteriores, e se ocorrer alteração significativa de um bloco ele é retransmitido. Periodicamente, todos os blocos são retransmitidos para contar as perdas que podem ter ocorrido na rede, que utiliza um método de compressão baseado em um algoritmo lossless desenvolvido na própria Cornell, e que explora a redundância espacial na direção vertical. O algoritmo de codificação CU-SeeMe foi projetado para rodar eficientemente sobre computadores Macintosh, e operar sobre linhas de 84 bit por pixel ou palavras de 32 bit, trabalhando bem em código assembly com 680x0. A taxa de transmissão básica do CU-SeeMe é de 80 Kbps. Este número é ajustado automaticamente através da analise do número de pacotes perdidos $[\operatorname{Re} 95]$.

\section{Indeo}

Esta técnica de compressão de vídeo foi projetada pela Intel e envolve tecnologia DVI (Digital Video Interactive). Indeo inicia-se com entradas YUV (Sistema de luminância e crominância usado pelo sistema PAL de televisão), sendo que $U$ e $V$ são subamostrados a uma razão de 4:1, tanto horizontal como verticalmente. Indeo suporta movimento estimativo, usando os frames anteriores para predizer os valores do frame corrente e os dados serão serão transmitidos se a diferença for significante. A codificação de transformação é feita usando uma transformação Slant Fast 8x8 na 
qual todas as operações são trocadas ou adicionadas (não múltiplos). Quantização e codificação runlength/entropy são usados como nos algoritmos anteriores. Indeo especifica que fluxo de bit codificado terá no máximo $60 \%$ dos dados de entradas; por isso, a compressão garante que na pior das hipóteses 1.7:1 [Re95].

\section{MPEG}

MPEG (Motion Picture Expert Group) envolve uma família de padrões de gravação e transmissão de informações de áudio e vídeo digital. A primeira série, MPEG-1, publicada com a referência de ISO 11172 (Le Gall,1991), é composta por várias partes distintas, incluindo [F195]:

- MPEG Video - IS 11172-2.

- MPEG-Audio - IS 11172-3.

- MPEG-System, que especifica como áudio e vídeo, pode ser multiplexada sobre um único canal de comunicação ou sobre um único dispositivo de armazenamento (Lu et al., 1994) IS-11172-1.

- MPEG-conformance testing - IS 11172-4.

- MPEG-Software - IS 11172-5.

- MPEG-2 foi publicado com a referência de ISO IS 13818.

Diferenças entre MPEG-1, MPEG-2, MPEG-4

O grupo ISO trabalhou na especificação de padrão de compressão de imagem em movimento em três fases, tendo cada uma um tipo particular de uso. Essas fases não são obrigatoriamente consecutivas e algumas sobreposições podem ocorrer entre elas.

Cada fase recebeu um nome : MPEG-1, MPEG-2, MPEG-3 e MPEG-4. Na prática, o desenvolvimento da MPEG-3 foi abandonada.

MPEG-1 é utilizado para armazenamento de qualidade VCR de seqüência de áudio e vídeo sobre CD-ROM. Funciona a uma taxa de 1.2 Mbps. MPEG-2 tem como objetivo a televisão com qualidade de estúdio e qualidade de CD com múltiplos canais de áudio, a 
uma taxa de 4 a 6 Mbps. Pode ser estendido para HDTV. MPEG-4 é uma nova iniciativa que tem como objetivo a qualidade de videoconferências, a uma taxa de transmissão muito baixa.

\section{Propósito do MPEG-1}

MPEG-1 foi a primeira versão do padrão MPEG. O nome oficial do documento é "Coding of Moving Picture and Associates Audio for Digital Storage Media at up to about 1.5 Mbps."

MPEG-1 foi desenvolvido para o armazenamento de áudio e sinais de animações coloridas sobre CD-ROM. Na prática, se o canal de áudio requisitar de 200 a 250 Kbps para qualidade de CD, a taxa do canal de vídeo não poderá ser superior a 1.15 ou $1.2 \mathrm{Mbps}$.

MPEG-1 é otimizado para uma resolução média. O modo ótimo é (Standard Interchange Format (SIF)).

$352 \times 240$ pixels para NTSC, $352 \times 288$ pixels para PAL/SECAM.

O taxa de compressão de vídeo é da ordem de 26:1.

\section{Propósito do MPEG-2}

O nome do documento que descreve o padrão MPEG-2 é "Generic Coding of Moving Pictures and Associated Audio."

MPEG-2 teve como intenção inicial a gravação e transmissão de animações com qualidade de estúdio a uma taxa de transmissão da ordem de 4 a 6 Mbps.

MPEG-2 foi projetado para resolução recomendada pelo ITU-R 601, que é 720 x 480 pixels para o sinal de luminância e 360 x 480 para o espaço de cor.

MPEG-2 pode operar tanto no modo progressivo como no modo entrelaçado. Na prática, MPEG-2 pode operar em taxa mais alta, conseguindo com isso qualidade de imagem HDTV. 


\section{MPEG-3 foi abandonada}

Inicialmente chamada de MPEG-3, tinha como objetivo a compressão e descompressão de HDTV. Contudo, com os resultados rápidos e positivos do desenvolvimento do MPEG-2, o MPEG-3 foi cancelado e o grupo do MPEG-2 ficou responsável para suportar HDTV.

\section{Propósito do MPEG-4}

O objetivo do MPEG-4 é reduzir drasticamente a taxa de transmissão. O título do documento que o descreve é "Very Low Bit Rate Audio-Visual Coding".

A taxa de transmissão considerada muito baixa é de 4.8 a $64 \mathrm{Kbps}$. A dimensão do frame $\left(\mathrm{n}^{\circ}\right.$ de nlinhas / $\mathrm{n}^{\circ}$ de colunas) é a recomendada pelo padrão ITU H.261. A taxa de frames é de 10 fps.

MPEG-4 é um padrão extremamente poderoso para qualidade de videoconferências a uma taxa de transmissão extremamente baixa. As aplicações podem ser por videoconferências e videofone.

\subsection{Compressão de áudio digital}

Da mesma forma que o vídeo digital, arquivos de áudio também necessitam de grande volume de armazenamento. Desta forma é necessário utilizar algum método de compressão para que possam ser transmitidos e armazenados. Existem muitas técnicas usadas para comprimir áudio digital, dentre as quais a comumente utilizadas estão descritas abaixo. Essas técnicas realizam compressão e descompressão em tempo real por meio de software ou hardware (geralmente de baixo custo) [Re95][Ba92].

\section{mu-law e A-law PCM}

Com métodos de codificação PCM (Pulse Code Modulation), cada amostra é representada por uma palavra código (word-code). PCM uniforme usa um quantizador uniforme de espaçamento. Executando uma transformação, o quantizador uniforme de espaçamento pode ser alterado para logarítmico (PCM logarítmico), permitindo que um intervalo maior de valores possam ser abrangidos com o mesmo numero de bits ( 8 bits por amostra). Com 8 bits por amostra utilizando PCM logarítmico pode-se representar intervalos maiores de valores, equivalentes ao requerido por 
14 bits para PCM linear [Pa93b]. Isto ocorre através de uma razão de compressão de 1.75:1 (quantia original de informação : quantia comprimida de informação). As técnicas de compressão de áudio mu-law e A-law utilizam esse tipo de transformação.

O formato de codificação PCM mu-law é comumente utilizado na América do Norte e no Japão em sistemas de telefonia digital com rede digital de serviço integrado (Integrated Services Digital Network, ISDN). O formato de codificação PCM A-law é utilizado com ISDN em outros países. G.711 é um padrão de áudio especificado em H.320 (discutido em [Re95]). Note-se que $8 \mathrm{kHz}, 8$ bits por amostra, e 1 canal, PCM mu-law ou A-law necessitam de uma largura de banda de 64 Kbps.

\section{ADPCM}

O método de codificação PCM codifica cada amostra de áudio independente das amostras adjacentes. Porém, as amostras adjacentes são semelhantes às outras e os valores de uma amostra podem ser prognosticados com a mesma precisão, usando o valor da amostra adjacente. Por exemplo, um método de predição simples é assumir que a amostra seguinte será a mesma da amostra corrente. O método de codificação ADPCM (Adaptive Differential Pulse Code Modulation) computa as diferenças entre as amostras e seu valor prognosticado e codifica a diferença (por isso o termo Differential). Com isso, apenas 4 bits são necessários para codificar a diferença. Recebe o termo de adaptativo por poder adaptar sinais característicos pela troca de parâmetros de predição e quantização. ADPCM obtém taxas de compressão de 2:1 quando comparado com o método PCM mu-law ou A-law.

Este método é utilizado em vários sistemas de videoconferência. A ITU-T possui várias recomendações definindo diferentes métodos ADPCM (G.721, G.722, G.723, G.726, G.727). Um dos métodos de codificação de áudio especificado pelo H.320 (discutido em [Re95] e [F195]) é o G.722, "7 kHz de codificação de áudio dentro de 64 Kbps", o qual usa codificação SB-ADPCM (SubBand ADPCM). O G.722 codifica amostras a uma taxa de $16 \mathrm{kHz}$ com 14 bits de precisão. Com o método SB-ADPCM, a freqüência de banda é dividida em duas sub-bandas (alta e baixa) e o sInal em cada sub-banda é codificados usando ADPCM. O G.722 tem três modos de operação: 64, 56 e $48 \mathrm{Kbps}$. Com os modos 56 ou $48 \mathrm{Kbps}$, o adicional 8 ou $16 \mathrm{Kbps}$ de largura de banda (assumindo um canal de comunicação de $64 \mathrm{Kbps}$ ) pode ser usado para outros dados. 


\section{LPC e CELP}

Alguns métodos de codificação foram desenvolvidos especialmente para voz, obtendo-se bons resultados. Esses métodos porém, não trabalham bem com sinais de áudio diferentes da voz. Dois métodos destinados para sinais de voz são LPC e CELP.

Um sinal de voz apropriado para o codificador LPC (Linear Predictive Coding) é um modelo analítico simples do sistema vocal. LPC é usado para comprimir áudio a 16 Kbps e abaixo disso. Um padrão que utiliza a codificação LPC simples é o padrão federal do U.S. 1015 que requer uma largura de banda de 2.4 Kbps. Do mesmo modo a codificação GSM (Groupe Speciale Mobite) usa uma variação do LPC chamado RPE-LPC (Regular Pulse Excited LPC). O GSM iteve início como padrão de codificação de voz para telefone celular na Europa. O GSM comprime 160 amostras de 13 bits (2080 bits) para 260 bits com uma razão de compressão de 8:1.

Um codificador CELP (Code Excited Linear Prediction) realiza o mesmo modelamento do sistema vocal como o codificador LPC. Com isso, ele computa o erro entre a voz de entrada e o modelo, e transmite o parâmetro do modelo e uma representação do erro. Os erros são representados como índices dentro de um livro código comum compartilhado pelos codificadores e decodificadores (por isso o termo Code Excited). O dado extra e a computação produzem uma codificação de alta qualidade comparada com a codificação LPC simples [Re95]. Um padrão que utiliza codificação CELP simples é o padrão federal do U.S. 1016 que requer uma largura de banda de 4.8 Kbps.

\section{MPEG}

O algoritmo de compressão de áudio MPEG é um padrão ISO para compressão de áudio com alta qualidade.

A família de padrões áudio MPEG é destinada a operar a uma taxa de bits comprimida que varia de 32 a $448 \mathrm{Kbps}$ por um canal monofônico. A taxa de amostragem pode ser 32, 44.1 ou 48 kHz. O MPEG-II adiciona três outras freqüências, 16 kHz, 22.05 e 24 kHz. O MPEG-I permite dois canais de áudio, enquanto que o MPEG-II permite mais cinco canais de áudio adicionais de baixa freqüência [Cr95]. 


\subsection{Qualidade de Serviço (QoS)}

O servidor de vídeo deve também ser capaz de suportar clientes heterogêneos (uma Workstation pode mostrar uma tela maior que um notebook) e que requeriram parâmetros de Qualidade de Serviço (QoS) diferentes, como o tamanho da tela, resolução, freqüência de frames, etc.

Do ponto de vista da CCITT, a qualidade de serviço irá determinar o grau de satisfação de um usuário final do serviço. Esta qualidade ao nível do usuário é abstraída pela manipulação do sistema através de alguns parâmetros [Ta93]. Essa parametrização permite a flexibilidade e a adaptação dos serviços, de modo que cada aplicação não implemente um novo conjunto de sistemas de primitivas de serviços [Na95].

Um sistema multimídia em rede consiste de pelo menos três abstrações de camadas abaixo das do usuário: um nível de aplicação; o nível sistema, incluindo serviços de comunicação e sistema operacional; e o nível de dispositivo, incluindo ambos os dispositivos de rede e multimídia. Visto que as três camadas incluem serviços, uma parametrização QoS é considerada em todas as camadas, (vide figura 3.4).

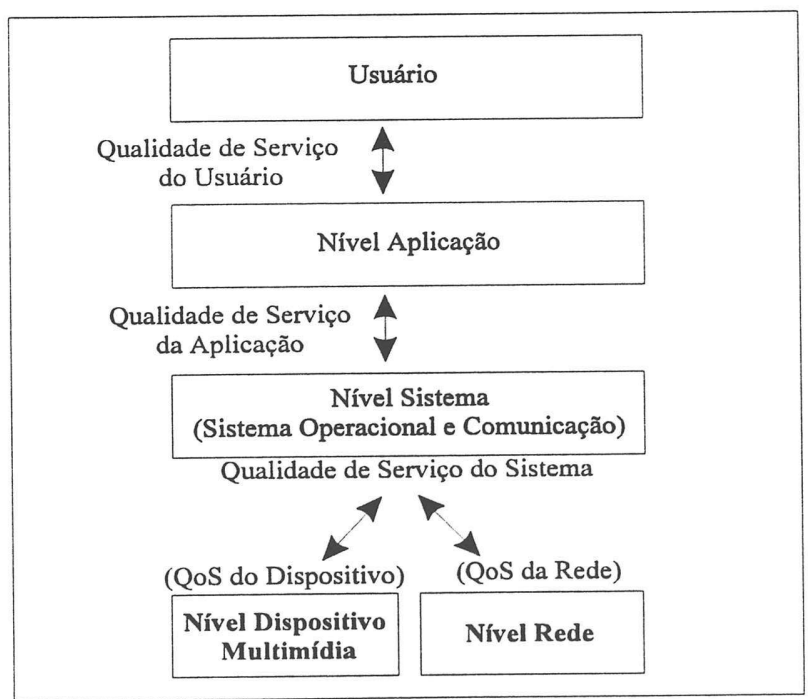

Figura 3.4 - Arquitetura de um sistema Multimídia em rede [Ta93] 
Parâmetros QoS da Aplicação descrevem os requisitos necessários de que a aplicação multimídia necessita, como por exemplo, qualidade do vídeo, som, características de transmissão tal como atraso ponto-a-ponto, etc.

Parâmetros QoS do Sistema descrevem as necessidades do sistema para a execução da aplicação. Esses parâmetros são especificados tanto em termos quantitativos como qualitativos. Quantitativos são aqueles que possuem medidas concretas, tais como bits por segundo, número de erros, tempo de processamento de tarefas, e tamanho das unidades de dados. Os qualitativos especificam o serviço esperado, como por exemplo, a entrega ordenada de dados, mecanismo de recuperação de erros, e mecanismo de escalonamento.

Parâmetros QoS da Rede podem ser especificados em termos de carga de rede e desempenho da mesma. A carga de rede refere-se aos requisitos do tráfego atual corrente tal como o tempo entre chegadas. O desempenho de rede descreve os requisitos que devem ser garantidos, tais como latência, taxa de transferência, e jïtter (a variância no atraso relacionado à quantidade de pacotes).

Parâmetros QoS do Dispositivo especificam as demandas de temporização e respostas para unidades de dados de mídia.

Os valores dos parâmetros determinam os tipos de serviços. Se os valores dos parâmetros QoS são especificados com qualquer limite determinístico ou estatístico, requerem garantia de serviço. Se o valor do parâmetro QoS está estimado baseado no comportamento passado do serviço, são requeridos serviços preditivos. Se nenhum dos parâmetros QoS for especificado, serviços de "melhor-esforço" são utilizados.

Os parâmetros QoS mais utilizados para multimídia são mostrados na figura 3.5. 


\begin{tabular}{|c|c|c|c|}
\hline Tipo da Média & $\begin{array}{l}\text { Parâmetro da } \\
\text { Qualidade de Serviço }\end{array}$ & Intervalo & Caracterização da Qualidade \\
\hline \multirow{5}{*}{$\begin{array}{l}\text { Áudio } \\
\text { QoS da } \\
\text { Aplicação }\end{array}$} & Tamanho da Amostra & 8 bits & Qualidade de voz de telefone \\
\hline & Taxa de Amostra & $8 \mathrm{KHz}$ & (Atraso Intermediário $125 \mu \mathrm{s}$ ) \\
\hline & Tamanho da Amostra & 16 bits & Áudio CD \\
\hline & Taxa de Amostra & $44.1 \mathrm{KHz}$ & (Atraso Intermediário $22.7 \mu \mathrm{s}$ ) \\
\hline & Ponto de Play-back & $=100$ até $150 \mathrm{~ms}$ & Depende do Atraso da Rede \\
\hline \multirow{9}{*}{$\begin{array}{l}\text { Áudio } \\
\text { QoS da Rede }\end{array}$} & Atraso ponto-a-ponto & 0 até $150 \mathrm{~ms}$ & Aceita muitos usuários apl. \\
\hline & & 150 até $400 \mathrm{~ms}$ & Impacto sobre algumas aplicações \\
\hline & & Acima $400 \mathrm{~ms}$ & Inaceitável \\
\hline & Atraso Round - Trip & Acima de $800 \mathrm{~ms}$ & Aceitável para conversação \\
\hline & Perda de Pacote & $<=10^{-2}$ & Qualidade de Telefone \\
\hline & Largura de banda & $16 \mathrm{Kbps}$ & Velocidade de Telefone \\
\hline & & $32 \mathrm{Kbps}$ & Velocidade de Audioconferência \\
\hline & & $64 \mathrm{Kbps}$ & Prox. a Qualidade do CD Áudio \\
\hline & & $128 \mathrm{Kbps}$ & Qualidade de CD Áudio \\
\hline \multirow{11}{*}{$\begin{array}{l}\text { Vídeo } \\
\text { QoS da Aplicação }\end{array}$} & Taxa de Frame & $30 \mathrm{fps}$ & Formato NTSC \\
\hline & & $25 \mathrm{fps}$ & Formato PAL \\
\hline & & $60 \mathrm{fps}$ & Formato HDTV \\
\hline & Largura do Frame & $<=720$ pixels & Sinal de Vídeo MPEG Codific. \\
\hline & Altura do Frame & $<=576$ pixels & Tamanho Vertical \\
\hline & Resolução das Cores & $8 \mathrm{bit} / \mathrm{pixel}$ & Resolução escala de cinza 256 \\
\hline & & 16 bits/pixel & 65.536 possíveis cores \\
\hline & Aspecto da Razão & $4: 3$ & Formato NTSC, PAL TV \\
\hline & & $16: 9$ & Formato HDTV \\
\hline & Razão de Compressão & $2: 1$ & Compressão Lossless de HDTV \\
\hline & & $50: 1$ & Compressão Lossy de HDTV \\
\hline \multirow{7}{*}{$\begin{array}{l}\text { Vídeo } \\
\text { QoS da Rede }\end{array}$} & Largura de banda & $<=1.86 \mathrm{Mbps}$ & Vídeo Codificado MPEG \\
\hline & & $64 \mathrm{Kbps}$ até $2 \mathrm{Mbps}$ & Vídeo Codificado H.261 \\
\hline & & Perto de $500 \mathrm{Mbps}$ & Compressão lossless HDTV \\
\hline & & $20 \mathrm{Mbps}$ & Compressão lossy HDTV \\
\hline & Taxa de Erro de Bit & $<=10^{-6}$ & Longa Taxa de Erro de Bit \\
\hline & Perda de Pacotes & $<=10^{-2}$ & Descompressão de Vídeo \\
\hline & & $<=10^{-11}$ & Compressão de Vídeo \\
\hline
\end{tabular}

Figura 3.5 - Parâmetros de Qualidade de Serviço (QoS) [Ta93]

\section{Especificações de recursos}

Sistemas multimídia em rede necessitam de recursos ativos e passivos para manipulação de dados. Um recurso ativo, tal como a CPU ou um adaptador de rede para processamento de protocolo, provê um serviço. Um recurso passivo, por exemplo, a memória principal ou largura de banda, são capacidades do sistema requeridos pelos recursos ativos.

Um recurso pode ser usado exclusivamente por um processo ou compartilhado entre processos. Por exemplo, um speaker é um recurso exclusivo, enquanto que a largura de banda da rede é um recurso compartilhado. 
Com isso, conclui-se que os parâmetros QoS especificam requisitos para a alocação de recursos do sistema bem como para disciplinas de serviço que gerenciam os recursos. Por exemplo, o parâmetro QoS de atraso ponto-a-ponto determina o comportamento dos serviços de transmissão ao longo do caminho entre a fonte e o destino da mídia com relação ao escalonamento de pacotes (alocação de a largura de banda), enfileiramento (alocação de buffer), e escalonamento de tarefas (alocação de tempo para processamento da CPU).

\section{Negociação e Tradução de Parâmetros QoS}

Uma arquitetura geral para comunicação de parâmetros QoS é composta de dois serviços: negociação e tradução de parâmetros QoS.

$A$ negociação envolve duas partes que são encontradas no processo de negociação QoS genérico, mostrado na figura 3.6. A negociação pode ser ponto-a-ponto (por exemplo, aplicação a aplicação) ou camada a camada (por exemplo, aplicação a sistema ou usuário a aplicação) [Na95].

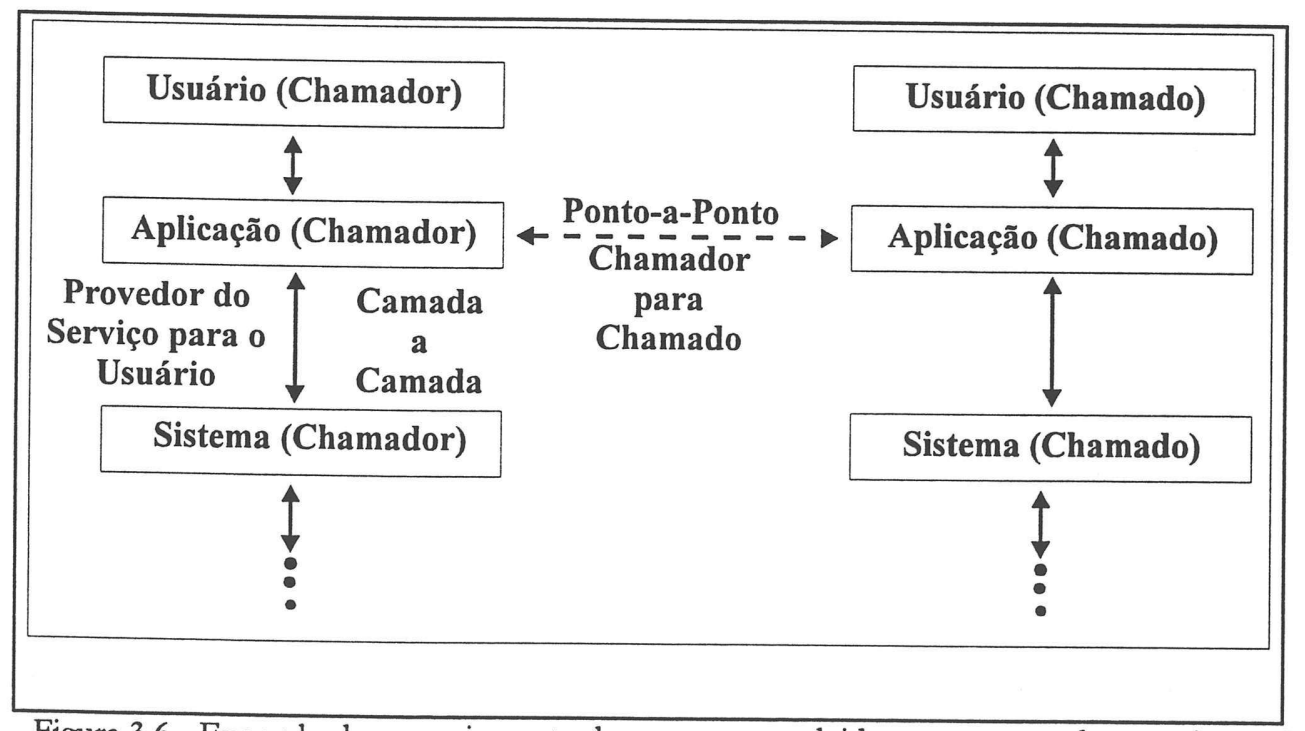

Figura 3.6 - Exemplo de gerenciamento de recursos envolvido no processo de negociação QoS

Os propósitos da negociação são: (1) estabelecer valores dos parâmetros QoS comuns entre os serviços dos usuários e dos fornecedores; e (2) capitalizar escassas capacidades de recursos, reservando somente a demanda real. As variações mais significativas de negociação entre o serviço do usuário (chamador/chamado) e o serviço do fornecedor são negociações bilaterais camada-acamada, ponto-a-ponto e triangular para um valor contratual. 


\subsection{Gargalos em potencial}

Num sistema multimídia todos os componentes (Sistema Operacional, Rede de Computadores, Meio de Armazenamento) são gargalos em potencial, já que se um deles não conseguir atender a requisição, todo o sistema estará prejudicado. Serão abordados os gargalos principais de um sistema multimídia:

\section{Sistema Operacional}

O sistema operacional controla todos os componentes de um sistema, como por exemplo, CPU, memória principal, armazenamento e todos os dispositivos de entrada e saída. Ele é fundamental para que um sistema multimídia tenha um bom desempenho. A maioria dos sistemas operacionais não foi desenvolvida para tratarem de aplicações multimídia, principalmente de serviços em tempo real (como vídeo e áudio), com tempo de latência fixo e troughput rígido. Por exemplo, na execução remota de um vídeo, a aplicação necessita que cada frame seja mostrado a uma taxa (precisa) de $33 \mathrm{~ms}$ [Hi92]. Contudo, a maioria dos sistemas operacionais não consegue oferecer esse serviço, pois o método de escalonamento não foi desenvolvido para aplicações em tempo real, e sim para atender de forma mais democrática possível, todas as requisições, por ordem de chegada.

Para solucionar esse problema foram desenvolvidos vários sistemas operacionais para atender as aplicações multimídia; entre eles estão :

Yartos (Yet Another Real-Time Operating System): Desenvolvido experimentalmente pela Universidade do Norte da Califórnia em Chapel Hill para comunicações em tempo real (principalmente aplicações de teleconferência), Yartos utiliza um algoritmo ótimo e preemptivo para o escalonamento das tarefas sobre um único processador e um esquema de sincronização integrado para acessar recursos compartilhados por um algoritmo EDF.As requisições são atendidas por um processo conhecido como real-time producer/consumer (RTP/C) [Hi92] [Sc96].

IBM OS/2 : oferece três modos possíveis para suporte multimídia, dentre os quais o mais utilizado é o gerenciamento de processo, estendido para processar mídias continuas como device drivers físicos (PDDs). Dessa forma o escalonamento em tempo real e o gerenciamento de processos são executados por um timer de alta resolução. Em principio, este é o esquema implementado pelo OS/2 Multimedia Presentation Manager, a extensão multimídia para o OS/2. 


\section{Rede de Computadores}

Os maiores empecilhos na transmissão de dados multimídia sobre uma rede de computadores, são : a largura de banda das redes tradicionais, relativamente baixas para atender uma comunidade de usuários, já que um vídeo comprimido necessita de pelo menos $1.2 \mathrm{Mbits}$ de banda passante, e as redes tradicionais operam a uma largura de banda máxima de 10 Mbits; outro problema é o delay não determinístico das redes, que é fundamental no serviço multimídia. Por exemplo, imagine-se um sistema telefônico, onde a comunicação sofra um atraso de 0.6 segundos perceber-sea que a comunicação fica bastante prejudicada. Experiências práticas com sistema de conferência multimídia e o padrão ITU sugerem um delay máximo de $150 \mathrm{~ms}$ para aplicações de vídeo interativos. Um outro problema é manter a sincronização das informações [He95].

Uma aplicação multimídia pode possuir fontes de informações diferentes (vídeo, áudio, figuras, etc). Também podem ser transferidas por diferentes rotas e, como foi visto anteriormente, uma aplicação multimídia deve manter um sincronismo entre estes dados, necessitando com isso a utilização de algum mecanismo de sincronização (um desses mecanismos é armazenar na estação toda a aplicação (downloading) e somente depois mostrar para o usuário).[Mo95b][Mo95c]

Quanto à largura de banda, como se viu anteriormente, já existem novas tecnologias de redes de alta velocidade, que possuem uma largura de banda maior e possuem as características necessárias para a execução de aplicações multimídia como, por exemplo, a rede ATM.

\section{Meio de Armazenamento}

O meio de armazenamento teve um grande avanço. Com a diminuição do custo do mesmo, foi possível o armazenamento de aplicações multimídia, já que estas ocupam grande volume de armazenamento. O maior empecilho no meio de armazenamento é a sua velocidade de acesso e transferência da informação. Por exemplo, um CD-ROM dupla velocidade possui uma taxa de transferência de $300 \mathrm{Kbps} / \mathrm{s}$, que é satisfatória para a maioria das aplicações multimídia, desde que utilizada somente por um único usuário. Já num servidor, o CD-ROM não é recomendado, assim como os discos magnéticos que utilizam o padrão E-IDE, que conseguem uma taxa de transferência de $20 \mathrm{MBps} / \mathrm{s}$ (utilizando modo PIO 4). As requisições de acesso ao disco são escalonadas pela CPU; com isso o processamento da CPU é paralisado para atender as requisições de I/O. Já os 
discos magnéticos que utilizam o padrão SCSI-II conseguem uma taxa de transferência de 40 $\mathrm{MBps} / \mathrm{s}$, para cada disco; além disso, todo o processo de recuperação ou armazenamento da informação é feito pela própria controladora SCSI, deixando a CPU livre para executar outras tarefas.[Ge95] 


\section{Tecnologias Empregadas}

Para a especificação e implementação de um sistema servidor de vídeo bem ajustado, foi necessário o estudo de várias tecnologias emergentes, tais como :

\subsection{Sistema Operacional Linux}

O Linux é um clone UNIX de distribuição livre inicialmente desenvolvido para PCs baseados em processadores 386/ 486/ Pentium, mas atualmente também existe versão para computadores Alpha da DEC, Sparcs da SUN, máquinas M68000 (semelhante a Atari e Amiga), MIPS e PowerPCs. Trata-se, portanto, de uma implementação completamente nova, pois não se baseou em nenhuma implementação anterior não havendo, incluse código proprietário em seu interior. O Linux pode ser livremente distribuído nos termos da GNU (General Public License).

O Linux possui todas as características que se pode esperar de um UNIX moderno, incluindo :

- Multitarefa real.

- Memória Virtual

- Biblioteca compartilhada

- Gerenciamento de memória própria

- Executáveis compartilhados

- Rede TCP/IP

- X Windows

A maioria dos programas aplicativos que rodam no Linux é freeware genérico para UNIX, dos quais muitos são provenientes do projeto GNU. 
Alguns benchmarks executados em sistemas Linux e que executam em 80486, tem mostrado que o Linux possui o mesmo desempenho de workstations médias da Sun e da Digital. Hoje em dia, seus usuários são milhares no mundo, direcionando a capacidade do sistema para o desenvolvimento de aplicativos, sistemas de rede e plataforma de usuário final. É, pois, uma alternativa real aos sistemas UNIX existentes, dado o baixo custo do sistema Linux,

\subsection{HTML e Applets}

O padrão HTML (Hypertext Markup Language)[Be94] tornou-se amplamente utilizado como formato para hiperdocumentos disponibilizados na WWW (World Wide Web). Esse formato, conhecido pelos browsers existentes (Netscape, Internet Explorer, etc), é formalmente definido por um DTD(define as regras para a especificação de uma classe de documentos) SGML(Standard Generalized Markup Language). Desse modo o padrão determina a maneira como um conjunto de elementos deve ser estruturado para compor um documento, além de. definir entre seus elementos, elos hipertexto e inclusão de outras mídias, referenciadas a Applets.[Le94a][Ni90][Tr97]

Uma applet Java é um programa Java transferido dinamicamente através de uma rede de computadores e apresentado através de browser que possuam a Java Virtual Machine. A diferença entre um applet e um arquivo de som ou vídeo, por exemplo, é que uma apllet não corresponde a uma animação ou a um arquivo de formato de mídia, mas sim a um código de programa. [Mo97]

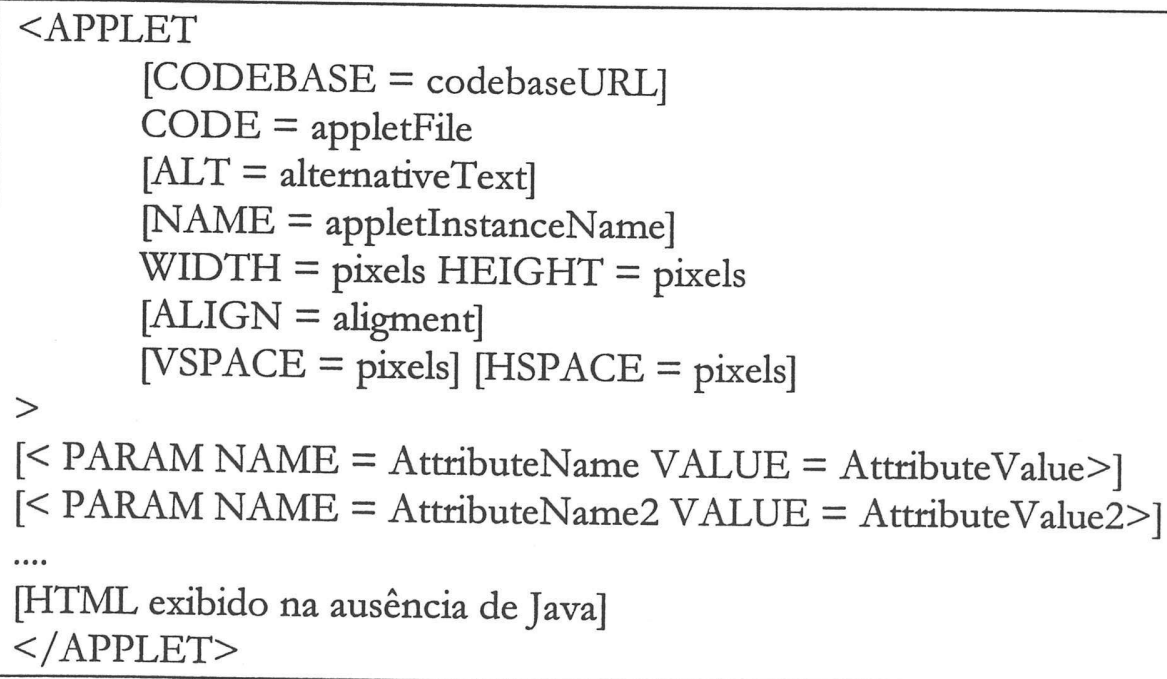

Figura 4.1 - Sintaxe de um applet 
A tag <applet> é usada para inicializar uma applet em um documento HTM. Sua sintaxe é mostrada na Figura 4.2.

A tag <applet> possui, como atributos obrigatórios, o nome do arquivo compilado que contém a applet(CODE), e o comprimento e a altura iniciais da janela em que a applet será exibida. Outro atributo importante é o codebase, que especifica uma URL onde o arquivo executável da applet é procurado. É possivel passar parâmetros para uma applet através do elemento PARAM.

\subsection{Java}

\subsection{1- Introdução}

Java é, ao mesmo, tempo um ambiente e uma linguagem de programação, desenvolvidos pela Sun Microsystems Inc., e e comercializada a partir de 1995. Seu desenvolvimento teve início em 1991, quando um grupo de desenvolvimento foi criado pela Sun Microsystem com o objetivo de desenvolver um ambiente de desenvolvimento de software multi-plataforma, para ser utilizado na programação de aparelhos eletrônicos portáteis (Ex: televisões interativas)[Wa96]Ja97].

A tecnologia Java ${ }^{[1]}$ consiste de uma linguagem Java, um ambiente de execução e um conjunto de ferramentas. É uma linguagem de programação orientada-a-objeto e derivada do C++, isto é, apesar de bastante similar, não se trata de um segmento da linha de linguagem C. A equipe responsável pelo estudo do Java, promoveram uma revisão das linguagens de programação (Objective-C, Smalltalk, Eiffel, Modula-3, e etc) e eliminaram vários itens desnecessários. Desse esforço, esta nova linguagem - Java - foi gerada, permitindo o rápido desenvolvimento de aplicativos. O resultado mais prático foi a economia de tempo e mão-de-obra.La97]

Uma das principais características que tornou o Java tão popular foi a sua arquitetura neutral, permitindo ao programador desenvolver um aplicativo que podesse rodar em qualquer plataforma : UNIX, Windows, Windows NT, OS/2 ou Macintosh, dentre outras. É apenas necessário que o computador em que estiver sendo executado o programa escrito em Java contenha a Plataforma Java que fará a interface entre a aplicação Java e o computador(hardware). A plataforma java é mostrada na figura 4.2.[Kr96] 


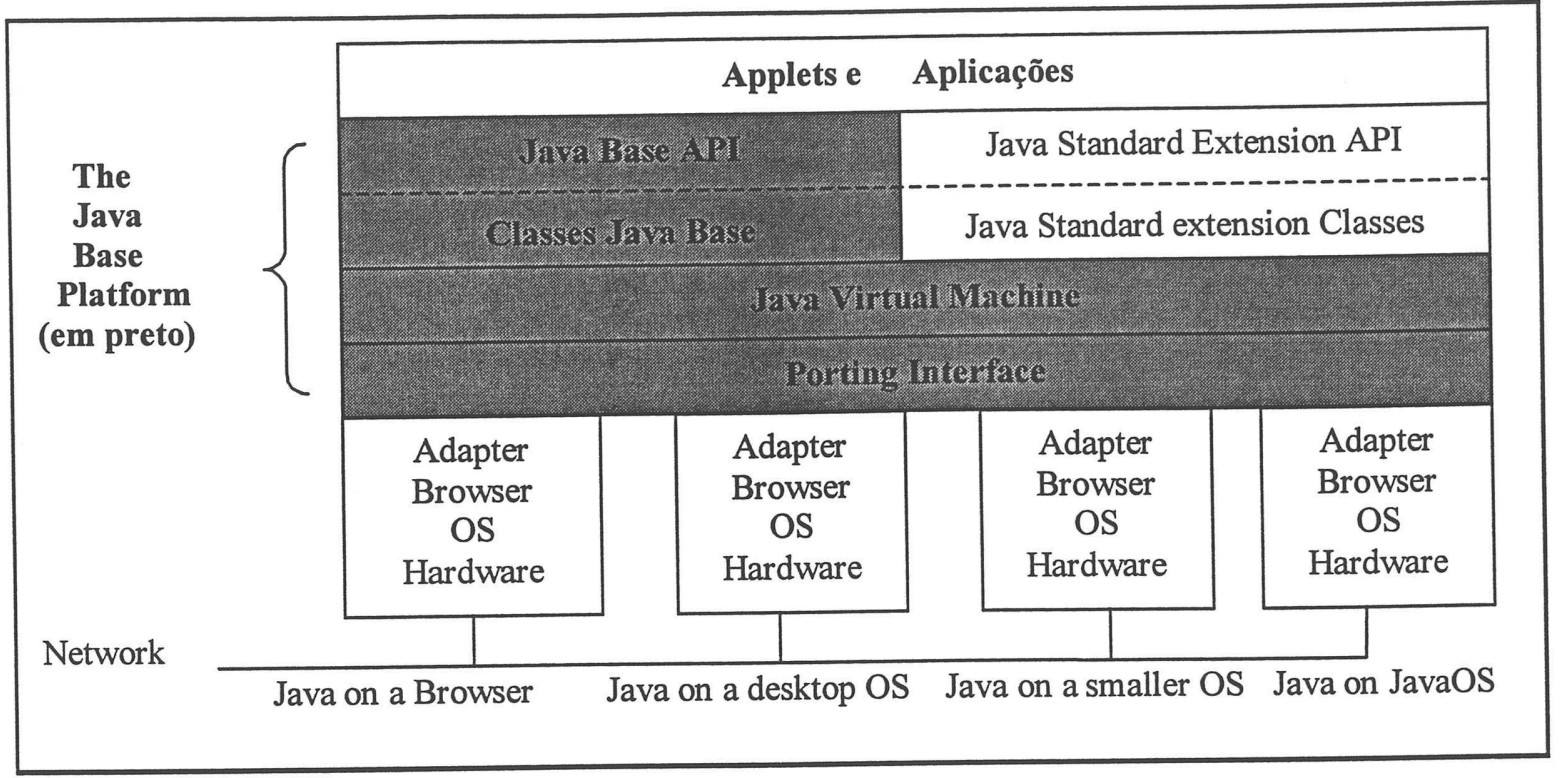

Figura 4.2 - Plataforma Java

\subsubsection{Plataforma Java}

A Plataforma Java possui duas partes principais: a Java Virtual Machine e a Java Api, como é mostrada na figura 4.2 .

Java Virtual Macbine - A Java Virtual Machine é um "software" computador que pode ser implementado em software ou hardware. É uma máquina abstrata, desenvolvida para ser implementada sob o topo de processadores existentes. A porting interface e adapters permitem que seja fácil a portabilidade para novos sistemas operacionais sem a necessidade de sua reescrita.

Java API - A Java API forma uma interface padrão para applets e aplicativos, independente do sistema operacional. A API Java é a estrutura essencial para o desenvolvimento de aplicações, pois ela especifica um conjunto de interfaces essenciais em um número crescente de áreas chaves, que os desenvolvedores poderão utilizar para construir suas aplicações Java.

Nesta figura, a Base da Plataforma Java é mostrada em preto, incluindo o bloco dos adaptadores. A Java API inclui as classes Java Base API, Java Standard Extension API, que são as implementações das API. A Java Virtual Machine é o núcleo da plataforma. A Porting Interface possuí uma parte independente da plataforma (mostrada em preto) e uma parte dependente da plataforma, mostrada como Adapters. O Sistema Operacional e JavaOS provêem a janela, 
arquivamento e funções de rede. Por fim, diferentes máquinas podem ser conectadas por uma rede, como é mostrado na figura 4.2 .

Java permite que os desenvolvedores criem dois tipos diferentes de programas, a saber:

- Applets : são programas que exigem um browser para ser executados. Quando a página é acessada por um usuário, tanto sobre a internet ou intranet coorporativas, o applet é automaticamente transferido do servidor e executado sobre o computador do cliente. Por serem transferidos, eles tendem a ser desenvolvidos de forma pequena ou modular, evitando, assim, longos tempos de transferência.

- Aplications : são programas que não necessitam de um browser para serem executados - eles podem ser embutidos em mecanismos de transferências, que seja: quando uma aplicação é chamada, ela é executada. Deste modo, esses aplicativos são iguais a programas de outras linguagens: podem efetuar tarefas tradicionais, como um editor de texto, planilha eletrônica ou aplicativos gráficos. Como um applet, estes aplicativos necessitam da Plataforma Java para poderem ser executados, contudo a plataforma ou pode estar disponível num programa separado, ou ser embutida direta e independentemente do sistema operacional, ou ainda, ser embutida dentro do próprio aplicativo.

\subsubsection{Características}

Orientada a objetos. As linguagens modeladas segundo este paradigma seguem a mesma filosofia básica de programação, mas diferem em sintaxe e estilo. Elas oferecem muitas vantagens sobre as linguagens procedurais tradicionais. Como os objetos encapsulam dados e funções relacionados em unidades coesas, é fácil localizar dependências de dados, isolar efeitos de alterações, realizar outras atividades de manutenção, e talvez o mais importante, as linguagens OO facilitam a reutilização dos códigos de programas.

Distribuída. Possui uma biblioteca de procedimentos TCP/IP incluída nos código-fonte, possibilitando, assim, o desenvolvimento de aplicações distribuídas.

Compilada e Interpretada. Um programa Java é compilado para o chamado "byte-code", que é similar às instruções de máquina, mas não de uma máquina real. $\mathrm{O}$ "bytecode" é um código de 
uma máquina virtual idealizada pelos criadores da linguagem Java, portanto pode ser mais rápida na execução que se fosse simplesmente interpretada.

Independente de arquitetura. A neutralidade da Java em relação à arquitetura embora fascinante, não é um conceito novo. Derivado da natureza distribuída de cliente/ servidor, um importante recurso do projeto do Java é o suporte a cliente e servidores em configurações heterogêneas de rede. O método escolhido para atingir esse objetivo foi uma representação binária de arquitetura neutra para os programas em Java.

Mutithreading. Os objetos binários de código de bytes de Java são formados por seqüências de execução múltiplas e simultâneas. Essas seqüências são conhecidas como contextos de execução ou processos leves. As linguagens $\mathrm{C}$ e $\mathrm{C}++$ são membros de um paradigma de execução em seqüência única, por não oferecerem suporte a seqüências no nível da linguagem. O Java, no entanto, oferece suporte no nível de linguagem para multitbreading, resultando em uma abordagem de programação mais funcional e de múltiplas threads.

Dinâmica. Os projetos dinâmicos permitem que os programas em Java se adaptem aos ambientes computacionais mutantes. Isso significa que mesmo havendo atualização de suas bibliotecas de classes (inclusão de novas variáveis de instância e métodos), não haverá problema nos programas, aplicativos e clientes já existentes, pois Java atrasa a união dos módulos, permitindo aos programadores total aproveitamento da orientação a objetos.

Segura. Por Java ter sido criado para ambientes de rede, os recursos de segurança receberam muita atenção. A eliminação do uso de ponteiros, em favor do uso de vetores, objetos e outras estruturas substitutivas resulta em benefícios em termos de segurança. O programador é proibido de obter acesso à memória que não pertence ao seu programa, além de não ter chances de cometer erros comuns, tais como "reference aliasing" e uso indevido de aritmética de ponteiros. Estas medidas são particularmente úteis quando pensamos em aplicações comerciais desenvolvidas para a internet.

A presença de mecanismos de tratamento de exceções torna as aplicações mais robustas, não permitindo que elas abortem sua execução, mesmo quando executados sob condições anormais.

Simples. Procurou-se criar uma linguagem familiar e de rápida aceitação no mundo do desenvolvimento Orientado a Objeto. Java é simples porque é pequeno:, o interpretador básico de 
Java ocupa aproximadamente $40 \mathrm{~KB}$ de RAM, excluindo-se o suporte à multitarefa e às bibliotecas padrões, que ocupam outros $175 \mathrm{~KB})$.

Desempenho. Há muitas situações em que a interpretação de objetos de códigos de bytes (bytecode) proporciona desempenho aceitável. No entanto, outras circunstâncias exigem desempenho mais alto. Java concilia tudo isso oferecendo a tradução dos códigos de bytes para o código nativo da máquina em tempo de execução. $O$ alto desempenho permite a implementação de Applets aplicativos WEB em Java na forma de programas pequenos e velozes, que podem ampliar significativamente os recursos tanto do cliente quanto do servidor.

\subsection{4 - Bibliotecas}

É necessário possuir um conjunto de bibliotecas de classes, que implementam funções vitais para qualquer applet Java, além de funções complementares que facilitam o desenvolvimento desses applets. Os pacotes de uso mais comum são:

- java.applet: contém as classes necessárias à implementação de applets. A principal classe é a Applet, que praticamente contém todos os métodos que usamos desse pacote.

- Java.awt: implementa as classes relacionadas aos elementos de interface gráfica do Java. Contém classes que implementam janelas, botões, áreas de texto, caixas de diálogo, listboxes, etc.

- java.io: contém classes que implementam várias formas de entrada e saída de dados baseadas em arquivos e streams.

- Java.lang: contém as classes que dão suporte ao modelo computacional do Java. É essencial para o funcionamento de quelquer programa em Java.

- Java.net: Contém os métodos necessários para desenvolver aplicações para a internet. Permite implementar, por exemplo, leitura de URLs, conexões através de sockets, endereços TCP/IP, etc.

- java.util: este pacote contém uma variedade de classes utilitárias, como pilhas, tabelas hash, vetores, geradores de tokens, etc. 
Java possui a capacidade de integrar novas bibliotecas para estender a sua funcionalidade e usabilidade, conhecidas como Application Programming Interfaces (APIs). Uma destas bibliotecas é a Java Databases Connectivity, ou JDBC[Pa96], que possui a função de conectar banco de dados à linguagem Java.

\subsubsection{JDBC (Java Database Connectivity)}

O JDBC teve seu projeto iniciado em janeiro de 1996 e suas especificações divulgadas em Junho de 1996. Atualmente a maioria das companhias que comercializam gerenciadores de banco de dados já desenvolveu o JDBC para suas plataformas, dentre eles Borland, Informix, DB2, Imaginary (mSQL), Sybases, Oracle, etc.[Pa96][je97]

JDBC foi baseado no padrão ANSI SQL-92. Pode ser dividido em duas partes: a programação em baixo nível e a interface de aplicação de alto nível. A programação de baixo nível e o driver JDBC são desenvolvidos pela própria companhia que comercializa os gerenciadores de banco de dados ou por desenvolvedores. Os drivers JDBC podem ser flexíveis. A implementação das conexões dos dados do banco de dados é deixada interamente para o driver JDBC.

A estrutura do JDBC inclui os seguintes conceitos :

- objetivo do JDBC são uma interface DBMS (database manager system) independente, com acesso genérico de banco de dados através de SQL; e uma interface única para as diferentes fontes de dados.

- o programador escreve somente uma interface. Usando JDBC, o programa pode acessar qualquer fonte de dado sem necessitar refazê-lo. 
A Figura 4.3 mostra a arquitetura JDBC. A classe DriverManager é utilizada para abrir a conexão com o banco de dados via driver JDBC, que precisa ser registrado junto a DriverManager antes da conexão ser feita. Uma vez conectado, o DriverManager escolhe da lista de drivers o tipo especifico da conexão. Após a conexão, são formadas, as chamadas das query e os resultados são feitos diretamente com o driver JDBC. O driver JDBC precisa implementar essas classes para processar as funções para o banco de dados específico, cuja especificação rígida permite que o drivers execute como o esperado. Essencialmente, o desenvolvedor que possui o driver JDBC para um determinado banco de dados não necessariamente precisa se preocupar sobre alterações do código para o programa java se um tipo diferente de banco de dados está sendo utilizado.

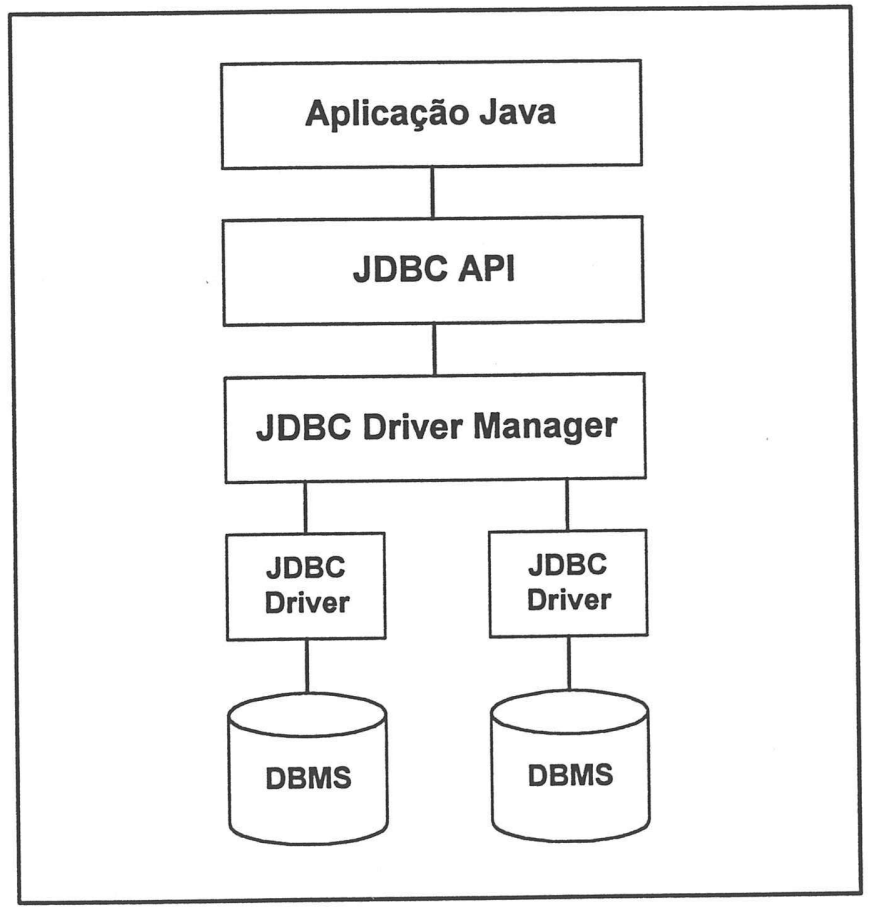

Figura 4.3 Arquitetura JDBC[Pa96]

O JDBC utiliza uma sintaxe URL para especificar o banco de dados. Por exemplo, uma conexão para o banco de dados $\mathrm{mSQL}$, seria:

jdbc:msql://chapinha.intermidia.icmsc.sc.usp.br:1112/serverdb 
Uma consulta em java seria, portanto :

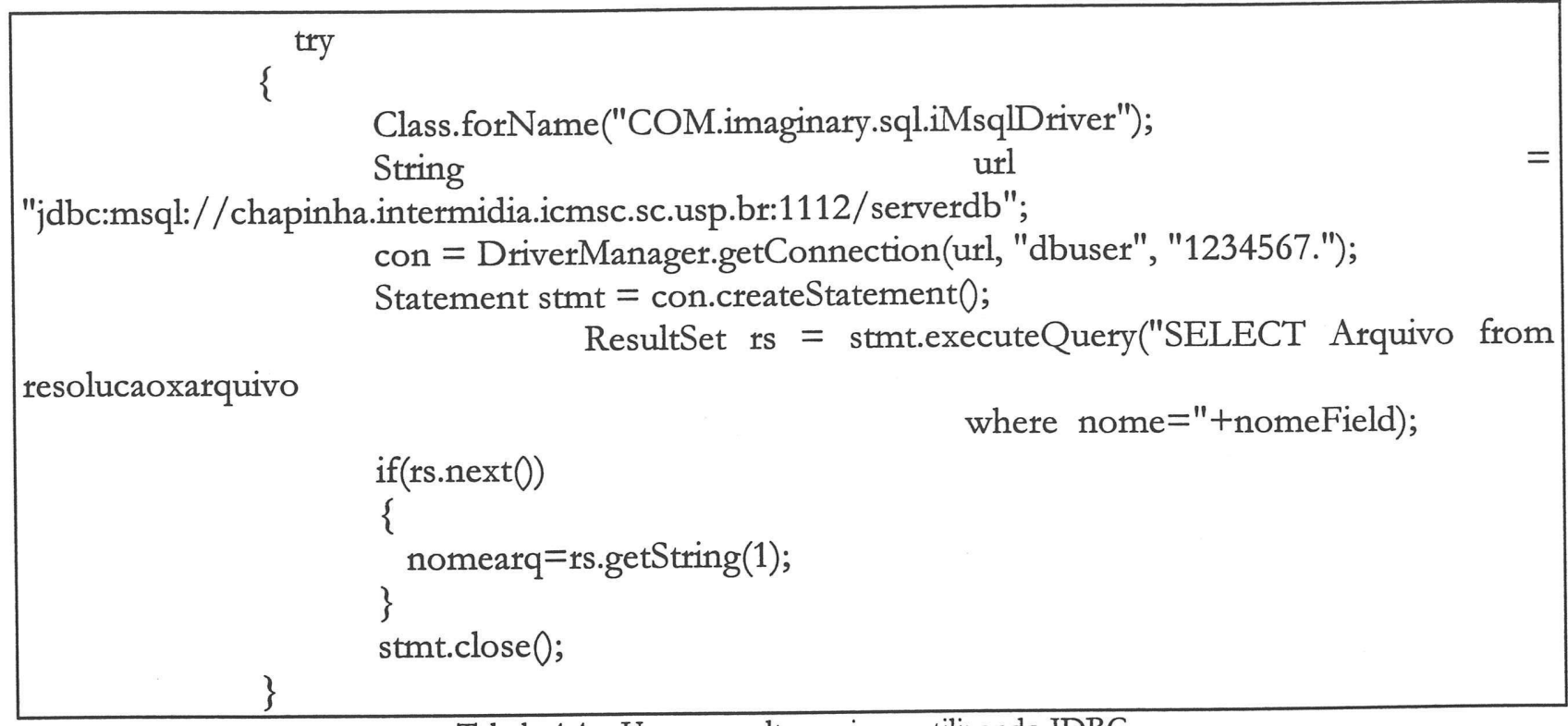

Tabela 4.4 - Uma consulta em java utilizando JDBC

$\mathrm{Na}$ sintaxe da URL, são especificados o transporte (jdbc) a ser utilizado, o tipo do banco de dados (msql), o nome do servidor(chapinha.intermidia.icmsc.sc.usp.br), a porta (1112) em que o servidor está utilizando e a base de dados(serverdb) a ser utilizada.

\subsubsection{Java Media Framework}

Com lançamento oficial pela JavaSoft em março de 1997, o Java Media Framework (JMF) provê uma API (Application Programming Interface) para execução e captura de mídias,além da videoconferência. A JMF API foi desenvolvida para suportar diversos tipos de mídia, incluindo MPEG-1, MPEG-2, QuickTime, AVI, WAV, AU, e MIDI. Usando Java Media player, um programador pode sincronizar e apresentar mídia baseada em tempo de diversas fontes.

Existem players sobre computadores pessoais que estão fortemente dependentes do código nativo, para tarefas de intenso processamento computacional, como é o caso de descompressão e renderização. Alguns Java Media Players necessitam de código nativo para suportar recursos específicos do hardware ou do sistema operacional. Como Java aceita tanto Java bytecode quanto métodos nativos, desenvolvedores e usuários podem escolher formas diferentes de implementação do player usando não só Java, como também objetos nativos.[mm97] 
O Java Media Player APIs suporta três níveis de uso:

- Nível Cliente - um programador pode criar e controlar um Java Media Player para qualquer tipo de mídia padrão para ser usado em algumas chamadas de métodos simples.

- Nível avançado - um programador pode modificar um player existente e adicionar novas funcionalidades. Para permitir a troca de partes de um player individual, JMF provê uma forma para adicionar funcionalidades para um player sem a necessidade de construir outro novo.

- Nível projeto - um programador pode adicionar novos players para suportar formatos novos de mídia. Novos players são criados por extensões da JMF, podendo ser utilizados lado a lado com os players já existentes.

\subsubsection{Origem da Mídia}

Um Java Media Player encapsula a mídia original; ele é construído para uma mídia original particular, identificada por uma URL (Universal Resource Locator) e não pode ser reutilizada por outras streams media.

Java Media Players pode obter os dados de mídia de uma grande variedades de origens, como arquivos locais e arquivos da rede.

Existe duas formas de ser feita a transmissão dos dados para o cliente, a saber:

- Reliable - o cliente recebe todo o pacote(arquivo) de uma fonte de dados confiável, como um arquivo local ou um arquivo da rede. Somente após o recebimento total é que o arquivo é executado. O protocolo utilizado para isto é o HTTP (Hypertext Transfer Protoco) ou FILE.

- Streaming - o dado de uma fonte media streaming não é garantida. Os tipos de dados streaming incluem a broadcast media, multicast media, e video-on-demand (VOD). Para dados broadcast, um dos protocolos utilizados é o RTP (Real-time Transport Prrotoco), desenvolvido pela Internet Engineering Task Force (IETF). O protocolo Media Bases desenvolvido pela SGI é o protocolo utilizado pelo $V O D$. 


\subsubsection{Criação de um applet para executar um arquivo de mídia}

Um programa-exemplo PlayerApplet demonstra como criar uma java Media player e apresentar um vídeo MPEG de um Java applet.

O tag Applet é usado para invocar PlayerApplet dentro de um arquivo HTML, sendo especificado na tag Applet os campos WIDTH e HEIGHT do HTML tag Applet determinam a dimensão da apresentação dentro da janela do browser. O tag $P A R A M$ identifica o arquivo de mídia para ser executado. Por exemplo, PlayerApplet pode ser invocado com :

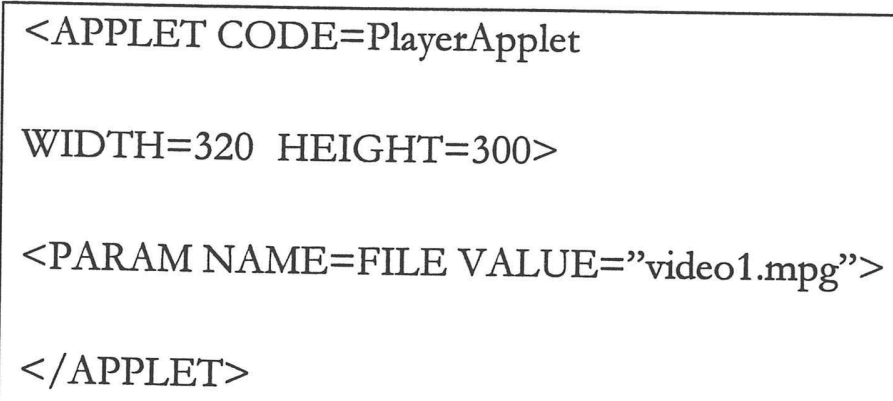

Quando o usuário abre a página que contém PlayerApplet, o applet carrega automaticamente o arquivo de vídeo e executa o vídeo em um espaço específico de apresentação, que contém os componentes visuais do player e os controles padrões. O player e iniciado e toca o vídeo mpeg uma vez, como é mostrado na figura 4.5. O usuário pode usar os controles para parar, reiniciar, ou apresentar novamente o vídeo. 


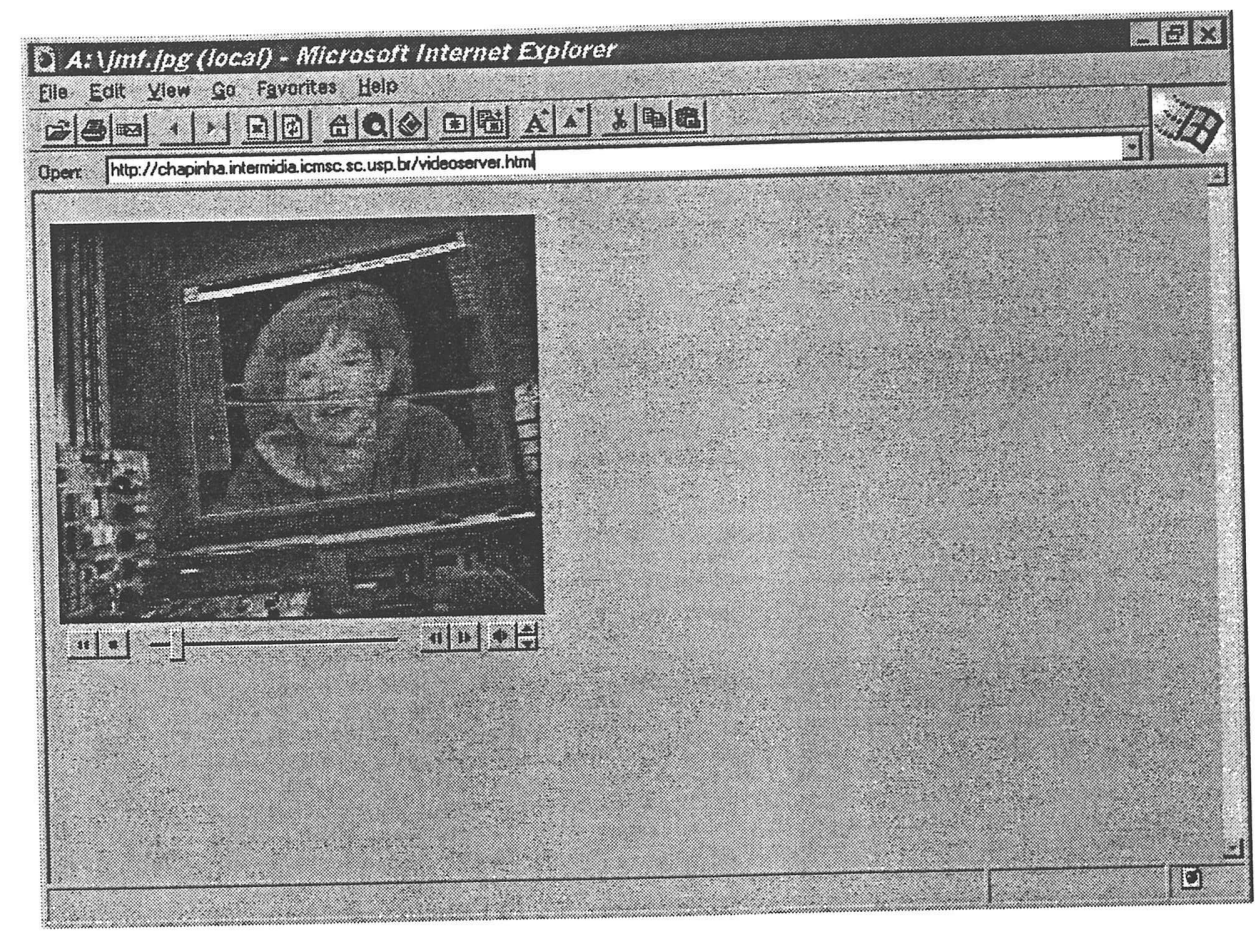

Figura 4.5 - Player de um vídeo MPEG sobre uma página html.

\subsection{Mini-SQL}

\subsection{1 - Introdução}

Mini-SQL é um banco de dados desenvolvido para prover acessos rápidos dos dados armazenados com uma baixa necessidade de memória. Ele suporta somente um subconjunto do SQL (no views, sub-queries, etc.) e está de acordo com as especificações do ANSI SQL. O pacote MSQL inclui o banco de dados, um programa monitor, um programa de administração do banco de dados, um viewer, e uma API da linguagem C. A API e o banco de dados foram desenvolvidos para trabalhar em ambientes cliente/servidor sobre uma rede TCP/IP.[Hu96]

\subsection{2 - Especificações}

A linguagem $m S Q L$ oferece um subconjunto significativo das funções providas pelo ANSI SQL, permitindo que um programa ou usuário armazene, manipule e recupere dados da tabela. 
Enquanto não possui suporte para todas as operações relacionais definidas pelas especificações ANSI, mSQL provê a capacidade de "joins" entre as múltiplas tabelas.

O Mini-SQL (mSQL) também se caracteriza como um gerenciador de banco de dados relacional, desenvolvido pela Imaginary, e que é de distribuição gratuita para fins educacionais. Pode ser executado nas mais diversas plataformas(Sun Solaris, Linux, Free BSD, etc), além de permitir. o acesso de múltiplas conexões e o recebimento de seqüências de requisições. Testes preliminares demostraram que o seu desempenho é igual ou melhor aos gerenciadores de banco de dados similares, de domínio público. Por exemplo, sobre um conjunto de queries incluindo inserts, updates e selects, o desempenho do $\mathrm{mSQL}$ é 4 vezes mais rápido que o Ingres do domínio público e 20 vezes mais rápido que o Progress sobre um computador Intel 486 executando Linux.[Hu96]

As principais cláusulas do $\mathrm{mSQL}$ são :

\section{- A cláusula Create}

A clausula create suportada pelo $\mathrm{mSQL}$ pode ser usada somente para criar uma tabela. Exemplo :

CREATE TABLE table_name (

$$
\text { col_name col_type [not null | primary key] }
$$

)

\section{CREATE TABLE serverDB (}

$\begin{array}{ll}\text { nome } & \text { char(30) primary_key, } \\ \text { descricao } & \text { char(60) not null, } \\ \text { Preview } & \text { char(60), } \\ \text { Tipo } & \text { int }\end{array}$

Os tipos de dados existentes são:

$\begin{array}{ll}\text { char (len) } & \text { String ou caracteres } \\ \text { int } & \text { Valor inteiro com sinal } \\ \text { real } & \text { Valor decimal ou notação cientifica }\end{array}$




\section{- A cláusula Insert}

A cláusula Insert serve para inserir um novo registro dentro de uma tabela. É necessário especificar um valor para cada campo, se esse não for especificado. Nesse caso, o campo será utilizado, conforme a ordem em que foram criados. Exemplo:

INSERT INTO table_name [(column[, column] $\left.\left.{ }^{* *}\right)\right]$

VALUES (value [,value] ${ }^{* *}$ )

INSERT INTO ServerDB (nome, descricao, preview, tipo)

VALUES ('video1', 'Video sobre hardware', 'video1.gif,1)

\section{- A cláusula Select}

A select oferecida pelo $m S Q L$ possui alguns recursos da especificação SQL:

- Joins - incluindo tabela aliases

- seleção de linhas distintas

- ordenacão por cláusulas

- expressões regulares

- comparação de coluna para coluna em clausulas WHERE

A sintaxe formal para select $m S Q L$ é :

SELECT [table.]column [,[table.]column]

FROM table [= alias][, table [= alias $]]$

[WHERE [table.]column OPERATOR VALUE

[AND | OR [table.]column OPERATOR VALUE] ]

[ORDER BY [table.]column [DESC][,[table.]column [DESC]]

OPERATOR pode ser $<,>,=,<=,>=,<>$, ou os valores podem ser o valor literar ou $\mathrm{o}$ nome de uma coluna. 
Um select simples pode ser :

SELECT nome, descrição FROM serverdb WHERE tipo='MPEG'

Seleciona todos os registros da tabela serverdb que o tipo seja igual a MPEG.

Pode ser feito a união de diversas tabelas durante uma query, por exemplo :

SELECT ServerDB.descricao,resolucaoxarquivo.arquivo

FROM ServerDB, resolucaoxarquivo

WHERE serverDB.nome=resolucaoxarquivo.nome

ORDER BY ServerDB.nome

\subsubsection{Gerenciador $m S Q L$}

O gerenciador $m S Q L$ possui todos os recursos básicos de um gerenciador de banco de dados. É de fácil instalação e utilização: o gerenciador pode ser acessado tanto por um socket TCP como por um socket de domínio UNIX, como o arquivo de sistema (/dev/msqld). O socket TCP é utilizado para o acesso por clientes sobre uma rede de computadores. $\mathrm{O}$ uso de socket TCP pode ser limitado para clientes em máquinas remotas que se comunicam melhor com o servidor via socket TCP, ao invés do socket UNIX, resultando numa perda substancial de performace.

O $m S Q L$ é formado por alguns programas, dentre eles :

\section{- mSQL Terminal Monitor}

Como todo banco de dados, $m S Q L$ possui um programa que permita ao usuário submeter queries para o banco de dados de forma interativa. É um programa simples chamado ' $m s q$. Possuidor de uma linha de comandos que, para acessar é iniciado pelo nome da base de dados. Uma vez iniciado, não há meios de mudar de base de dados sem reiniciar o programa.

O monitor aceita dois flags na linha de comandos:

- -h host Conecta com o servidor mSQL do host.

- -q Processa uma query e termina a execução 
Por exemplo :

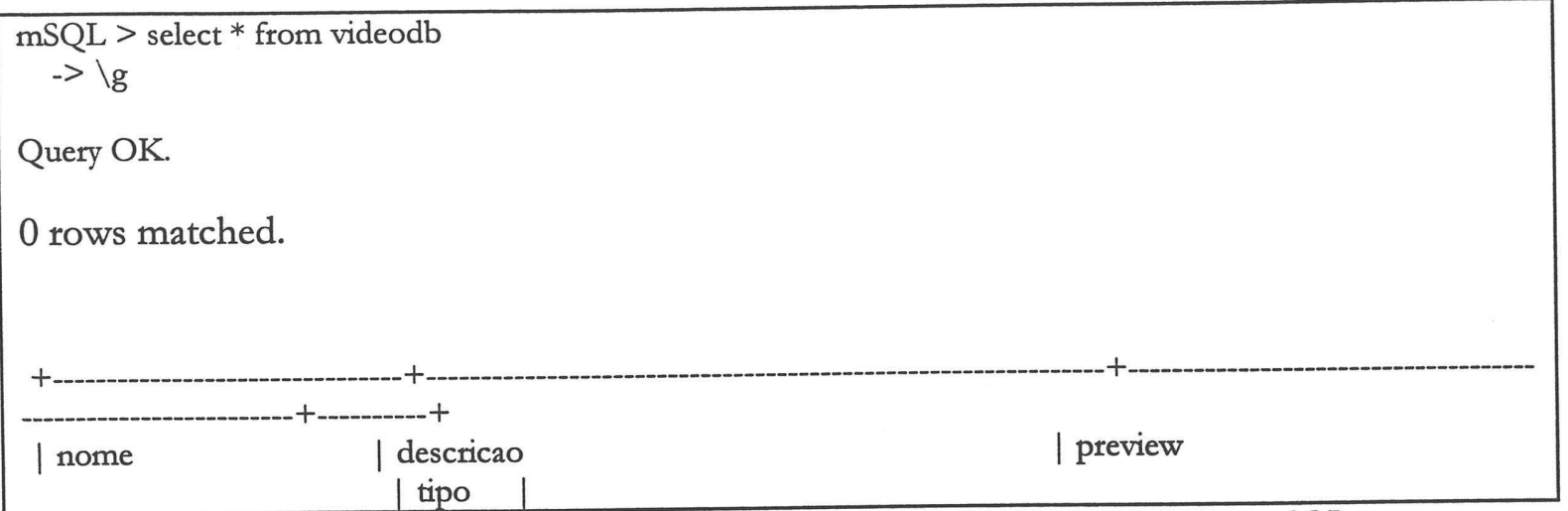

Figura 4.6 - Tela do resultado de uma query utilizando o programa mSQL

\section{- Databases Administration}

O banco de dados é administrado usando os comandos do msqadmin. Muitas tarefas administrativas, como criar novas bases de dados e forçar o shutdown de um servidor, são executadas pelo msqladmin. Os comandos disponíveis pelo msqladmin são:

- creat databases Cria uma nova base de dados

- drop databases Deleta uma base de dados

- shutdown Termina um servidor

- reload Força o servidor a carregar novamente as informações de controle

- version Mostra as informações de versão do servidor

\section{- Schema Viewer}

O mSQL provê o programa relshow para mostrar a estrutura da base de dados. Se executado sem nenhum argumento, relshow lista todas as bases de dados disponíveis. Se for executado com o nome da base de dados, relshow lista as tabelas da base de dados especificadas. Por fom, se forem informadas as base de dados e o nome da tabela, relshow mostrará a estrutura da tabela, incluindo os nomes dos campos, tipos, e tamanhos. 
Por exemplo :

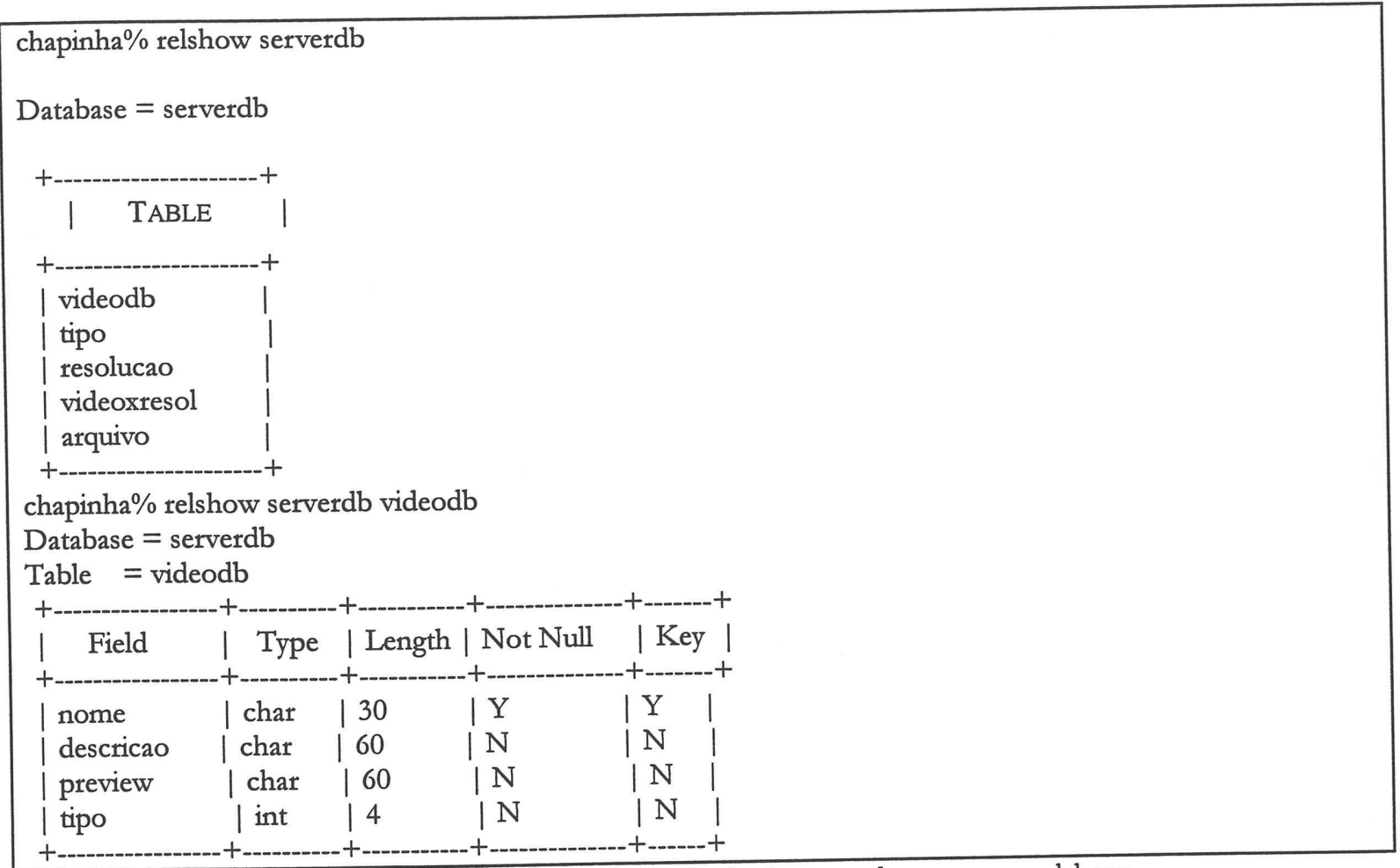

Figura 4.7 - Tela de resultado da query do programa relshow

\subsubsection{Controle de Acesso}

O controle de acesso é gerenciado por um arquivo (msql.acl) instalado no diretório do msql. Esse arquivo é dividido em entradas para cada base de dados a ser controlada. Se esse arquivo não existir ou detalhes de uma base de dados em particular não estiver configurada, é definido o acesso global de leitura e gravação. Um exemplo de entrada ACL :

$$
\begin{aligned}
& \text { databases }=\text { serverdb } \\
& \text { read }=* \\
& \text { write }=\text { shiro, dbuser } \\
& \text { host }=* \\
& \text { access }=\text { local, remote }
\end{aligned}
$$


Usando a definição, base de dados 'serverdb' pode ser acessada tanto em conexões locais como remotas de outros computadores (bost). O acesso de leitura é permitido a todos, já a. manipulação da base de dados somente é permitida somente ao usuário dbuser.

O driver JDBC já foi desenvolvido para o gerenciador $m S Q L$ possibilitando, com isso, a construção de applets em Java para acessar e manipular bases de dados.

\subsection{RAID (Redunce Array of Inexpensive Disk)}

Essa tecnologia consiste na criação de uma pilha de discos, onde vários discos são agrupados fazendo com o que o sistema operacional os reconheça como se fossem um único. Com isso, quando um arquivo é copiado para esse disco (lógico) cada parte do arquivo fica armazenado em um dos discos (físico) que compõe o disco lógico, como é mostrado na figura 4.8. A vantagem desse procedimento é o aumento do número de requisições que o computador pode atender concorrentemente, já que, na verdade, o acesso está ocorrendo em vários discos e não em um único.[Lo93][Le94b]

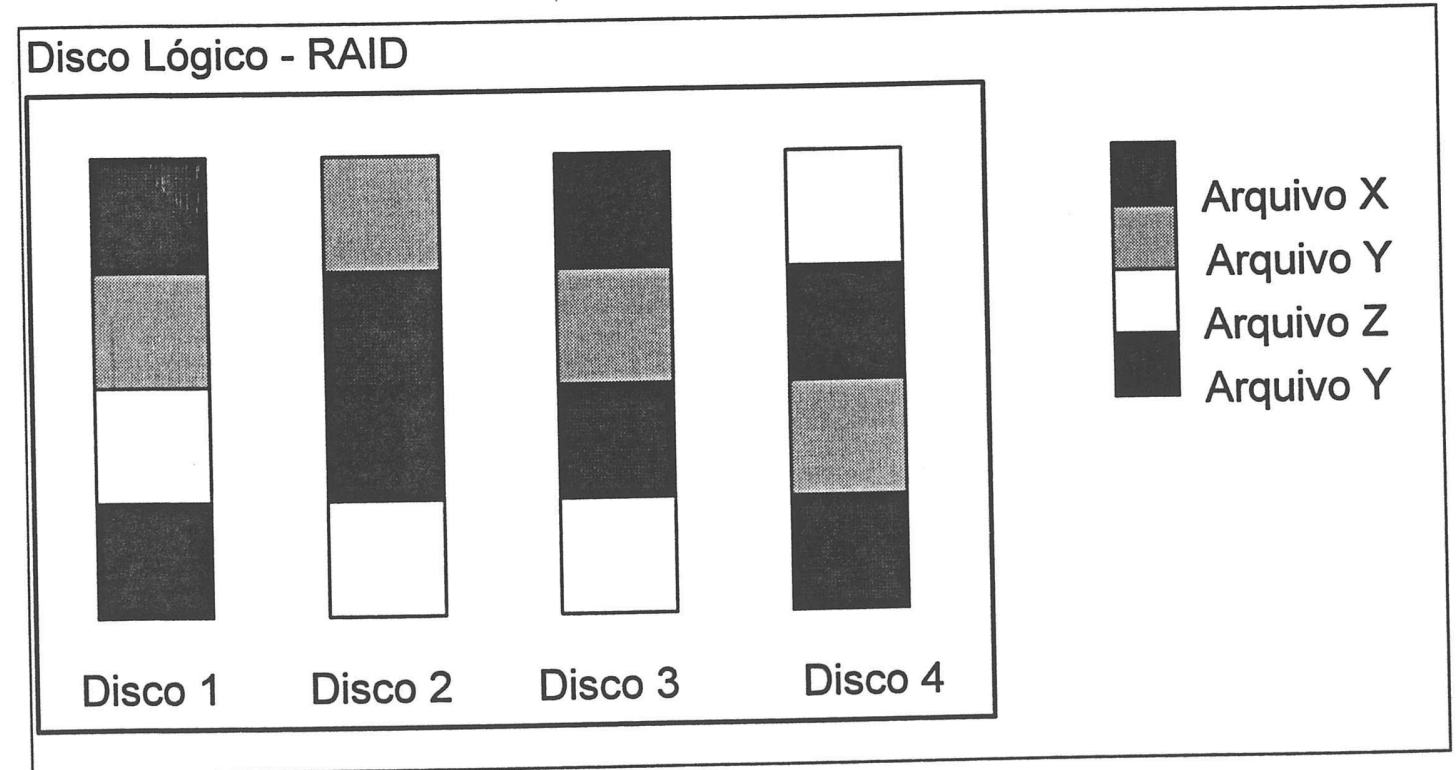

Figura 4.8-Sistema RAID

. Existem diferentes níveis do uso da tecnologia RAID, que são: [Ka97] 


\subsubsection{Os diferentes níveis de RAID}

RAID-0. O nível 0 não é redundante: os dados são divididos entre os discos, resultando em uma alta taxa de transmissão de dados. Como não há informações redundantes no armazenamento, o desempenho é muito bom, mesmo existindo a desvantagem de, se algum disco falhar, haver perda de dados.

RAID-1. Esse nível provê a redundância de dados pela gravação de todos os dados para dois ou mais discos. O desempenho do nível 1 tende a ser lento para as gravações e mais rápido para ler se comparado com um único disco, porém possui a vantagem de, se um dos discos falhar, nenhum dado é perdido.

RAID-3. Nesse nível, os blocos dos dados são em nível de byte entre muitos discos, possui um mecanismo de segurança contra falhas que consiste na gravação de informações adicionais (paridade), que possibilita a recuperação das informações. Nesse nível a paridade é armazenada sobre um único disco. Ele é similar ao nível 4. O nível 3 requer suporte de hardware para seu uso eficiente.

RAID-4. Nesse nível os blocos são a nível de bloco entre muito discos, a paridade é armazenada sobre um único disco. O desempenho do nível 4 é muito bom para leitura (o mesmo do nível 0). Para a escrita, contudo, necessita que os dados de paridade a cada vez. Esse método é lento para gravações randômicas, no entanto, para gravações de arquivos grandes ou seqüências, é bastante rápido. Isso ocorre porque somente um disco armazena dados redundantes. $\mathrm{O}$ custo por megabyte do nível 4 pode ser extremamente baixo.

RAID-5 É similar ao nível 4, mas distribui os dados de paridade entre os discos. Eles podem ser rápidos para a gravação de pequenas quantidades de dados sobre sistemas multiprocessados, desde que o disco de paridade não se torne o gargalo. $O$ desempenho para leitura, contudo, tende a ser mais lento para leitura que o nível 4 . O custo por megabyte é o mesmo pelo nível-4.

\subsubsection{Hardware vs Software}

A diferença entre RAID por hardware ou software é fundamental. Soluções de Raid por hardware são normalmente independentes de plataforma e usa seus próprios processadores para fazer os cálculos necessários. Já as soluções Raid por software utilizam o processador do 
computador e a sua memória para armazenar suas funções. Ambos possuem um sobre o outro, dependendo do nível de Raid que está sendo utilizado. Tipicamente, os Raid de nível 0 e 1 são executados mais rapidamente sobre Raid por software, enquanto os Raid de nível 3, 4 e 5 são mais rápidos sobre Raid por hardware. [Ka97]

\subsubsection{Suporte do Linux}

A partir do kernel do linux versão 2.0.29 foi inserido o suporte a $\mathrm{MD}$ (Multiple Devices) no kernel, que passa a suportar os níveis 0 e 1 de RAID. O suporte para os níveis 4 e 5 estão em fase de conclusão.[Ve97]

O próximo capítulo refere-se ao ambiente desenvolvido para provimento de vídeo. 


\section{Desenvolvimento do sistema servidor de vídeo}

O servidor de vídeo é parte fundamental de um projeto maior (figura 5.1) que consiste no provimento de um ambiente para criação, apresentação, armazenamento e entrega de material multimídia a uma população de clientes, cujo fins sejam educacionais. Uma atenção especial é dada ao servidor de vídeo (proposta do mestrado), já que o armazenamento de dados multimídia em ambiente WWW é um ponto chave: o fornecimento do material desejado deve ser gerenciado de forma eficiente para evitar sobrecarga do sistema, devido ao grande volume dos dados e ao eventual grande número de usuários acessando o sistema.

A utilização de servidores de dados multimídia baseados em sistemas VOD (Video-OnDemand) [Flu95] é uma alternativa para se alcançar a eficiência exigida. Esses servidores realizam o armazenamento de dados como áudio, vídeo e gráficos, entre outros, em algum tipo de dispositivo físico (disco, fita, $\mathrm{CD}$, etc).

Esse projeto de mestrado consistiu na definição e implementação do servidor de vídeo, o qual tem de ser capaz de atender, sob demanda, uma comunidade de clientes disposta em um ambiente WWW. Para isso foi feito o estudo e avaliação dos diversos componentes envolvidos na cadeia de elementos e dutos(rede, cpu, meios de armazenamento, etc) que se encontram no caminho entre o armazenamento (no servidor de vídeo) e a apresentação (no cliente). Após o estudo, foi feita a especificação do sistema, com a definição da plataforma, sistema operacional, tipo de CPU, quantidade de memória RAM, o tipo e quantidade de discos rígidos, o tipo de placa de rede, linguagem de programação do sistema de gerenciamento, etc. 


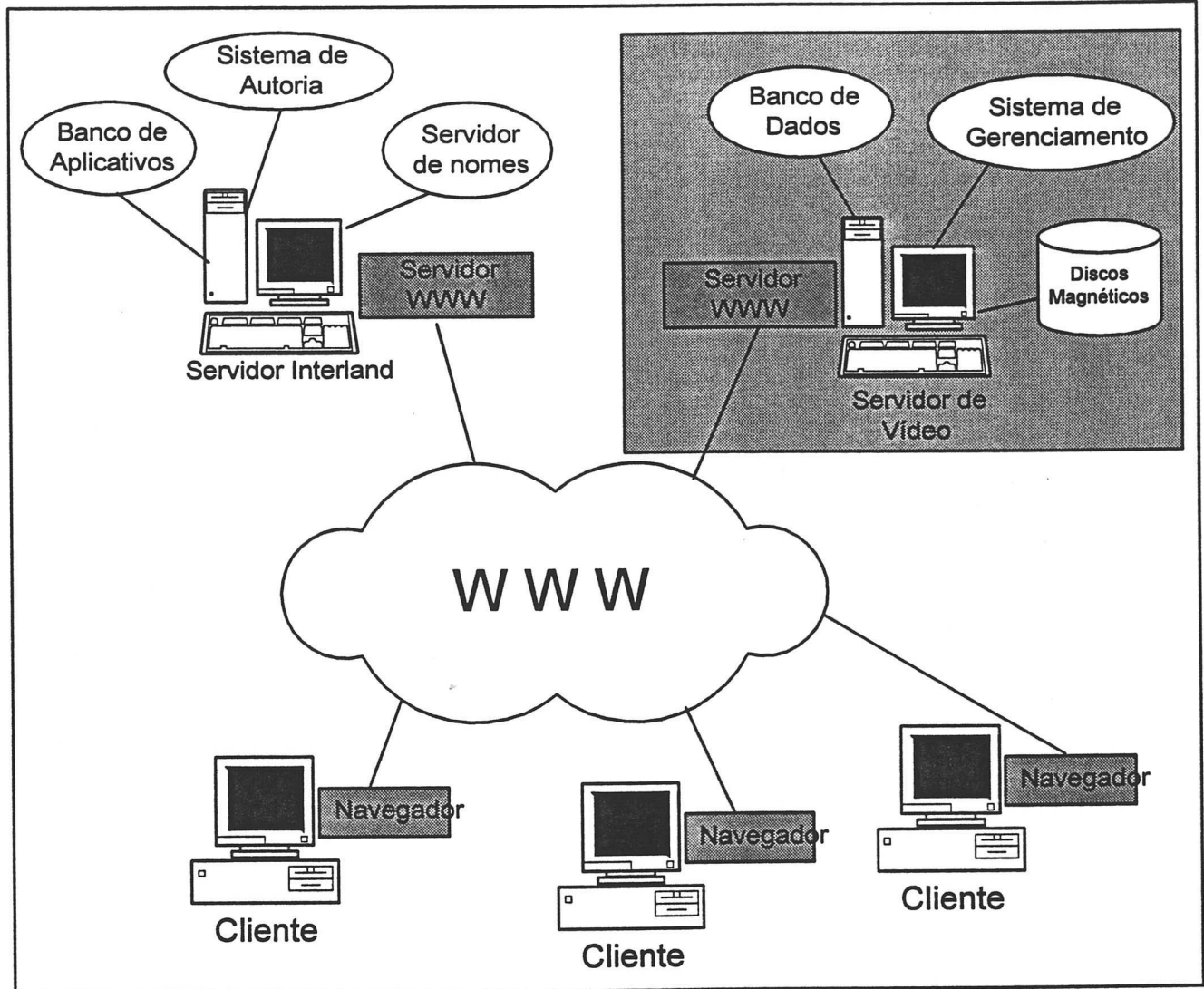

Figura 5.1 - O ambiente

O segundo momento do estudo consistiu na instalação do hardware e software de compõem o servidor, além de testes de desempenho do mesmo. Por último, houve o desenvolvimento de ferramentas para o gerenciamento dos dados multimídia armazenados no servidor. Essas ferramentas têm como objetivo facilitar a manutenção e localização das informações armazenadas, e isso é feito através de applets Java e uma base de dados, que são acessadas através da WWW. As ferramentas estão localizadas no próprio servidor de vídeo.

\subsection{Hardware}

Foi especificado e implementado o hardware que compõe o servidor de vídeo:

- Microcomputador Pentium/200 MMX, 
- $96 \mathrm{MB}$ de memória RAM,

- placa de vídeo Trident $1 \mathrm{MB}$,

- monitor Sansung Syncmaster 3,

- 1 disco SCSI seagate de 2 GB

- 1 disco SCSI quantum fireball de 2 GB

- 2 disco SCSI quantum fireball de 4GB

- placa controladora SCSI Adaptec 3985,

- placa de rede ethernet 3 com isa (10Mbps)

Não nos preocupamos com a placa de vídeo ou o monitor: o servidor não necessita de uma resolução gráfica boa, pois todo acesso ao servidor será feito no próprio microcomputador do cliente.

Definimos uma grande quantidade de memória principal(RAM) com o intuito de diminuir o acesso ao disco, já que o sistema operacional Linux, armazena, na memória principal (cache), os últimos dados acessados. Com isso, se dois ou mais usuários acessarem o mesmo arquivo, somente um acesso ao disco será feito..

Em um disco SCSI de 2GB foi instalado o sistema operacional, assim como todos os softwares que compõem o servidor. Os arquivos de vídeo encontram-se nos outros três discos SCSI que compõem o disco lógico do sistema RAID nível 0.

Foi escolhida a controladora SCSI Adaptec 3985 por possuir uma característica especial em relação às controladoras tradicionais: três canais de dados independentes - como se fossem três controladoras SCSI - sendo que cada canal trabalha a uma taxa de transmissão de $10 \mathrm{MB} / \mathrm{s}$, resultando numa taxa total de $30 \mathrm{MB} / \mathrm{s}$. Dessa forma, cada disco que compõe o RAID (discutida na seção 4.6) foi colocado em um canal diferente, fornecendo uma taxa agregada que pode chegar a 30 $\mathrm{MB} / \mathrm{s}$, melhorando o serviço em acessos simultâneos. 


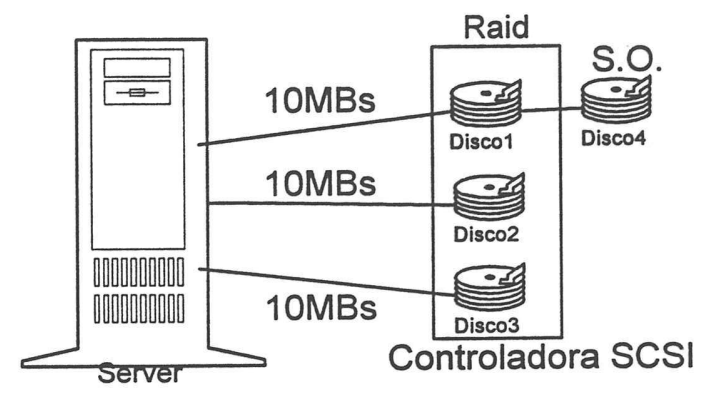

Figura 5.2 sistema de disco do servidor de vídeo

Foram utilizadas várias placas de rede: Ethernet NE2000, Ethernet 3com, Fast-Ethernet 3Com, FDDI digital, o qual foram utilizadas para medir o desempenho do servidor.

\subsection{Software}

Foi adotado como sistema operacional do servidor o Linux (kernel 2.0.30) (detalhado na seção 4.1), por este ser de domínio público, rodar sobre a plataforma Intel, já estar preparado para ser utilizado sobre uma rede de computadores (Internet) e por possuir todas as características necessárias para a execução do software servidor, tais como: suporte a linguagem Java, suporte ao gerenciador de banco de dados Mini-SQL, servidor httpd, driver para a controladora SCSI adaptec 3985, possuir no próprio kernel suporte a Raid, suporte à placa de rede FDDI e rede Fast Ethernet, etc.

Foi adotado como servidor de httpd o Apache, por ser shareware e acompanhar o pacote do Sistema Operacional Linux. Também foi adotado o gerenciador de banco de dados Mini-SQL (detalhado na seção 4.5), por possuir o driver para acesso via JDBC e ser de domínio público para fins acadêmicos,

Finalmente foi adotada a linguagem Java(vide seção 4.3) versão 1.1.3 no desenvolvimento dos sistema de gerenciamento, por ser multiplataforma, portanto conveniente a ambientes distribuídos baseados em WWW, e por possuir uma vasta biblioteca de funções que facilita a programação dos módulos do sistema. 


\subsection{Base de Dados}

Foi implementada uma base de dados experimental com o objetivo de facilitar o acesso e gerenciamento dos dados armazenados no servidor, permitindo a utilização do sistema por usuários experientes ou não.

Está sendo utilizado um gerenciador de banco de dados para o gerenciamento das informações dos vídeos. Além disso, adotado o gerenciador de banco de dados Mini-SQL, por ser sharewvare para fins educacionais e já possuir os drivers necessários para a comunicação com Java através de JDBC (Java DataBase Connectivity) [Pa96], possibilitando com isso a manutenção da base de dados através de páginas feitas em $\mathrm{btml}$.

As informações contidas na base de dados são do tipo: nome do vídeo, descrição, duração, tipo, usuários, resolução, preview, etc. Através da Base de Dados é possível gerenciar e monitorar todas as requisições feitas pelos clientes, como por exemplo: “Quantas pessoas estão utilizando o sistema". Quais vídeos estão sendo usados. Quais vídeos uma determinada pessoa está utilizando. Qual o tipo de cada vídeo".[Na95] Para tanto, foi criada uma base de dados capaz de atender a todas essas requisições, cuja especificação se encontra abaixo. 


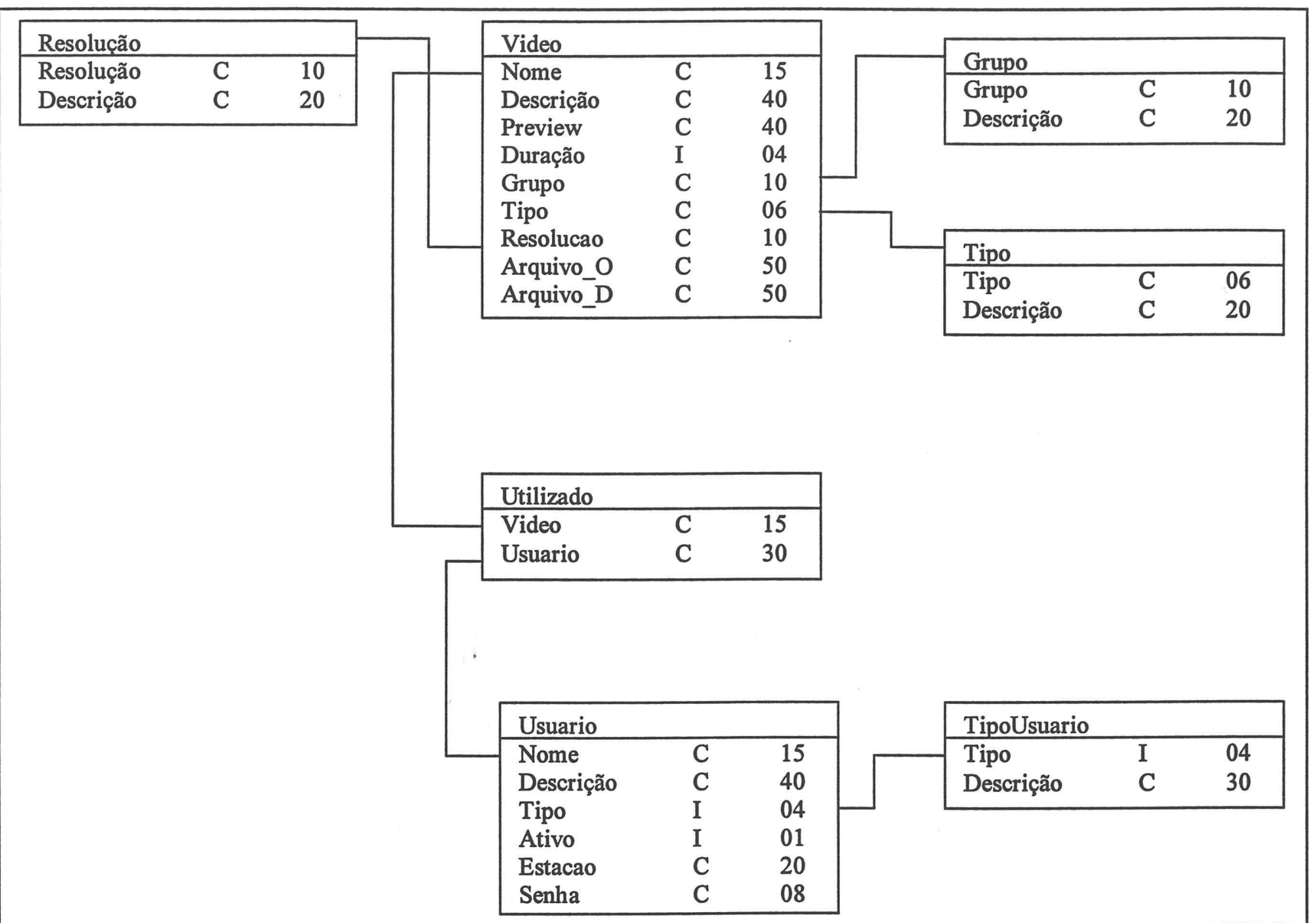

Figura 5.3 Tabela RMT da base de dados ServerDB

A manutenção dessa base de dados, está sendo feita através de um sistema de gerenciamento desenvolvido em Java e que utiliza a biblioteca JDBC.

\subsubsection{Sistema de gerenciamento da base de dados}

O sistema de gerenciamento foi inteiramente desenvolvido em applet Java, tornando possível o acesso através de qualquer browser (Netscape, Internet Explorer, etc), além de permitir a multiplataforma. Esses sistema de gerenciamento se encontra no próprio servidor de vídeo, onde o usuário de seu próprio computador pode acessar através da WWW. O sistema possui um mecanismo de segurança que consiste na autenticação do usuário através de um login. 


\section{Login/ Logout}

No momento em que o usuário (professor) acessa o sistema, serão requisitados pelo sistema um nome e uma senha (figura 5.4), consultados pelo sistema em sua base de dados. Se o usuário e a senha forem válidos, será fornecido pelo sistema um menu principal, para que o usuário possa gerenciar a base de dados.

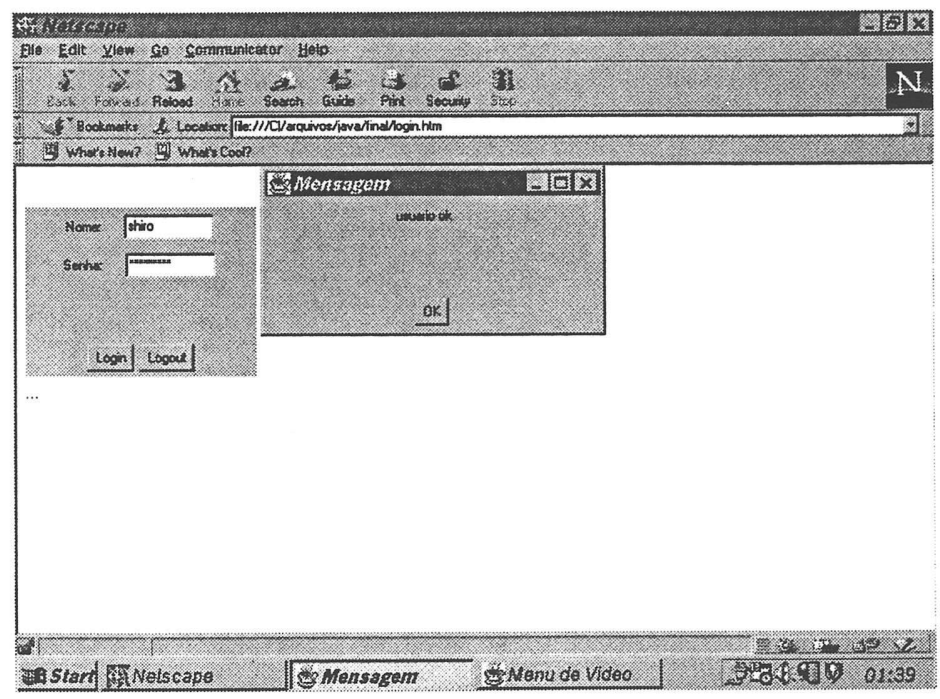

Figura 5.4 Tela de login/ Logout

\subsubsection{Menu Principal}

O menu principal consiste em três sub-menus (figura 5.5), a saber:

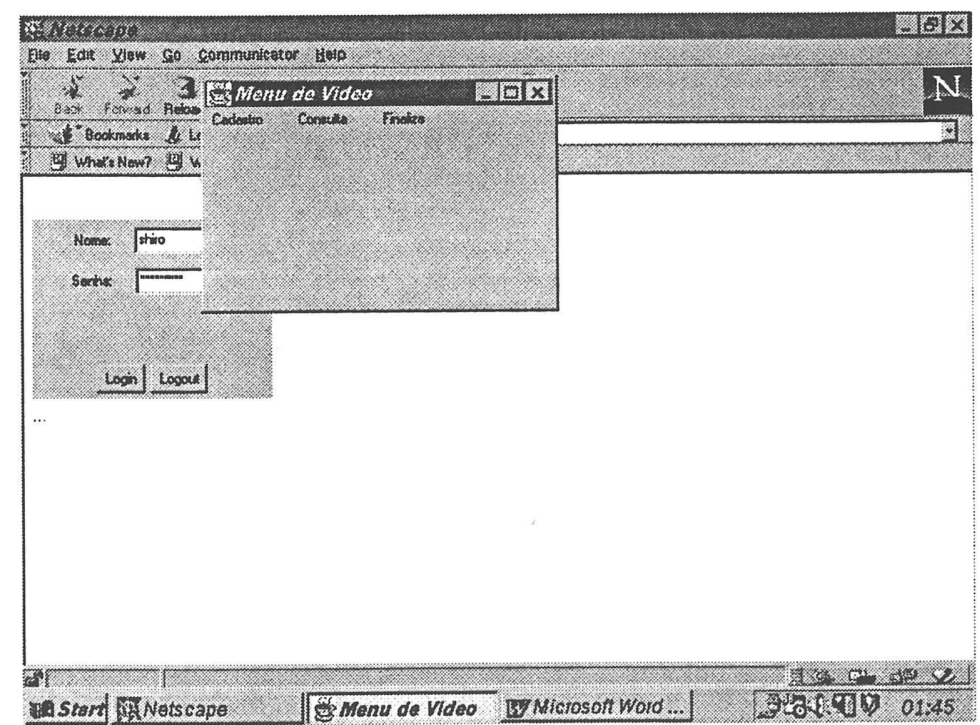

Figura 5.5 Tela do menu principal 
Cadastro - O usuário pode fazer a manutenção (incluir, alterar, excluir) das tabelas através deste sub-menu. Por exemplo, a tela de cadastro de vídeo (figura 5.6).

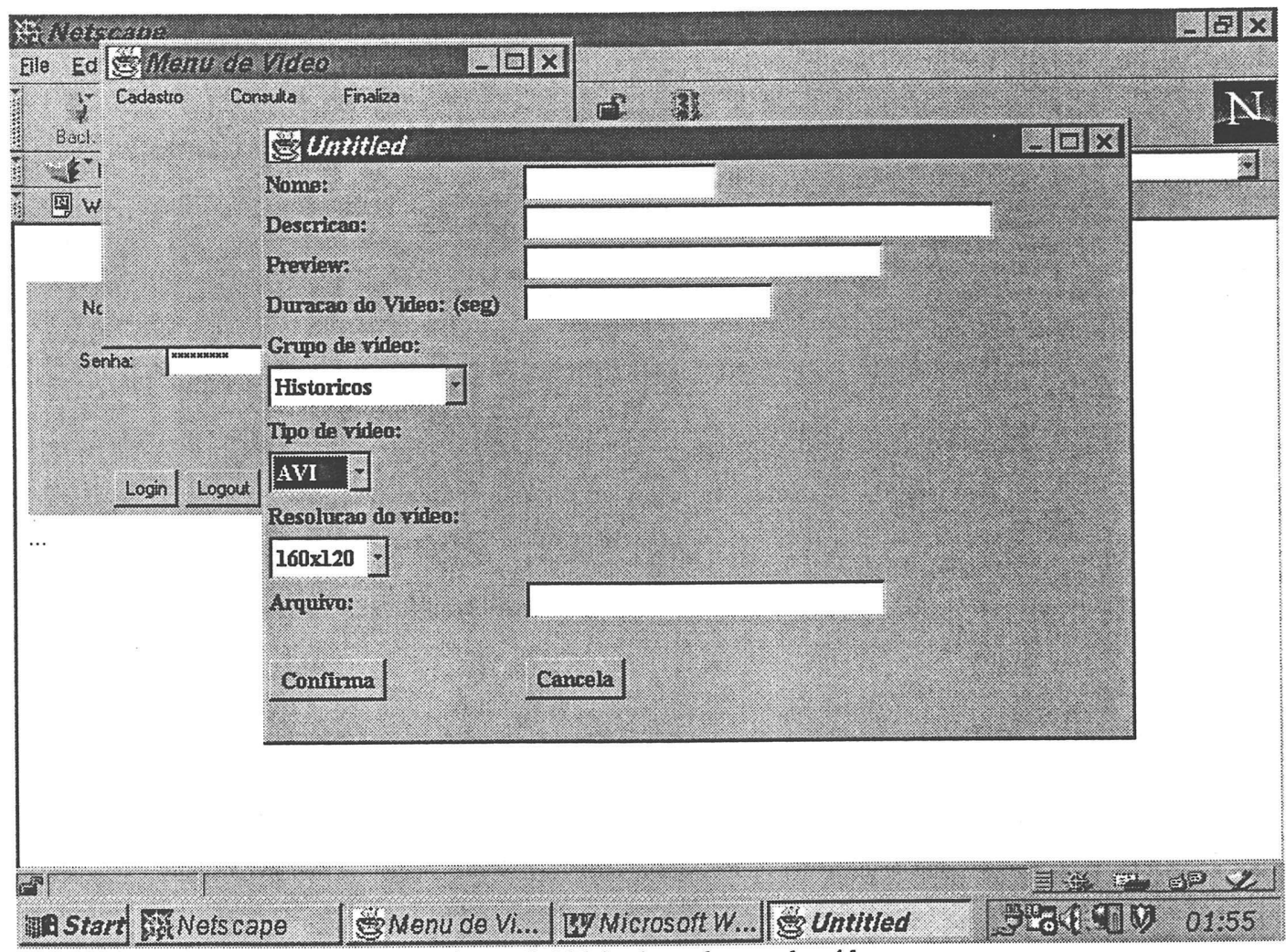

Figura 5.6 Tela de cadastro de vídeo

A programação em Java da inserção dos dados na base de dados mSQL é mostrada abaixo:

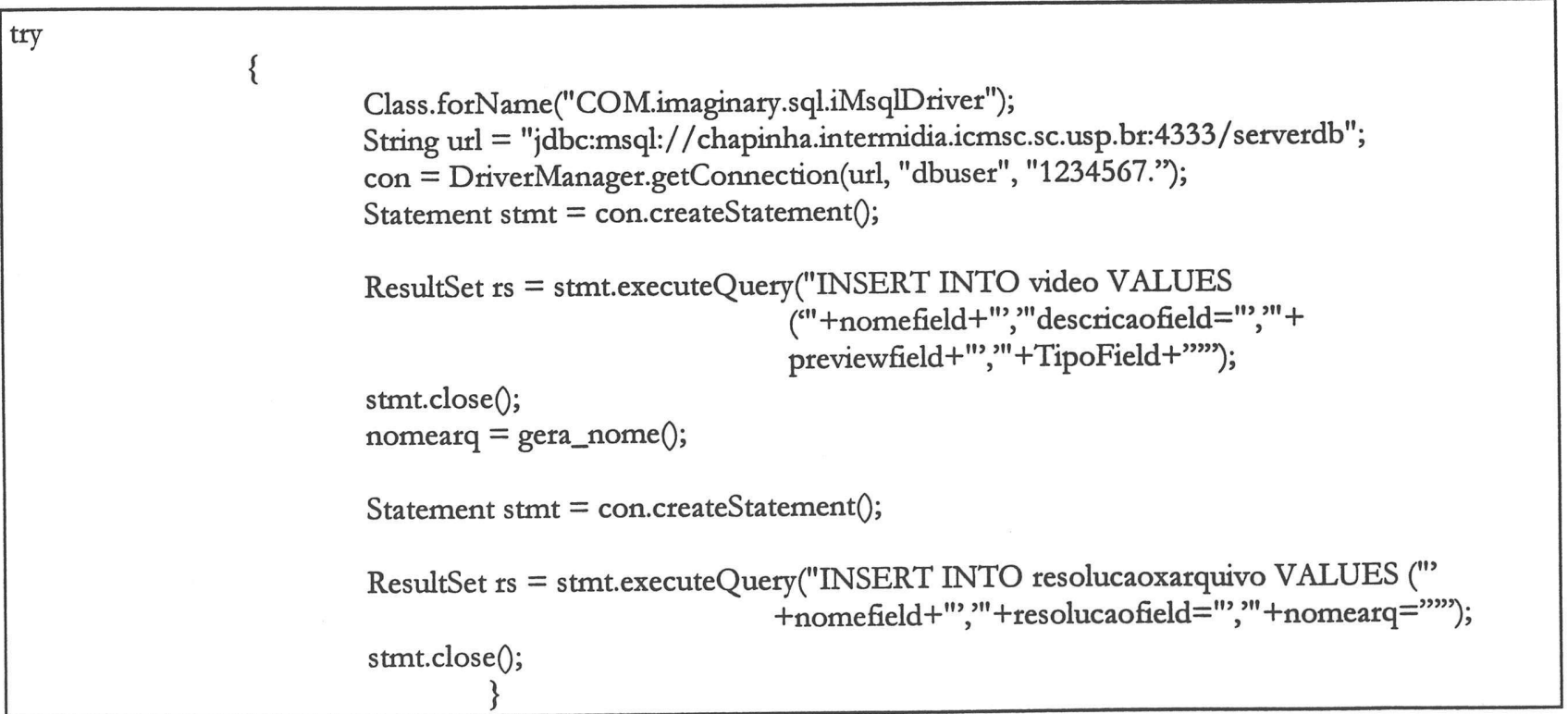

Figura 5.7 Rotina de cadastro em java 
O cadastro de um novo vídeo difere de outros cadastros(resolução, tipos, etc), pois no cadastro de vídeo o arquivo de vídeo precisa ser transferido do computador do cliente para o servidor. Para tanto foi desenvolvido um programa Java que fica responsável por transferir o arquivo da estação do cliente para o servidor de vídeo, conforme explicaremos adiante .

Consultas - Através do sub-menu de consultas (figura 5.8) o usuário pode fazer os mais diversos tipos de consultas na base de dados: vídeos, usuários ativos, vídeos que estão sendo utilizados, etc.

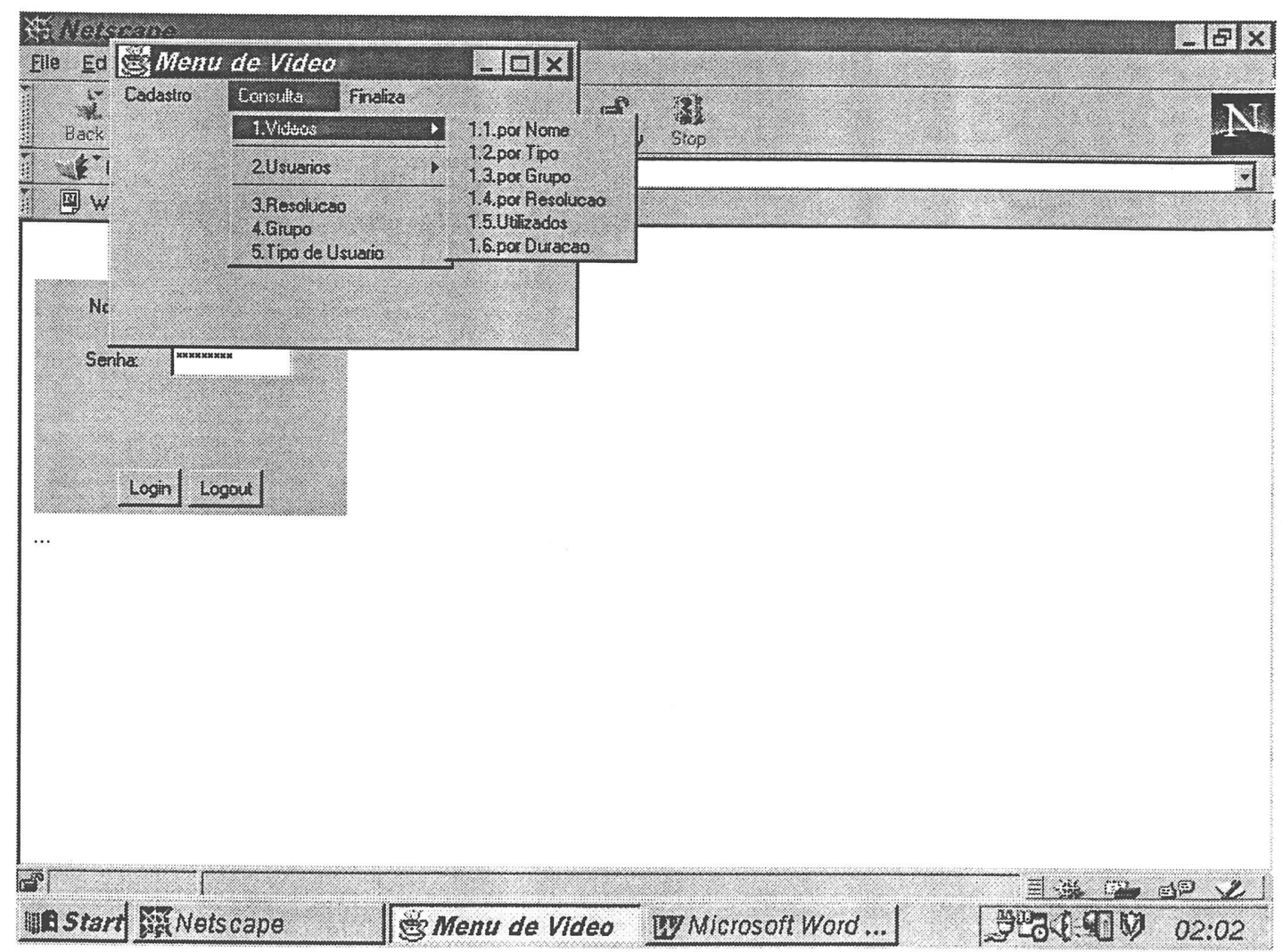

Figura 5.8 Tela do menu de consulta

Finaliza - Este sub-menu efetua o término da execução do sistema de gerenciamento.

\subsubsection{Aplicativo FTP}

Como foi explicado anteriormente, foi desenvolvido um aplicativo responsável pela transferência do arquivo de vídeo para o servidor. Ele funciona como um daemon que fica aguardando requisições através de uma conexão socket. Foi definida uma porta padrão (porta 4321), 
assim, quando o usuário confirma um novo cadastro de vídeo, o sistema de gerenciamento tranfere para o aplicativo o nome do arquivo do vídeo-origem e o nome do arquivo-destino; o programa ftp estabelece, então, a conexão com o servidor de ftp do servidor de vídeo ${ }^{[1]}$, possuidor de todos os comandos necessários, e transfere o vídeo da estação do cliente para o servidor de vídeo (figura 5.9).

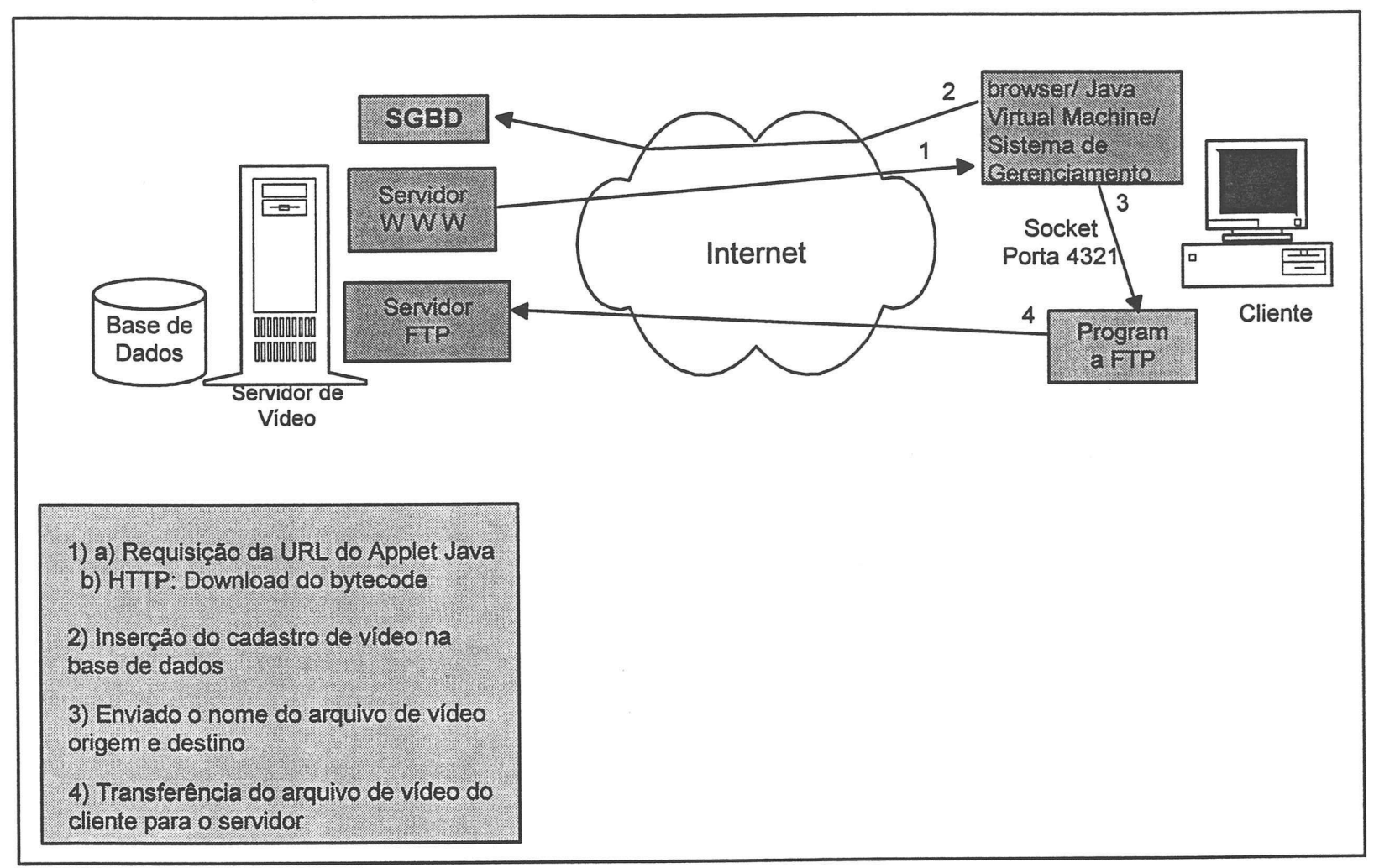

Figura 5.9 Funcionamento do cadastro de vídeo 
A programa em Java da rotina de conexão e transmissão é mostrado abaixo :

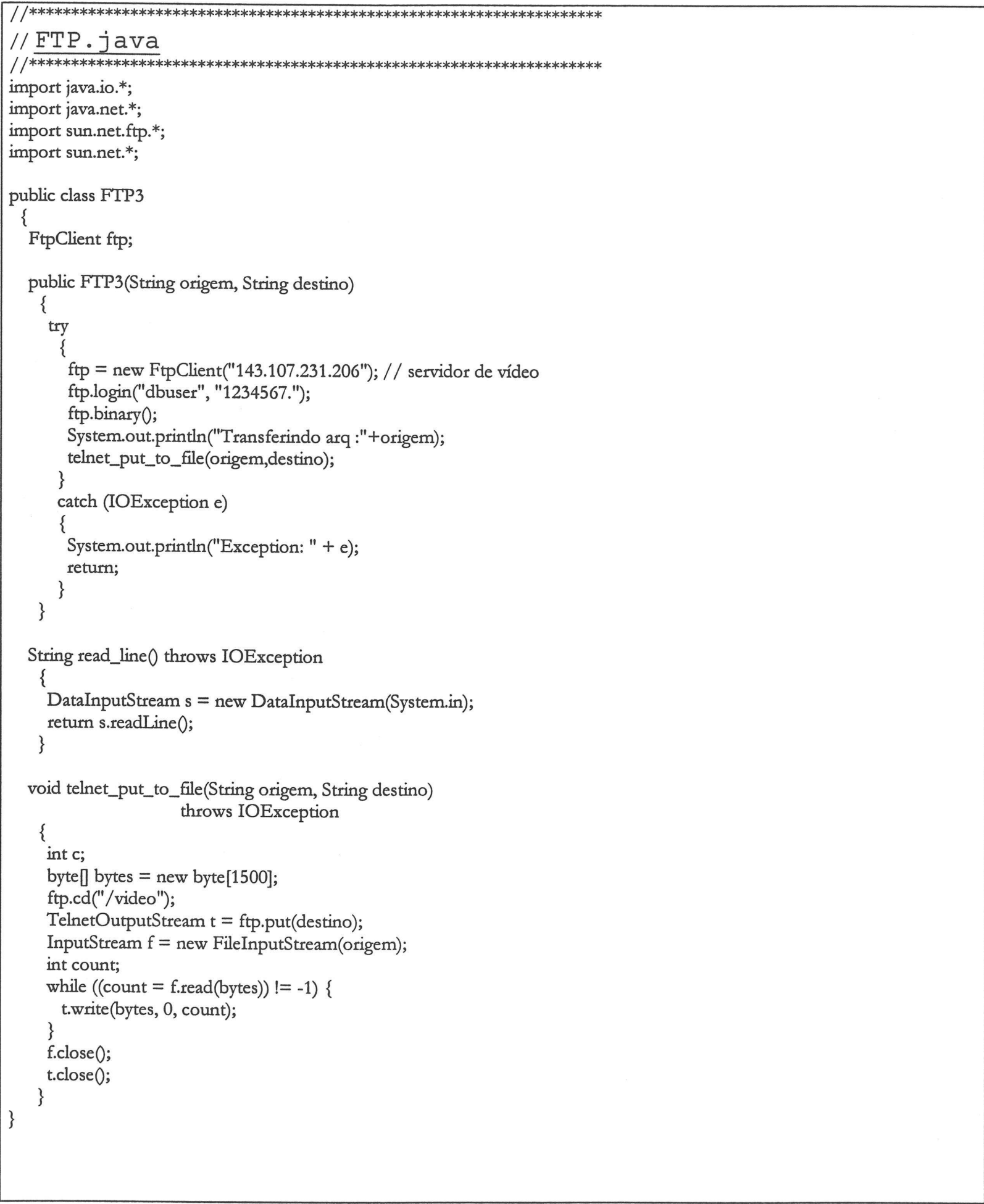

Figura 5.10 - Rotina de conexão e transmissão do arquivo via FTP 


\subsection{Clientes}

Para o cliente, a utilização do servidor é totalmente transparente: ele precisa somente informar quê tipo de vídeo ele quer executar,e isso é feito através de um applet "Mostravídeo". O servidor fica responsável pela procura desse vídeo na base de dados e disponibilização para o cliente do mesmo. Está sendo utilizada a biblioteca JMF(Java Media Framework) para a transferência e execução do vídeo, cujo seu funcionamento é apresentado na figura abaixo.

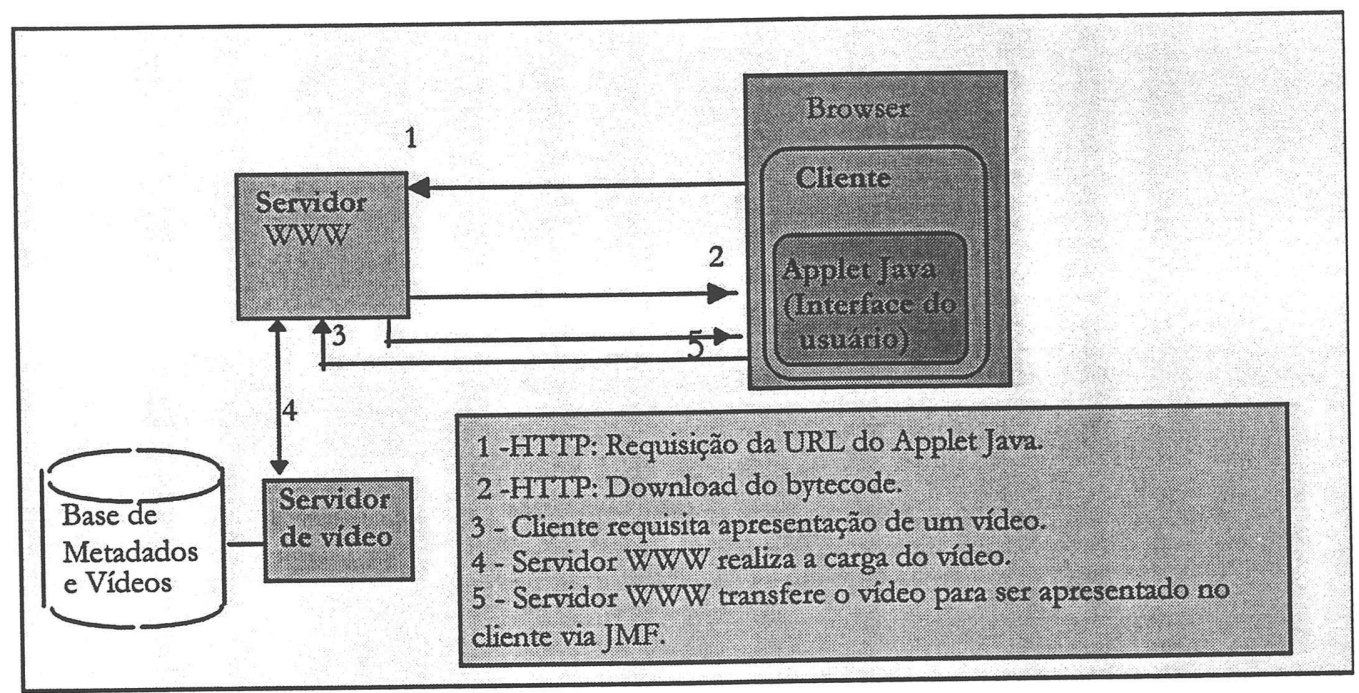

Figura 5.11 - Funcionamento do Cliente do Servidor de Vídeo

O passo seguinte foi testar e avaliar o desempenho do servidor de vídeo e a detecção dos gargalos existentes, estes testes estão descritos no capítulo seguinte. 


\section{Avaliação de Performance do Sistema}

Como parte do projeto, foram efetuados testes no sistema servidor de vídeo com o objetivo de medir o desempenho do servidor, assim como detectar possíveis gargalos nos componentes que compõem o sistema completo de provimento: sistema operacional, disco e rede.

Para a realização dos testes foi montado um ambiente (figura 6.1) com as seguintes características:

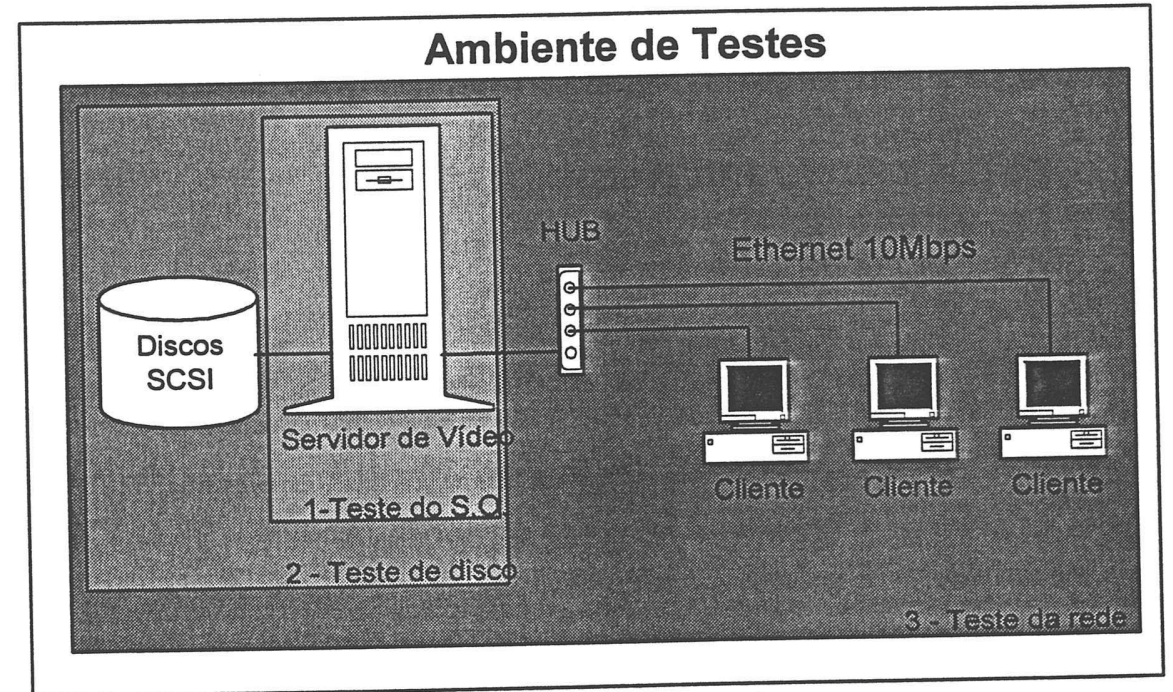

Figura 6.1 - Ambiente de testes

O servidor de vídeo segue a especificação da seção 5.1 (figura 5.2). Os clientes são microcomputadores Pentium de $166 \mathrm{MHz}$, com $32 \mathrm{MB}$ de memória RAM e discos rígidos de 1.7 GB (IDE), com placas de rede Fast-Ethernet 3Com PCI 10/100 Mbps. Foram também utilizados equipamentos de conectividade para realizar os testes de avaliação do sistema de rede, são eles:

- Switch digital DECswitch 900EF, possui uma porta FDDI, uma porta AUI e 4 portas RJ45 Ethernet $10 \mathrm{Mbps}$

- Hub digital DECrepeater 900TM, possui 24 portas RJ45 Ethernet 10Mbps

- Placa FDDI digital DEFPA-AA, possui uma porta FDDI. 


\subsection{Metodologia Adotada}

A análise de desempenho de cada componente do sistema, foi realizada utilizando-se o programa FTP, já que ele fornece o tempo total da transmissão, a taxa de transmissão na transferência de arquivo, está disponível nas duas plataformas em questão, e funciona de forma muito similiar àquela quando é requisitado pelo cliente um arquivo no ambiente WWW. Foram utilizados dois arquivos padrões, um de $7 \mathrm{MB}$ e outro de $81 \mathrm{MB}$, com o objetivo de verificar o sistema de cache e o desempenho na busca de informações de cada plataforma..

Os testes realizados foram os seguintes:

- Teste 1 - transferência de um arquivo de $7 \mathrm{MB}$.

- Teste 2 - dois acessos concorrentes à mesma cópia do arquivo de 81MB.

- Teste 3 - três acessos concorrentes à mesma cópia do arquivo de 81MB.

- Teste 4 - dois acessos concorrentes a três cópias diferentes do arquivo de 81MB.

- Teste 5 - três acessos concorrentes a três cópias diferentes do arquivo de $81 \mathrm{MB}$.

As medições foram divididas em vários testes, com o objetivo de medir em cada um deles um componente isolado do sistema. Esses testes foram:

- Teste A - Comparação de Discos Rígidos : medir o desempenho dos discos rígidos quanto à taxa de transferência.

- Teste B - Comparação de Controladoras SCSI : o intuito desse teste foi o de verificar o impacto de se utilizar controladoras SCSI diferentes, o padrão SCSI-I e o SCSI-II.

- Teste C - Comparação de Sistemas Operacionais : visa medir o desempenho do sistema operacional no atendimento de requisições de disco e requisições da rede. Os testes foram feitos utilizando dois tipos de rede: a Ethernet $10 \mathrm{Mbps}$ no servidor e clientes, e FDDI $100 \mathrm{Mbps}$ no servidor e Ethernet 10Mbps nos clientes conectados através de uma Switch Ethernet. 
- Teste D - Desempenho comparativo do Sistema de Arquivo: visa medir o desempenho da utilização do sistema de arquivo tradicional(único disco) e da utilização do sistema de arquivo com tecnologia Raid-0. Esses testes foram realizados utilizando o sistema operacional Linux.

- Teste E - Desempenho do Sistema de Arquivo sobre uma rede ethernet: visa medir o desempenho da utilização do sistema de arquivo tradicional(único disco) e da utilização do sistema de arquivo com tecnologia Raid-0 sobre uma rede ethernet.

- Teste F - Desempenho do Sistema de Arquivo sobre uma rede FDDI: visa medir o desempenho da utilização do sistema de arquivo tradicional(único disco) e da utilização do sistema de arquivo com tecnologia Raid-0 sobre uma rede FDDI.

Em cada um dos testes, o servidor era mantido nas mesmas características, com exceção daquele componente que estava sendo avaliado (sistema operacional, disco, etc.). Cada teste foi repetido várias vezes, anotando-se a média obtida em cada um.

\subsection{Teste A - Comparação de Discos Rígidos}

Os primeiros testes foram feitos sobre o disco rígido. $O$ servidor possui vários tipos diferentes de discos rígidos SCSI: um Seagate de 2GB, 1 Quantum de 2 GB e 2 Quantum de 4GB. Foram testados os dois discos de 2 GB sobre o sistema operacional Linux e controladora SCSI Adaptec 3985. 
Foi feita uma seqüência de testes padrões com o intuito de medir o desempenho na transferência de arquivo e no acesso concorrente das informações. Os resultados obtidos foram:

\begin{tabular}{|c|c|c|}
\hline Teste & Seagate (kbytes/seg) & Quantum (kbytes/ seg) \\
\hline $\mathbf{1}$ & 3354,11 & 6425,00 \\
\hline $\mathbf{2}$ & 932,64 & 1671,84 \\
\hline $\mathbf{3}$ & 683,38 & 1331,02 \\
\hline 4 & 656,45 & 898,37 \\
\hline $\mathbf{5}$ & 429,65 & 653,76 \\
\hline
\end{tabular}

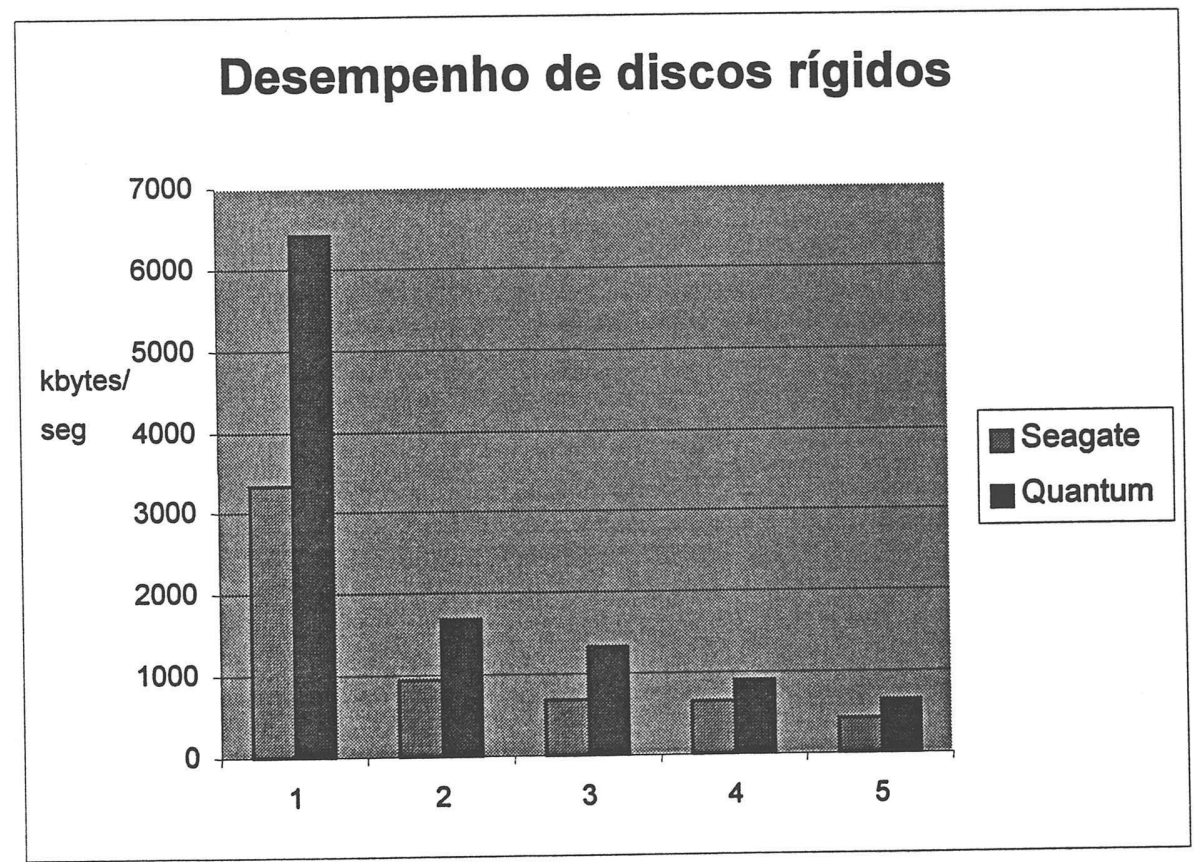

Figura 6.2 - Desempenho do Disco Rígido

\subsection{Teste B - Comparação de Controladoras SCSI}

Foram testadas duas controladoras SCSI(a Adaptec 1740 ISA e a Adaptec 2940 PCI), sendo que a primeira trabalha no padrão SCSI-I e a segunda no padrão SCSI-II. Os testes foram feitos utilizando o Sistema Operacional Windows NT e o disco rígido SCSI quantum 4GB. O objetivo deste teste foi verificar se a controladora SCSI pode se tornar um gargalo em potencial. Os resultados obtidos foram:

\begin{tabular}{|c|c|c|}
\hline Teste & Adaptec $\mathbf{1 7 4 0}$ (kbytes/seg ) & Adaptec 2940 (kbytes/ seg) \\
\hline $\mathbf{1}$ & 1509,29 & 1702,92 \\
\hline $\mathbf{2}$ & 315,14 & 745,38 \\
\hline $\mathbf{5}$ & 312,69 & 571,44 \\
\hline
\end{tabular}




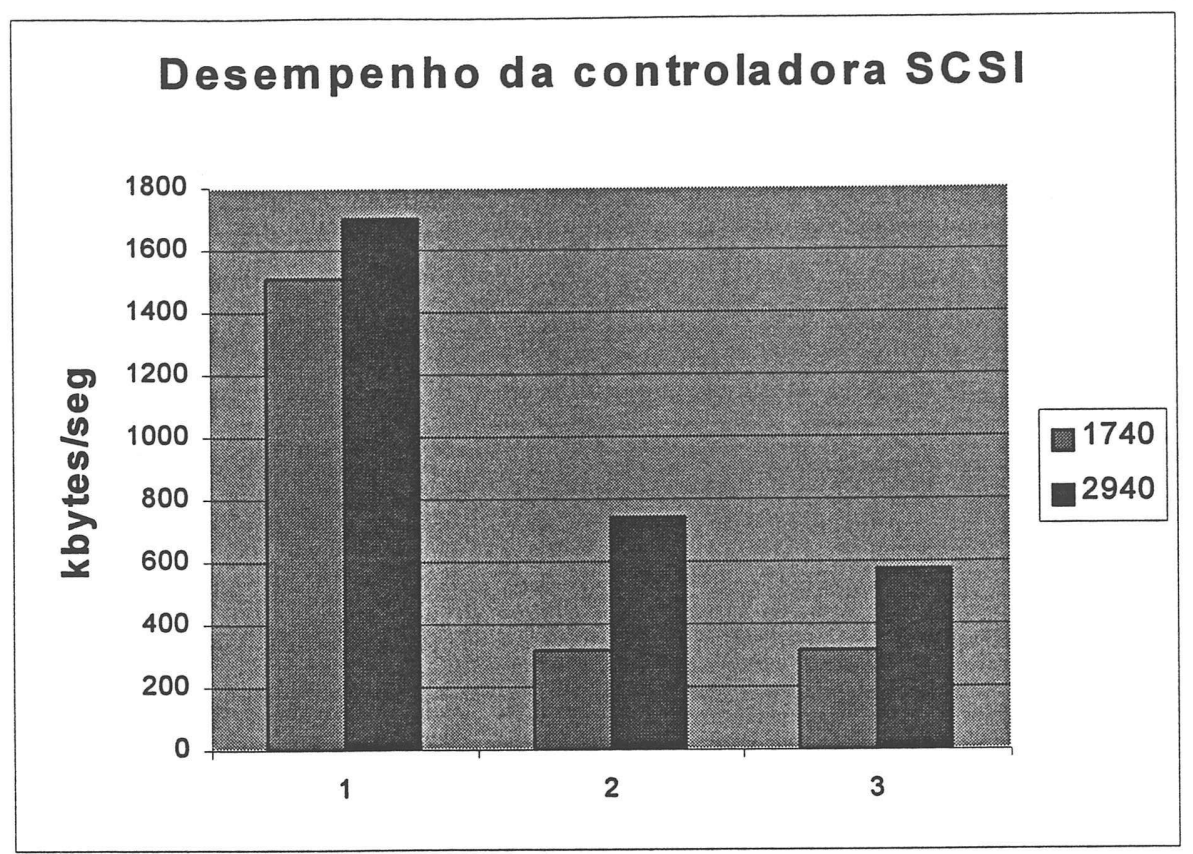

Figura 6.3 - Desempenho da Controladora SCSI

\subsection{Teste C - Comparação de Sistemas Operacionais}

Foram testados os Sistemas Operacionais Microsoft Windows NT versão 4.0 e o Linux (Slakware 3.3 kernel 2.0.30). Os testes foram realizados utilizando-se a controladora SCSI Adaptec 2940 e disco rígido SCSI quantum 4.0GB. Os testes foram divididos em duas etapas: a primeira com o objetivo de medir o desempenho no atendimento de requisições de arquivo, e a segunda, de medir o desempenho no atendimento de requisições de rede.

\subsubsection{Desempenho do acesso ao disco do S.O.}

\begin{tabular}{|r|c|c|}
\hline Teste & WindowsNT (kbytes/seg ) & Linux (kbytes/ seg) \\
\hline $\mathbf{1}$ & 1372,31 & 2780,60 \\
\hline $\mathbf{2}$ & 745,38 & 1917,47 \\
\hline $\mathbf{3}$ & 522,99 & 1482,56 \\
\hline $\mathbf{4}$ & 571,44 & 898,37 \\
\hline $\mathbf{5}$ & 416,75 & 660,12 \\
\hline
\end{tabular}




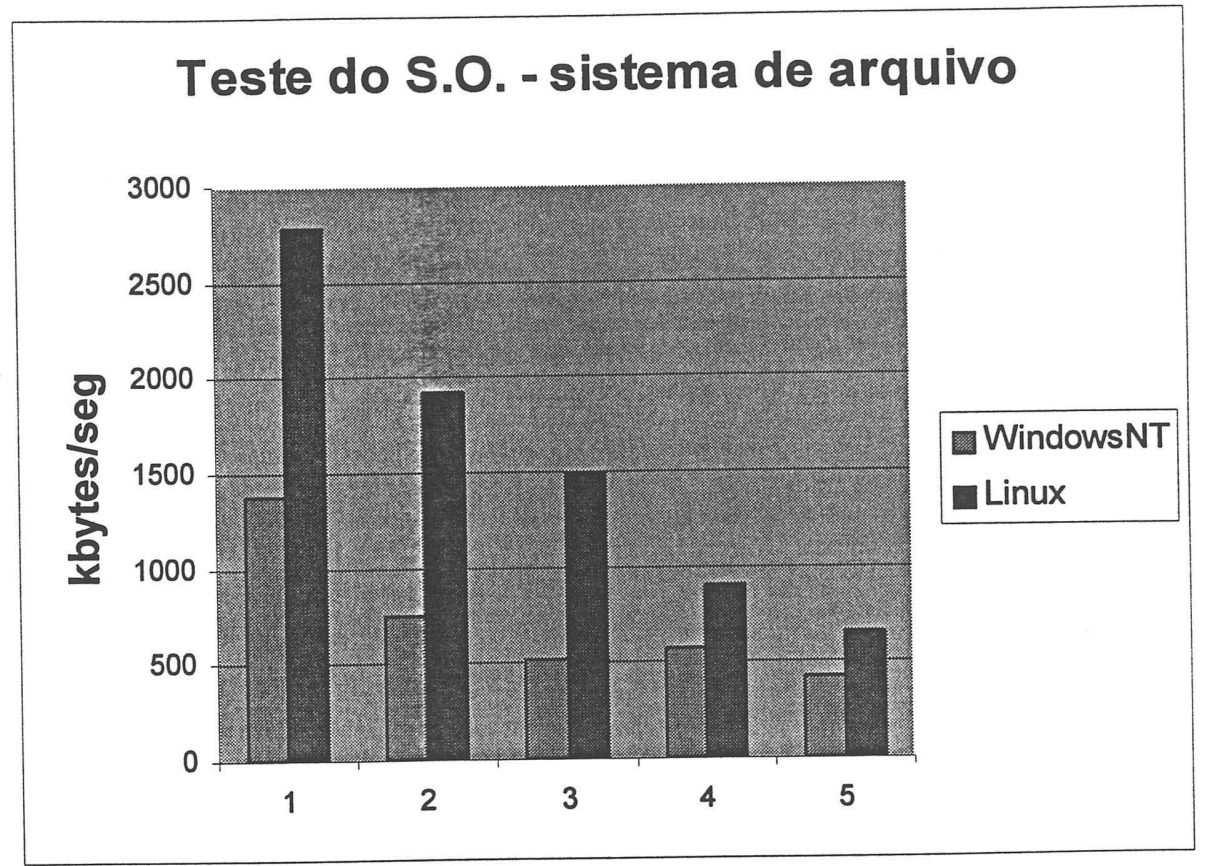

Figura 6.4 - Desempenho do S.O. - sistema de arquivo

\subsubsection{Desempenho do Sistema de Rede do S.O.}

Os testes para medir o desempenho do sistema de rede do sistema operacional foram subdivididos em duas partes: a primeira visa medir o desempenho do sistema operacional, onde o servidor e estações estão conectados através de uma rede ethernet (10Mbps); a segunda parte visa medir o desempenho do sistema operacional, onde o servidor está conectado através de uma rede FDDI (100Mbps) e as estações estão conectadas através de uma switch ethernet (10 Mbps).

\subsubsection{Desempenho sobre uma rede ethernet (10Mbps) (figura 6.1)}

\begin{tabular}{|r|c|c|}
\hline Teste & WindowsNT (kybtes/ seg) & Linux (kbytes/ seg) \\
\hline $\mathbf{1}$ & 783,38 & 1069,42 \\
\hline $\mathbf{2}$ & 524,58 & 569,65 \\
\hline $\mathbf{3}$ & 420,76 & 426,59 \\
\hline $\mathbf{4}$ & 553,41 & 568,67 \\
\hline $\mathbf{5}$ & 380,70 & 386,04 \\
\hline
\end{tabular}




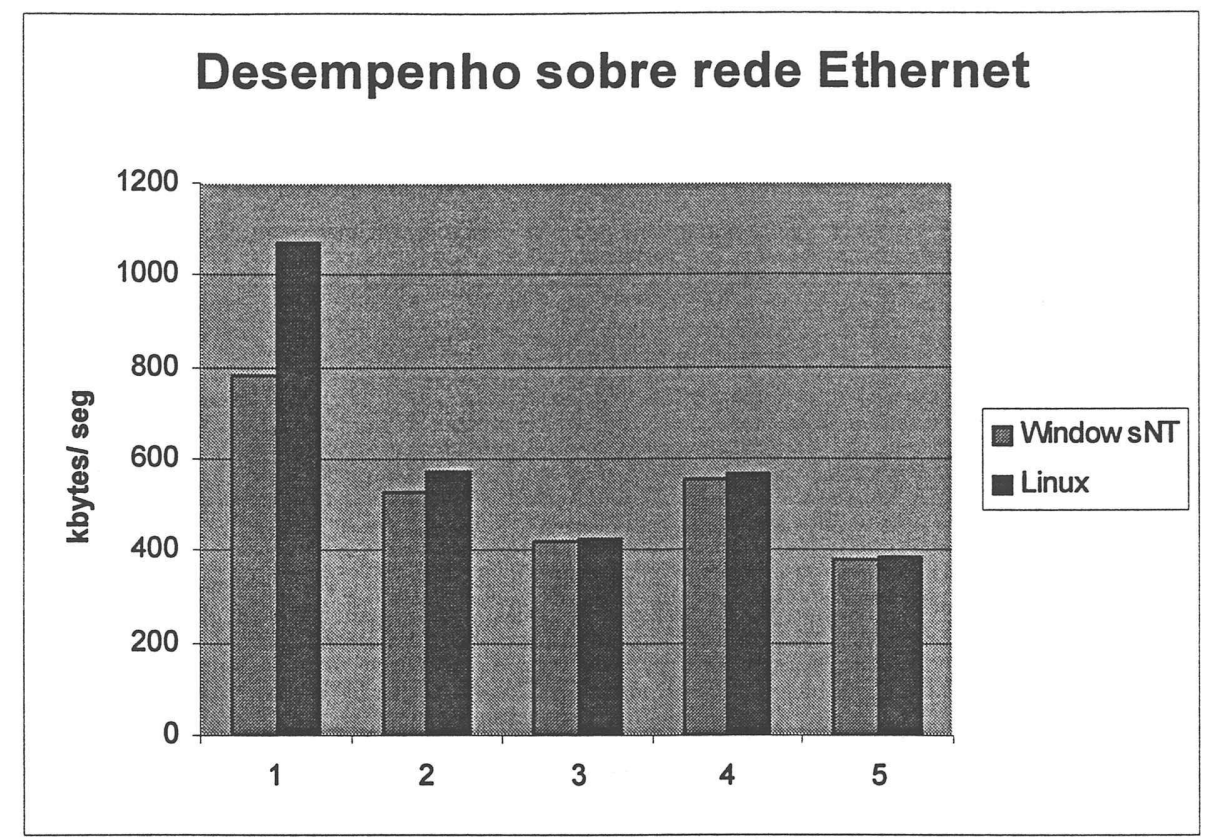

Figura 6.5-Desempenho do S.O. - sistema de rede ethernet

\subsubsection{Desempenho sobre uma rede FDDI + Switch Ethernet}

Foi montado um outro ambiente de testes onde o servidor esta conectado através de um anel FDDI e as estações através de uma switch ethernet (10Mbps)(Figura 6.6).

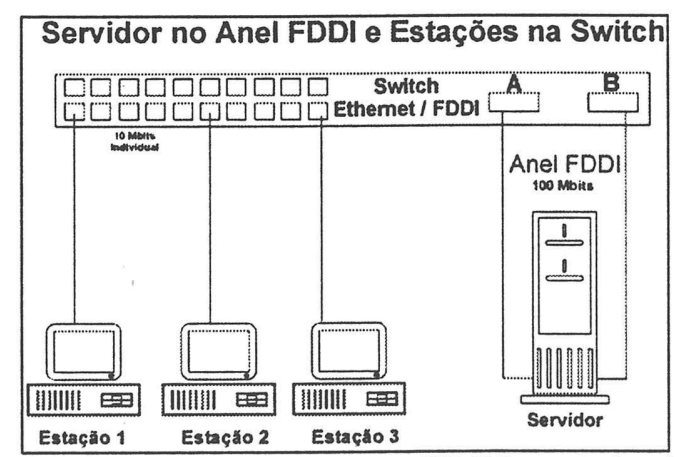

Figura 6.6 Ambiente de testes com FDDI e switch ethernet

\begin{tabular}{|c|c|c|}
\hline Teste & WindowsNT (kybtes/ seg) & Linux (kbytes/ seg) \\
\hline $\mathbf{1}$ & 1039,68 & 1069,32 \\
\hline $\mathbf{2}$ & 1060,42 & 1075,39 \\
\hline $\mathbf{3}$ & 1000,06 & 1065,30 \\
\hline $\mathbf{4}$ & 986,52 & 1064,93 \\
\hline $\mathbf{5}$ & 779,16 & 1008,27 \\
\hline
\end{tabular}




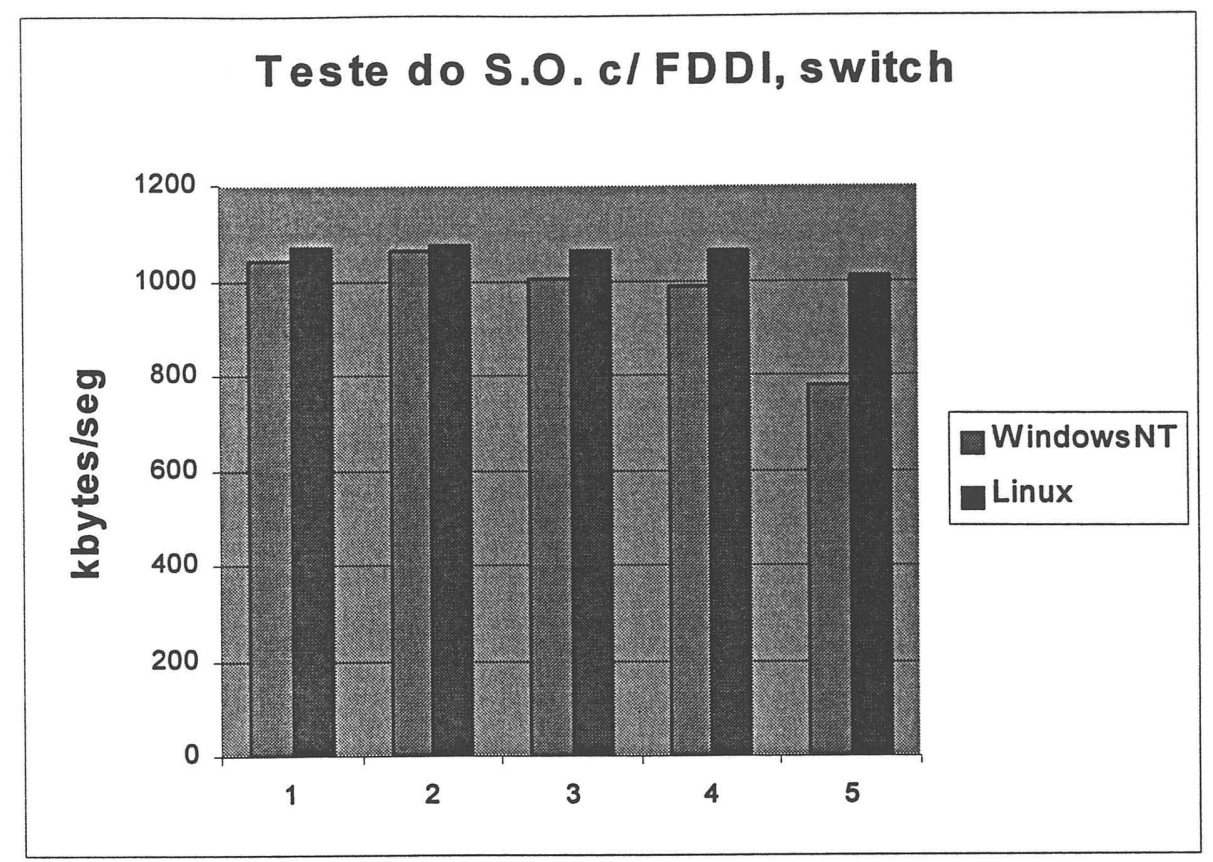

Figura 6.7 - Desempenho do S.O. - sistema de rede FDDI + Switch Ethernet

\subsection{Teste D - Desempenho comparativo do Sistema de Arquivo(melhoria mostrada} pelo RAID)

Foram feitos testes para medir o desempenho ao se utilizar um sistema de arquivo tradicional(único disco) e utilizando o sistema de arquivo com a tecnologia RAID-0. Os testes foram realizados sobre o Sistema Operacional Linux e com a controladora SCSI Adaptec 3985. O disco lógico Raid foi montado sobre os três discos rígidos SCSI quantum (1 de 2GB e 2 de 4GB). Como os testes anteriores demonstraram que o disco rígido Seagate apresenta um desempenho inferior, os testes para medir o desempenho do sistema de arquivo tradicional também foram feitos sobre o disco rígido de $4 \mathrm{~GB}$ quantum. Os resultados obtidos foram :

\begin{tabular}{|c|c|c|}
\hline Teste & $\begin{array}{l}\text { Sistema de arquivo tradicional } \\
\text { (kbytes/seg) }\end{array}$ & Tecnologia Raid(kbytes/ seg) \\
\hline $\mathbf{1}$ & 2780,60 & 3530,94 \\
\hline $\mathbf{2}$ & 1917,47 & 2687,63 \\
\hline $\mathbf{3}$ & 1482,56 & 2138,77 \\
\hline $\mathbf{4}$ & 898,37 & 1483,91 \\
\hline $\mathbf{5}$ & 660,12 & 948,39 \\
\hline
\end{tabular}




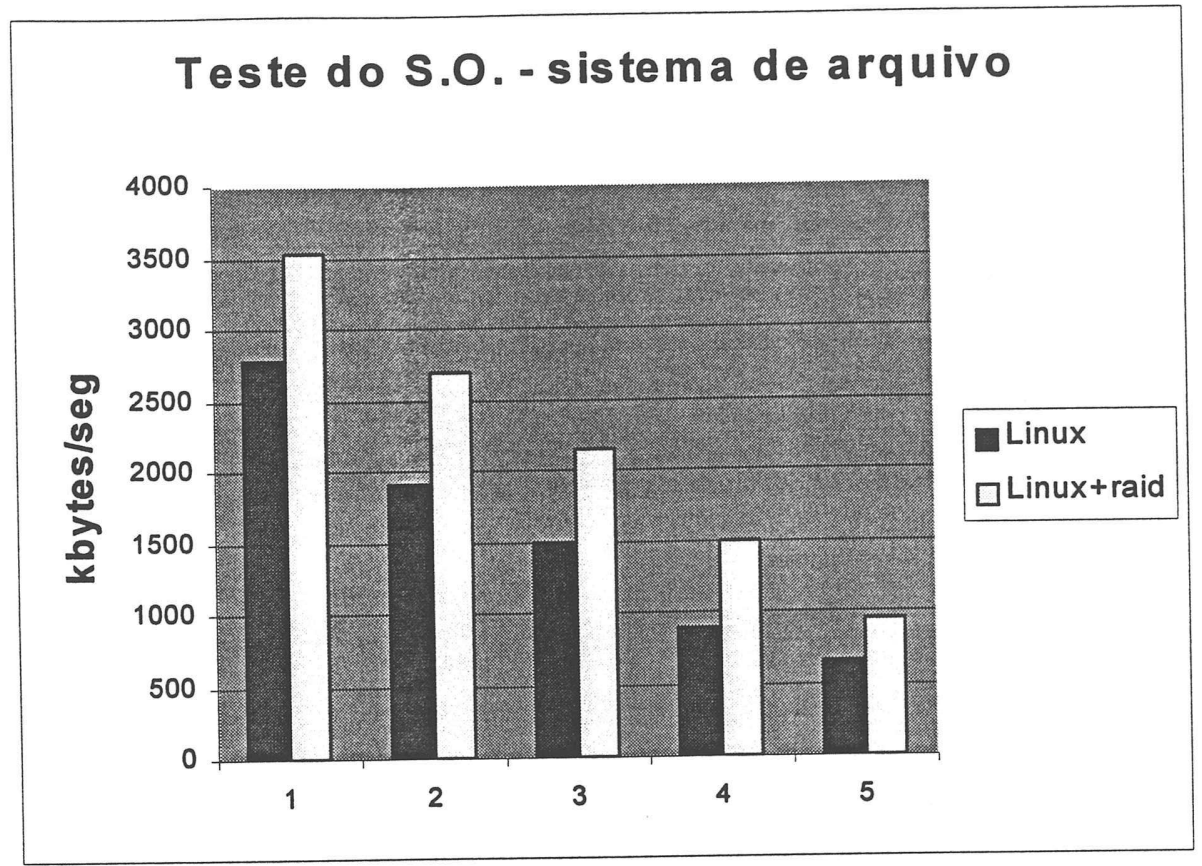

Figura 6.8 - Desempenho do Sistema de Arquivo

\subsection{Teste E - Desempenho do Sistema de Arquivo sobre uma rede ethernet}

Foram feitos testes para medir o desempenho da rede ao se utilizar um sistema de arquivo tradicional(único disco) em contraste com o sistema de arquivo com a tecnologia Raid-0 sobre uma rede de computadores. Os testes foram realizados sobre o Sistema Operacional Linux e com a controladora SCSI Adaptec 3985. O disco lógico Raid foi montado sobre os três discos rígidos SCSI quantum (1 de $2 \mathrm{~GB}$ e 2 de $4 \mathrm{~GB}$ ). Os resultados obtidos foram :

\begin{tabular}{|c|c|c|}
\hline Teste & $\begin{array}{l}\text { Sistema de arquivo tradicional } \\
\text { (kbytes/seg) }\end{array}$ & Tecnologia Raid(kbytes/ seg) \\
\hline $\mathbf{1}$ & 1064,22 & 1069,42 \\
\hline $\mathbf{2}$ & 579,84 & 569,65 \\
\hline $\mathbf{3}$ & 427,08 & 426,59 \\
\hline $\mathbf{4}$ & 559,26 & 568,67 \\
\hline $\mathbf{5}$ & 388,93 & 386,04 \\
\hline
\end{tabular}




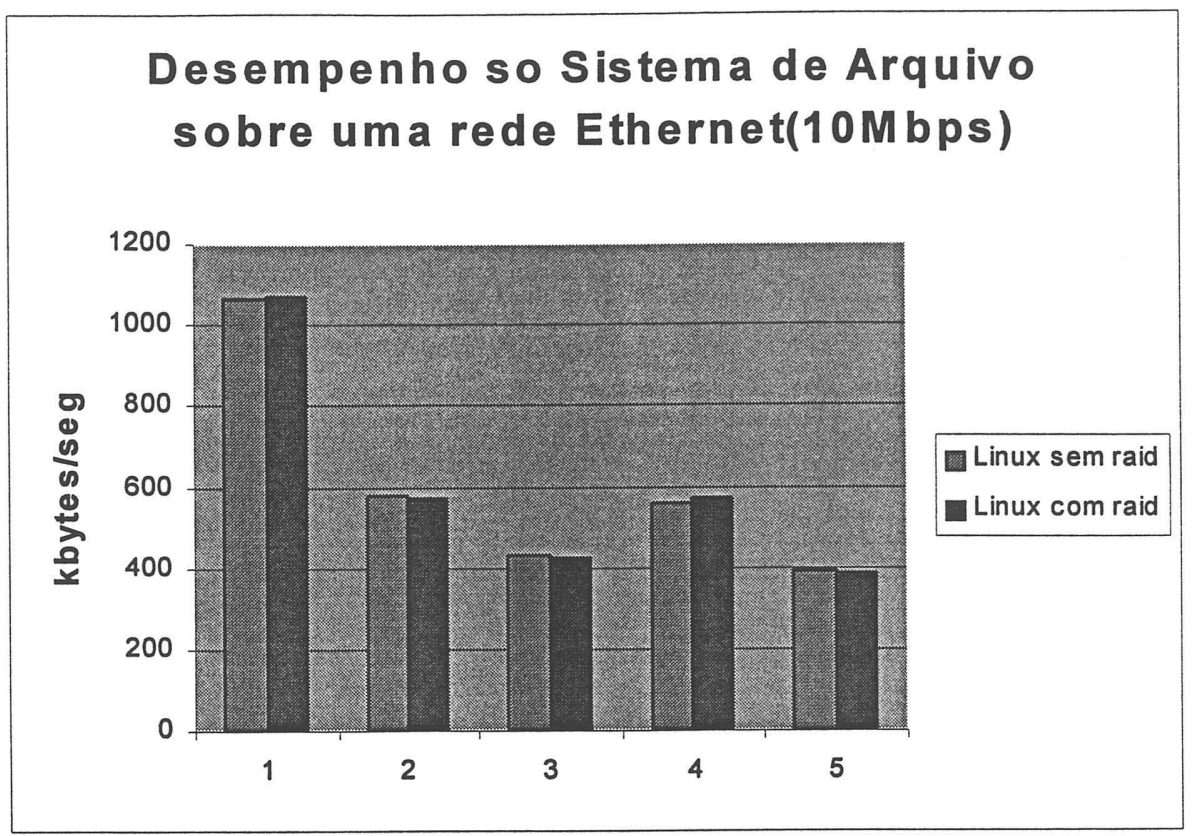

Figura 6.9 - Desempenho do Sistema de Arquivo sobre uma rede Ethernet(10Mbps)

\subsection{Teste F - Desempenho do Sistema de Arquivo sobre uma rede FDDI}

Este teste visa medir o desempenho no atendimento de requisições da rede ao se utilizar um sistema de arquivo tradicional e utilizando o sistema de arquivo com a tecnologia Raid-0 sobre uma rede onde o servidor está conectado através de uma rede FDDI(100Mbps) e as estações estão conectados através de uma switch ethernet(10Mbps)(figura 6.6). Os resultados obtidos foram :

\begin{tabular}{|c|cc|c|}
\hline Teste & $\begin{array}{l}\text { Sistema de arquivo tradicional } \\
\text { (kbytes/seg) }\end{array}$ & Tecnologia Raid(kbytes/ seg) \\
\hline $\mathbf{1}$ & 1064,22 & 1069,42 \\
\hline $\mathbf{2}$ & 579,84 & 569,65 \\
\hline $\mathbf{3}$ & 427,08 & 426,59 \\
\hline $\mathbf{4}$ & 559,26 & 568,67 \\
\hline $\mathbf{5}$ & 388,93 & 386,04 \\
\hline
\end{tabular}




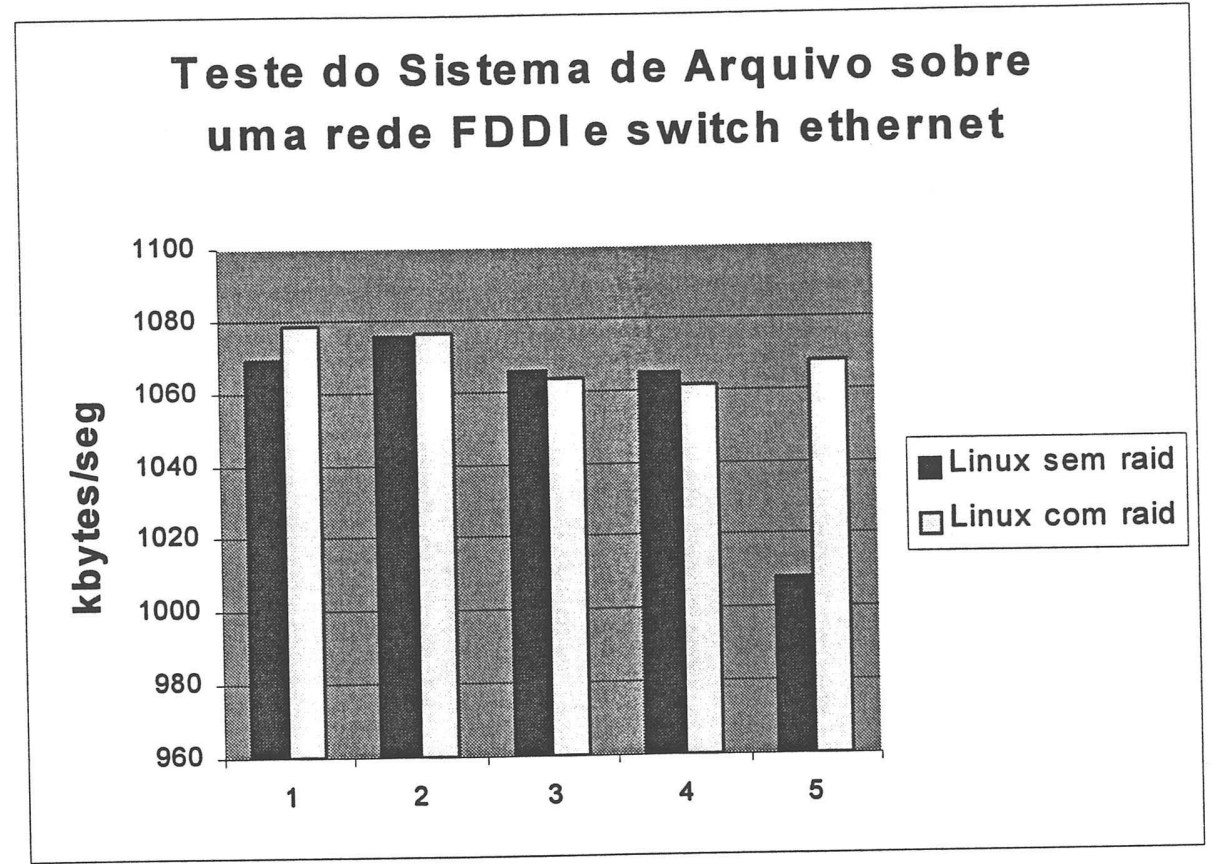

Figura 6.10-Desempenho do Sistema de Arquivo sobre uma rede FDDI e switch ethernet

\subsection{Avaliação dos resultados}

Através dos testes realizados no servidor de vídeo, podemos chegar à conclusão que todos os componentes do servidor podem ser um gargalo em potencial, desde o disco rígido até a rede de computadores. Cada teste (1 a 5) realizado possui um objetivo especifico, que são:

- Teste 1 - Possui o objetivo de medir o desempenho de um único acesso ao disco, verificando com isso a velocidade de acesso sequëncial do disco.

- Teste 2- Possui o objetivo de medir o desempenho de dois acessos concorrentes, além de verifica o sistema de cache, já que os dois acessos é para o mesmo arquivo.

- Teste 3- Possui o objetivo de medir o desempenho de três acessos concorrentes, além de verifica o sistema de cache, já que os três acessos é para o mesmo arquivo. 
- Teste 4- Possui o objetivo de medir o desempenho de dois acessos concorrentes, nesse teste cada cliente esta acessando uma cópia diferente do arquivo, verificando com isso a velocidade de acesso aleatório do disco.

- Teste 5- Possui o objetivo de medir o desempenho de três acessos concorrentes, nesse teste cada cliente esta acessando uma cópia diferente do arquivo, verificando com isso a velocidade de acesso aleatório do disco.

Através da avaliação dos testes, detectamos os seguintes gargalos :

- Como ficou demonstrado na figura 6.2 podemos concluir que o disco rígido, se não for bem escolhido, pode ser um gargalo que resulta no baixo desempenho do servidor. Como podemos observar pela figura 6.2, o disco rígido Seagate apresentou um desempenho bastante inferior ao disco quantum.

- Através da figura 6.3 concluimos que há a necessidade de uma avaliação mais cuidadosa da controladora SCSI, pois os testes demonstraram que não basta possuir um disco rígido de bom desempenho, se a controladora apresentar um desempenho baixo.

- Como demostra a figura 6.4 concluimos que o sistema operacional WindowsNT, em sua configuração padrão apresenta um desempenho inferior ao sistema operacional Linux quanto ao atendimento de requisição de arquivos.

- Através da figura 6.5 concluimos que (1) o sistema de rede do WindowsNT possui um desempenho inferior ao do sistema operacional Linux; (2) que a rede ethernet(10Mbps/s) também se torna um gargalo para um número médio de clientes. Analisando a figura 6.11 podemos observar que no teste 1 , o gargalo é o sistema de rede do windowsNT. Já nos testes seguintes o gargalo é a rede ethernet(10Mbps), pois a sua utilização chega a $90 \%$, o que para a rede ethernet é uma taxa alta. No sistema operacional Linux, o gargalo sempre é a rede. 


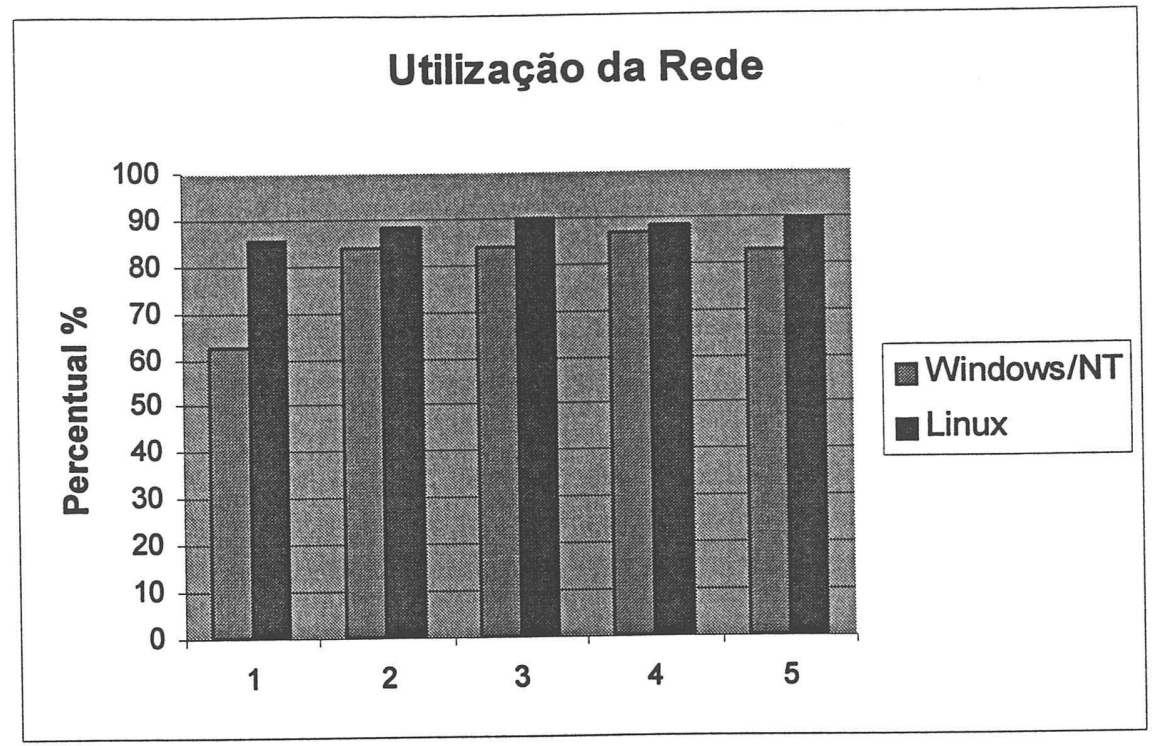

Figura 6.11 - Percentual de utilização da rede ethernet

- Através da figura 6.7 podemos concluir que o gargalo inicialmente é a rede ethernet(10Mbps), porém para um número maior de clientes, o gargalo se torna o próprio sistema de arquivo. Constamos ainda que o sistema de arquivo do WindowsNT é menos eficiente que o do Linux.

- Pela figura 6.8 concluímos que, utilizando a tecnologia Raid no sistema de arquivo, conseguimos um desempenho superior em relação ao sistema de arquivo tradicional (único disco).

- Através da figura 6.9 concluímos que o gargalo do sistema é a rede ethernet(10Mbps/s): tanto o sistema de arquivo tradicional quanto o sistema de arquivo com tecnologia Raid apresentaram resultados semelhantes. A utilização da rede nesse teste foi de aproximadamente $90 \%$, o que é considerado um índice alto para a rede ethernet(10Mbps/s).

- Pela figura 6.10 concluímos que o gargalo do sistema inicialmente é a rede ethernet $(90 \%$ de utilização). Contudo, com um número médio de clientes (três clientes), a figura 6.10 demostrou que o sistema de arquivo tradicional(único disco) se torna o gargalo..

No próximo capítulo são discutidas as contribuições e as propostas de continuidade desse trabalho. 


\section{Conclusões e Trabalhos Futuros}

À medida que se verifica o aumento do número de computadores na sociedade e a interconexão dos mesmos através de uma rede de computadores, surge uma nova classe de aplicações dos mesmos. Uma das aplicações - a utilização de áudio e vídeo - começou a aparecer com certo destaque. Isso vem demonstrar que torna-se cada vez mais complexa a criação de um ambiente computacional capaz de atender a essas necessidades de maneira eficiente, pois a confecção de material multimídia (notadamente com fins educacionais) envolvem fatores como o armazenamento, a editoração e a apresentação eficiente desse material.

A questão do armazenamento de dados multimídia em ambientes WWW é ponto fundamental, uma vez que o fornecimento do material desejado deve ser gerenciado de forma eficiente para evitar sobrecarga do sistema devido ao grande volume dos dados e ao eventual grande número de usuários acessando o sistema.

Apresentamos no decorrer desse trabalho, o desenvolvimento de um sistema servidor para aplicações multimídia sobre o ambiente WWW. O sistema implementado foi integrado ao projeto maior (Ambiente de auxilio à atividade didática), no qual o servidor de vídeo é responsável pelo gerenciamento dos dados multimídia. O objetivo deste trabalho foi o estudo, definição e implementação deste servidor para aplicações multimídia, capaz de disponibilizar dados (vídeo e áudio) a uma população de clientes. Esses dados podem ser disponibilizados através de uma rede padrão ethernet $(10 \mathrm{Mbits} / \mathrm{s})$ e acessados através do ambiente $\mathrm{W} \mathrm{W} \mathrm{W}$. O trabalho compreendeu também a implementação de ferramentas que auxiliem os usuários a gerenciar e apresentar os dados multimídias armazenados no servidor.

As contribuições mais significativas desse trabalho as seguintes:

- A implementação de um servidor bem ajustado, especificado desde o hardware que compõe o servidor(Plataforma, quantidade de memória, tamanho e quantidade de discos magnéticos, etc.), como também os softwares, desde o sistema operacional até a linguagem de programação do sistema de gerenciamento. 
- Com a realização de testes de desempenho do servidor de vídeo, foi possível não só medir o desempenho do servidor, como também detectar os gargalos nos componentes que compõem o servidor, tais como : sistema operacional, disco, rede, etc. O principal gargalo do sistema é o sistema de rede, especialmente quando se utiliza a rede ethernet(10Mbps/s), entretanto foi constatado que todos os componentes do servidor são gargalos em potencial, desde o disco rígido até a placa de rede.

- Desenvolvimento de ferramentas que auxiliam o usuário no gerenciamento(inserção, remoção de dados multimídia) e apresentação dos dados multimídia armazenados no servidor através do ambiente WWW.

- A monitoração pelo professor ou pelo administrador do servidor de vídeo, através de qualquer computador através do ambiente WWW, capaz de saber tudo o que está acontecendo no servidor, como por exemplo: quais vídeos estão sendo utilizados:quais vídeos estão armazenados, qual vídeo determinado usuário está utilizando, etc.

- Apesar do sistema poder ser utilizado na "grande rede", prevemos uma demanda maior para serviços como este em redes locais (empresas e escolas). Vários esquemas diferentes de rede podem ser utilizados para a distribuição. Os testes nesta área mostram o ganho que se pode ter quando se utiliza switches que possuem portas de alto desempenho (no caso foi utilizado FDDI) para conexão do servidor à switch. Por exemplo, supondo-se que uma aplicação necessitasse de $600 \mathrm{KBytes}$ por segundo (padrão MPC3) e que esta fosse utilizada simultaneamente por 20 máquinas, a quantidade agregada de dados transmitidos seria de 12 MBytes por segundo (96 Mbits por segundo). Uma configuração possível de rede seria a conexão das 20 estações numa switch ethernet com porta FDDI para o servidor. Neste caso, precisaríamos de um servidor melhor configurado que o utilizado nos testes, com custo adicional relativamente baixo (vide, na figura 6.10 que, com 3 máquinas acessando o sistema, já se nota a limitação do acesso ao disco no caso sem RAID. Se o teste tivesse sido continuado com mais máquinas clientes, chegaríamos também a notar o limite do sistema com RAID). Situações de demanda maior de largura de banda precisaria de diferente arquitetura de rede, pois no caso descrito a conexão FDDI está próxima do limite de sua capacidade. Uma troca de FDDI por ATM a $155 \mathrm{Mbps} / \mathrm{s}$ poderia prover uma capacidade adicional ao sistema. 
- O sistema foi desenvolvido utilizando-se de tecnologias de baixo custo, se comparados a sistemas semelhantes existentes no mercado. Demonstramos, enfim que é viável a sua utilização se o sistema for utilizado por um número médio de usuários (1 laboratório). Considerando-se, ainda, o avanço tecnológico das redes, aliado ao aumento da velocidade de transmissão, acreditamos que sistemas como esse possam ser utilizados não só internamente a uma instituição, mas também como uma ferramenta no auxílio do ensino à distância

\subsection{Sugestões para Trabalhos Futuros}

As seguintes sugestões podem gerar trabalhos futuros dando continuidade ao sistema em questão, ou ainda motivando o desenvolvimento de outros sistemas:

- Outro trabalho de grande importância, seria o estudo e avaliação do servidor em um ambiente de rede diferente, tal como : o desempenho do mesmo sobre redes de alta velocidade(por exemplo:FDDI, Fast Ethernet, ATM, etc), tendo como objetivo descobrir os novos gargalos inerente ao sistema servidor, pois como foi verificado no capitulo 6 , o principal gargalo encontrado no sistema foi o sistema de rede, porém foi constatado que todos os componentes que compõem o servidor, são gargalos em potencial, desde o disco rígido até a placa de rede.

- Explorar melhor a tecnologia Raid para o aumento da velocidade de acesso e avaliar sua dependência com CPU, cache e RAM.

- Desenvolvimento de interfaces que auxiliem os usuários no gerenciamento dos dados multimídia armazenados no servidor, fazendo uso das técnicas de Interface Homem Computador. 


\section{Glossário}

ADC Analog to Digital Converter. Refere-se ao processo de transformação de um sinal analógico em um sinal digital.

ADPCM Adaptive Differential Pulse Code Modulation. Uma ténica de codificação predictiva derivada do PCM, que somente codifica a diferença entre o valor atual da amostra e um valor predictivo que resulta de alguma forma de extrapolação do valor anterior, usando uma função de predição variável. Exemplo: esquema ITU-TS G.723 para telefone.

API Application Programming Interface. Especifica como um programador deve escrever um aplicativo para acessar the behavior e estados de classes e objetos.

Applet Um programa escrito em java para ser executado sobre um navegador web compatível java, com Hotjava ou Netscape Navigator.

Amplitude No processamento de sinais, o valor obtido de um sinal. Em processamento digital, amplitude refere-se ao valor obtido de amostras individuais.

ATDM Asyncbronous Time Division Multiplexing. A técnica de multiplexação por divisão de tempo (TDM) permite misturar comunicações diferentes sobre o mesmo meio de transmissão, realizando alocação de slots por tempo, quando um bloco de informação for ser transmitido. Usado em meio compartilhado LANs, IP, X.25, ou rede ATM. Também chamado ATDM. Oposto de multiplexação por divisão de tempo síncrono.

ATM Asynchronous Tranfer Mode. Padrão da ITU destinada para altas taxas de bits para redes $W A N$ com estrutura broadband ISDN, desenvolvido e baseado no princípio de multiplexação por divisão de tempo assíncrono. A tecnologia também é destinada para redes locais. Baseado no transporte de pequenoas unidades de dados de tamanho fixo (53 bytes) que recebe o nome de célula.

B-ISDN Broadcasting-Integrated Services of Digital Network. Termo genérico estudado e padronizado pela ITU e ISO para uma tecnologia de alta largura de banda, suportando todos os tipos de serviços digitais em um caminho integrado. 
Bandwidth Largura de Banda. Em transmissão, o número de frequencias que um sistema pode transmitir sem excessiva redução. Em redes de dados, usado para referir a capacidade de uma rede expressado em bits por segundo.

Broadcasting Em telecomunicações, broadcasting é a propagação de um fluxo de informação de uma fonte para todos os destinos. Exemplo: canal de TV.

Bytecode código independente de máquina gerado por um compilador Java e executado por um interpretador Java.

CCITT Comitê Consultatif International Téléphonique et Télégraphique. Comitê que faz parte da ITU que produz padrões para telefone e sistema de comunicação de dados. Foi renomeado para ITU-TS.

CELP Code Excited Linear Prediction. Um esquema de compressão baseado em quantização de vetor para voz.

CIF Common Intermediate Format. Troca de Formatos para imagens de vídeo em movimento.

Comutação de Pacotes Técnica de multiplexação por divisão de tempo usado em comunicação de dados onde o fluxo de bits são divididos em pequenas unidades de dados mandados um a um com um intervalo de tempo, e são também chamados de pacotes, frames, ou células.

Compilação Um programa é traduzido do código original para um código que possa ser executado por um computador. Um compilador Java traduz o fonte java para bytecode Java.

Crominância Termo usado para se referir as diferenças de cor. Em analogia a TV broadcast, sinais de crominância são construídos pela combinação linear de sinais de diferentes cores.

DAC Digital to Analog Converter. Refere-se ao processo de transformação do sinal digital para um fenômeno físico que o humano pode sentir (ver, ouvir).

Descompressão Em computador, refere-se ao processo pelo qual as informações comprimidas são expandidas pela adição de informações redundantes eliminadas no estágio de compressão. 
DPCM Difference Pulse Code Modulation. Uma técnica de codificação predictiva derivada do PCM, onde somente a diferença entre o valor atual e o valor da amostra é codificada. DPCM usa uma função de predição constante.

HDTV High-Definition Television. Refere-se a tecnologia de TV com qualidade superior a TV broadcast convencional. 1920 pixels/linha, 1080 linhas/frame a alta taxa de $60 \mathrm{fps}$.

HTML HyperText Markup Language. Isto é um formato de arquivo, baseado sobre SGML, para documentos hypertextos sobre a Internet. Ele é muito simples e fácil para a associação de imagens, sons, streams de vídeo, formulários e textos simples formatados.

HTTP Hypertext Transfer Protocol. O protocolo Internet, baseado em TCP/IP, utiliza para fetch objetos hypertextos de computadores remotos.

Java Platform A máquina virtual java e a classes Java core make up a plataforma java. A plataforma java provê uma interface de programação uniforme para um programa $100 \%$ java sem a necessidade de escrever uma linha de código na linguagem do sistema operacional.

Jitter Em comunicação de dados, é a variação sobre o tempo de atraso do tráfego da rede.

LPC Linear Predictive Coding. Um esquema de compressão baseado na quantização de vetor para voz.

Multithreaded Descreve um programa que é desenvolvido para Ter partes que serão executador concorrentemente.

PAL Pbase Alternating Line. Nome do padrão de TV colorida broadcast usado na Alemanha, parte da África e parte da Ásia. 625 linhas e $25 \mathrm{fps}$.

PCM Pulse Code Modulation. Técnica de digitalização que consiste de um passo de amostragem seguido por uma quantização e geração de palavra código, onde cada amostra é quantizada independentemente da outra. Particularmente usado para digitalização e voz.

Posix Portable Operating System - IX. Um padrão que define uma linguagem de interface entre o sistema operacional Unix e um programa aplicativo com um conjunto minimo de funções suportadas. 
QoS Quality of Service. Em rede, um conceito que as aplicações usam para especificar as necessidades para o sistema, antes da transmissão inicial.

SGML Standardized Generalized Markup Language. Um padrão ISSO/ANSI/ECMA que especifica um meio para anotações de documentos texto com informações sobre tipos de seções de um documento.

Thread A unidade básica de execução do programa. Um processo pode Ter várias threads rodando concorrentemente, cada um fazendo um trabalho diferente, como por exemplo esperar por um evento ou uma operação que o programa não necessita ser completado antes going on. Quando uma thread termina o serviço, a thread é supensa ou destruída.

URL Uniform Resource Locator. Um padrão para escrever uma referência de texto para um pedaço arbitrário de dados em uma WWW. Uma URL looks like "protocol://host/localinfo"onde a especificação de um protocolo para usar para fetch o objeto (como HTTP ou FTP), host especifica um nome Internet de um host sobre o qual se encontra, e localinfo é uma string passada para o protocolo sobre um host remoto.

Virtual Machine Uma especificação abstrata para um dispositivo computacional que pode ser implementado de diferentes formas, em um software ou hardware. Você compila para o conjunto de instruções da máquina virtual para o conjunto de instruções de um microprocessador. A Máquina Virtual Java consiste de um conjunto de instruções bytecode, um conjunto de registradores, uma pilha, um heap, e uma área para armazenar os métodos.

YUV Em televisão colorida, refere-se a um sistema de três sinais: o sinal de luminância Y e dois sinais de crominância U e V. Sistema usado pelo padrão PAL. 


\section{Referências Bibliográficas}

[Ba92] BASTOS, T. L. P., SOARES, L. F. G.; Análise de Algoritmos para Reprodução em Tempo Real de Voz em Redes de Pacotes. In $10^{\circ}$ SBRC Simpósio Brasileiro de Redes de Computadores, p. 445-463, Recife, Abril, 1992.

[Ba93] BASTOS, C. A., STANTON, M.; Serviços e Redes de Comunicação em Alta Velocidade. In: SIMPÓSIO BRASILEIRO DE REDES DE COMPUTADORES, 11., Campinas, 1993. Tutoriais e Minicursos.

[Bi93] BIAGIONI, E., COOPER, E., SANSOM, R.; Designing a Pratical ATM LAN. IEEE Network Magazine, v. 7, n.2, p. 32-39, Março 1993.

[Bo92] LE BOUDEC, J-Y., The Asynchronous Transfer Mode: a Tutorial. Computer Network and ISDN Systems, n.24, p. 279-309, 1992.

[Bo94a] Borko, F. Multimedia Systems : An Overview. IEEE Multimedia, p. 47-59,Spring 1994.

[Da94] Dagdeviren, N.; Newell, J. A.; Spindel, L. A.; Stefanick, M. J. Global Network with ISDN. IEEE Comunication Magazine, p.26-32,Junho, 1994.

[Fe94a] Federighi, C; Rowe, L. A. A Distributed Hierarchical Storage for a Video-onDemand System, Symp. On Elec. Imaging Sci. \& Tech., San Jose, Fevereiro, 1994.

[F195b] Fluckiger, F. Understanding Networked Multimedia applications and technology. Prentice Hall, 1995.

[Ge95] Gemmell, D. J.; Vin, H. M.; Kandlur, D.D.; Rangan, P. V.; Rowe, L. A. Multimedia Storage Servers : A Tutorial, IEEE Computer, pag.40-48, Maio, 1995.

[Gu94] Guarneri, R.; Lanting, C. J. M. Frame Relaying as a Common Acess to N-ISDN and B-ISDN data Services. IEEE Communications Magazine, p.39-43, Junho, 1994. 
[Hu96] Hughes technologies Pty Ltd. Mini SQL : A Lightweight Database Engine, 1996.

Ja97] Jackson, J.R., McClellan, A. L. Java by example, Prentice Hall Title, 1997

[Je97] Jepson, B., Programando banco de dados em Java, Makron Books, 1997.

[Ka97] KAO, P. RAID: A Necessary Requirement for Today Networking, novembro, 1997, disponível em http://www.artecon.com/raid/raidwpaper.html

[Kr96] KRAMMER, D. The Java Platform : A White Paper, maio, 1996, disponível em $\mathrm{ftp}: / / \mathrm{ftp}$.javasoft.com/docs/papers/javaplatform.ps

[La97] Lalani, S., Jamsa, K.; JAVA: biblioteca do programador, Makron Books, 1997

[Le94a] Berners-Lee,T. et al. The World-Wide Web. Communications of the ACM. Vol.37, pp.76-82, n. 8, 1994.

[Le94b] Lee, E.K.; Chen, P.M.;Hartman,J.H.;Drapeau, A.L.C.; Miller, E.L.; Katz, R.H.; Gibson, G.A.; Patterson, D.A. RAID-II: A Scalable Storage Architecture for HighBandwidth Network Filse Service. $21^{\text {st }}$ International Symposium on Computer Architecture, Chicago, Illinois, Abril, 1994.

[Li95] LIEIRA, J.; MOREIRA, E.D.S. - "Utilização de Som e Imagem em Sistemas de Gerenciamento de Redes de Computadores", submetido para o SEMISH, Canela, RS, 1995.

[Lo93] Lougher, P.; Shepherd, D. The Design of a Storage Server for Continuous Media, The Computer Journal, pag. 32-41, Vol. 36, No. 1, 1993. 
[Mo95a] MOREIRA, E.D.S; Reami, Eldercley Regis; Pissioli, Mauricio - "Live Video for Distributed Multimedia/Hypermedia Applications: Directly Connecting Video Sources to TCP/IP Networks", aceito para apresentação e publicação nos proceedings do 18th Annual International Conference MIPRO' 95 on Multimedia/Hypermedia Systems, Croacia, maio, 1995.

[Mo95b] MOREIRA, E.D.S. et allu - "Design Issues for the Process of Developing a Hypermedia-based Distributed Tutoring System (HyDTS)", submetido para o SBIA, Florianópolis, SC, out/ 95.

[Mo97] Morandini, M.; Castro, M.A.S.; Pimentel, M.G.C. Princípios de Interação UsuárioComputador Aplicados ao Projeto de um Quiosque Hipermídia: uma Experiência. Submetido ao WoHM97 (III Workshop em Sistemas Hipermídia e Multimídia), São Carlos, 1997.

[Na95] Nahrstedt, K.; Hossain, A.; Kang, S.M. Probe-based Algorithm for QoS Specification and Adaptation, University of Illinois, 1995.

[Na96] Naughton, P. The Java Handbook. Osborne McGraw-Hill, Berkeley, 1996.

[Ni90] Nielsen, J. Hypertext \& Hypermedia. Academic Press, 1990.

[Nu93] Nunes, M.G.V et al. Uso de Hipertexto/ Hipermídia em Sistemas Tutores Inteligentes. Nota Didática do ICMSC, n..$^{\circ}$, 1993.

[Oh94] Ohr, S.Digital video spearheads TV and videoconferencing applications, Computer Designing, pag. 59-70, dezembro, 1994.

[Ra94] Rarig, H. ISDN Signal Distribution Network. IEEE Communication Magazine, p.34-43, Junho, 1994.

[St94] Strauss, P. An ISDN SURVIVAL Guide. Datamation, p.59-65, Outubro. 1994. 
[St95] Stüttgen, H. Network Evolution and Multimedia Communication. IEEE Multimedia, p.42-59, Fall, 1995.

[St95a] Steinmetz, R. Analyzing the Multimedia Operating System. IEEE Multimedia, p.68-84, Spring, 1995.

[Ta93] Tawbi, W.; Horn, F.; Horlait,E.; Stefani, J.B. Video Compression Standardsand Quality os Service, The Computer Journal, pag. 43-54, Vol. 36, No. 1, 1993.

[Tr97] TRINDADE, C.C., Minimal Hyperlinking Hy'Time Documents: Especificação e Apresentação de Estruturas Clássicas de Hipertexto. Dissertação de Mestrado apresentada ao ICMSC-USP em Fevereiro de 1997. 


\section{Apêndice : Artigos Submetidos}

Foram submetidos dois artigos como resultado do projeto:

- Aspectos de Desenvolvimento e Avaliação de Servidores de Video-On-Demand em Redes de Computadores, submetido para o $16^{\circ}$ SBRC (Simpósio Brasileiro de Redes de Computadores).

- Avaliação de Desempenho de um ambiente computacional para provimento de vídeo, submetido para a Revista Colloquium (Centro de Pós-Graduação da Unoeste "Universidade do Oeste Paulista”). 


\section{ASPECTOS DE DESENVOLVIMENTO E AVALIAÇÃo DE SERVIDORES DE VIDEO-ON-DEMAND EM REDES DE COMPUTADORES}

Rudinei Goularte, Antonio Marcos M. Hachisuca, Edson dos Santos Moreira, Ronaldo C. M. Correia Departamento de Ciências de Computação e Estatística - ICMSC - USP - São Carlos

ICMSC-USP, Seção de Pós-Graduação, Av. Dr. Carlos Botelho, 1465. Cx. Postal 668 São Carlos - SP

E-mail:\{rgoulart, shiro, edson, ronaldo\}@icmsc.sc.usp.br

\section{RESUMO}

Este artigo discute alguns dos problemas de implementação de um sistema de distribuição de vídeo utilizando tecnologia Internet. A atenção especial é dada ao servidor de vídeo. Além do armazenamento e da distribuição, outro ponto importante é a forma de organizar o acesso aos dados no servidor de modo a obter eficiência e flexibilidade na manipulação dos mesmos. Uma base de metadados é implementada para obter a organização desejada. O artigo apresenta, como ponto principal, testes realizados para a avaliação comparativa de várias alternativas tecnológicas para os vários componentes do sistema. As avaliações incluem a interface de aplicação com a rede e com as bases de dados (verificando o impacto do uso de CORBA e de JDBC), o sistema operacional (NT e Linux), o sistema de armazenamento (SCSI e RAID) e a rede (ethernet e uma switch ethernet com uma porta FDDI para o servidor). $\mathrm{O}$ artigo descreve a metodologia utilizada e os resultados encontrados. Como exemplo de aplicação, o sistema é utilizado em um ambiente educacional onde a editoração e a apresentação são facilitadas.

\section{ABSTRACT}

This paper discusses some of the problems on the implementation of an Internet-based video delivery system. Special attention is given to the video server. Besides storage and delivery, another important point is how to handle the server's data in a way to provide efficiency and flexibility on the multimedia data access. A metadata-based database is used for that purpose. The paper also describes tests carried out to comparatively evaluate several hardware and software tecnological alternatives for the different components of the system. The evaluations include the application interface with the network and the database (verifying the impact of CORBA and JDBC), operating systems (NT an Linux), storage system (SCSI alone and RAID) and network (single-bus ethernet and switched ethernet with a FDDI port for the server). The paper describes the metodology used and the results obtained. As an application example, the system is used in an educational environment where editing and presentation are facilitated.

\section{INTRODUÇÃo}

A entrega de vídeo através de redes de computadores envolve fatores como armazenamento, entrega, organização dos dados e apresentação. A questão do armazenamento e a questão da entrega de dados de vídeo (e de dados multimídia em geral) em ambientes distribuídos (como a WWW) são pontos chave, uma vez que o fornecimento do material desejado deve atender a uma comunidade de usuários dispostos na rede em plataformas heterogêneas. $\mathrm{O}$ grande volume dos dados multimídia e o eventual grande número de usuários realizando acessos ao sistema (simultaneamente) podem levar sistemas convencionais (de armazenamento e entrega) à sobrecarga, comprometendo o atendimento da demanda.

\section{VIDEO-ON-DEMAND}

A utilização de servidores de dados multimídia baseados em sistemas VOD (Video-OnDemand) [Flu95, Lit94] é uma alternativa para se alcançar a eficiência exigida. Em um sistema VOD os vídeos são armazenados em um servidor de vídeo remoto, ao invés de replicar a coleção de vídeos utilizada (muito grande) em cada cliente. Um sistema VOD pode receber acessos simultâneos de centenas de usuários com diferentes preferências. $\mathrm{O}$ sistema deve ser 
capaz de garantir uma qualidade de serviço satisfatória a todos os clientes. No desenvolvimento de um sistema VOD, pesquisadores têm que resolver alguns problemas. Primeiro, o sistema deve prover mecanismos para o usuário localizar um vídeo desejado. Segundo, o sistema deve armazenar e gerenciar uma grande coleção de dados de vídeos estruturados. Terceiro, o sistema deve transportar um vídeo selecionado para o usuário final e executá-lo [Ber95].

De acordo com o nível de interatividade, os serviços de vídeo podem ser classificados em [Flu95]:

- Serviços Broadcast (No-VOD), similar aos canais de televisão, em que o usuário é um participante passivo e não possui nenhum controle sobre a sessão.

- Serviço Pay-Per-View (PPV), em que o usuário paga por uma programação específica, similar ao serviço existente em CATV (Cable TV).

- Serviço Quasi Video-On-Demand (Q-VOD), em que os usuários são agrupados pelo interesse comum que possuem. Os usuários possuem um controle rudimentar, ativado por chaveamento para os diferentes grupos.

- Serviços Near Video-On-Demand (N-VOD), em que funções de avançar e voltar são simuladas por transições em um intervalo de tempo discreto (da ordem de cinco minutos). Isto é feito utilizando vários canais que possuem a mesma programação, porém em tempos diferentes.

- Serviço True Video-On-Demand (T-VOD), em que o usuário possui total controle sobre a apresentação. O usuário tem todas as funções de VCR (Video Cassete Recorder), incluindo avançar, voltar, congelar e posicionar diretamente. T-VOD aloca para cada usuário um canal exclusivo; com isso, o número de usuários do serviço fica limitado pelo número de canais disponíveis. T-VOD necessita de um sinal bidirecional entre o usuário e o controle central. Serviços T-VOD são essenciais para aplicações como jogos interativos, onde todas as ações de um jogador são vistas pelos outros jogadores.

\section{ARMAZENAMENTO}

Em sistemas VOD o armazenamento de dados como áudio, vídeo e gráficos (entre outros) é realizado em algum tipo de dispositivo físico (disco, fita, etc.). $\mathrm{O}$ armazenamento e o gerenciamento de vídeo digital são difíceis devido à grande demanda de espaço de armazenamento requerida por esse material e, devido ao custo resultante desse armazenamento. Dessa forma, o armazenamento geralmente é realizado com a ajuda de técnicas como RAID (Redundant Array of Inexpensive Disks) [Lee94], armazenamento hierárquico [Fed94] ou armazenamento terciário [Lou93] para aumentar a eficiência na gravação e no acesso aos dados.

\section{BUSCA E RECUPERAÇÃO DE DADOS}

Outra questão, tão importante quanto o armazenamento dos dados, é a forma de se localizar o material de interesse no repositório. Grande parte dos acessos ao servidor multimídia realizados pelos usuários visa obter informações sobre os dados armazenados, como: tamanho do arquivo, data de criação, tipos de vídeo disponíveis, duração do vídeo, etc. Mesmo com mecanismos poderosos de armazenamento e transmissão, não é uma boa idéia enviar um vídeo completo ao cliente quando se deseja saber apenas o assunto sobre o qual o vídeo trata.

Para localizar um vídeo desejado uma interface amigável deve ser criada, ajudando o usuário a encontrar o vídeo no repositório. $\mathrm{O}$ projeto da interface de pesquisa deve considerar quais tipos de pesquisas devem ser suportadas e como as pesquisas devem ser especificadas.

Adicionalmente, para fins de editoração e apresentação de material multimídia, são necessárias ferramentas que aliem interatividade a mecanismos poderosos de busca. A utilização de índices para responder aos tipos de pesquisa necessários é uma boa alternativa, porém dados de mídia contínua (mídias que variam com o tempo como vídeos, animações e áudios) necessitam de novas técnicas de indexação, como a utilização de metadados. 


\section{SISTEMA OPERACIONAL}

O sistema operacional é fundamental para que um sistema multimídia obtenha bons resultados durante as apresentações. Sistemas operacionais convencionais foram projetados para oferecer um uso justo dos recursos do sistema entre os programas concorrentes, porém, tais sistemas sofrem a falta de serviços de tempo real necessários para o bom desempenho de aplicações multimídia.

Os sistemas operacionais convencionais apresentam problemas para suportar aplicações de mídia contínua. Segundo Buford [Buf94] alguns desses problemas são:

- Gerenciamento de Deadline e Recuperação. Ao contrário de aplicações de tempo real, muitas aplicações de mídia contínua possuem um deadline (prazo de entrega) inerentemente mais suave. Por exemplo, pode-se prosseguir uma videoconferência mesmo que a imagem de vídeo mais recente não possa ser processada a tempo. A perda de um deadline não leva ao caos total, porém a notificação da perda é uma informação importante, pois baseada nessa informação a aplicação pode querer mudar o nível de QoS (Quality of Service), como diminuir a taxa de frames sendo apresentados. Quando a aplicação perde um deadline devido à sobrecarga ou a erros de hardware ou software, o programa do usuário deve estar apto a tomar uma decisão. A decisão geralmente é uma recuperação que, freqüentemente, deve executar com uma prioridade maior que a atividade principal, logo, necessita aumentar sua prioridade primeiro.

- Latência de Interrupção. A grande latência das interrupções é uma das razões pelas quais os sistemas operacionais convencionais não suportam muito bem atividades de tempo real. Aplicações de mídia contínua produzem um número freqüente de interrupções no kernel resultando em pesadas trocas de contexto. Todo kernel não preemptivo provê latência de interrupção muito grande. $\mathrm{O}$ processamento dos eventos de tempo real que disparam uma nova thread (ou um novo processo) deve esperar até que o processamento atual do kernel termine, e isto demora vários milissegundos.

- Gerenciamento de Qualidade de Serviço e Controle de Admissão. Sistemas operacionais convencionais não possuem um mecanismo para manter um nível de QoS para aplicações de mídia contínua ou esquemas de gerenciamento e prevenção de sobrecarga (através de técnicas de controle de admissão), o que pode acarretar problemas de espera (delay) não predizível e jitter (descontinuidade no sinal provocada pela perda de um deadline) [Buf94, Ste95].

\section{REDE DE COMUNICAÇÃO}

Similarmente ao armazenamento o transporte e a execução de dados de vídeo requer um certo custo por stream, isso porque os dados de vídeo requerem entrega em tempo real e consomem considerável largura de banda de rede quando transmitidos [Ber95].

Em sistemas multimídia distribuídos as redes de comunicação devem dar suporte a um conjunto de serviços e requisitos como: tráfego em tempo real, garantia de alto desempenho e difusão múltipla. Os protocolos existentes como o IPX e o TCP/IP não satisfazem esses requisitos. Eles foram projetados para operar em sub-redes de baixa confiabilidade. Apesar da predominância dos protocolos da família TCP/IP, eles são inadequados para a utilização de multimídia pois: o protocolo de transporte (TCP) não suporta nenhum parâmetro de qualidade de serviço, a verificação de erros por checksum e o controle de fluxo através de janelas deslizantes introduzem um overhead muito grande na transmissão, existe a ausência de conexões multiponto, não há limite máximo garantido para atraso nem para o jitter e não possui a previsibilidade necessária para operar em tempo real. $\mathrm{O}$ uso de protocolos TCP/IP é viável para aplicações multimídia quando a sub-rede de comunicação assegura alto desempenho e confiabilidade. Existe uma grande expectativa em torno das redes digitais de serviços integrados em banda larga (BISDN) usando tecnologia ATM [Com95, Cou94]. 
As limitações apresentadas por sistemas operacionais, redes e protocolos de comunicação convencionais não impossibilitam a construção ou execução de aplicações multimídia distribuídas. Hoje em dia existem diversas dessas aplicações e o que se almeja é o oferecimento de uma qualidade melhor das mesmas. Por exemplo, espera-se que a apresentação de um vídeo em computador tenha a mesma qualidade que a apresentação em televisão, porém, para uma apresentação de vídeos através de uma rede de computadores dificilmente conseguese uma apresentação em tela cheia; normalmente a janela de apresentação é pequena (120x 260 geralmente). A melhoria na qualidade pode ser alcançada através de arquiteturas, algoritmos e técnicas que compensem ou anulem os problemas mencionados. No entanto, para algumas classes de aplicações essas limitações são perfeitamente aceitáveis (seção 5).

Este artigo está dividido da seguinte forma: a seção 2 mostra a arquitetura que compõe o servidor de vídeo; a seção explica como o acesso as dados está estruturado; a seção 4 apresenta os testes para avaliação de desempenho do servidor; a seção 5 dá um exemplo de ambiente que utiliza o servidor de vídeo e a seção 6 apresenta as conclusões sobre as avaliações realizadas e sobre as perspectivas do servidor de vídeo.

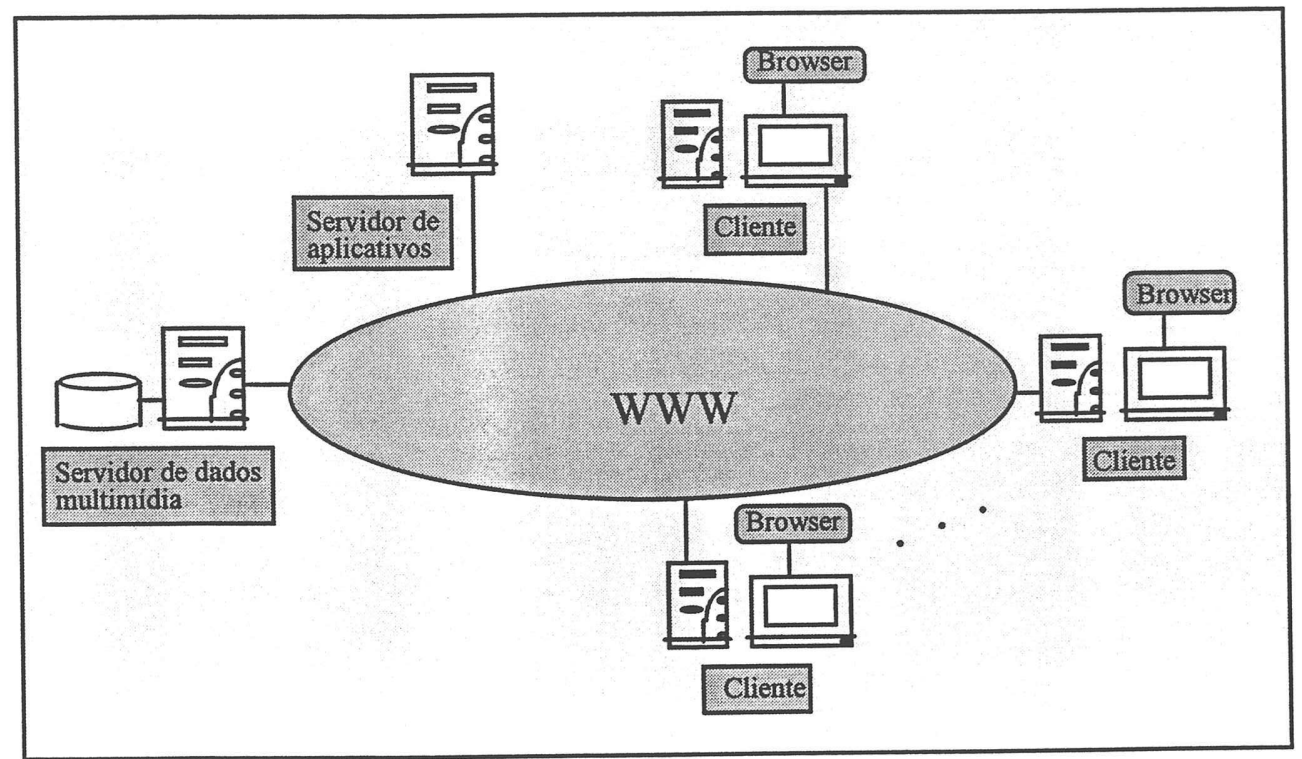

Figura 1 - Visão geral do sistema na WWW.

\section{2 - ARQuiteTURa do SERVIIDOR DE VÍDEO}

O servidor de vídeo deve atender, sob demanda, a uma comunidade de clientes disposta em um ambiente WWW. Como vídeos são objetos volumosos, eles requerem formas de armazenamento e entrega diferentes das convencionais, que forneçam eficiência no atendimento a vários clientes simultâneos.

O servidor de vídeo utiliza técnica RAID para o armazenamento (figura 2). O RAID consiste na criação de uma pilha onde vários discos são agrupados fazendo com que o sistema operacional os reconheça como um único disco lógico. A tecnologias RAID possui vários níveis (de 0 a 5), sendo que o nível adotado foi o nível 0 (por este apresentar um desempenho melhor em relação aos níveis $1,2,3,4$ e 5). O nível 0 funciona da seguinte forma: quando um arquivo é copiado para o disco lógico cada bloco do arquivo é armazenado, paralelamente, em um disco físico. Por exemplo, em um RAID com três discos, três blocos de um arquivo são armazenados paralelamente, um bloco em cada disco físico. A vantagem é uma redução no tempo de armazenamento e leitura dos arquivos armazenados. 


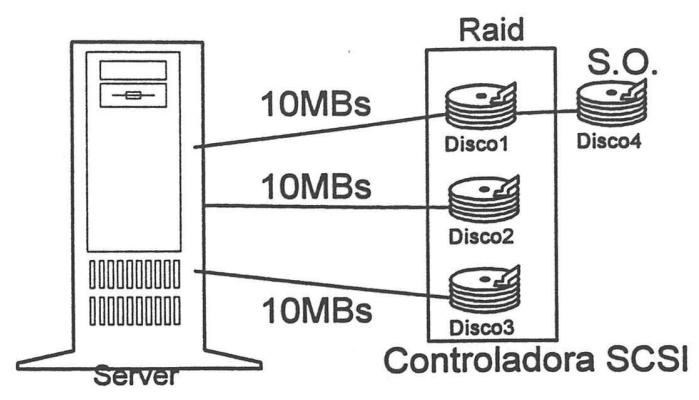

Figura 2 - Sistema de discos do servidor de vídeo.

O hardware que compõe o servidor de vídeo está especificado abaixo:

- Microcomputador Pentium/200 MMX.

- $96 \mathrm{MB}$ de memória RAM.

- 1 disco SCSI quantum de 2 GB.

- 1 disco SCSI seagate de 2 GB.

- 2 discos SCSI seagate de 4GB.

- placa controladora SCSI Adaptec 3985.

Em um disco SCSI de 2GB foi instalado o sistema operacional, assim como todos os softwares que compõem o servidor. Os arquivos de vídeo encontram-se nos outros três discos SCSI que compõe o disco lógico do sistema RAID nível 0.

Foi escolhida a controladora SCSI Adaptec 3985 por esta possuir uma característica especial em relação às controladoras tradicionais. Ela possui três canais de dados independentes (como se fossem três controladoras SCSI), sendo que cada canal trabalha a uma taxa de transmissão de $10 \mathrm{MB} / \mathrm{s}$, resultando em uma taxa total de $30 \mathrm{MB} / \mathrm{s}$. Dessa forma, cada disco que compõe o RAID foi colocado em um canal diferente, fornecendo uma taxa agregada que pode chegar a $30 \mathrm{MB} / \mathrm{s}$, melhorando o serviço em acessos simultâneos.

O sistema operacional utilizado pelo servidor é o Linux versão 2.0.30, por este ser de domínio público, estar disponível para plataforma Intel e por possuir todas as características necessárias para a execução do software servidor, tais como: suporte à linguagem JAVA, suporte a drivers JDBC, possuir uma opção de instalação de um servidor httpd (Apache), entre outras.

\section{3 - ORgANIZAÇÃo dOS DADOS}

Para que usuários inexperientes possam ter um acesso fácil ao conteúdo armazenado no servidor é necessário um mecanismo de gerenciamento dos dados armazenados que: facilite o trabalho de editoração fornecendo ferramentas interativas de busca e acesso aos dados e que forneça suporte ao compartilhamento de dados multimídia. A utilização de índices para acesso aos dados fornece interatividade, porém dados multimídia (como vídeo) requerem técnicas de indexação diferentes das convencionais. Quando uma busca por um nome é realizada, o conteúdo a ser indexado são os caracteres ASCII que compõe o nome e esses caracteres representam a informação procurada. Quando se procura pela imagem de um carro, por exemplo, o conteúdo da imagem é composto de valores binários (zeros e uns), mas o que gostaríamos de indexar é a informação semântica que esses valores representam (um carro) e não os valores em si.

A chave para a construção de uma ferramenta de busca interativa eficiente (para os propósitos discutidos) é a implantação de uma base de metadados que contenha os atributos referentes aos vídeos armazenados no servidor. Esses atributos constituem índices para responder às perguntas do usuário. Os índices podem ser: bibliográficos (título, assunto, gênero, 
diretor, produtor, elenco, etc.); estruturais (formando a hierarquia filme-segmento-cena); de conteúdo (para buscas baseadas em conteúdo ou em palavras-chave associadas a um conteúdo) [Ber95].

A utilização desses índices traz a vantagem adicional de prover suporte ao compartilhamento dos dados multimídia armazenados no servidor. Por exemplo, uma página HTML pode usar um segmento de um vídeo, realizando acessos aos índices para esse segmento, em vez de copiar o segmento desejado em outro arquivo de vídeo.

A seguir temos um modelo físico [Elm94] da base de metadados implantada, composto pelas seguintes tabelas e seus atributos:

documento $=\{$ ident, nomedoc, datacri, criador, tipo, comentário, instituição, endereco_doc $\}$

indicebib $=\{$ ident $b$, título, resumo, dataentrada, produtor, tamanho, grupo, disciplina, assunto, tipo_vídeo, tipo_compressão, taxa_frame, tipo_cor, tamanho_frame, tempo\}

pessoa $=\{$ ident obj pessoa, nome, sexo, biografia $\}$

objeto $=\{$ ident_obj_objeto, nomeobj, posição, forma, cor, textura, ação, descrição_obj\}

p_chave $=\{$ palavra, tipoitem, ocorrência $\}$

cena $=\{$ idcena, id_doc_cena, cena_segmento, tempo_início_cena, tempo_fim_cena,

descrição_cena, objeto_cena, localização_cena, frame_início_cena, frame_fim_cena\}

frame $=\{$ nframe, idcena, descrição_frame $\}$

lista_de_frames $=\{\underline{\text { If_idframe, }}$ If_idobj $\}$

lista_de_cenas $=\{\underline{\text { lc idcena, }}$ lc_idobj $\}$

indice_obj $=\{$ ident obj, tipo, ndocs, iddoc_obj $\}$

item_frame $=\{$ palavra chave, numframe, numcena $\}$

item_pessoa $=\{$ palavra_chave, nome_pessoa, ocorrência_pessoa $\}$

item_doc $=\{$ palavra chave, id doc item, ocorrência_doc $\}$

item_bib $=\{$ palavra_chave, id bib_item, ocorrência_bib

item_obj $=\{$ palavra_chave, id_obj_item, ocorrência_obj $\}$

item_cena $=\{$ palavra cena, id cena item, ocorrência_cena $\}$

ocor_doc $=\{$ palavra, nocordoc $\}$

cast $=\{$ ident $b$, nomeator $\}$

elenco_cena $=\{$ idcena, nome ator_cena $\}$

obj_cena $=\{$ id_cena, nome obj_cena $\}$

Além do hardware, o servidor de vídeo é composto por um software servidor e um software cliente. Para o desenvolvimento dos módulos cliente e servidor do sistema foi adotada a linguagem JAVA, por esta ser multiplataforma (conveniente a ambientes distribuídos baseados em WWW) e por possuir uma vasta biblioteca de funções que facilitam o esforço de programação.

O servidor é responsável por receber requisições (de apresentação de vídeos ou de busca por informações) dos clientes tratá-las e enviar a resposta adequada ao cliente. Os dados sobre os vídeos estão armazenados na base de metadados e o servidor realiza acessos a tais dados através da tecnologia Java DataBase Connectivity (JDBC). O JDBC corresponde a uma API de forma que cada fabricante de gerenciadores de bases de dados desenvolve um driver JDBC para que seu produto possa ser usado em conjunto com a linguagem JAVA. Por simplicidade, as referências no texto ao driver JDBC utilizado (PostgreSQL) serão feitas como JDBC simplesmente. O servidor é implementado como uma aplicação JAVA (JAVA application) e está instalado na máquina servidora de aplicativos.

$\mathrm{O}$ cliente é implementado como um applet JAVA, ficando instalado em cada máquina cliente e sendo apresentado em um browser. O cliente inclui funções para cadastro (de vídeos, cenas e frames), para busca e possui um player para apresentação de vídeos. O player é implementado através da utilização do Java Media Framework (JMF).

A comunicação cliente/servidor foi desenvolvida utilizando-se a ferramenta Visibroker 3.0, que implementa o padrão CORBA (Common Object Request Broker), trazendo as 
vantagens da distribuição de objetos [Vin97]. Por simplicidade, as referências no texto à ferramenta Visibroker serão feitas como CORBA simplesmente.

A figura 3 ilustra o funcionamento do servidor de vídeo.

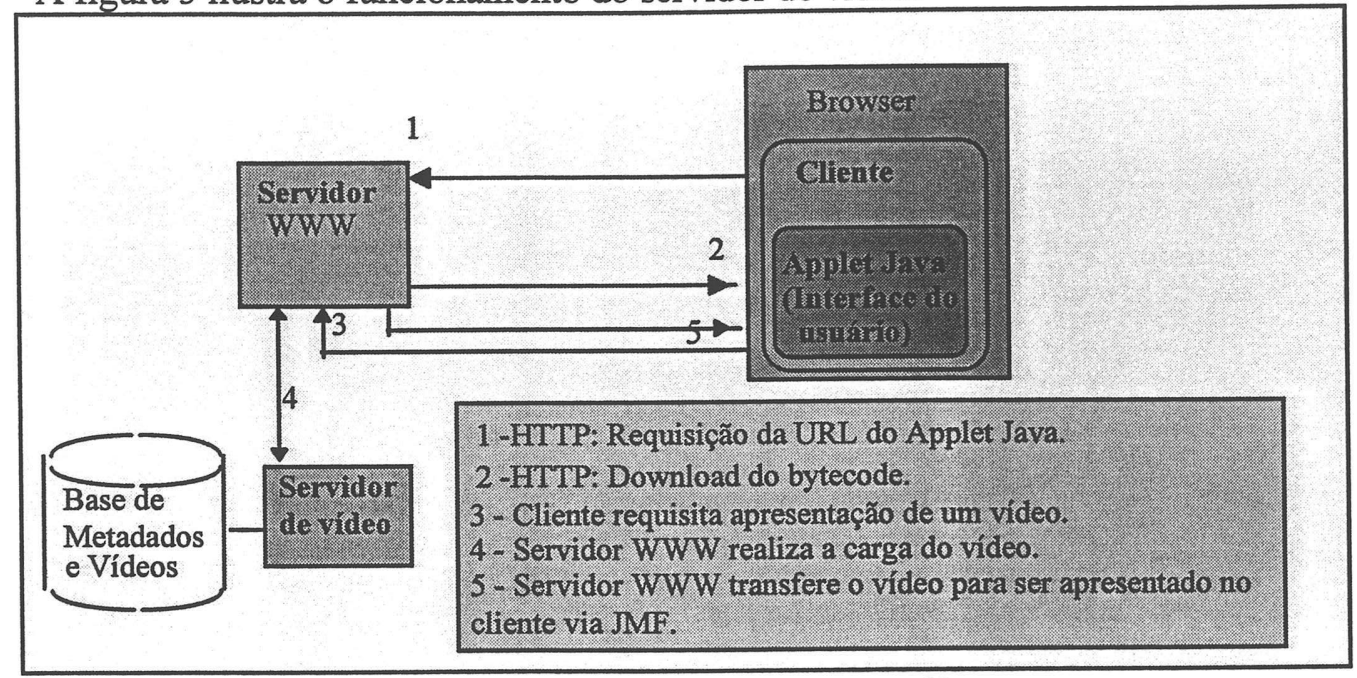

Figura 3 - Funcionamento do servidor de vídeo.

\section{4 - TESTES REALIZADOS}

Os testes realizados têm como objetivo detectar os gargalos no sistema servidor a partir de uma visão ampla do mesmo, para que se tenha uma noção clara dos pontos que podem oferecer perda de desempenho. Os testes avaliam o impacto da aplicação (de acesso, distribuição e apresentação), que utiliza tecnologias de distribuição de objetos e de acesso aos dados em ambientes heterogêneos. Os testes avaliam como o sistema operacional influi no desempenho do servidor, qual o desempenho do servidor utilizando RAID comparado a um sistema sem RAID e qual o impacto da rede de comunicação no desempenho do servidor. Com isso, avaliam-se todas as camadas por onde passam os dados durante sua transmissão.

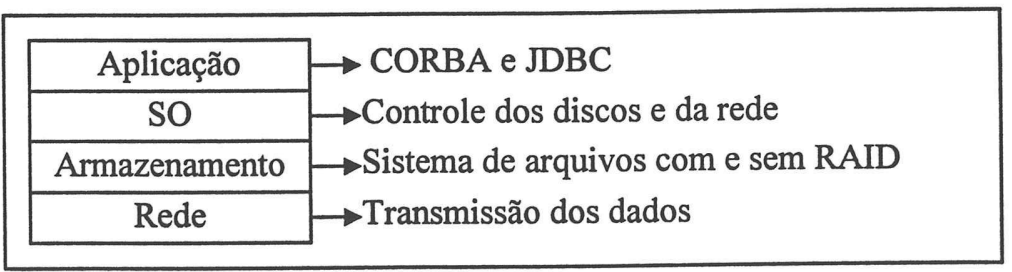

Figura 4 - Camadas do sistema.

\section{1 - AvaliaÇÃo da CAMAda de APlicaÇão}

O objetivo da análise da utilização das tecnologias CORBA e JDBC no sistema foi verificar o impacto que as mesmas causam no tempo de resposta às consultas do usuário. A análise baseou-se na comparação dos tempos para a realização de uma consulta pelo sistema através de uma aplicação.

A versão da ferramenta Visibroker (versão 3.0) utilizada, que implementa o padrão CORBA, não é disponível para plataforma LINUX (que é a utilizada pelo servidor de vídeo). Dessa forma, provisoriamente, a base de metadados está instalada em uma máquina diferente da máquina servidora de vídeo.

Para que as comparações pudessem ser válidas, duas versões do sistema (cliente e servidor) foram desenvolvidas. Uma versão foi implementada utilizando-se CORBA na comunicação, a outra foi implementada utilizando-se sockets para a comunicação. Ambas as 
versões foram desenvolvidas como aplicações JAVA, eliminando a presença de um servidor WWW no sistema.

Como ilustra a figura 5 , a única diferença entre as duas versões utilizadas para a coleta dos tempos de transmissão é exatamente a presença em uma delas da camada de software do padrão CORBA.

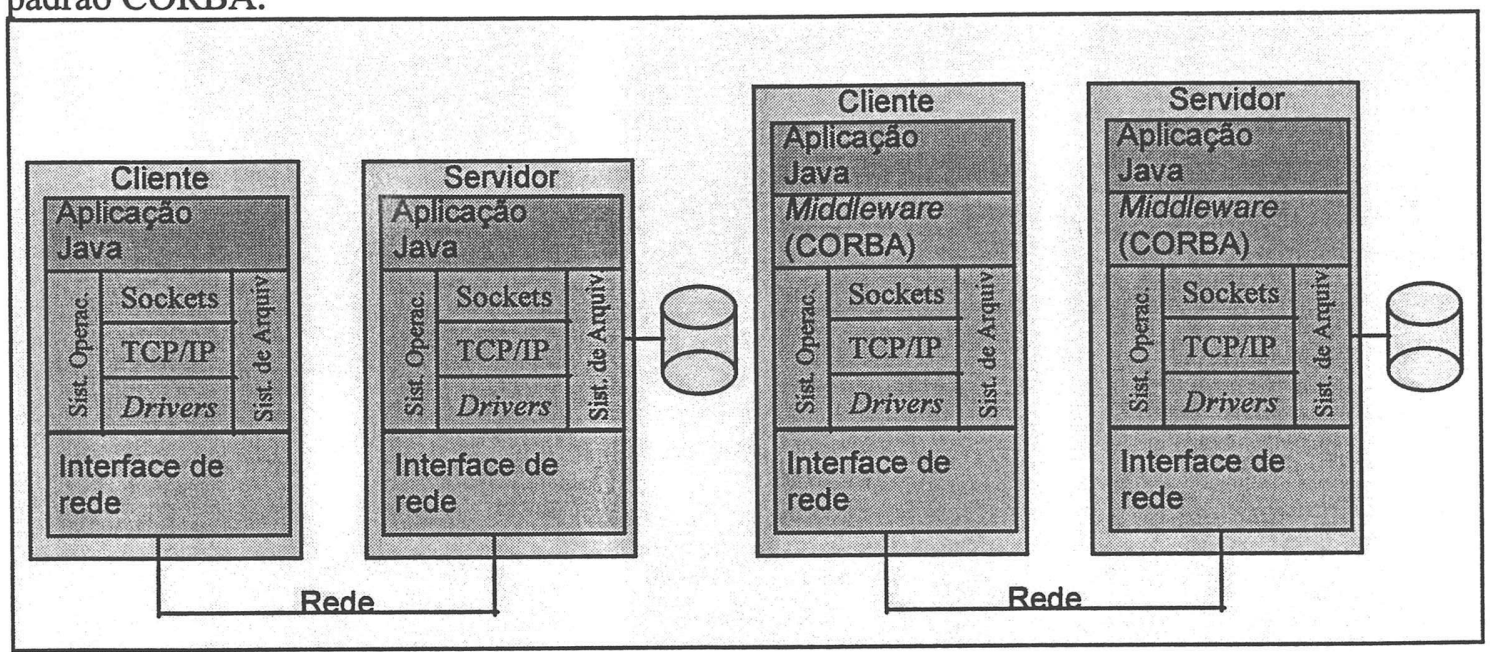

Figura 5 - As duas versões do sistema utilizadas na análise.

Os compiladores utilizados foram o JDK 1.1.3 e o VBJ 3.0 (parte do Visibroker 3.0), sendo que o VBJ foi utilizado apenas para gerar os stubs e os skeletons necessários para o estabelecimento da comunicação cliente/servidor segundo o padrão CORBA. O JDK foi utilizado para a geração dos bytecodes do cliente e do servidor de ambas as versões.

A Java Virtual Machine fornecida pelo JDK foi utilizada para a execução dos programas das duas versões do sistema.

Os testes foram realizados utilizando-se duas máquinas Sun SparcStation 5 com $32 \mathrm{MB}$ de memória RAM, executando o sistema operacional Solaris 2.5, conectadas a uma rede Ethernet de 10 Megabits (figura 6).

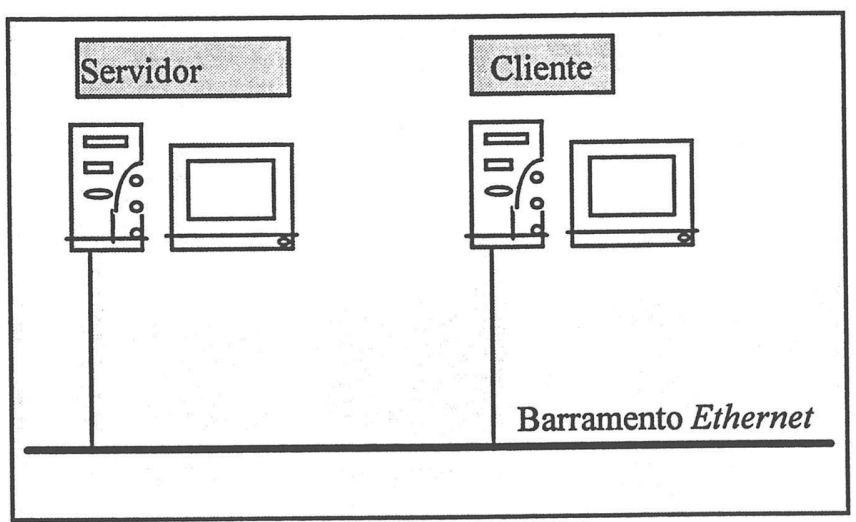

Figura 6 - Rede isolada para testes.

Foram realizadas as seguintes consultas à base de metadados: select * from cena; select * from cena, documento; select * from cena, documento,frame; select * from cena, documento,frame,objeto; 
Essas consultas retornam todos os atributos das tabelas indicadas após a cláusula from. As strings contendo as respostas às consultas têm, respectivamente, tamanhos de 588 bytes, 1328 bytes, 13008 bytes e 19728 bytes.

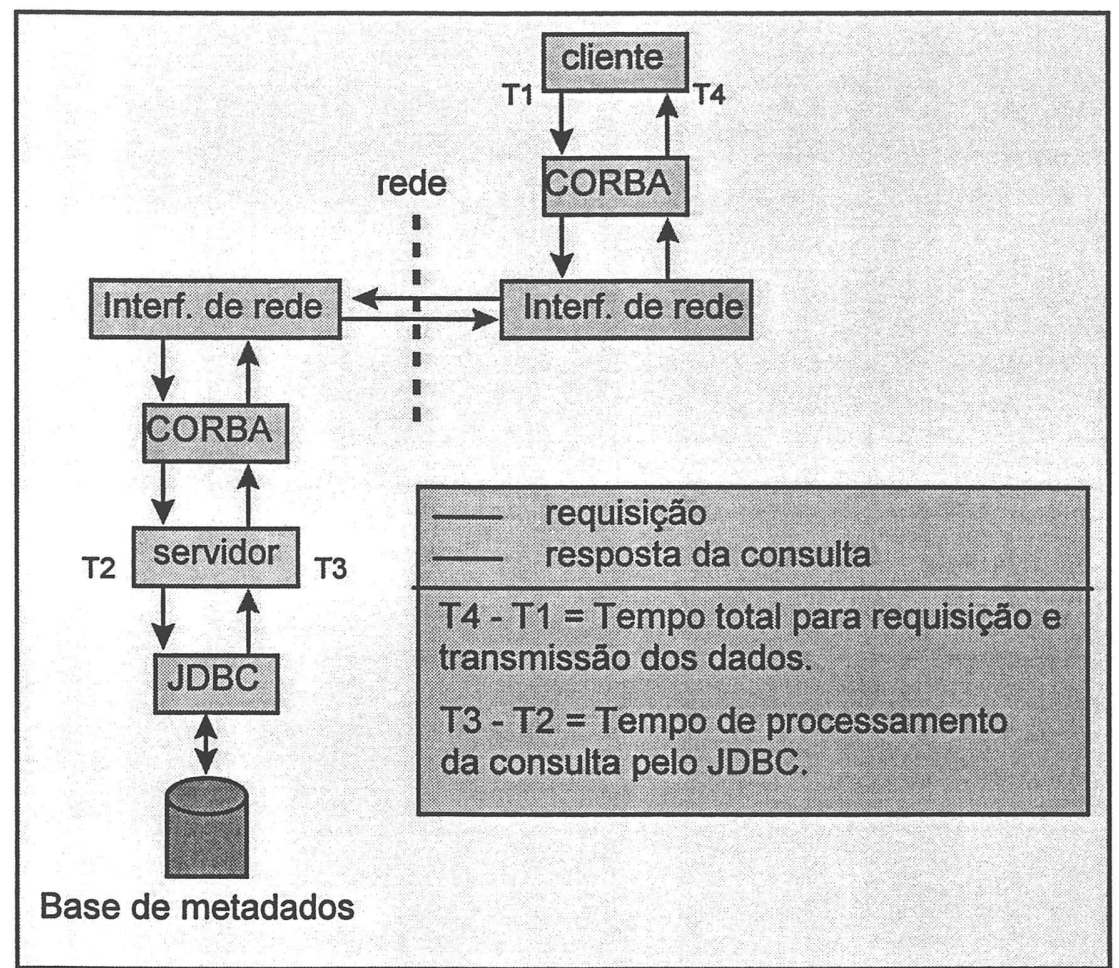

Figura 7 - Pontos de coleta dos tempos.

A figura 7 ilustra a coleta de uma amostra feita com a versão que utiliza CORBA na comunicação. Cada coleta registra o tempo em que a requisição foi enviada (T1) e o tempo em que o cliente obteve a resposta da consulta (T4). T1 e T4 são obtidos pelo relógio da máquina cliente. Na máquina servidora, foi registrado o momento em que a requisição foi passada ao JDBC (T3) e o momento em que o JDBC retorna a resposta da consulta ao servidor (T4). Para cada consulta de teste foram realizadas 30 coletas de tempo com um cliente, $30 \mathrm{com}$ dois clientes e $30 \mathrm{com}$ três clientes. Nas coletas com dois e três clientes as requisições eram feitas simultaneamente a partir de uma única máquina, e cada cliente enviou 30 requisições.

$\mathrm{O}$ mesmo procedimento de coleta foi utilizado na versão do sistema que utiliza sockets na comunicação.

Após a coleta dos dados, obteve-se a média dos tempos de resposta de uma consulta, em cada caso (tamanho de mensagem e número de clientes), e dos tempos de processamento do JDBC, tempos esses medidos em milissegundos. As médias foram anotadas desprezando-se as casas decimais.

$\mathrm{Na}$ análise de desempenho do JDBC buscou-se medir, em média, qual a porcentagem do tempo total de uma consulta que o JDBC ocupava.

A tabela 1 sumariza os resultados obtidos onde a coluna "JDBC" representa a média do tempo (em milissegundos) de processamento do JDBC para cada número de clientes em cada tamanho de mensagem. As colunas "Tempo Total" representam as médias dos tempos (em milissegundos) entre a requisição de uma consulta e a obtenção da resposta, para cada tamanho de mensagem em cada versão do sistema de teste (socket e CORBA). As colunas "\%" indicam a taxa porcentual procurada.

Os resultados apontados na tabela 1 (e na figura 8) mostram que para mensagens pequenas o JDBC ocupa uma parte substancial do tempo total para a realização de uma consulta, ficando entre 57 e $62 \%$ na versão socket e entre 46 e $58 \%$ na versão CORBA. 
Tabela 1 - Porcentagem do Tempo Total gasto pelo JDBC.

\begin{tabular}{|c|c|c|c|c|c|}
\hline \multicolumn{6}{|c|}{ Mensagem de 588 bytes } \\
\hline & & \multicolumn{2}{|c|}{ Socket } & \multicolumn{2}{|c|}{ CORBA } \\
\hline & JDBC & Tempo Total & $\%$ & Tempo Total & $\%$ \\
\hline 1 cliente & 725 & 1232 & 58 & 1320 & 54 \\
\hline 2 clientes & 832 & 1356 & 61 & 1547 & 53 \\
\hline 3 clientes & 969 & 1696 & 57 & 1736 & 55 \\
\hline \multicolumn{6}{|c|}{ Mensagem de 1328 bytes } \\
\hline & & \multicolumn{2}{|c|}{ Socket } & \multicolumn{2}{|c|}{ CORBA } \\
\hline & JDBC & Tempo Total & $\%$ & Tempo Total & $\%$ \\
\hline 1 cliente & 838 & 1367 & 61 & 1467 & 57 \\
\hline 2 clientes & 1016 & 1659 & 61 & 1746 & 58 \\
\hline 3 clientes & 1281 & 2051 & 62 & 2776 & 46 \\
\hline \multicolumn{6}{|c|}{ Mensagem de 13008 bytes } \\
\hline & & \multicolumn{2}{|c|}{ Socket } & \multicolumn{2}{|c|}{ CORBA } \\
\hline & JDBC & Tempo Total & $\%$ & Tempo Total & $\%$ \\
\hline 1 cliente & 1069 & 3629 & 29 & 3945 & 27 \\
\hline 2 clientes & 1731 & 3990 & 43 & 6570 & 26 \\
\hline 3 clientes & 2730 & 7653 & 35 & 12315 & 22 \\
\hline \multicolumn{6}{|c|}{ Mensagem de 19728 bytes } \\
\hline & & \multicolumn{2}{|c|}{ Socket } & \multicolumn{2}{|c|}{ CORBA } \\
\hline & JDBC & Tempo Total & $\%$ & Tempo Total & $\%$ \\
\hline 1 cliente & 1623 & 5210 & 31 & 5723 & 28 \\
\hline 2 clientes & 2536 & 7308 & 34 & 7792 & 32 \\
\hline 3 clientes & 3739 & 9463 & 39 & 19213 & 19 \\
\hline
\end{tabular}

Observa-se que aumentando o tamanho da mensagem a porcentagem diminui. Isso porque o tempo total para processamento de uma consulta (tempo entre o cliente requisitar a consulta e obter a resposta) aumenta a uma taxa maior que o tempo de processamento da consulta pelo JDBC no servidor. Por exemplo, o tempo de processamento do JDBC para três clientes com mensagem de 1328 bytes foi de 1281 milissegundos e aumentou para 3739 milissegundos com três clientes e mensagem de 19728 bytes, um aumento de $291 \%$. Considerando-se o mesmo número de clientes e os mesmos tamanhos de mensagens, o tempo total da versão CORBA aumentou de 2776 para 19213, um aumento de 692\% (a versão socket aumentou $461 \%)$.

Com isso conclui-se que para os propósitos do sistema, que utilizará mais freqüentemente mensagens pequenas, o driver JDBC utilizado constitui um "gargalo". 


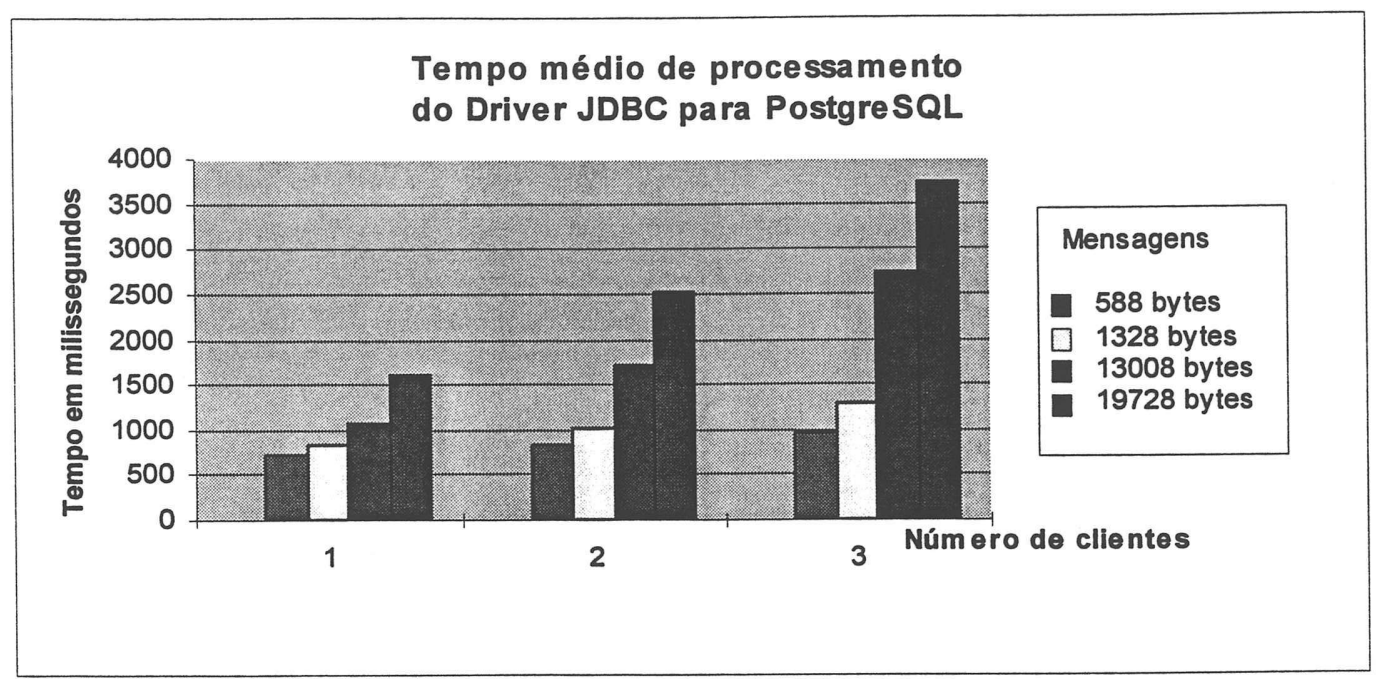

Figura 8 - Gráfico do tempo médio de processamento do JDBC.

Com relação à utilização de CORBA, analisando-se os dados obtidos e comparando-se o desempenho das duas versões de teste do sistema, chegou-se aos resultados contidos na tabela 2. Esta tabela mostra as médias do tempo total gasto pelo sistema entre o cliente requisitar uma consulta e obter a resposta (Socket e CORBA), subtraídas do tempo gasto pelo JDBC para o processamento das consultas. A coluna socket mostra o tempo médio de transmissão das mensagens, sem computar o tempo de processamento do JDBC no servidor. A coluna CORBA mostra o tempo médio da transmissão das mensagens, também sem computar o tempo de processamento do JDBC, mas incluindo o tempo gasto pela camada CORBA. A diferença entre essas duas colunas (contida na coluna milissegundos) é o atraso medido em milissegundos imposto pela utilização de CORBA no sistema. A coluna "\%" mostra em termos porcentuais o quanto a versão de teste do sistema utilizando CORBA foi mais lenta que a versão utilizando sockets.

Tabela 2 - Comparação de desempenho entre as versões Socket e CORBA.

\begin{tabular}{|c|c|c|c|c|}
\hline \multicolumn{5}{|c|}{ Mensagem de 588 bytes } \\
\hline & Socket & CORBA & $\%$ & Milissegundos \\
\hline 1 Cliente & 526 & 576 & 9 & 50 \\
\hline 2 Clientes & 534 & 704 & 31 & 170 \\
\hline 3 Clientes & 551 & 942 & 70 & 391 \\
\hline \multicolumn{5}{|c|}{ Mensagem de 1328 bytes } \\
\hline & Socket & CORBA & $\%$ & Milissegundos \\
\hline 1 Cliente & 548 & 607 & 10 & 59 \\
\hline 2 Clientes & 566 & 807 & 42 & 241 \\
\hline 3 Clientes & 609 & 1656 & 171 & 1047 \\
\hline \multicolumn{5}{|c|}{ Mensagem de 13008 bytes } \\
\hline & Socket & CORBA & $\%$ & Milissegundos \\
\hline 1 Cliente & 2570 & 2866 & 11 & 296 \\
\hline 2 Clientes & 2894 & 4203 & 45 & 1309 \\
\hline 3 Clientes & 4359 & 10149 & 132 & 5790 \\
\hline \multicolumn{5}{|c|}{ Mensagem de 19728 bytes } \\
\hline & Socket & CORBA & $\%$ & Milissegundos \\
\hline 1 Cliente & 3609 & 4077 & 12 & 468 \\
\hline 2 Clientes & 3956 & 6071 & 53 & 2115 \\
\hline 3 Clientes & 5059 & 16138 & 218 & 11079 \\
\hline
\end{tabular}


Os testes mostraram que a utilização de CORBA impõe um atraso na comunicação cliente/servidor, como esperado (figura 9). Em termos porcentuais as diferenças são consideráveis (tabela 2), porém o tempo que o usuário final terá que esperar a mais por uma resposta não é tão significativo para os tamanhos de mensagens que serão mais utilizados no sistema (entre 100 e 5000 bytes). Por exemplo, um usuário que requisitar uma consulta cujo tamanho da mensagem de resposta seja de 13008 bytes terá que esperar 0,296 segundos (em média) a mais se utilizar CORBA na comunicação cliente/servidor.

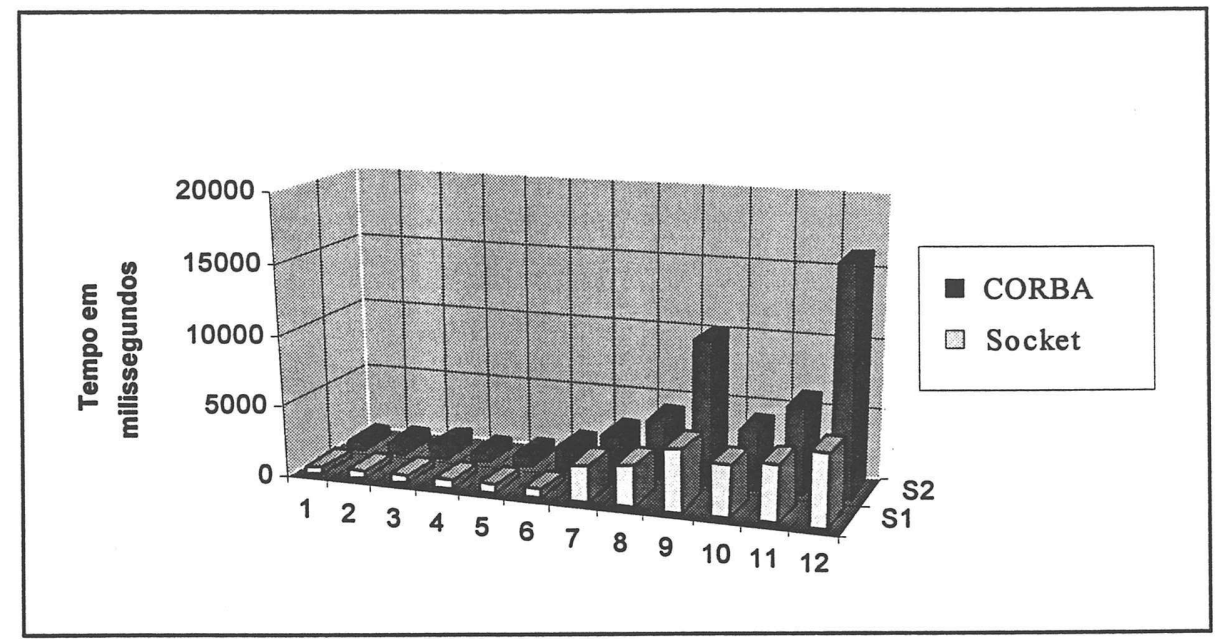

Figura 9 - Gráfico comparativo do desempenho entre as versões CORBA e Sockets.

$\mathrm{Na}$ figura 9 as colunas de 1 a 3 representam as mensagens de 588 bytes, as colunas de 4 a 6 representam as mensagens de 1328 bytes, as colunas de 7 a 9 representam as mensagens de 13008 bytes e as colunas de 10 a 12 representam as mensagens de 19728 bytes.

Tabela 3 - Desvio padrão das amostras.

\begin{tabular}{|c|c|c|c|}
\hline \multicolumn{4}{|c|}{ Mensagem de 588 bytes } \\
\hline & $\begin{array}{l}\text { CORBA (Desv. } \\
\text { Padrão; Média) }\end{array}$ & $\begin{array}{c}\text { Socket (Desv. Padrão; } \\
\text { Média) }\end{array}$ & $\begin{array}{l}\text { JDBC (Desv. Padrão; } \\
\text { Média) }\end{array}$ \\
\hline 1 cliente & $186 ; 1320$ & $172 ; 1232$ & $104 ; 725$ \\
\hline 2 clientes & $289 ; 1547$ & $304 ; 1356$ & $219 ; 832$ \\
\hline 3 clientes & $524 ; 1736$ & $331 ; 1696$ & $327 ; 969$ \\
\hline \multicolumn{4}{|c|}{ Mensagem de 1328 bytes } \\
\hline & $\begin{array}{l}\text { CORBA (Desv. } \\
\text { Padrão; Média) }\end{array}$ & $\begin{array}{l}\text { Socket (Desv. Padrão; } \\
\text { Média) }\end{array}$ & $\begin{array}{c}\text { JDBC (Desv. Padrão; } \\
\text { Média) }\end{array}$ \\
\hline 1 cliente & $137 ; 1467$ & $127 ; 1367$ & $95 ; 838$ \\
\hline 2 clientes & $177 ; 1746$ & $373 ; 1659$ & $285 ; 1016$ \\
\hline 3 clientes & $1074 ; 2776$ & $689 ; 2051$ & $560 ; 1281$ \\
\hline \multicolumn{4}{|c|}{ Mensagem de 13008 bytes } \\
\hline & $\begin{array}{l}\text { CORBA (Desv. } \\
\text { Padrão; Média) }\end{array}$ & $\begin{array}{c}\text { Socket (Desv. Padrão; } \\
\text { Média) }\end{array}$ & $\begin{array}{c}\text { JDBC (Desv. Padrão; } \\
\text { Média) }\end{array}$ \\
\hline 1 cliente & $605 ; 3945$ & $187 ; 3629$ & $98 ; 1069$ \\
\hline 2 clientes & $856 ; 6570$ & $709 ; 3990$ & $953 ; 1731$ \\
\hline 3 clientes & $3250 ; 12315$ & $2893 ; 7653$ & $1305 ; 2730$ \\
\hline \multicolumn{4}{|c|}{ Mensagem de 19728 bytes } \\
\hline & $\begin{array}{l}\text { CORBA (Desv. } \\
\text { Padrão; Média) }\end{array}$ & $\begin{array}{c}\text { Socket (Desv. Padrão; } \\
\text { Média) }\end{array}$ & $\begin{array}{c}\text { JDBC (Desv. Padrão; } \\
\text { Média) }\end{array}$ \\
\hline 1 cliente & $476 ; 5723$ & $329 ; 5210$ & $158 ; 1623$ \\
\hline 2 clientes & $2190 ; 7792$ & $848 ; 7308$ & $1241 ; 2536$ \\
\hline 3 clientes & $7693 ; 19213$ & 2216; 9463 & $1874 ; 3739$ \\
\hline
\end{tabular}




\subsection{TeSTeS COM SOS Diferentes - LINUX E WINDOWS/NT}

\section{Metodologia Aplicada}

Antes de apresentar os resultados do teste com o sistema operacional, vale descrever a metodologia utilizada. Vale também ressaltar que essa metodologia foi empregada em todos os testes, com exceção da avaliação da utilização das tecnologias CORBA e JDBC. Para a realização dos testes de desempenho do servidor de vídeo o ambiente ilustrado na figura 10 foi montado.

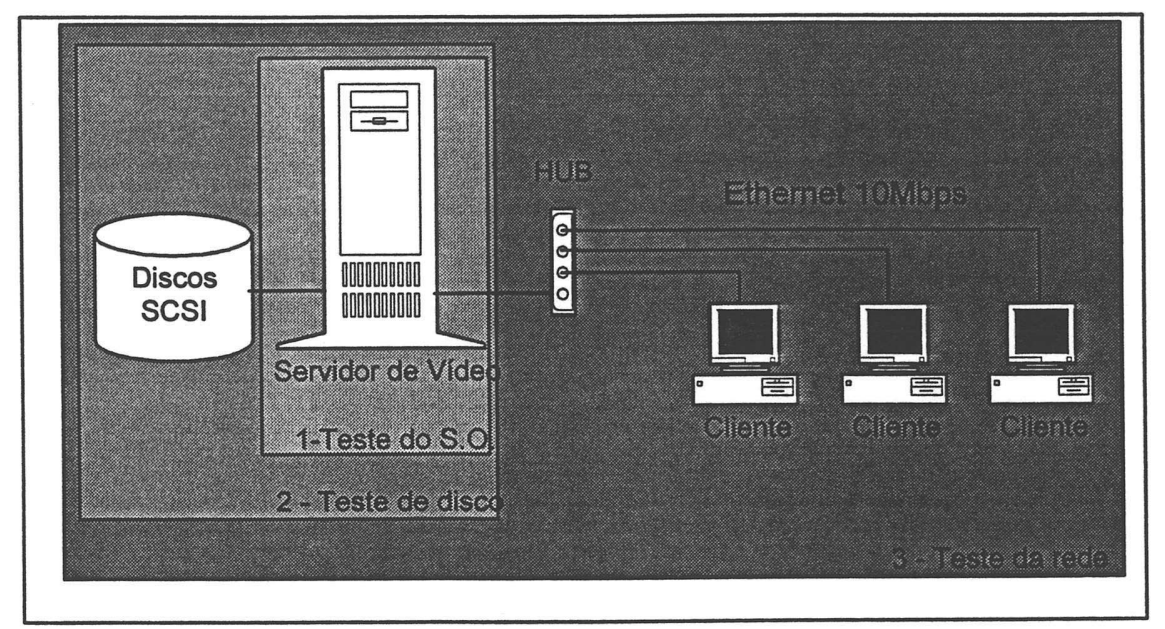

Figura 10 - Ambiente de testes.

O servidor de vídeo segue a especificação da seção 2 (figura 2). Os clientes são microcomputadores Pentium de $166 \mathrm{MHz}$, com $32 \mathrm{MB}$ de memória RAM e discos rígidos de 1.7 GB (IDE), com placas de rede Fast-Ethernet 3Com PCI 10/100 Mbps.

Os testes consistiram na transferência de dois arquivos, um de $7 \mathrm{MB}$ e outro de $81 \mathrm{MB}$, de forma local e de forma remota. Para a transferência dos arquivos foi utilizado o programa FTP por este fornecer a taxa e o tempo de transferência de um arquivo e, por estar disponível para as plataformas utilizadas.

Os testes realizados foram os seguintes:

- Teste 1 - transferência de um arquivo de 7MB.

- Teste 2 - dois acessos concorrentes à mesma cópia do arquivo de 81MB.

- Teste 3 - três acessos concorrentes à mesma cópia do arquivo de $81 \mathrm{MB}$.

- Teste 4 - dois acessos concorrentes a três cópias diferentes do arquivo de $81 \mathrm{MB}$.

- Teste 5 - três acessos concorrentes a três cópias diferentes do arquivo de $81 \mathrm{MB}$.

\section{DESEMPENHO DO SISTEMA OPERACIONAL}

O objetivo desse teste é comparar o desempenho do servidor de vídeo (com e sem a tecnologia RAID) em dois sistemas operacionais diferentes, Linux (versão Slakware 3.3 kernel 2.0.30) e Windows/NT 4.0. Os dois SOs foram instalados no servidor de vídeo. Foram realizadas transferências de arquivos seguindo a metodologia descrita acima.

Os testes realizados compararam o desempenho do servidor, em plataforma Linux, quando esta utiliza e quando não utiliza RAID. Também comparam o desempenho do servidor em plataformas diferentes (Windows/NT e Linux) sem utilizar RAID. Nesse teste não foi possível comparar o desempenho do servidor entre os dois sistemas operacionais utilizando a tecnologia RAID, já que o Windows/NT não possui suporte para a placa Adaptec 3985 (controladora de RAID). Para os testes sem a tecnologia RAID empregou-se um (único) disco 
rígido SCSI quantum de $4.0 \mathrm{~GB}$ e uma placa controladora SCSI Adaptec 2940AU. A tabela 4 mostra os resultados obtidos com os testes, que expressam a taxa de transferência dos arquivos em KiloBytes por segundo.

Tabela 4 - Desempenho do servidor com SOs diferentes.

\begin{tabular}{|c|c|c|c|}
\hline Teste & WindowsNT (kbytes/ seg) & Linux (kbytes/ seg) & Linux c/ RAID (kbytes/ seg) \\
\hline $\mathbf{1}$ & 1372 & 2780 & 3530 \\
\hline $\mathbf{2}$ & 745 & 1917 & 2687 \\
\hline $\mathbf{3}$ & 522 & 1482 & 2138 \\
\hline $\mathbf{4}$ & 571 & 898 & 1483 \\
\hline $\mathbf{5}$ & 416 & 660 & 948 \\
\hline
\end{tabular}

Conclui-se que o sistema operacional Windows/NT, em sua configuração padrão, apresenta um desempenho inferior ao sistema operacional Linux no atendimento a requisição locais de arquivos (tabela 4 e figura 10). Outra constatação é que a utilização da tecnologia RAII (de forma local) no gerenciamento do sistema de arquivos obtém um desempenho superior em relação do sistema de arquivos tradicional (único disco).

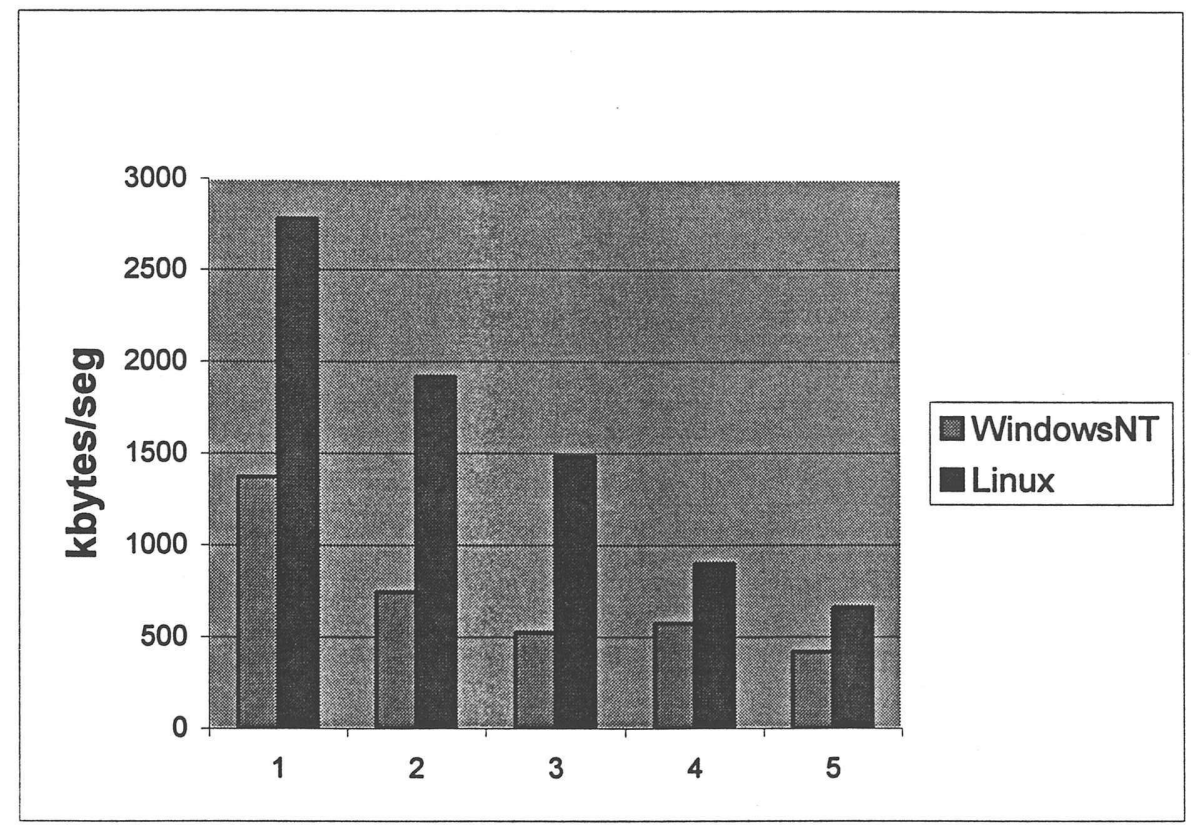

Figura 11 - Desempenho do servidor com sistemas operacionais diferentes.

\section{3 - TESTES COM A REDE}

O teste anterior apontou um desempenho melhor do servidor de vídeo, em ambiente local, com a plataforma Linux. Como os sistemas operacionais em questão possuem formas diferentes de gerenciar o envio de informações pela rede, buscou-se verificar se o Linux continuaria oferecendo um melhor serviço quando a transferência de arquivos ocorresse de forma remota.

Utilizaram-se duas configurações de rede diferentes. Em uma configuração o servidor e as estações clientes estão conectados através de uma rede Ethernet de $10 \mathrm{Mbps}$ (figura 12), na outra é utilizada uma rede FDDI de 100Mbps conectando o servidor e os clientes através de um Switch Ethernet de $10 \mathrm{Mbps}$ (figura 13). A configuração do servidor utilizada nesse teste foi a mesma configuração sem RAID do teste anterior. 
Servidor no Anel FDDI e Estações na Switch
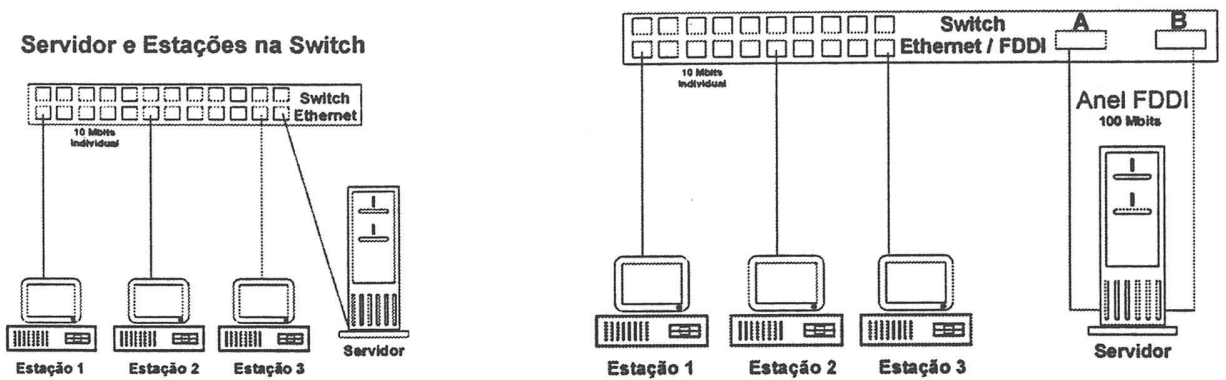

Figura 12 - Rede Ethernet para testes. Figura 13 - Rede FDDI+Switch ethernet para testes.

Os resultados obtidos dos testes sobre a rede Ethernet são mostrados na tabela 5 e na figura 14. Os resultados dos testes sobre a rede FDDI são mostrados na tabela 6 e a figura 15. A figura 16 compara o porcentual de utilização da rede Ethernet entre os dois sistemas operacionais.

Tabela 5 - Desempenho sobre rede Ethernet.

\begin{tabular}{|c|c|c|}
\hline Teste & WindowsNT (kybtes/ seg) & Linux (kbytes/ seg) \\
\hline $\mathbf{1}$ & $\mathbf{7 8 3}$ & 1069 \\
\hline $\mathbf{2}$ & 524 & 569 \\
\hline $\mathbf{3}$ & 420 & 426 \\
\hline $\mathbf{4}$ & 553 & 568 \\
\hline $\mathbf{5}$ & 380 & 386 \\
\hline
\end{tabular}

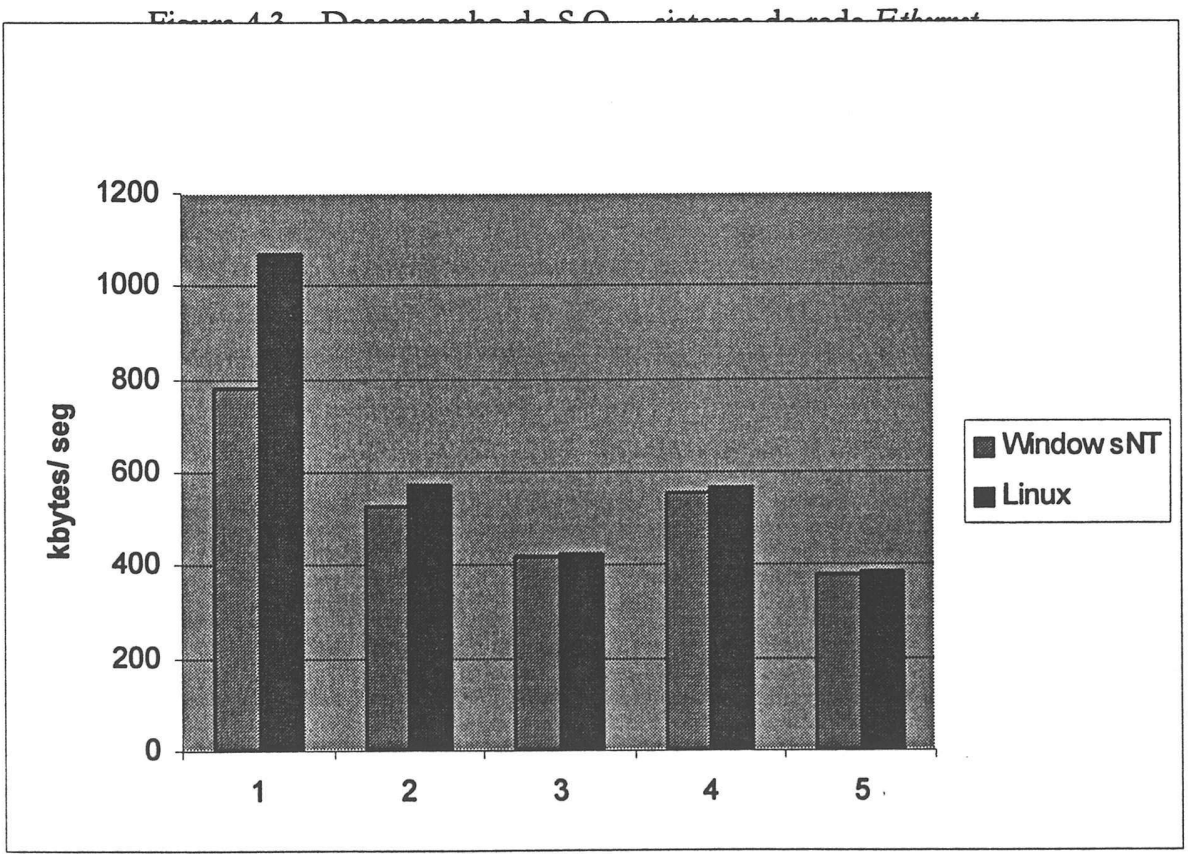

FIGURA 14 - DESEMPENHO DO SO SOBRE UMA REDE Ethernet. 
Tabela 6 - Desempenho sobre rede FDDI.

\begin{tabular}{|c|c|c|}
\hline Teste & WindowsNT (kybtes/ seg) & Linux (kbytes/ seg) \\
\hline $\mathbf{1}$ & 1039 & 1069 \\
\hline $\mathbf{2}$ & 1060 & 1075 \\
\hline $\mathbf{3}$ & 1000 & 1065 \\
\hline $\mathbf{4}$ & 986 & 1064 \\
\hline $\mathbf{5}$ & 779 & 1008 \\
\hline
\end{tabular}

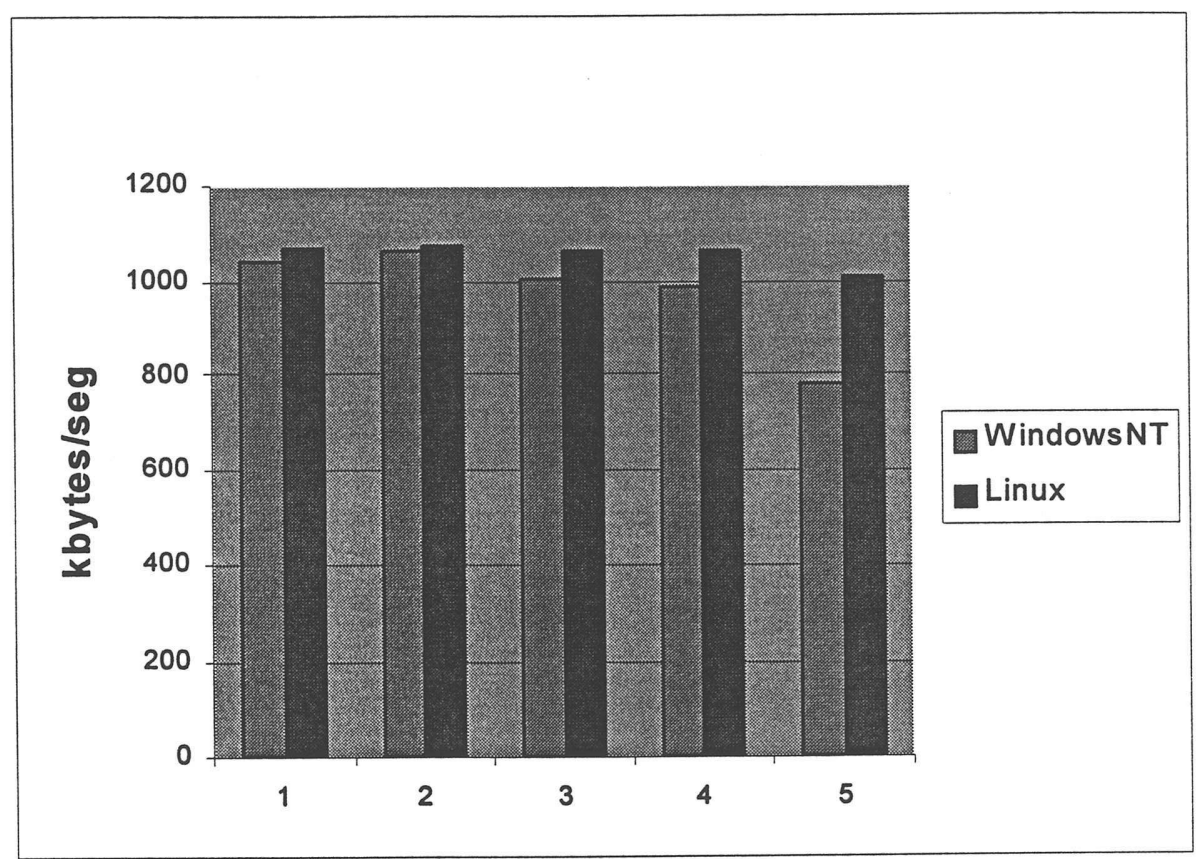

Figura 15 - Desempenho do S.O. - sistema de rede FDDI + Switch Ethernet.

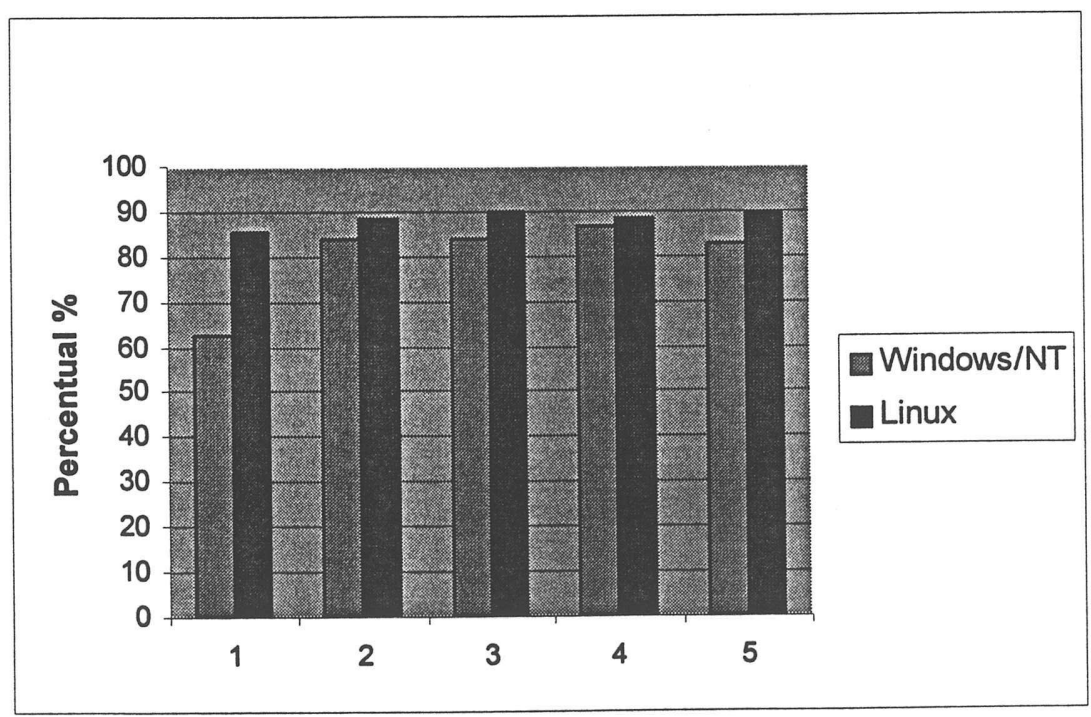

Figura 16 - Porcentual de utilização da rede Ethernet.

O Windows/NT apresentou um desempenho inferior ao Linux na transferência dos arquivos nos dois casos analisados (Ethernet e FDDI). 
Outra conclusão é que a rede Ethernet se torna um gargalo para um número médio de clientes (figura 14). Analisando a figura 16 podemos observar que no teste 1 , o gargalo é o sistema de rede do Windows/NT, já nos testes seguintes o gargalo é a rede Ethernet (10Mbps), já que a sua utilização chega a $90 \%$, que para a rede Ethernet é uma taxa alta. No sistema operacional Linux, o gargalo sempre é a rede.

$\mathrm{Na}$ figura 15 podemos concluir que o gargalo inicialmente é a rede Ethernet (10Mbps), porém para um número maior de clientes, o gargalo se torna o sistema de arquivo, concluímos também que gerenciamento de acesso ao disco do WindowsNT é menos eficiente que do Linux.

\section{4 - AVAliaÇão do ACESSo Remoto Ao Disco Via ETHERNET}

Quando o sistema RAID é instalado em um computador, ele promove mudanças na forma de acesso e armazenamento dos dados, modificando o sistema de arquivos.

O objetivo desse teste foi comparar o desempenho do servidor de vídeo, sobre uma rede de computadores, ao se utilizar um sistema de arquivo tradicional (único disco) e utilizando o sistema de arquivo com a tecnologia Raid-0. O mesmo teste já foi realizado de maneira local (descrito na seção 4.2) e os resultados estão na tabela 4. Os testes foram realizados sobre o sistema operacional Linux. O servidor foi configurado com a controladora SCSI Adaptec 3985 (controladora de RAID) e o disco lógico RAID foi montado sobre os três discos rígidos SCSI quantum (1 de $2 \mathrm{~GB}$ e 2 de 4GB). Os resultados obtidos são mostrados na tabela 7 e na figura 17.

Tabela 7 - Desempenho do servidor sobre ethernet.

\begin{tabular}{|c|c|c|}
\hline Teste & Um único disco SCSI (kbytes/seg) & Tecnologia RAID (kbytes/ seg) \\
\hline $\mathbf{1}$ & 1064 & 1069 \\
\hline $\mathbf{2}$ & 579 & 569 \\
\hline $\mathbf{3}$ & 427 & 426 \\
\hline $\mathbf{4}$ & 559 & 568 \\
\hline $\mathbf{5}$ & 388 & 386 \\
\hline
\end{tabular}

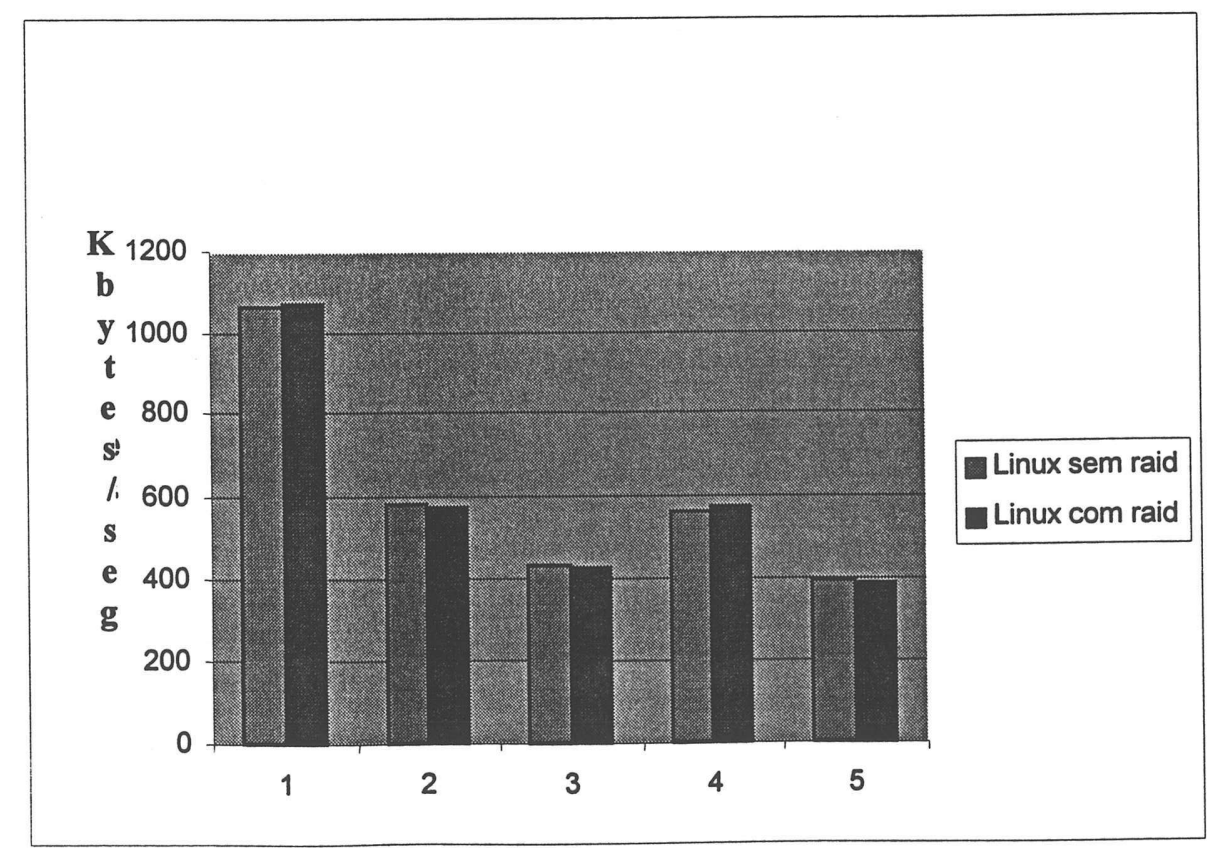

Figura 17 - Desempenho do Sistema de Arquivo sobre uma rede Ethernet (10Mbps). 
Conclui-se que o gargalo do sistema é a rede Ethernet (10Mbps). Tanto o sistema de arquivo tradicional quanto no sistema de arquivo com tecnologia RAID apresentaram resultados semelhantes. A utilização da rede neste teste foi de aproximadamente $90 \%$, que é alta para a rede Ethernet (10Mbps).

\section{5 - AVAliaÇão do ACESSo Remoto Ao DiSCO VIA FDDI}

Este teste visa medir o desempenho ao se utilizar um sistema de arquivo tradicional e utilizando o sistema de arquivo com a tecnologia Raid-0 sobre uma rede onde o servidor está conectado através de uma rede FDDI (100Mbps) e as estações estão conectados através de uma switch Ethernet (10Mbps). Os testes foram realizados sobre o Sistema Operacional Linux e com a controladora SCSI Adaptec 3985, o disco lógico RAID foi montado sobre os três discos rígidos SCSI quantum (1 de 2GB e 2 de 4GB), placa de rede digital FDDI DEFPA-AA. Os resultados obtidos são mostrados na tabela 8 e na figura 18.

Tabela 8 - Desempenho do servidor sobre rede FDDI.

\begin{tabular}{|c|c|c|}
\hline Teste & Um único disco SCSI (kbytes/seg) & Tecnologia RAI (kbytes/ seg) \\
\hline $\mathbf{1}$ & 1069 & 1078 \\
\hline $\mathbf{2}$ & 1075 & 1076 \\
\hline $\mathbf{3}$ & 1065 & 1063 \\
\hline $\mathbf{4}$ & 1064 & 1061 \\
\hline $\mathbf{5}$ & 1008 & 1067 \\
\hline
\end{tabular}

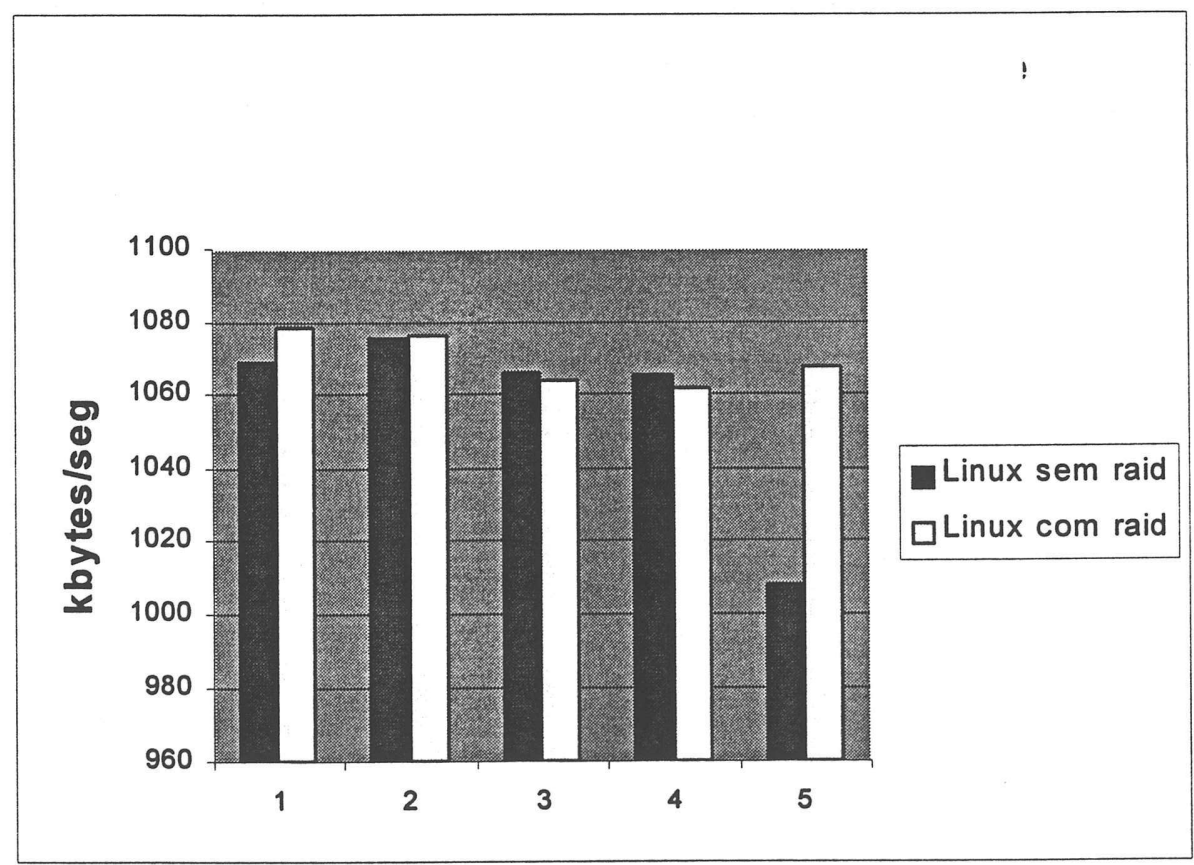

Figura 18 - Desempenho do Sistema de Arquivo sobre uma rede FDDI e switch Ethernet.

Concluímos que o gargalo do sistema inicialmente é a rede Ethernet (10Mbps), porém com um número médio de clientes, demonstrou que o sistema de arquivo tradicional se torna $o$ gargalo, o gráfico demonstra também que o gargalo sempre é a rede no sistema de arquivo com tecnologia RAID. 


\section{EXEMIPLO de UTILIZAÇÃo dO SERVIDOR}

Como exemplo de utilização do sistema servidor de vídeo podemos considerar um ambiente de auxílio ao ensino [Cas97], que é composto por aplicações de autoria e de apresentação hipermídia, implementadas pensando-se nos usuários finais: professores e alunos. Um componente interessante desse ambiente, que pode ser utilizado em diversas situações de treinamento, é a sessão de vídeo controlada. A função desse componente é permitir a apresentação de um trecho de vídeo (eventualmente, mais de um) para diversos alunos ao mesmo tempo e, além disso, permitir que o professor tenha total controle sobre a execução do mesmo.

Um caso de uso desse componente ocorre na situação em que o professor deseja apresentar um vídeo e parar em posições predeterminadas, ou não, para explicar um assunto correlacionado e depois continuar a execução. Se, por exemplo, um aluno solicitar um detalhamento sobre um ponto específico do vídeo, o professor pode marcar um trecho do mesmo através de seu console e executar novamente esse trecho em todas as máquinas que estão assistindo a sessão, em um subconjunto dessas máquinas ou apenas na máquina do aluno que solicitou a informação.

Em termos de autoria, o professor deverá apenas escolher esse componente e fornecer parâmetros como o trecho de vídeo a ser utilizado; e a ferramenta de edição será responsável pela inclusão dos tags e scripts necessários na página HTML para execução do componente.

Em termos de apresentação, os alunos deverão carregar a página contendo o componente e este último encarregar-se-á, transparentemente, de tarefas como: registro com o servidor de controle e início da transferência do trecho do vídeo do servidor apropriado para a máquina local. Alternativamente, em sistemas não baseados em páginas como a WWW, o professor pode ativar o programa de apresentação controlada de vídeo nas máquinas dos alunos através de comandos remotos.

Restrições quanto à utilização desse componente em aplicações voltadas para a Internet certamente são aplicáveis, uma vez que a infra-estrutura existente ainda não fornece suporte para entrega de dados em tempo real e garantia de qualidade de serviço. No entanto, a utilização de vídeo em redes internas (intranets) é uma realidade.

\section{6 - CONCLUSõeS}

Os testes realizados mostram que é perfeitamente possível a implementação de sistemas de distribuição de vídeo via tecnologias de rede Internet. Para contornar os problemas oriundos da precariedade dos protocolos TCP/IP e ethernet para a transmissão de mídia contínua, nota-se o aparecimento de várias tecnologias que possibilitam o uso de um sistema de armazenamento remoto de vídeo e sua apresentação local com razoável qualidade sem a utilização de sincronismo durante todo o processo (p. ex. Vxtreme, RealVideo, CU-Seeme e o padrão JMF). Desta forma, a questão principal torna-se o provimento de largura de banda necessária para a aplicação. A maioria dos problemas inseridos pela rede e pelos sistemas operacionais são resolvidos através de esquemas avançados de bufferização.

Este trabalho avaliou várias opções de tecnologias "convencionais", mostrando configurações possíveis de serem utilizadas para o serviço de armazenamento e distribuição de vídeo. Em termos gerais, a única peça não-convencional utilizada pelo sistema é uma placa especial SCSI, com 3 canais. A utilização de RAID é alcançada via software padrão embutido no Linux.

A tabela 4 mostra que a configuração melhor testada consegue entregar 7,060 MBytes por segundo ( 2 vezes 3,530, pois cada transferência envolve dois acessos ao disco). Este número é altamente dependente da configuração (CPU, discos, controladora, RAM, etc). Temse notícia de plataformas Linux provendo taxas de acesso médias de 27 MBytes por segundo 
(dual pentium $300 \mathrm{MHz}, 1$ GBytes de memória; 8 discos SCSI 4 GBytes e controladora DPT ultrawide).

Apesar do sistema poder ser utilizado na "grande rede", prevemos uma demanda maior para serviços como este em redes locais (empresas e escolas). Vários esquemas diferentes de rede podem ser utilizados para a distribuição. Os testes nesta área mostram o ganho que se pode ter quando se utiliza switches que possuem portas de alto desempenho (no caso foi utilizado FDDI) para conexão do servidor à switch. Por exemplo, supondo-se que uma aplicação necessitasse de 600 KBytes por segundo (padrão MPC3) e que esta fosse utilizada simultaneamente por 20 máquinas, a quantidade agregada de dados transmitidos seria de 12 MBytes por segundo (96 Mbits por segundo). Uma configuração possível de rede seria a conexão das 20 estações numa switch ethernet com porta FDDI para o servidor. Neste caso, precisaríamos de um servidor melhor configurado que o utilizado nos testes, com custo adicional relativamente baixo (vide, na figura 16 que, com 3 máquinas acessando o sistema, já se nota a limitaçÃo do acesso ao disco no caso sem RAID. Se o teste tivesse sido continuado com mais máquinas clientes, chegaríamos também a notar o limite do sistema com RAID). Situações de demanda maior de largura de banda precisaria de diferente arquitetura de rede, pois no caso descrito a conexão FDDI está próxima do limite de sua capacidade. Uma troca de FDDI por ATM a $155 \mathrm{Mbps}$ poderia prover uma capacidade adicional ao sistema.

Os testes de medida de performance no acesso a bases de dados e à rede também são reveladoras, principalmente por mostrarem que o acesso via JDBC impõe um delay razoável. No processo de apresentação do vídeo este delay não é significativo, pois aparece apenas na fase inicial (requisição) da transmissão do vídeo Vale salientar aqui que deve-se levar em consideração que implementações de CORBA e de JDBC podem variar muito em termos de performance. Uma avaliação comparativa entre várias implementações mostrou-nos ser uma tarefa interessante para o futuro.

Finalmente, devemos ressaltar que, apesar de não avaliado quantitativamente, a organização do sistema, dividido em uma base de dados de títulos (servidor de metadados) e uma base de dados de conteúdo torna o processo de edição e apresentação de vídeo bastante eficiente e flexível.

\section{REFERÊNCIAS BIBLIOGRÁFICAS}

[Ber95] Berger, D. Video-on-Demand Metadata Query Interfaces. Tese de metrado, Universidade da Califórnia, Berkeley, 1995.

[Buf94] Buford, J. F. K. Multimedia Systems. Addison-Wesley, 1994.

[Cas97] Castro, M.Alice.S; Goularte, R.; Reami, E. R.; Moreira, E.D.S. Infra-Estrutura de Suporte a Editoração de Material Didático Utilizando Multimídia. Revista Brasileira de Informática na Educação, n. 1, pp. 61-70, setembro, 1997.

[Com95] Comer, D. E. Internetworking Whit TCP/IP. Vol. 1, Prentice-Hall, 1995.

[Cou94] Couloris, G. F.; Dollimore, J. Distributed Systems. Addison-Wesley Publishing Company, 1994.

[Elm94] Elmasri, R; Navathe, S. B. Fundamentals of Database Systems. The Benjaming/Cummings Publishing Company, Inc, 1994.

[Fed94] Federighi, C.; Rowe, L. A. A Distributed Hierarchical Manager for a Videoon-Demand System. Anais do Symp. On Elec. Imaging Sci. \& Tech., pp. 185197, fevereiro, 1994.

[Flu95] Fluckiger, F. Understanding Networked Multimedia Applications and Technology. Hemel Hempstead - UK, Prentice-Hall, 1995. 
[Lee94] Lee, E. K.; Chen, P. M.; Hartman, J. H.; Drapeau, A. L. C.; Miller, E. L.; Katz, R. H.; Gibson, G. A.; Patterson, D. A. RAID-II: A Scalable Storage Architecture for High-bandwidth Network File Service. Anais do $21^{\text {st }}$ International Symposium on Computer Architcture, pp. 234-244, abril, 1994.

[Lit94] Little, T.D.C.; Venkatesh, D. Client Server Metadata Management for the Delevery of Movies in a Video-on-Demand System. Anais do 1st Intl. Workshop on Services in Distributed and Netwoked Enviroments, pp. 11-18, junho, 1994.

[Lou93] Lougher, P.; Shepherd, D. The Design of a Storage Server for Continuous Media. The Computer Journal, vol. 36, n. 1, pp. 32-42, 1993.

[Mat94] Mattison, P. Practical Digital Video with Programming Examples in C. Wiley Professional Computing, 1994.

[Mor95] Moreira, E. S.; Nunes, M. G. V.; Pimentel, M. G. C. Design Issues for a Distributed Hypermedia-based Tutoring System (HyDTS). Anais do International Conference on Computer Application in Industry, pp. 108-113, dezembro, 1995.

[Ste95] Steinmetz, R.; Narstedt, K. Multimedia: Computing, Communications and Applications. Prentice-Hall, 1995.

[Vin97] Vinoski, S. CORBA: Integrating Diverse Applications Within Distributed Heterogeneous Environments. IEEE Communications Magazine, vol. 14, n. 2, fevereiro, 1997. 


\title{
AVALIAÇÃo de DESEMPENHO DE UM AMBIENTE Computacional para Provimento de Vídeo
}

\author{
Antonio Marcos M. Hachisuca, Ronaldo C. M. Correia, Edson dos Santos Moreira \\ Departamento de Ciências de Computação e Estatística - ICMSC - USP - São Carlos \\ ICMSC-USP, Seção de Pós-Graduação, Av. Dr. Carlos Botelho, 1465. Cx. Postal 668 São Carlos - SP \\ E-mail:\{shiro, ronaldo, edson\}@icmsc.sc.usp.br
}

\section{RESUMO}

Este artigo discute as principais necessidades e problemas de um ambiente para provimento de vídeo via Internet. Testes foram realizados para a avaliação comparativa de várias alternativas tecnológicas para os vários componentes do sistema. As avaliações incluem sistema operacional (NT e Linux), o sistema de armazenamento (SCSI e RAID) e a rede (etbernet e uma switch ethernet com uma porta FDDI para o servidor)..

\section{ABSTRACT}

This paper discusses the main requirements and the problems concerned to the development an enviroment for video delivery over the internet. The tests were carried out to comparatively evaluate several hardware and software tecnological alternatives for the different components of the system. The evaluations include the operating systems (NT an Linux), storage system (SCSI alone and RAID) and network (single-bus ethernet and switched ethernet with a FDDI port for the server).

\section{Introdução}

À medida que se verifica o aumento do número de computadores na sociedade e a interconexão dos mesmos através de uma rede de computadores, surge também uma nova classe de aplicações dos mesmos. Dentro desta classe, aplicações que utilizam áudio e vídeo, começaram a aparecer com destaque. Torna-se cada vez mais complexas a criação de um ambiente computacional capaz de atender estas necessidades de maneira eficiente, pois a confecção de material multimídia (notadamente com fins educacionais) envolvem fatores como o armazenamento, a editoração e a apresentação eficiente desse material. [Mo97] [F195]

A questão do armazenamento de dados multimídia em ambientes WWW é ponto chave, uma vez que o fornecimento do material desejado deve ser gerenciado de forma eficiente para evitar sobrecarga do sistema devido ao grande volume dos dados e ao eventual grande número de usuários acessando o sistema. [Fe94] [Le94]

Apresentamos neste artigo a avaliação de um sistema servidor para aplicações multimídia sobre o ambiente WWW (Figura 1). O servidor tem que ser capaz de atender, sob demanda, a uma comunidade de clientes disposta em um ambiente WWW. Para o cliente, a utilização do servidor é totalmente transparente, ele precisa somente direcionar o browser para o endereço do vídeo (Figura 2). O servidor fica responsável pela procura deste vídeo na base de dados e disponibilização do mesmo. [Lo93] 


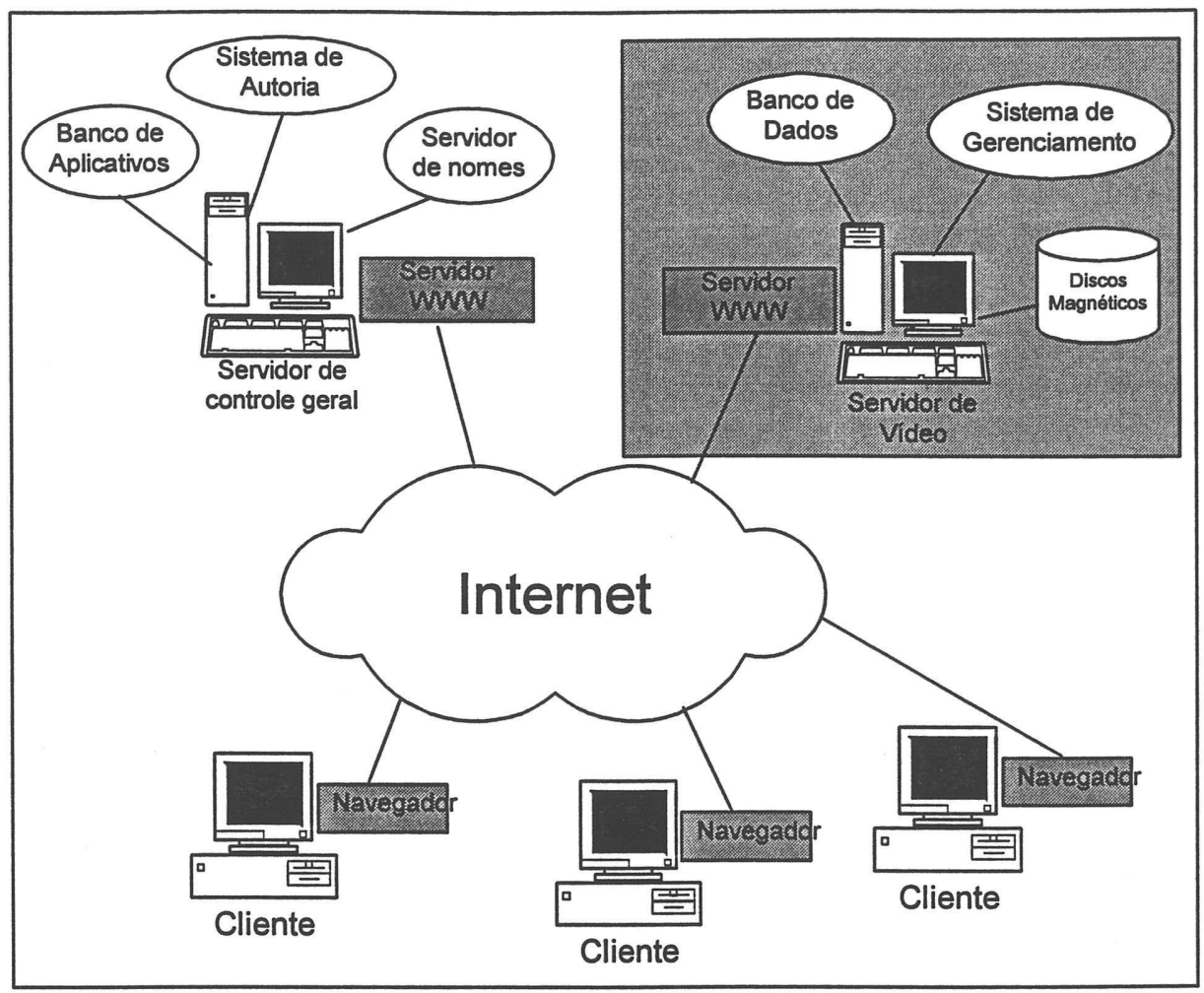

Figura 1 - O ambiente WWW

Estudo e avaliação dos diversos componentes envolvidos na cadeia de elementos e dutos (rede, cpu, meios de armazenamento, etc) que se encontram no caminho entre o armazenamento (no servidor de vídeo) e a apresentação (no cliente) foram realizados. Após o estudo, definiu-se a especificação do sistema, com a escolha da plataforma, sistema operacional, tipo de CPU, quantidade de memória RAM, o tipo e quantidade de discos rígidos, o tipo de placa de rede, etc.

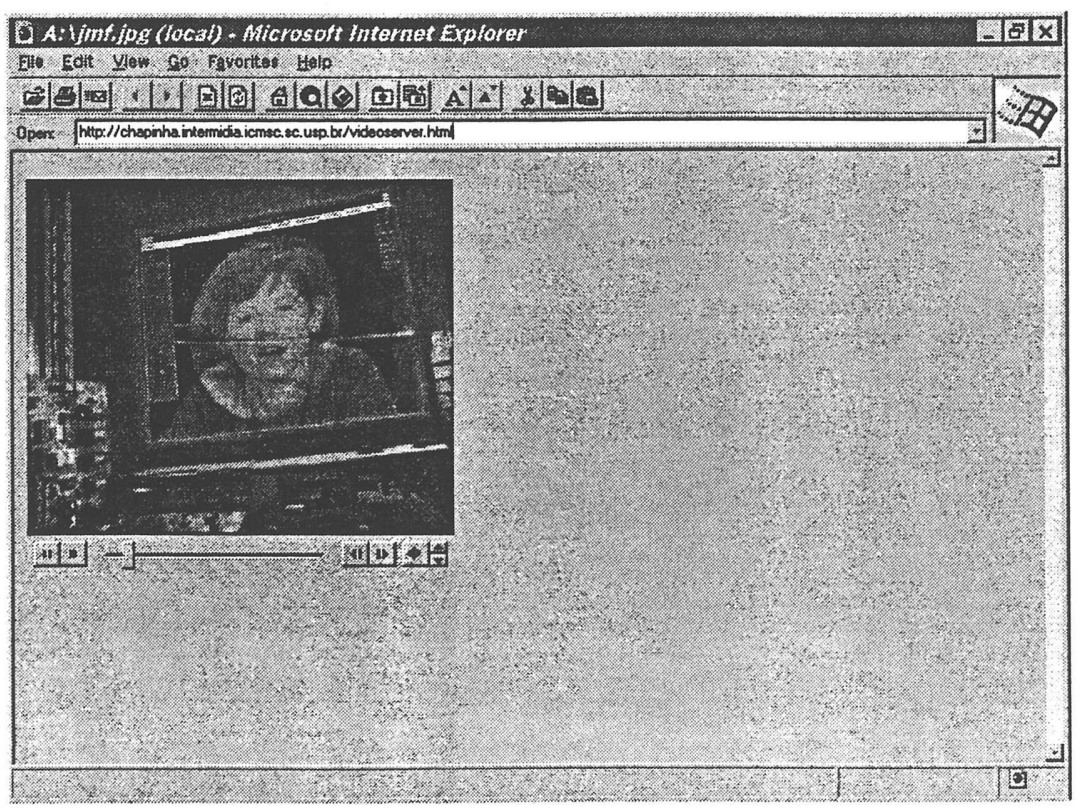

Figura 2-O ambiente do cliente 


\section{Especificação do Ambiente}

Para a realização das avaliações, foi montado um ambiente (figura 3) com as seguintes características:

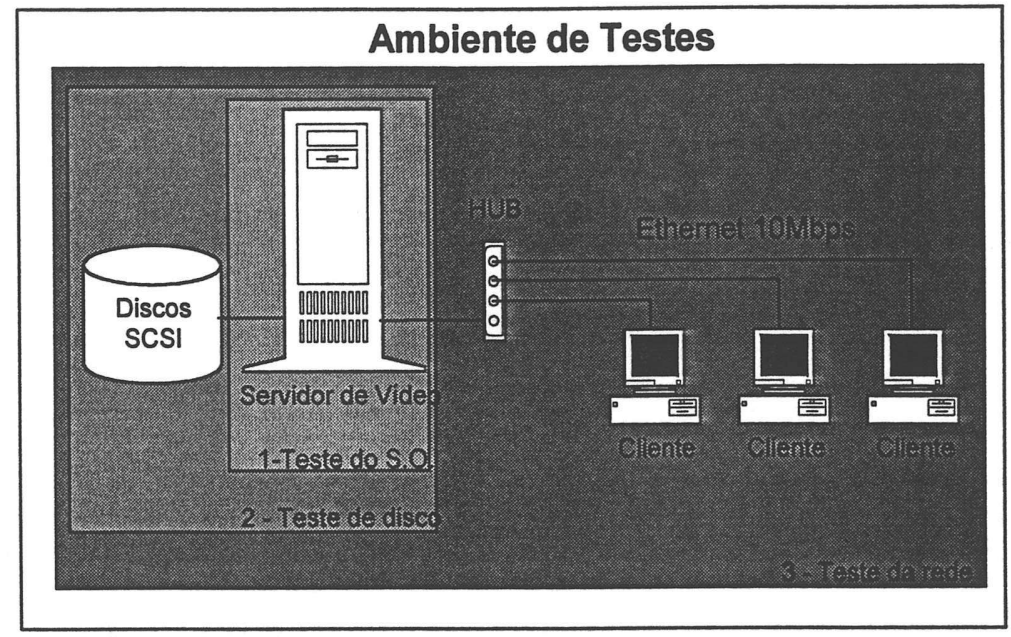

Figura 3 - Ambiente de testes

\subsection{0 hardware do servidor :}

- Processador Pentium/200 MMX

- $96 \mathrm{MB}$ de memória RAM

- 1 disco rígido Seagate 2 GB - SCSI

- 1 disco rígido Quantum 2 GB - SCSI

- 2 discos rígidos Quantum 4 GB - SCSI

- Placa controladora SCSI - Adaptec 3985

- Placa controladora SCSI - Adaptec $1740 *$

- Placa controladora SCSI - Adaptec 2940AU *

- Placa de rede ethernet 3 com ISA

2.2 O hardware que compõem as estações, são :

- Processador Pentium/166 Mhz

- $32 \mathrm{MB}$ de memória RAM

- 1 disco rígido $1.7 \mathrm{MB}-\mathrm{IDE}$

- Placa de Rede Fast-Ethernet 3Com PCI 10/100 Mbps 


\subsection{Equipamentos de conectividade :}

- Switch digital DECswitch 900EF, possui uma porta FDDI, uma porta AUI e 4 portas RJ45 Ethernet 10Mbps

- Hub digital DECrepeater 900TM, possui 24 portas RJ45 Ethernet 10Mbps

- Placa FDDI digital DEFPA-AA, possui uma porta FDDI.

Não nos preocupamos com a placa de vídeo ou o monitor, o servidor não necessita de uma resolução gráfica boa, todo acesso ao servidor será feito no próprio microcomputador do cliente.

Definimos uma grande quantidade de memória principal(RAM) com o intuito de diminuir o acesso ao disco, já que o sistema operacional Linux, armazena na memória principal (cache) os últimos dados acessados. Com isso se dois ou mais usuários acessarem o mesmo arquivo, somente um acesso ao disco será feito.

Foi adotado o uso de discos SCSI, pela vantagens que ele oferece em relação a discos IDE, principalmente quando utilizados em servidores de arquivos. No primeiro disco SCSI (2GB) foi instalado o Sistema Operacional, assim como todos os softwares que compõe o servidor (servidor de httpd, gerenciador $\mathrm{mSQL}$, linguagem java, etc). Os arquivos de vídeo encontram-se nos outros 3 discos SCSI, que estão configurado para se tornar único disco lógico, através da tecnologia RAID, que consiste na criação de uma pilha de discos, onde vários discos são agrupados fazendo com o que o sistema operacional os reconheça como se fossem um único disco. Com isso quando um arquivo é copiado para este disco (lógico) cada parte do arquivo fica armazenado num dos discos (físico) que compõe este disco lógico. A vantagem disto é o aumento do número de requisições que o computador pode atender concorrentemente, já que, na verdade, o acesso está ocorrendo em vários discos e não num único. Desta forma quando um arquivo é copiado para esse disco lógico cada bloco do arquivo é armazenado, paralelamente, em um disco físico. A vantagem é uma redução no tempo de armazenamento e leitura dos arquivos armazenados. [Lo93]

Foi escolhida a controladora SCSI Adaptec 3985 por esta possuir uma característica especial em relação as controladoras tradicionais, pois esta possui 3 canais de dados independentes ( como se fosse três controladoras SCSI), sendo que cada canal trabalha numa taxa de transmissão de $10 \mathrm{MBs}$, resultando com isso numa taxa total de $30 \mathrm{MBs}$. Desta forma cada disco que compõe o Raid foi colocado num canal diferente, com o objetivo de permitir acessos das informações de vídeo a uma taxa de $30 \mathrm{MBs}$, além de melhorar o acesso concorrentes das informações. [Lo93]. 


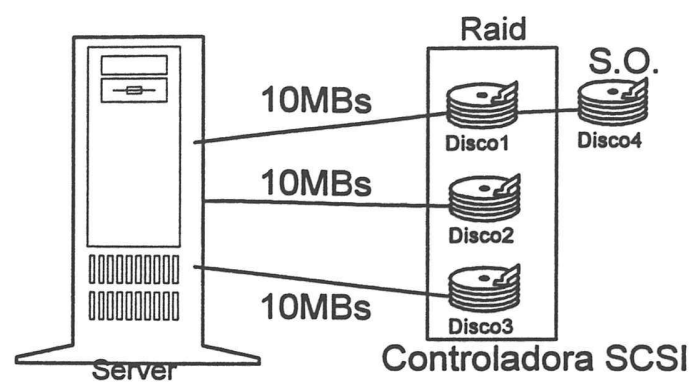

Figura 4 - Sistema de disco do servidor de vídeo

Foi utilizado várias placas de rede: Ethernet NE2000, Ethernet 3com, FastEthernet 3Com, FDDI digital, o qual foram utilizadas para medir o desempenho do servidor

\section{Metodologia Adotada}

A análise de desempenho de cada componente do sistema, foi feita utilizando o programa FTP, pois ele fornece o tempo total e taxa de transmissão na transferência de arquivo e está disponível em duas plataformas (Windows NT e Linux), além de funcionar de forma muito parecida daquela quando é requisitado pelo cliente um arquivo no ambiente WWW. Foram utilizados dois arquivos padrões, um de $7 \mathrm{MB}$ e outro de $81 \mathrm{MB}$, com o objetivo de verificar o sistema de cache e o desempenho na busca de informação de cada plataforma.

Os testes foram divididos em várias etapas, com o objetivo de medir em cada etapa um componente isolado do sistema, estas etapas foram:

- Sistema Operacional : visa medir o desempenho do sistema operacional no atendimento de requisições de disco e requisições da rede, foram feitos testes utilizando dois tipos de rede, a Ethernet $10 \mathrm{Mbps}$ no servidor e clientes, e FDDI $100 \mathrm{Mbps}$ no servidor e Ethernet $10 \mathrm{Mbps}$ nos clientes conectados através de uma Switch Ethernet.

- Acesso ao Disco : visa medir o desempenho do disco no atendimento de uma requisição feita por uma população de clientes, foram sub-divididos em várias partes:

- utilizando uma rede Ethernet no servidor e clientes, com sistema de arquivo tradicional.

- utilizando uma rede Ethernet no servidor e clientes, com sistema de arquivo com tecnologia Raid-0.

- Utilizando uma rede FDDI (100Mbps) no servidor e clientes conectados através de uma switch ethernet (10Mbps), com sistema de arquivo tradicional.

- Utilizando uma rede FDDI (100Mbps) no servidor e clientes conectados através de uma switch ethernet (10Mbps), com sistema de arquivo com tecnologia raid-0. 
Nas tabelas que se seguem os números dos testes significam:

- 1 - 1 único acesso ao disco;

- 2 - 2 acessos concorrentes ao disco, utilizando o mesmo arquivo;

- 3 - 3 acessos concorentes ao disco, utilizando o mesmo arquivo;

- 4 - 2 acessos concorrentes ao disco, utilizando arquivos diferentes;

- 5 - 3 acessos concorrentes ao disco, utilizando arquivos diferentes;

\section{Testes Realizados}

Os testes realizados foram:

\subsection{Testes com Sistemas Operacionais Diferentes - Linux e Windows NT}

O objetivo desse teste é comparar o desempenho do servidor de vídeo (com e sem a tecnologia RAID) em dois sistemas operacionais diferentes, Linux (versão Slakware 3.3 kernel 2.0.30) e Windows/NT 4.0. Os dois SOs foram instalados no servidor de vídeo. Foram realizadas transferências de arquivos seguindo a metodologia descrita acima.

\section{Desempenho do Sistema Operacional Local}

Os testes realizados compararam o desempenho do servidor, em plataforma Linux, quando esta utiliza e quando não utiliza RAID. Também comparam o desempenho do servidor em plataformas diferentes (Windows/NT e Linux) sem utilizar RAID. Nesse teste não foi possível comparar o desempenho do servidor entre os dois sistemas operacionais utilizando a tecnologia RAID, já que o Windows/NT não possui suporte para a placa Adaptec 3985 (controladora de RAID). Para os testes sem a tecnologia RAID empregou-se um (único) disco rígido SCSI quantum de 4.0 GB e uma placa controladora SCSI Adaptec 2940AU. A tabela 1 mostra os resultados obtidos com os testes, que expressam a taxa de transferência dos arquivos em KiloBytes por segundo.

Tabela 1 - Desempenho do servidor com SOs diferentes.

\begin{tabular}{|c|c|c|c|}
\hline Teste & WindowsNT (kbytes/ seg) & Linux (kbytes/ seg) & Linux c/ RAID (kbytes/ seg) \\
\hline $\mathbf{1}$ & 1372 & 2780 & 3530 \\
\hline 2 & 745 & 1917 & 2687 \\
\hline 3 & 522 & 1482 & 2138 \\
\hline 4 & 571 & 898 & 1483 \\
\hline $\mathbf{5}$ & 416 & 660 & 948 \\
\hline
\end{tabular}




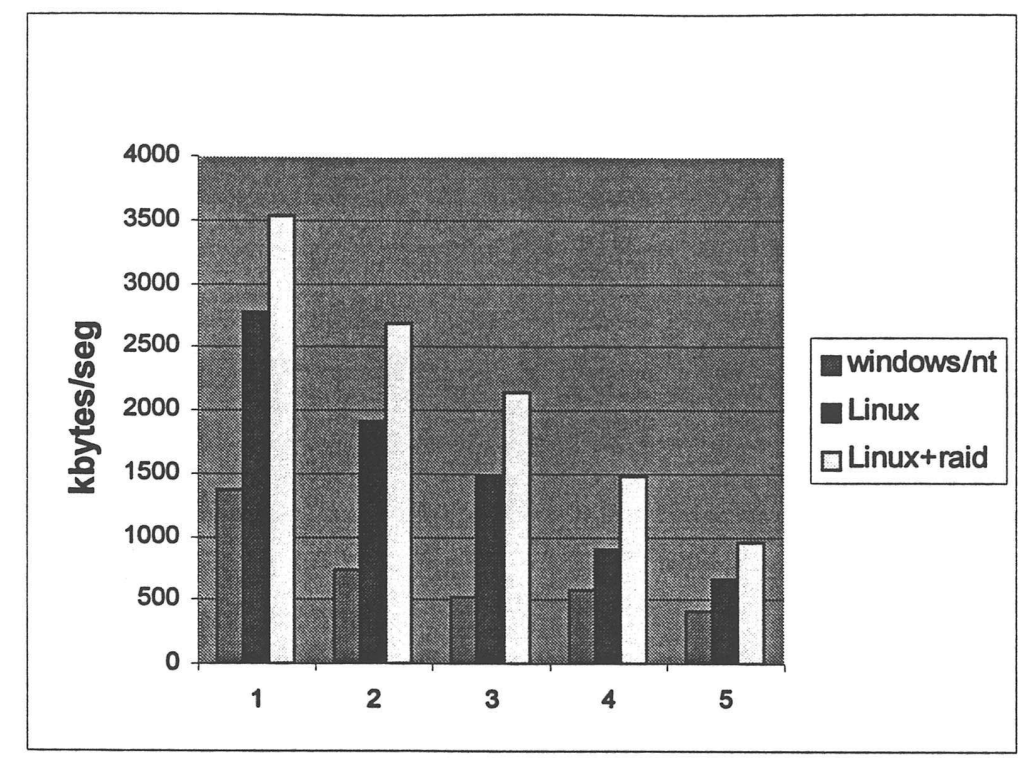

Figura 5 - Desempenho do servidor com sistemas operacionais diferentes.

Conclui-se que o sistema operacional Windows/NT, em sua configuração padrão, apresenta um desempenho inferior ao sistema operacional Linux no atendimento a requisição locais de arquivos (tabela 1 e figura 5). Outra constatação é que a utilização da tecnologia RAID (de forma local) no gerenciamento do sistema de arquivos obtém um desempenho superior em relação do sistema de arquivos tradicional (único disco).

\section{Desempenho do Sistema Operacional em Rede}

O teste anterior apontou um desempenho melhor do servidor de vídeo, em ambiente local, com a plataforma Linux. Como os sistemas operacionais em questão possuem formas diferentes de gerenciar o envio de informações pela rede, buscou-se verificar se o Linux continuaria oferecendo um melhor serviço quando a transferência de arquivos ocorresse de forma remota.

Utilizaram-se duas configurações de rede diferentes. Em uma configuração o servidor e as estações clientes estão conectados através de uma rede Ethernet de $10 \mathrm{Mbps}$ (figura 6), na outra é utilizada uma rede FDDI de 100Mbps conectando o servidor e os clientes através de um Switch Ethernet de $10 \mathrm{Mbps}$ (figura 7). A configuração do servidor utilizada nesse teste foi a mesma configuração sem RAID do teste anterior.

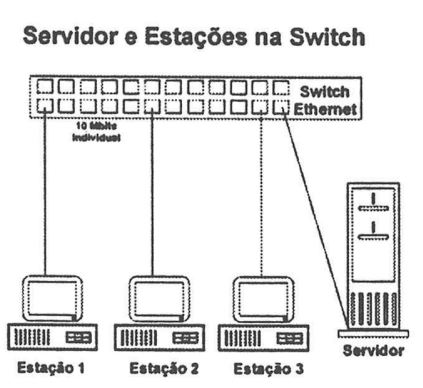

Figura 6 - Rede Ethernet para testes
Servidor no Anel FDDI e Estaçōes na Switch

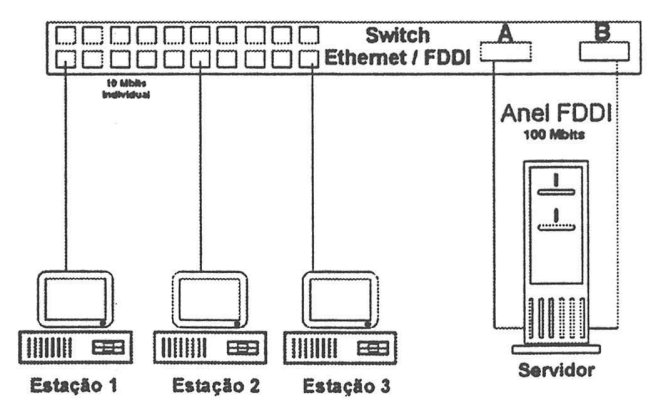

Figura 7 - Rede FDDI+Switch ethernet para testes 
Os resultados obtidos dos testes sobre a rede Ethernet são mostrados na tabela 2 e na figura 8. Os resultados dos testes sobre a rede FDDI são mostrados na tabela 3 e a figura 9. A figura 10 compara o percentual de utilização da rede Ethernet entre os dois sistemas operacionais.

Tabela 2 - Desempenho sobre rede Ethernet.

\begin{tabular}{|c|c|c|}
\hline Teste & WindowsNT (kybtes/ seg) & Linux (kbytes/ seg) \\
\hline $\mathbf{1}$ & 783 & 1069 \\
\hline $\mathbf{2}$ & 524 & 569 \\
\hline 3 & 420 & 426 \\
\hline 4 & 553 & 568 \\
\hline $\mathbf{5}$ & 380 & 386 \\
\hline
\end{tabular}

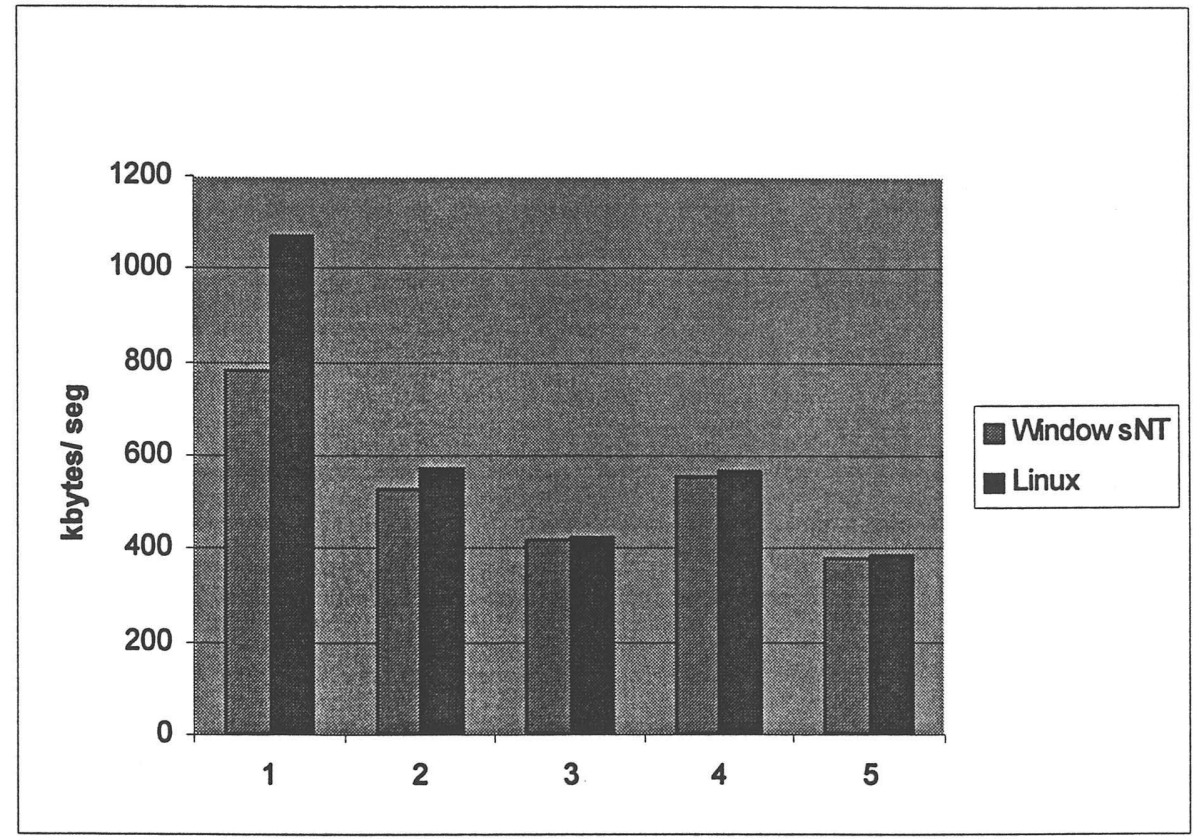

Fiqura 8 - Desempenho do S.O. - sistema de rede Ethernet

Tabela 3 - Desempenho sobre rede FDDI.

\begin{tabular}{|c|c|c|}
\hline Teste & WindowsNT (kybtes/ seg) & Linux (kbytes/ seg) \\
\hline $\mathbf{1}$ & 1039 & 1069 \\
\hline 2 & 1060 & 1075 \\
\hline 3 & 1000 & 1065 \\
\hline 4 & 986 & 1064 \\
\hline 5 & 779 & 1008 \\
\hline
\end{tabular}




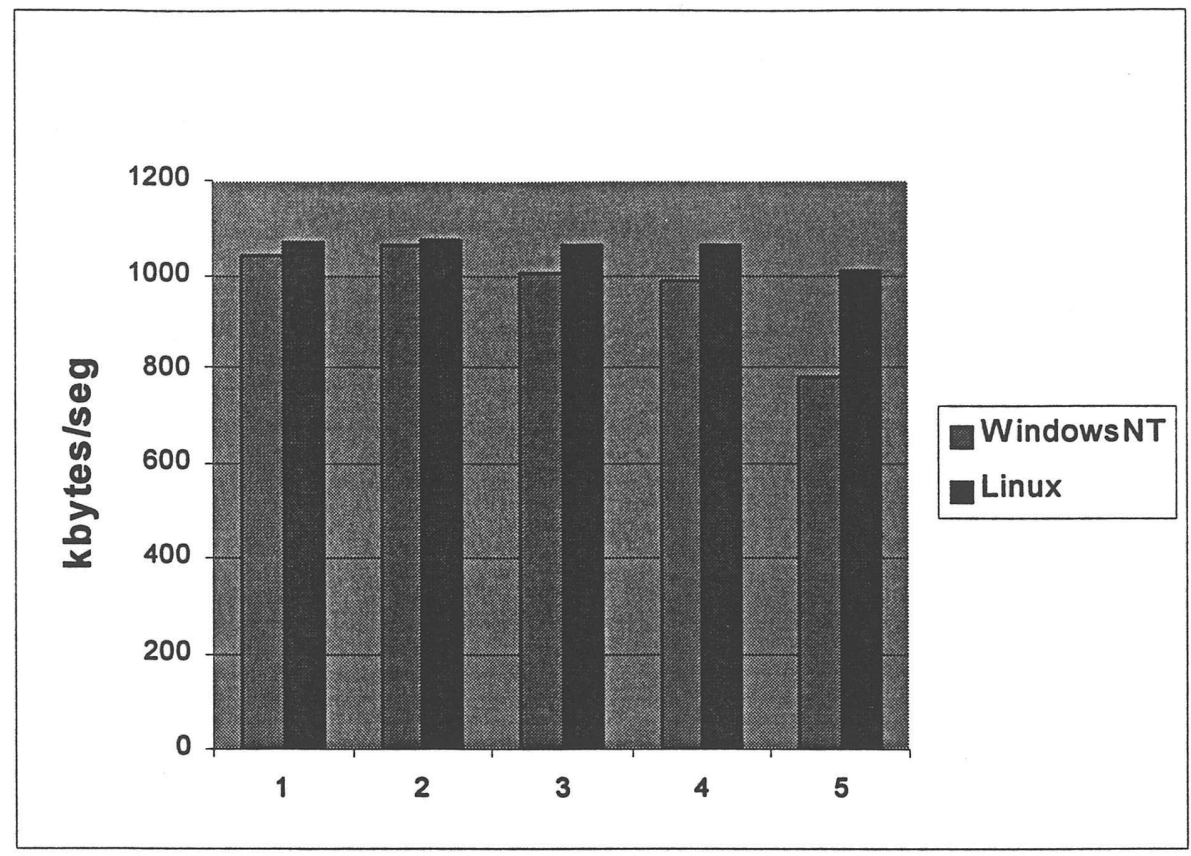

Figura 9 - Desempenho do S.O. - sistema de rede FDDI + Switch Ethernet.

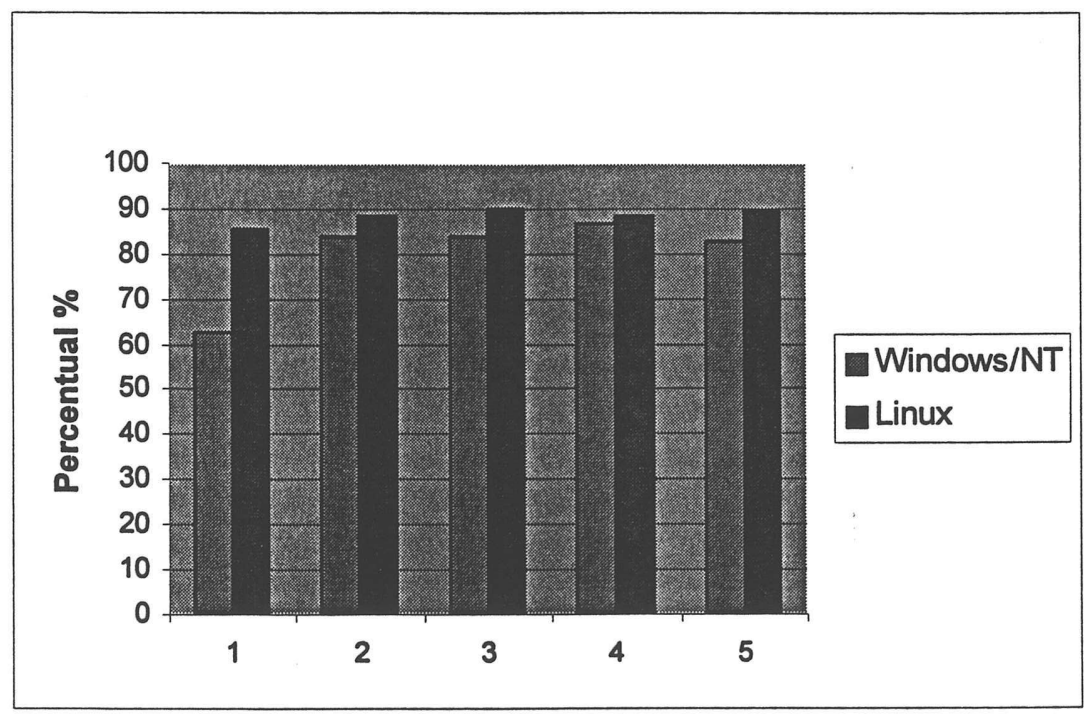

Figura 10 - Percentual de utilização da rede Ethernet.

O Windows/NT apresentou um desempenho inferior ao Linux na transferência dos arquivos nos dois casos analisados (Ethernet e FDDI).

Outra conclusão é que a rede Ethernet se torna um gargalo para um número médio de clientes (figura 8). Analisando a figura 10 podemos observar que no teste 1, o gargalo é o sistema de rede do Windows/NT, já nos testes seguintes o gargalo é a rede Ethernet (10Mbps), já que a sua utilização chega a $90 \%$, que para a rede Ethernet é uma taxa alta. No sistema operacional Linux, o gargalo sempre é a rede. 
$\mathrm{Na}$ figura 9 podemos concluir que o gargalo inicialmente é a rede Ethernet (10Mbps), porém para um número maior de clientes, o gargalo se torna o sistema de arquivo, concluímos também que gerenciamento de acesso ao disco do WindowsNT é menos eficiente que do Linux.

\subsection{Avaliação do Acesso Remoto ao Disco via Rede Ethernet}

Quando o sistema RAID é instalado em um computador, ele promove mudanças na forma de acesso e armazenamento dos dados, modificando o sistema de arquivos.

O objetivo desse teste foi comparar o desempenho do servidor de vídeo, sobre uma rede de computadores, ao se utilizar um sistema de arquivo tradicional (único disco) e utilizando o sistema de arquivo com a tecnologia Raid- 0 . Os testes foram realizados sobre o sistema operacional Linux. O servidor foi configurado com a controladora SCSI Adaptec 3985 (controladora de RAID) e o disco lógico RAID foi montado sobre os três discos rígidos SCSI quantum (1 de 2 GB e 2 de 4GB). Os resultados obtidos são mostrados na tabela 4 e na figura 11.

Tabela 4 - Desempenho do servidor sobre ethernet.

\begin{tabular}{|c|c|c|}
\hline Teste & Um único disco SCSI & Tecnologia RAID (kbytes/ \\
\hline $\mathbf{1}$ & 1064 & 1069 \\
\hline 2 & 579 & 569 \\
\hline 3 & 427 & 426 \\
\hline 4 & 559 & 568 \\
\hline 5 & 388 & 386 \\
\hline
\end{tabular}

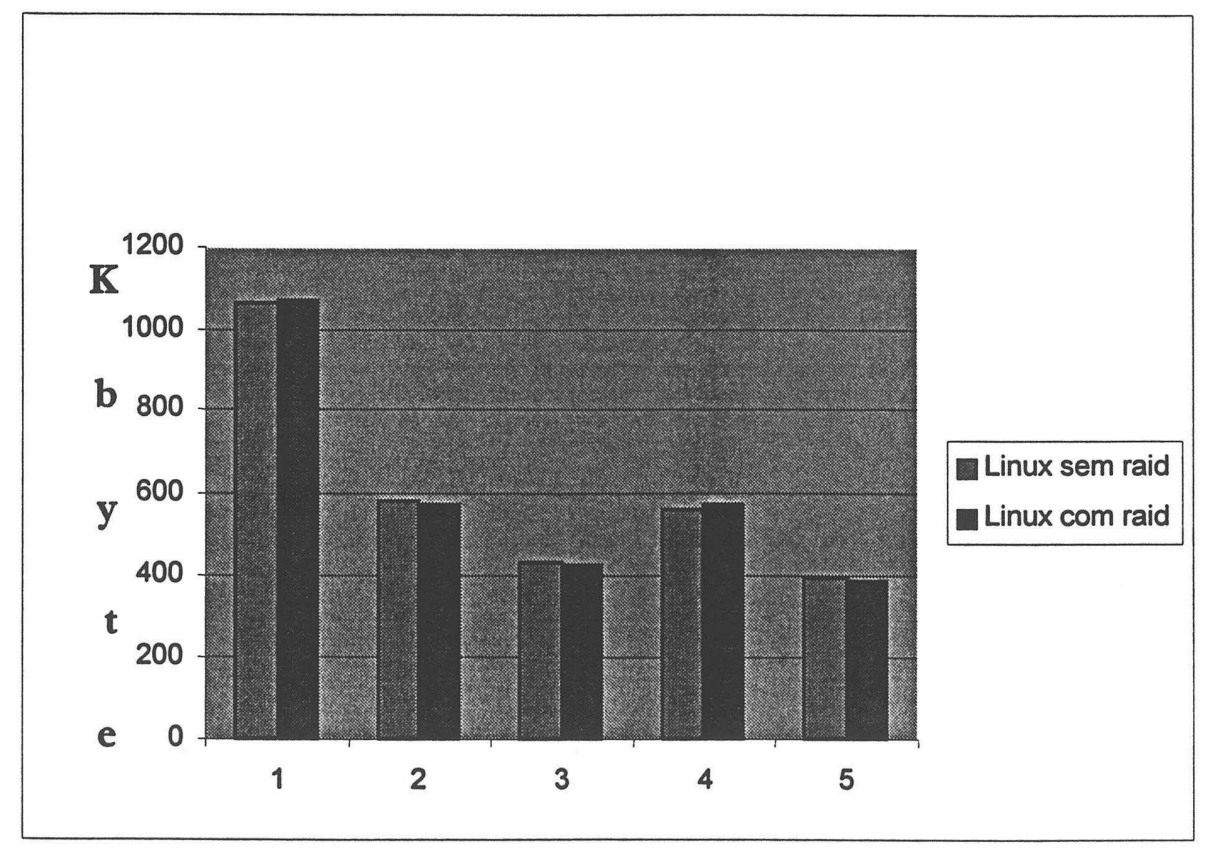

Figura 11 - Desempenho do Sistema de Arquivo sobre uma rede Ethernet (10Mbps).

Conclui-se que o gargalo do sistema é a rede Ethernet (10Mbps). Tanto o sistema de arquivo tradicional quanto no sistema de arquivo com tecnologia RAID apresentaram resultados 
semelhantes. A utilização da rede neste teste foi de aproximadamente $90 \%$, que é alta para a rede Ethernet (10Mbps).

\subsection{Avaliação do Acesso Remoto ao Disco via Rede FDDI}

Este teste visa medir o desempenho ao se utilizar um sistema de arquivo tradicional e utilizando o sistema de arquivo com a tecnologia Raid-0 sobre uma rede onde o servidor está conectado através de uma rede FDDI (100Mbps) e as estações estão conectados através de uma switch Ethernet (10Mbps). Os testes foram realizados sobre o Sistema Operacional Linux e com a controladora SCSI Adaptec 3985, o disco lógico RAID foi montado sobre os três discos rígidos SCSI quantum (1 de $2 \mathrm{~GB}$ e 2 de 4GB), placa de rede digital FDDI DEFPA-AA. Os resultados obtidos são mostrados na tabela 5 e na figura 12.

Tabela 5 - Desempenho do servidor sobre rede FDDI.

\begin{tabular}{|c|c|c|}
\hline Teste & Um único disco SCSI & Tecnologia RAID (kbytes/ \\
\hline $\mathbf{1}$ & 1069 & 1078 \\
\hline 2 & 1075 & 1076 \\
\hline 3 & 1065 & 1063 \\
\hline 4 & 1064 & 1061 \\
\hline 5 & 1008 & 1067 \\
\hline
\end{tabular}

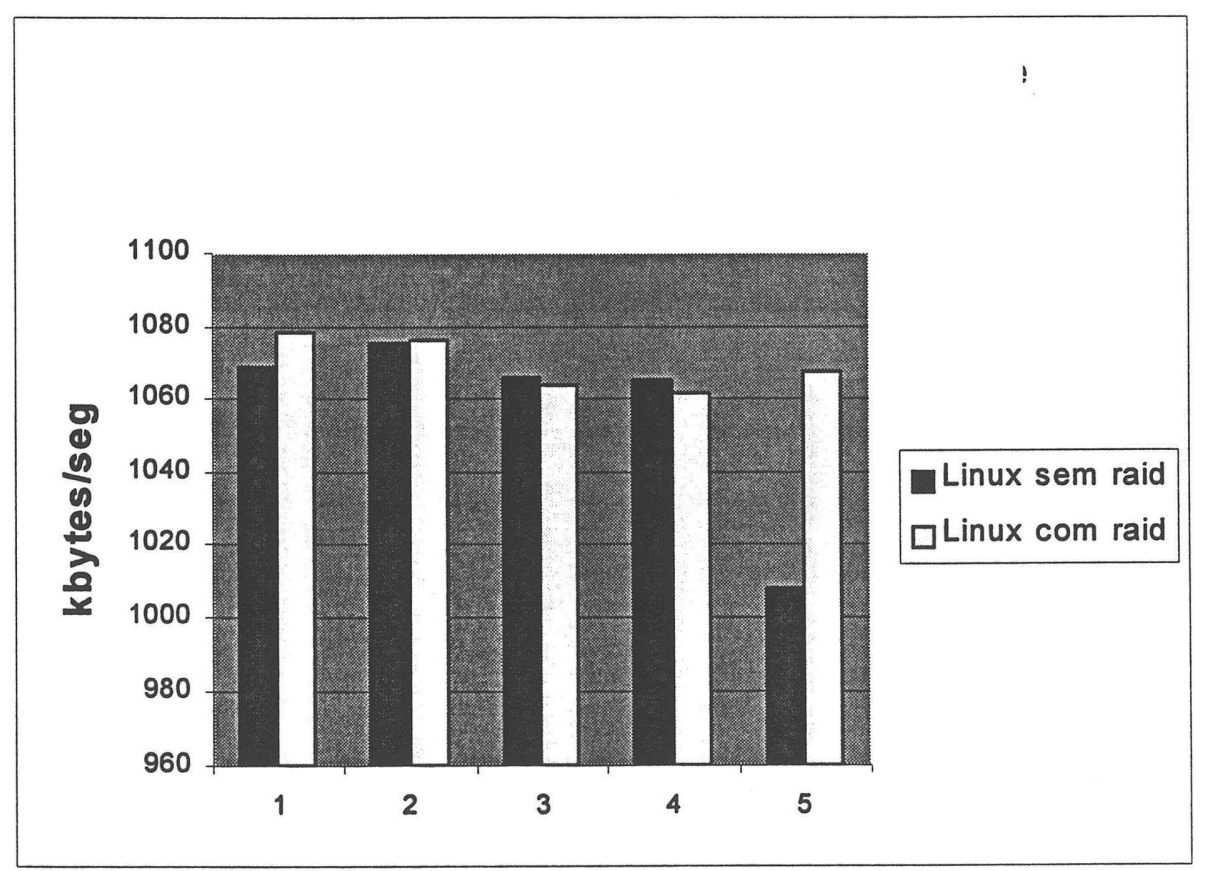

Figura 12 - Desempenho do Sistema de Arquivo sobre uma rede FDDI e switch Ethernet.

Concluímos que o gargalo do sistema inicialmente é a rede Ethernet (10Mbps), porém com um número médio de clientes, demonstrou que o sistema de arquivo tradicional se torna o gargalo, 
o gráfico demonstra também que o gargalo sempre é a rede no sistema de arquivo com tecnologia RAID.

\section{Estudo de Caso}

Em um ambiente educacional (Figura 13), onde o professor possui o controle total da aplicação e há necessidade de transmissão de vídeos em uma resolução de $352 \times 240$ padrão MPEG1 (1.5 Megabits por segundo), do servidor para um número elevado de clientes (20 estações), uma grande quantidade agregada de dados deverá ser transmitida pela rede (30 Megabits), mas sabemos que as redes padrões Ethernet suportam no máximo 10 Megabits tornando-se então uma aplicação inviável.

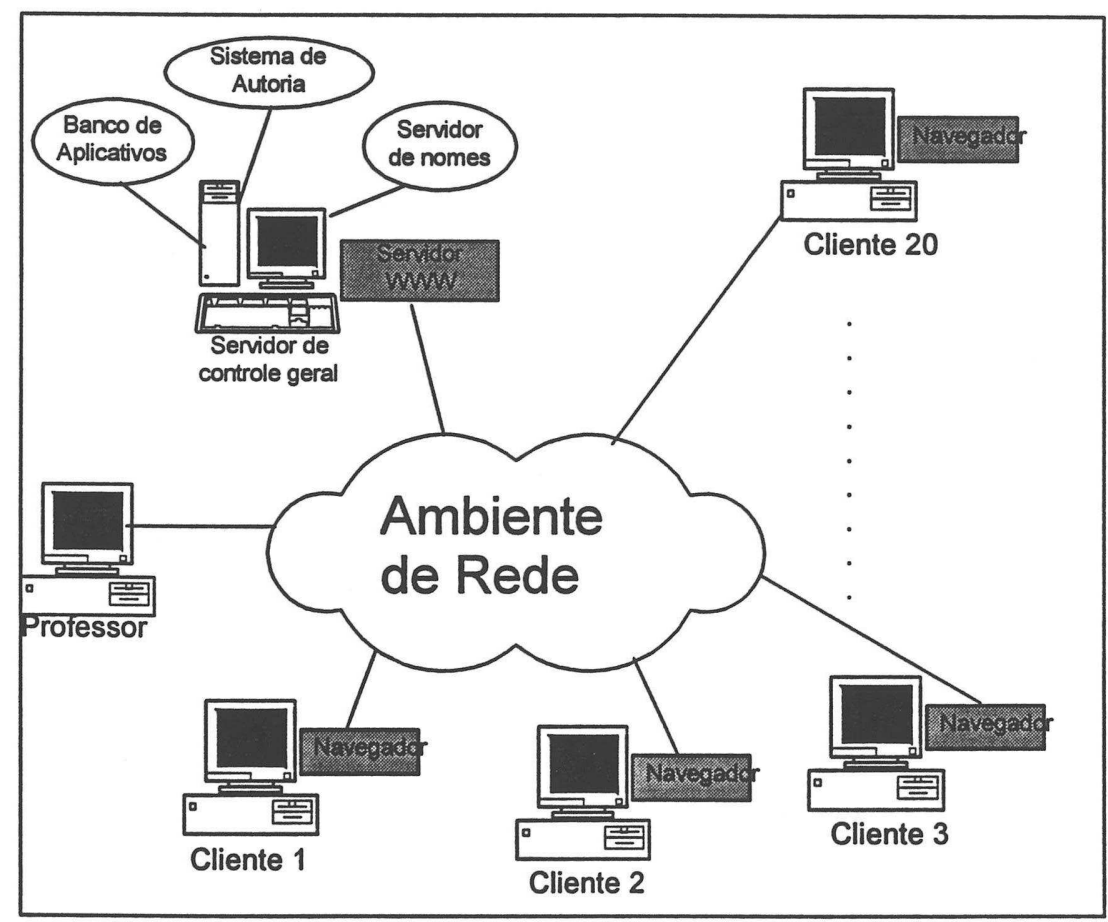

Figura 13 - Modelo de um Ambiente Educacional para Aplicações Multimídia

Problemas deste tipo são resolvidos através da utilização de tecnologias de redes de alta velocidade (Switch/ FDDI) e servidores de alto desempenho no atendimento de requisições de arquivos, conforme especificados nos testes acima (Figura 12).

\section{Conclusões}

Os testes realizados mostram que é perfeitamente possível a implementação de sistemas de distribuição de vídeo via tecnologias de rede Internet. Para contornar os problemas oriundos da precariedade dos protocolos TCP/IP e ethernet para a transmissão de mídia contínua, nota-se o aparecimento de várias tecnologias que possibilitam o uso de um sistema de armazenamento remoto de vídeo e sua apresentação local com razoável qualidade sem a utilização de sincronismo durante todo o processo (p. ex. Vxtreme, RealVideo, CU-Seeme e o padrão JMF). Desta forma, a questão principal torna-se o 
provimento de largura de banda necessária para a aplicação. A maioria dos problemas inseridos pela rede e pelos sistemas operacionais são resolvidos através de esquemas avançados de bufferização.

Este trabalho avaliou várias opções de tecnologias "convencionais", mostrando configurações possíveis de serem utilizadas para o serviço de armazenamento e distribuição de vídeo. Em termos gerais, a única peça não-convencional utilizada pelo sistema é uma placa especial SCSI, com 3 canais. A utilização de RAID é alcançada via software padrão embutido no Linux.

O servidor foi desenvolvido utilizando-se tecnologias de baixo custo, se comparados a sistemas semelhantes existentes no mercado. Considerando-se ainda que com o avanço tecnológico das redes, aliado com o aumento da velocidade de transmissão, acreditamos que um ambiente de provimento de vídeo como este possa ser utilizados não somente internamente a uma instituição, mas também como uma ferramenta no auxílio do ensino a distância.

\section{Referências Bibliográficas}

[Fe94] Federighi, C.; Rowe, L. A. A Distributed Hierarchical Manager for a Videoon-Demand System. Anais do Symp. On Elec. Imaging Sci. \& Tech., pp. 185197, fevereiro, 1994.

[F195] Fluckiger, F. Understanding Networked Multimedia Applications and Technology. Hemel Hempstead - UK, Prentice-Hall, 1995.

[Le94] Lee, E. K.; Chen, P. M.; Hartman, J. H.; Drapeau, A. L. C.; Miller, E. L.; Katz, R. H.; Gibson, G. A.; Patterson, D. A. RAID-II: A Scalable Storage Architecture for High-bandwidth Network File Service. Anais do $21^{\text {st }}$ International Symposium on Computer Architcture, pp. 234-244, abril, 1994.

[L093] Lougher, P.; Shepherd, D. The Design of a Storage Server for Continuous Media. The Computer Journal, vol. 36, n. 1, pp. 32-42, 1993.

[Mor97] Morandini, M.; Castro, M.A.S.; Pimentel, M.G.C. Princípios de Interação Usuário-Computador Aplicados ao Projeto de um Quiosque Hipermídia: uma Experiência. Submetido ao WoHM97 (III Workshop em Sistemas Hipermídia e Multimídia), São Carlos, 1997. 